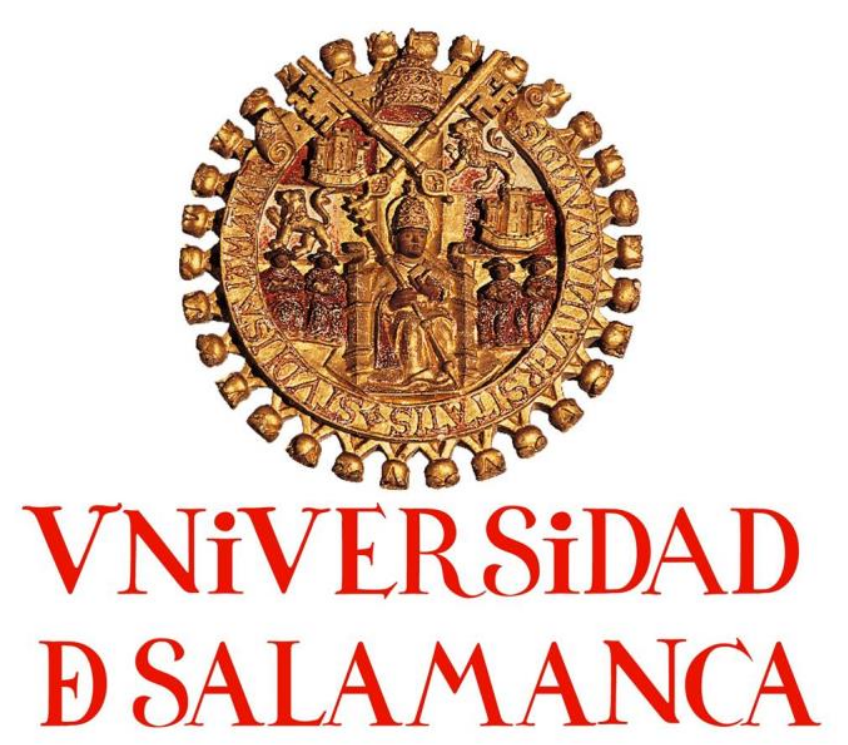

INSTITUTO DE IBEROAMÉRICA

Doctorado en Estudios Latinoamericanos

\title{
MICRO-CRÉDITOS O MACRO-DEUDAS, SISTEMAS FINANCIEROS ALTERNATIVOS EN CONTEXTOS DE CRISIS ECONÓMICA: \\ EL CASO DE LA REGIÓN DE LA CIÉNAGA DE CHAPALA, MÉXICO
}

DIRECTORES:

Dr. Iñigo González de la Fuente

Dr. Ángel B. Espina Barrio

Raquel M. Miranda Ortiz

-Septiembre de 2017- 



\section{INDICE}

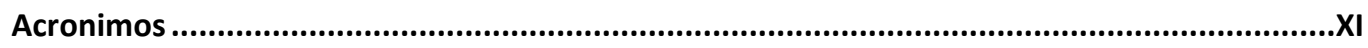

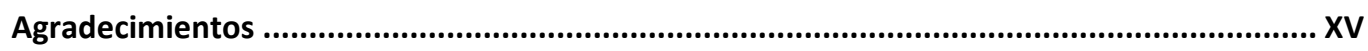

BLOQUE I. ASPECTOS TEÓRICOS Y METODOLÓGICOS................................................. - 35 -

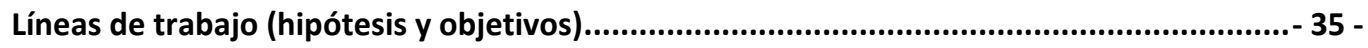

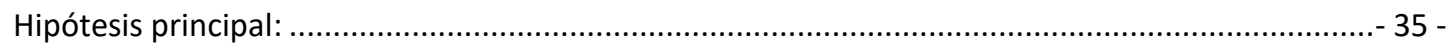

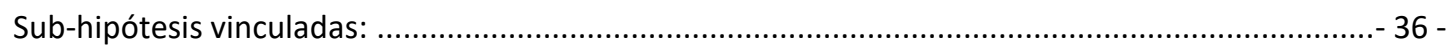

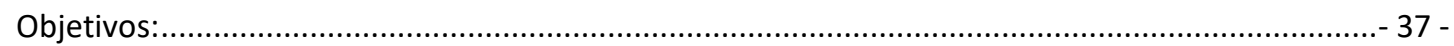

1.2. Horizonte teórico y discusión conceptual sobre la teoría económica ........................... 39 -

1.2.1. Las tres escuelas que fundamentaron el capitalismo: Mercantilismo, Fisiocracia y

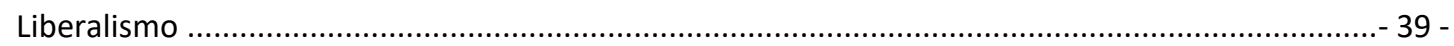

1.2.2. Catalaxia, Economía Neoclásica y Microeconomía ........................................................... 48 -

1.2.3. La hegemonía del equilibrio general de la competencia perfecta. La economía convertida en ideología. $50-$

1.2.4. La periferia, dependencia y subdesarrollo que promueven la generación de una resistencia- 53 -

1.2.5. El sistema financiero, el molino satánico y la crisis ....................................................... 58 -

1.2.6. El momento Minsky de 2008 y el canibalismo financiero ................................................... 60 -

1.3 Horizonte teórico y discusión conceptual sobre la antropología económica ................. 62 -

1.3.1. El debate entre Formalistas y Sustantivistas .................................................................. 67 -

1.3.2. La Gran Transformación ................................................................................................ 70 -

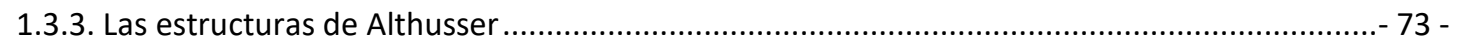

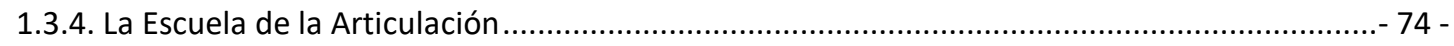

1.3.5. El marxismo estructuralista de Godelier................................................................. 77 -

1.3.6. La escuela de la Economía Política ................................................................................ 79 -

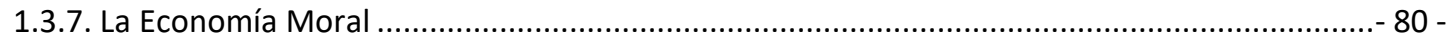

1.4. Conceptos clave para la investigación cualitativa de los sistemas financieros 
alternativos 83 -

1.4.1. La reciprocidad, el intercambio y el consumo como estrategias económicas $-83-$

1.4.2. El sector informal. $90-$

1.4.3. Solidaridad circunscrita y Capital Social. $94-$

1.4.4. La antropología económica durante la crisis de 2008 $100-$

1.5. El trabajo de campo: observaciones, metodología y técnicas empleadas 101 -

1.5.1. Conocimiento situado. Reflexiones epistemológicas y compromiso con la realidad $102-$

1.5.2. Desarrollo del trabajo de campo $107-$

1.5.3. Técnicas y recursos utilizados $110-$

1.5.4. Reflexiones sobre las técnicas utilizadas $115-$

\section{BLOQUE II. LA CIÉNAGA DE CHAPALA. CONTEXTUALIZACIÓN HISTÓRICA Y DESCRIPCIÓN}

DE LAS COMUNIDADES

2.1. México: economía, sistema financiero y sector informal. Desde el sexenio de Salinas de Gortari hasta Peña Nieto (1988-2012) 118

2.2. La sociedad rural del siglo XXI, reconversión productiva $-127-$

2.3. Michoacán como experimento: ruralidad, desaparición de los poderes del Estado y aumento de la desigualdad 131 -

2.4. La Ciénaga de Chapala y el Distrito de Desarrollo Rural 089 140

2.4.1. La llegada de la economía neoliberal. Salinas de Gortari (1988-1994) $146-$

2.4.2. La tradición migratoria en la Ciénaga de Chapala y su organización $148-$

2.5. Jiquilpan "pueblo mágico" y Sahuayo "ciudad comercial". Cardenismo Souvenir vs. Santiago, Joselito y los negocios 154 -

2.5.1. Las fiestas en la región, ejemplo de las particularidades de los municipios...... $-161-$

2.5.2. Jiquilpan de Juárez $171-$

2.5.3. Sahuayo de Morelos 177 


\section{BLOQUE III. LOS SISTEMAS FINANCIEROS PRESENTES EN LA CIÉNAGA DE CHAPALA, DDR}

089 $-185-$

3.1. Sistemas financieros formales .......................................................................... 186 -

3.1.1. La Banca Múltiple .................................................................................................. 188 -

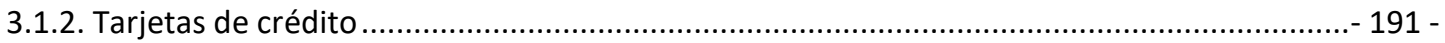

3.1.3. La compra de bienes y servicios a través del pago fraccionado. Bancoppel y Banco Azteca - 194 -

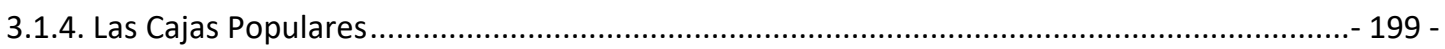

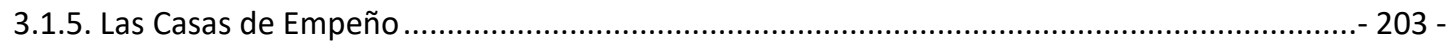

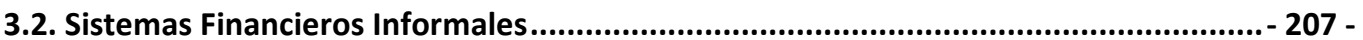

3.2.1. Los apartados. La modalidad informal del pago fraccionado ............................................. 209 -

3.2.2. Las kermeses....................................................................................................... 213 -

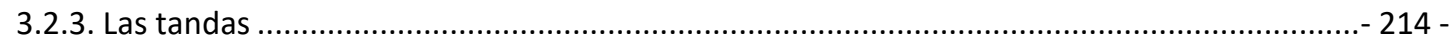

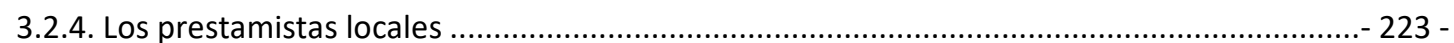

BLOQUE IV. NINGUNO SOMOS MONEDITA DE ORO ….......................................... - 225 -

4.1. Karen la vendedora. Los pagos fraccionados y las tandas no son siempre un buen

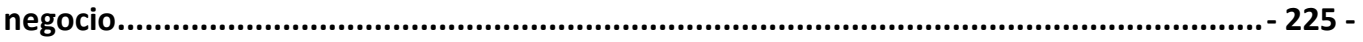

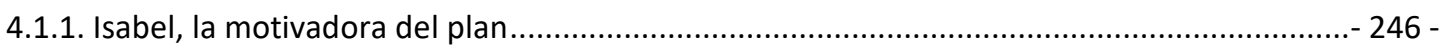

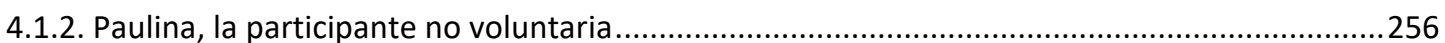

4.1.3. Guadalupe y Mercedes. La participación de la tanda como excusa para mantener las

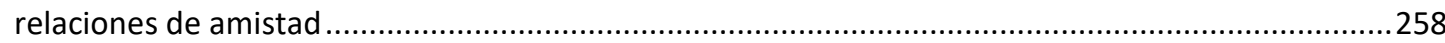

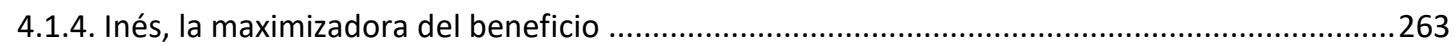

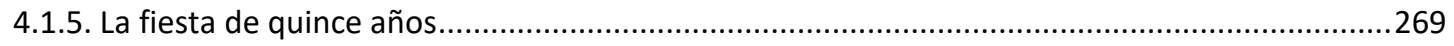

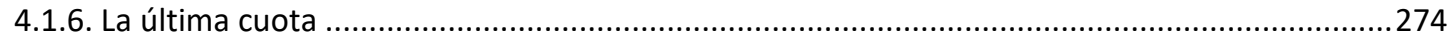

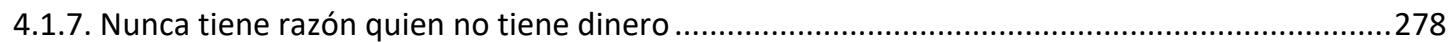

4.1.8. Ni tanto que queme al santo, ni tanto que no lo alumbre ...................................................28

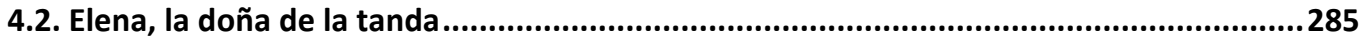

4.2.1. Jorge, consigue financiamiento para su tratamiento médico a través de la tanda ..................298 
4.3. Humberto, el prestamista 307

4.3.1. Aquí no tenemos huevitos al gusto 309

4.3.2. La llegada de los pochos. Las remesas colectivas para la comunidad de origen

4.3.3. Rodrigo, los lazos familiares a veces atan

4.4. Gustavo, trabajador de una casa de empeño 318

4.4.1. La casa de empeño 329

4.4.2. Gerardo, los abonos chiquitos que fueron creciendo .333

4.4.3. Ana María, remesas, deudas y el futuro de sus hijos

4.4.4. Esteban, empeñar los bienes para evitar los males.

4.4.5. La tanda de Julia

BLOQUE V. CONCLUSIONES

BLOQUE VI. BIBLIOGRAFÍA 


\section{INDICE DE FOTOGRAFÍAS}

Fotografía 1, Estadio 18 de marzo....................................................................... 162 -

Fotografía 2, Aniversario de la Revolución mexicana, 20 de noviembre ................- 163 -

Fotografía 3, Procesión de los faroles .................................................................- 164 -

Fotografía 4, Procesión Santiago Apóstol. Fiestas del Patrón Santiago...................- 166 -

Fotografía 5, Desfile de los Tlahualiles. Fiestas del Patrón Santiago ....................... 168 -

Fotografía 6,.Fiestas en Honor a la Virgen de Guadalupe........................................ 168 -

Fotografía 7, Fiestas en Honor a la Virgen de Guadalupe.......................................- 170 -

Fotografía 8, Nombramiento de Pueblo Mágico ...................................................... 175 -

Fotografía 9, Nombramiento de Pueblo Mágico .....................................................- 176 -

Fotografía 10, Calle Constitución.......................................................................... 180 -

Fotografía 11, Capilla de José Sánchez del Río .................................................... 181 -

Fotografía 12, Cartel de Malas Pagas ...................................................................- 212 - 


\section{INDICE DE TABLAS}

Tabla 1, Ocupación y Empleo, Michoacán.

$133-$

Tabla 2, Ingresos por remesas familiares, Michoacán. Serie trimestral de 2008 a 2014

en millones de dólares $134-$

Tabla 3, Indicadores seleccionados de pobreza, Michoacán, 2014 $135-$

Tabla 4, Población y Edad Media por género, DDR-089 $141-$

Tabla 5, Principales comunidades de Jiquilpan $172-$

Tabla 6, Comunidades con Tenencia de Jiquilpan $173-$

Tabla 7, Asentamientos irregulares de Jiquilpan $173-$

Tabla 8, Principales comunidades de Sahuayo $178-$

Tabla 9, Asentamientos irregulares de Sahuayo. $179-$

Tabla 10, Sucursales de Banca Múltiple en DDR-089 $189-$

Tabla 11, Créditos y Subsidios para vivienda por municipios y programas en el DDR089 $191-$ 


\section{INDICE DE GRÁFICOS}

Gráfico 1, Ocupación y Empleo, Michoacán, 2007-2014

$132-$

\section{INDICE DE FIGURAS}

Figura 1, La tanda organizada por Karen ......................................................... 250

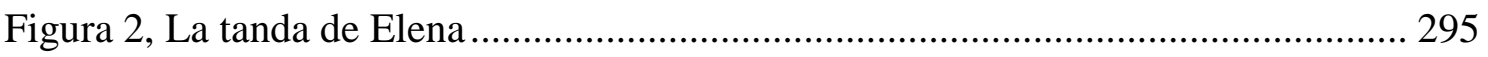

Figura 3, Diagrama de parentesco de los participantes en la tanda ............................. 344

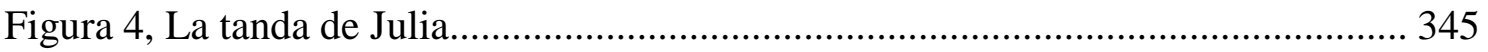




\section{Acrónimos}

ACM- Acción Católica Mexicana

ANACE- Asociación Nacional de Casas de Empeño

ANAGSA- Aseguradora Nacional Agrícola y Ganadera S.A.

BANCOMEXT- Banco Nacional de Comercio Exterior

BANJERCITO- Banco Nacional del Ejército, Fuerza Aérea y Armada

BANRURAL- Banco Nacional de Crédito Rural

BANSEFI- Banco de Ahorro Nacional y Servicios Financieros, Sociedad Nacional de Crédito

BM- Banco Mundial

BNCE- Banco Nacional de Crédito Ejidal

CAT- Costo Anual Total

CBTIS- Centro de Bachillerato Tecnológico, Industrial y de Servicios

CEPAL-Comisión económica para América Latina y el Caribe

CESO- Centro de Estudios Socioeconómicos de la Universidad de Chile

CIIDIR- Centro Interdisciplinario de Investigación para el Desarrollo Integral Regional

CNVB- Comisión Nacional Bancaria y de Valores

CONAVI- Comisión Nacional de Vivienda

CONDUSEF- Comisión Nacional para la Protección y Defensa de Servicios Financieros

CONEVAL- Consejo Nacional de Evaluación de la Política de Desarrollo Social 
COPLAMAR- Coordinación General del Plan Nacional de Zonas Deprimidas y Grupos Marginados

DDR- Distrito de Desarrollo Rural

EUA- Estados Unidos de América

EZLN-Ejercito Zapatista de Liberación Nacional

FECADEMICH- Federación Californiana de Michoacanos

FEDECMI- Federación de Clubes Michoacanos en Illinois

FMI- Fondo Monetario Internacional

FOBAPROA- Fondo Bancario de Protección al ahorro

FONHAPO- Fideicomiso Fondo Nacional de Habitaciones Populares

FOVISSSTE- Fondo de la Vivienda del Instituto de Seguridad y Servicios Sociales de los Trabajadores del Estado

FP- Fuerza Popular

GATT- Acuerdo General sobre aranceles aduaneros y comercio

HSBC- Centro Bancario Hong Kong Shanghái

IFE- Instituto Federal Electoral

IMF- Institución Micro-Financiera

INEGI- Instituto Nacional de Estadística y Geografía

INFONAVIT- Instituto del Fondo Nacional de la Vivienda para los Trabajadores

IPN- Instituto Politécnico Nacional 
LGSC- Ley General de Sociedades Cooperativas

NAFIN- Nacional Financiera

OCDE- Organización para la cooperación y desarrollo económicos

OIT- Organización Internacional del Trabajo

OMC-Organización Mundial del Comercio

ONG- Organización no Gubernamental

PAN-Partido de Acción Nacional

PDM- Partido Demócrata Mexicano

PGR- Procuraduría General de la Republica

PRD- Partido Revolucionario Democrático

PREALC- Programa Regional de Empleo para América Latina y el Caribe

PRI-Partido Revolucionario Institucional

PROCAMPO- Programa de Apoyos al campo

PRONASOL-Programa Nacional de Solidaridad

SAM- Sistema Alimentario Mexicano

SC de AP de RL de CV-Sociedad Cooperativa de Ahorro y Préstamo de Responsabilidad Limitada de Capital Variable

SEDESOL-Secretaria de Desarrollo Social

SECTUR- Secretaría de Turismo

SEMAR- Secretaría de la Marina 
SHF- Sociedad Hipotecaria Federal

SFF- Sistema Financiero Formal

SOCAP- Sociedad Cooperativa de Ahorro y Préstamo

SOFINCO- Sociedad Financiera Comunitaria

SOFIPO- Sociedad Financiera Popular

SOFOL- Sociedad Financiera de Objeto Limitado

SOFOM- Sociedades Financieras de Objeto Múltiple

TLCAN- Tratado de Libre Comercio de América del Norte

UAER- Unidad Académica de Estudios Regionales

UFC- Unión Femenina Católica

UNAM- Universidad Autónoma de México

UNID- Universidad Interamericana para el Desarrollo

UNS- Unión Nacional Sinarquista 


\section{Agradecimientos}

Durante los cinco años que han abarcado los estudios de doctorado hay muchas personas a las que agradecer su ayuda y buenos consejos. Sin ellos, esta tesis no hubiera sido posible o hubiese quedado incompleta ya que, a su modo, realizaron una contribución valiosa para el desarrollo de la misma.

Agradezco su apoyo, seguimiento y buenos consejos a los dos tutores de esta investigación, el Doctor Iñigo González de la Fuente y el Doctor Ángel Espina Barrio. También a la Universidad de Salamanca, “alma mater”, que me ofreció la oportunidad de realizar una estancia en la Universidad Nacional Autónoma de México sin la cual, esta investigación no se hubiese realizado. Igualmente, a la Universidad Nacional Autónoma de México, y en especial a la Unidad Académica de Estudios Regionales ubicada en Jiquilpan por acogerme. Entre las personas que conforman esta unidad académica cabe hacer especial mención al Doctor Guillermo Paleta que asesoró parte del trabajo de campo.

También me gustaría resaltar que la financiación de esta investigación no hubiese sido posible sin la oportunidad de trabajar en la Casa de Cultura de Jiquilpan, la Universidad del Valle de Atemajac en su sede de Zamora y la Universidad de Zamora, por lo que les estoy agradecida de ofrecerme la oportunidad de impartir docencia en sus instituciones.

Me gustaría destacar mi agradecimiento a los sujetos que participaron en la investigación, compañeros y amigos, los cuales durante los años de mi residencia en México me permitieron adentrarme en su vida cotidiana. 
Por último, mostrar mi gratitud hacia las personas que con el paso de los meses se convirtieron en amigos y confidentes, y a mi familia por las preocupaciones y desvelos que mi ausencia haya ocasionado. 


\section{Introducción}

La presente investigación parte motivada por acontecimientos políticos y económicos desencadenados durante la última década. La crisis económica de 2008, los consecuentes rescates financieros y la creciente desigualdad ocurridos en Europa han provocado la necesidad de mirar hacia América Latina como antecesora de muchos de los procesos en los que ahora el viejo continente está sumergido. El desencanto del ciudadano europeo que durante décadas había confiado ciegamente en el sistema, tanto en su faceta política como económica, se ha traducido en nuevos movimientos sociales, manifestaciones y la aparición de nuevos partidos políticos.

En la faceta económica de esta reestructuración del sistema, los ciudadanos, feligreses de un sistema financiero que ellos consideraban su aliado, han visto cómo los desahucios de viviendas, la contratación de preferentes, el aumento de los tipos de interés de sus créditos y todas las que podemos calificar "malas artes" del sistema financiero han jugado en su contra. Los países del sur de Europa presenciaron el desfile por los pasillos de sus instituciones de "los hombres de negro" del BCE y FMI mientras los noticieros usaban términos como deuda externa, fondos de inversión, agencias de calificación y prima de riesgo para alertar a los ciudadanos que, bajo los cimientos de sus casas y sus cuentas bancarias, se estaba abriendo un abismo. Estos términos no eran del todo desconocidos, pero hasta entonces solo habían sido utilizados en la sección de noticias internacionales. Durante los siguientes años se fueron explicando las $5 \mathrm{~W}^{1}$ pero nadie podía contestar a $1 \mathrm{H}^{2}$. La respuesta al "cómo" tardaría años en llegar. Esta pregunta

\footnotetext{
${ }^{1}$ What?, When?, Who?, Where?, Why?- ¿Qué?, ¿Cuándo?, ¿Quién?, ¿Dónde?, ¿Por qué?

${ }^{2}$ How?- ¿Cómo?
} 
derivó en dos corrientes: una institucional, periodística y más tarde judicial que, motivada por entender el cómo se había producido esta hecatombe financiera, explicaba los acontecimientos primero, como un caso de sobreendeudamiento de los hogares, después como el último intento de dominación de los mercados y la desaparición de la clase media, y en su etapa actual como un entramado de corrupción. La otra corriente que no tuvo tanto protagonismo pero que se convirtió en la primordial de la clase trabajadora intentaba entender cómo poder mantenerse, cómo sobrevivir sin salir perjudicado de esta crisis.

España es el país de los antes y el después, hay muchos antes y después en el imaginario colectivo que nos ayudan a entender cómo llegamos a donde nos encontramos. Estos puntos de no retorno, en los que de alguna manera cambió la idiosincrasia del país para convertirse en alguna cosa en cierto modo diferente son utilizados por los ciudadanos para encontrar la justificación de su actual situación. El antes y después de la crisis, no tanto para las instituciones o los medios de comunicación, pero sí para los ciudadanos de España y parte de Europa fue la llegada de la moneda única, el euro. Además de la inflación, el déficit y la especulación que habia originado cumplir con los requisitos necesarios para formar parte del "club" (datos por otra parte no contemplados en el día a día de los ciudadanos), los acontecimientos ocurridos durante los primeros años de la crisis tuvieron en el imaginario colectivo un culpable oculto que redireccionaba la culpa hacia los endeudados, que a su vez dirigían sus reclamos hacia el sistema bancario. La banca y los mercados financieros se erigieron en culpables y victimas del caos mientras defendían sus actividades bajo el imperativo "L'État, cést moi”, y el poder político les dio la razón una vez más.

El uso de los sistemas financieros formales por parte de la población experimentó una reducción notable y la desconfianza en los bancos aumentó según se iba desarrollando la crisis. El alto índice de inclusión financiera en Europa había generado que la crisis 
afectara a un gran número de personas que tenían créditos, hipotecas o valores, así como planes de pensión o inversiones. No era la primera vez, pero la generación más joven no sabía encontrar una alternativa al mismo sistema que les había llevado a esa situación.

Esta investigación se conformó dentro de este contexto y desde una perspectiva antagónica a un gran número de investigaciones que analizan el bajo índice de inclusión financiera como un problema al que hay que buscar solución. Este estudio no pretende ensalzar los beneficios de la inclusión financiera, ni presentar la economía informal como marginal o peligrosa. Su objetivo principal es presentar la realidad etnográfica de los sistemas financieros alternativos desde su heterogeneidad, los discursos, practicas, condicionantes, problemas y conductas que dan origen a que estos sistemas se encuentren incrustado en el tejido social. Al igual que sucediese con los microcréditos desde la década de los noventa, la inclusión financiera se ha convertido en un meta, algunas veces desde una perspectiva desarrollista o modernizadora, y otras como elemento indispensable para la implantación de medidas neoliberales y el crecimiento de la clase media. Por ello, es innegable que esta investigación parte de la premisa contraria, evitando con ello hacer apología de los beneficios de la economía informal, sino intentando buscar un equilibrio que permita que ninguna de las dos variantes, la formal y la informal, tomen el control absoluto.

Si bien la economía formal, la inclusión financiera y el acceso a servicios financieros de gran parte de la población puede ser entendida como una oportunidad de crecimiento, otorgar el poder absoluto de nuestras finanzas a un sistema que persigue la maximización del beneficio puede llevarnos a capitalizar en exceso y ser individuos vulnerables a meced de los mercados.

La economía informal por su parte puede ignorar los principios básicos de convivencia, favorecer las actividades delictivas, excluir a parte de la población y operar 
fuera de las leyes, pero también servir de soporte a la población y, con ello, darle una independencia sobre su dinero que de otra forma no puede conseguir.

Existe una disputa no resuelta en el mundo académico sobre la mejor manera de denominar a los sistemas financieros que operan en la informalidad. Entre la multitud de denominaciones podemos encontrar la economía no regulada (Portes, 1995); economías cotidianas o economías sociales (Narotzky, 2013); economía informal (Portes y Haller, 2004) y otros trabajos académicos que analizan alguno de estos sistemas, como las tandas (Anderson, 1966; Gamble, 1944; Geertz, 1962; Kerry, 1976; Kurtz y Showman, 1978; Adler Lomnitz, 1977). Otros autores, sin mencionar ninguno de estos conceptos, presentan estos sistemas financieros como elementos de resistencia al modelo capitalista y en otras ocasiones también podemos encontrar estos mismos sistemas presentados como capaces de generar desarrollo y modernización. Junto a esta confusión de términos apareció el anteriormente mencionado "microcrédito" fomentado por organismos oficiales y la ONU, acuñando esta denominación solo para los créditos enfocados en combatir la pobreza.

Ante la profusión de términos presentados y con la única intención de simplificar el debate para una mayor comprensión de la investigación, se ha utilizado el término "alternativo" para englobar estas prácticas. El uso de este término no supone que sea mejor o peor, sino únicamente calificarlo como otra opción, utilizada con multitud de motivaciones, y con diferentes resultados.

Con el fin de enterder los procesos y cambios, tanto económicos como sociales derivados de la crisis financiera de 2008, presentamos un análisis pormenorizado del paisaje financiero de la Ciénaga de Chapala, región que ha tenido una notable transformación a raíz de la implantación de las medidas neoliberales de las últimas décadas del siglo XX. 
El paisaje financiero (Bouman y Horpes, 1994), condicionado por los cambios históricos y los particularismos regionales será analizado cualitativamente como el conglomerado de normas, relaciones, acciones, relaciones sociales y procesos internos de la comunidad que configuran las transacciones, factores de selección, participación o exclusión en los sistemas financieros y el funcionamiento de los roles de ahorradores, prestamistas, prestatarios y avalistas.

La presente investigación se desarrolla en México, país que durante las últimas décadas ha implantado políticas neoliberales. Este hecho ha generado un aumento en los sistemas financieros alternativos, en algunos casos debido al aumento del sector informal, y en otros por la desconfianza o incertidumbre hacia los sistemas formales.

Los sistemas financieros informales abarcan un gran numero de estrategias destinadas a solventar dentro de lo posible el ahorro y el crédito sin recurrir al sector formal de la economía.

En esta obra se depositan cinco años de trabajo en los que se ha pretendido entender la formación, funcionamiento y resultados del paisaje financiero mexicano, enfocando el interés primordial en el sistema informal. Para ello se ha realizado una investigación del paisaje financiero de la Ciénaga de Chapala (Michoacán), y más concretamente de dos localidades vecinas, Jiquilpan y Sahuayo. Aunque estas guardan particularidades en algunos casos opuestas a su vecino, configuran una población que se sitúa entre el mundo rural y urbano. Este carácter dual permite que los lazos sociales y la percepción de comunidad por sus habitantes sigan vigentes mientras el carácter urbano e individualista también está presente.

La elección de esta comunidad estuvo determinada por las características ya mencionadas, pero también porque sus particularidades confrontadas presentaban dos 
Méxicos contemporáneos que cohabitan en relativa armonía. Uno desarrollista, laico y nostálgico de la herencia revolucionaria y otro tradicional, católico y conforme con las políticas neoliberales.

La región, con sus luchas internas de poder y dominio, sufre las luchas e inseguridad ocasionadas por el narcotráfico y los enfrentamientos armados entre los Cárteles de La Familia Michoacana y los Templarios (Cárteles más importantes de Michoacán) contra Nueva Generación (Cártel de Jalisco). La Ciénaga de Chapala, en situación de frontera entre los dos estados ha experimentado una degradación de la confianza de los ciudadanos hacia sus gobernantes o las fuerzas policiales. La suma de estos factores, los cambios históricos, la implantación de las medidas neoliberales, la descomposición de los poderes del estado, y la desconfianza de los ciudadanos hacia las instituciones ha generado un paisaje financiero donde los sistemas financieros informales (alternativos) captan cada vez un mayor porcentaje de la población.

Para esta investigación se ha llevado a cabo una etnografía que presenta la cotidianeidad de individuos que precisan, prestan o deben dinero dentro de los sistemas financieros que operan fuera de la formalidad. Como hipótesis principal se intenta confirmar si los sistemas financieros informales utilizados por los habitantes de la Ciénaga de Chapala, y en concreto, aquellos que forman parte del DDR 089, desempeñan funciones financieras incrustadas en el tejido social para atender las necesidades de la población excluida de los sistemas financieros formales. Esta hipótesis principal pretende sentar las bases para entender el nivel de incrustamiento de los sistemas financieros en el tejido social y cuál es el nivel de dependencia que existe entre dichos sistemas y el tejido social. 
Para una mejor comprensión de los sistemas y su papel como recurso que parte desde el tejido social se han contemplado dos subhipótesis que intentan atisbar las dependencias y correlaciones que surgen entre los sistemas y el tejido social.

La primera de estas subhipótesis está inscrita en el debate emprendido por múltiples estudios sobre el origen de este tipo de sistemas, donde se cuestiona si su procedencia es local o una importación.

En segundo lugar, planteamos que el funcionamiento de los sistemas financieros alternativos es posible gracias a la articulación de tres elementos indispensables, el don como obligación moral, la posesión de capital social como facultad que permite la confiabilidad, y la intervención de las economías afectivas capaces de conducir la conducta. Estos tres elementos guiaran el trabajo de campo etnográfico, siendo los predecentes teóricos de la antropología económica.

Los objetivos propuestos para la realización de la investigación pretender validar dichas hipótesis y ahondar en la estructuración del paisaje financiero y su desempeño en las relaciones sociales de la comunidad.

El primer objetivo desempeña una función descriptiva y analítica, destinado a definir el paisaje financiero de la región de la Ciénaga de Chapala, su funcionamiento y los procesos internos que es capaz de generar.

El segundo objetivo pretende poner en relieve las pautas sociales que intervienen en la conformación de grupos de individuos que usan estos sistemas financieros informales y las penalizaciones sociales que pueden sufrir en caso de incumplimiento del compromiso adquirido.

La investigación parte de una premisa no dulcificada de los sistemas financieros informales pretendiendo con ello no enfocar el análisis únicamente en la población 
excluida del sistema financiero formal. Para ello, han sido seleccionados sujetos de diferentes niveles económicos evitando presentar estos sistemas como único recurso de parte de la población. Aunque es cierto que para una parte de la población mexicana los sistemas financieros informales son el único acceso a sistemas de financiación, sus usuarios no son solo ellos, pudiéndose encontrar estas modalidades de crédito entre la población de diferentes niveles económicos.

El conjunto de la investigación se ha estructurado en cuatro bloques temáticos:

1- Breve repaso de los aspectos teóricos y metodológicos de la investigación, donde se presentan las líneas de trabajo, el horizonte teórico, tanto económico como antropológico y la metodología utilizada.

2- Descripción de la comunidad estudiada, en la que se presenta una contextualización del paisaje financiero mexicano durante las últimas décadas y el análisis pormenorizado a las características regionales de la Ciénaga de Chapala y el DDR 089.

3- Un análisis del paisaje financiero del DDR 089 en su conjunto, tanto formal como informal.

4- La presentación de los datos recabados durante el trabajo de campo a través de los sujetos participantes en la etnografía.

El primer bloque temático, dividido en cinco capítulos, pretende poner de manifiesto el núcleo teórico y metodológico de la investigación, a lo que se suma los objetivos e hipótesis anteriormente mencionados. Después del primer capítulo dedicado a presentar las líneas de investigación, se expone el horizonte teórico y discusión 
conceptual sobre la ciencia económica que posteriormente será debatida, tanto por su funcionamiento como por los efectos. En este segundo capítulo se encuentran los referentes teóricos y escuelas que dieron origen al sistema económico actual, haciendo especial hincapié en las tres escuelas que fundamentaron la configuración de la teoría económica capitalista actual. Con la intención de presentar algunos rasgos de la ciencia económica que son susceptibles de ser debatidos desde la antropología, se realiza en esta sección una demarcación del objeto de estudio de la economía como ciencia, tomando como referente teórico a la Escuela Austriaca. Es en esta escuela donde se produce la primera demarcación sobre dos facetas económicas, aquella analizada y desarrollada por la ciencia económica en extenso, proponiendo una sociedad cataláctica (von Mises, 2001) en la que el comportamiento colectivo persigue la maximización del beneficio, y la perspectiva praxeológica en la cual, la acción humana tiene como elementos de análisis las conductas, valores y fenómenos sociales y donde el ámbito económico es una faceta dependiente de esta complejidad.

El debate emprendido por la Escuela Austriaca es utilizado en esta investigación para definir el espacio operacional de la antropología económica. Frente al desarrollo de la Escuela Neoclásica que postula necesidades infinitas y bienes escasos y utilizando una metodología puramente cuantitativa (Jevons, 1875), la rama praxeológica definida por la Escuela Austriaca presenta un espacio investigador mucho más complejo en el cual la acción humana y la toma de decisiones económicas no obedece a la ciencia de la escasez, sino a una metodología cualitativa, de carácter holista y enfocada en el estudio de la acción humana como inscrita en un espacio social con múltiples referentes ideológicos y conductuales, el espacio ocupado por la antropología económica.

Esta división de la esfera económica es difícil de entender sin tomar como referente las dos categorías en torno a la ideología presentadas por Gramsci. Frente a una 
ideología intelectual, definida por el autor como doctrina, que inscribe al individuo actual con las características del Homo Oeconomicus que definió el liberalismo, se encuentra enfrentada una ideología moral. Esta ideología se compone de los valores, las prácticas y representaciones sociales dentro de una cultura concreta. Como señala Gramsci (1980), no todos los elementos de una cultura son susceptibles de ser considerados parte de la ideología moral, ya que tan solo aquellos que permiten una operación de legitimación de las relaciones de dominación son capaces que moldear los componentes de la ideología moral.

La teoría económica y la ideología como elementos para modelar representaciones sociales, prácticas y valores culturales son presentados en esta primera sección bajo la premisa de la capacidad que la ciencia económica tiene de crear ideología. Como referente para el estudio de los sistemas financieros alternativos, esta concepción de la economía como dependiente y a la vez creadora de patrones culturales nos sirve para ampliar la comprensión de las dinámicas sociales y los agentes motivadores en el uso, funcionamiento y exclusión de dichos sistemas.

La segunda parte del primer bloque, subcapítulos cuatro, cinco y seis, están destinados a presentar un estado actual del sistema económico capitalista, su expansión y su contextualización en los acontecimientos más cercanos. Por un lado, encontramos la Teoría de la Dependencia (Presbich, 1950) y las relaciones de dominación entre naciones, dentro de las categorías de Centro y Periferia para referirnos a la potencialidad económica de cada una de ellas. Estas relaciones de dominación se establecen a través de la acumulación por desposesión (Harvey, 2004), capaz de someter a ciertas naciones en beneficio de aquellas que pertenecen al centro. Este proceso, junto con la financiarizacion del sistema económico, son los antecedentes del considerable número de la población mundial que se encuentra en el sector informal al que posteriormente nos referiremos y 
en el que operan parte de los sistemas financieros aquí presentados. Para finalizar, se describe algunos componentes y resultados de la crisis económica de 2008, siendo esta contemporánea a la realización de esta investigación.

El tercer capítulo de este bloque se ha dedicado íntegramente a realizar un repaso histórico al desarrollo teórico y metodológico de la antropología económica. En él podemos encontrar las primeras aportaciones etnográficas en torno a los sistemas económicos de las sociedades primitivas y el posterior debate entre formalistas y sustantivistas en sus dos etapas. En adelante, y realizando una selección de autores y escuelas que han servido de influencia y guía para esta investigación y en especial para la recogida de datos y su posterior discusión, presentamos la economía desde una perspectiva antropológica como necesariamente incrustada en el tejido social (Polanyi, 2011), compuesta de diferentes estructuras que operan articuladas entre sí (Rey, 1971). No solo nos limitaremos a presentar los sistemas financieros alternativos como estructuras, sino que planteamos un análisis de estas estructuras en base a su composición de clase, entendiendo que el uso, participación o exclusión de estos sistemas forma parte de la ideología moral anteriormente mencionada.

Una vez finalizada esta retrospectiva a las dos ramas de conocimiento que se funden en esta investigación, la económica y la antropológica, hemos considerado necesario incluir un cuarto capítulo en el que se presentan algunos de los conceptos clave con los que posteriormente trabajaremos en la etnografía. Entre ellos presentamos la reciprocidad, el intercambio y el consumo como pilares básicos para emprender el estudio y análisis de la investigación, introduciendo posteriormente el sector informal y el capital social.

El primer bloque de esta investigación está finalizado con la metodología y técnicas empleadas para la realización de esta tesis. Los primeros subcapítulos están 
destinados a la descripción y contextualización del sujeto investigado, para posteriormente realizar un breve repaso del desarrollo del trabajo de campo durante los cuatro años de su realización, 2012-2016. Las técnicas utilizadas, entre las que se encuentra la observación participante y las entrevistas abiertas semiestructuradas, todas ellas realizadas en un entorno de co-habitabilidad, serán presentadas en bloques posteriores.

El bloque dos examina el espacio investigado, partiendo de lo global hasta llegar a lo local. El primer capítulo está dedicado a un breve análisis del desarrollo histórico de la economía mexicana, haciendo especial hincapié en el sistema financiero, los conflictos y la implantación de políticas neoliberales. Este recorrido inicia con la presidencia de Salinas de Gortari, para terminar con el primer año de Peña Nieto, año en el que inicia esta investigación. En él se presentan los factores que originaron la concentración bancaria, el aumento del sector informal y la exclusión financiera desde una perspectiva nacional condicionada por las medidas tomadas por los distintos gobiernos en las últimas décadas. El desarrollo de las transformaciones vividas por el país es complementado con las medidas tomadas por parte del gobierno mexicano para combatir el narcotráfico. La introducción del aumento de la violencia generada por narcotráfico está intrínsecamente relacionada con la cotidianeidad que se recoge en la etnografía, estando presentes los problemas de inseguridad y violencia durante el transcurso del trabajo de campo.

El segundo capítulo reproduce la discusión en torno a las transformaciones acontecidas en el mundo rural, la reconversión productiva y la pluriactividad. Algunas de estas transformaciones quedarán patentes cuando se describa la región objeto de estudio.

Los capítulos 3, 4 y 5 tienen como objetivo realizar un zoom sobre la región que permita al lector conocer mejor las particularidades e identidades del territorio. Iniciando con el estado de Michoacán, la implantación del monocultivo en parte de su territorio, la 
migración hacia los Estados Unidos de América, la conflictividad existente en los territorios causada por diferentes Cárteles (grupos dedicados a la delincuencia organizada), la creciente desigualdad y la desaparición y/o desvirtuación de los poderes del Estado en ciertas regiones definen la contemporaneidad en la cual se desarrolla la etnografía.

La Ciénaga de Chapala, y específicamente el Distrito de Desarrollo Rural 089, región de estudio en esta investigación, son analizados desde el contexto histórico como un conjunto de municipios que co-habitan y a la vez se mantienen en conflicto. La llegada de las políticas neoliberales ha provocado múltiples transformaciones, no solo en el terreno, sino que estas se encuentran patentes en las identidades locales. Ejemplo de ello son las organizaciones de migrantes.

Para terminar este segundo bloque se realiza una descripción de los municipios de Jiquilpan y Sahuayo, principales localidades en las que se realizó la etnografía. Se presenta, a través de elementos como las festividades, el aspecto urbano y la ideología, tanto intelectual como moral, una descripción de las identidades de los dos municipios.

El tercer bloque ha sido utilizado para poner de manifiesto algunos datos cuantitativos de la investigación. Con el fin de presentar una imagen completa del sistema financiero, tanto formal como informal, de la región de la Ciénaga de Chapala se exponen las diferentes modalidades encontradas en el trabajo de campo que se encuentran presentes en los municipios estudiados. Entre los sistemas financieros formales, podemos encontrar sucursales bancarias presentes en la región y el uso de créditos para vivienda ofrecidos por diferentes programas estatales. Estos sistemas de financiamiento son utilizados para la obtención de grandes sumas de dinero, destinado en su mayoría para la compra de vivienda, autos o inversiones. En el caso de precisar dinero para el consumo más cotidiano, las opciones dentro del sistema financiero formal son las tarjetas de crédito 
y el pago fraccionado. Las tarjetas de crédito, aun formando parte de la Banca Múltiple ${ }^{3}$, han sido recogidas en un apartado distinto con la intención de remarcar su función diferente, ya que durante la investigación se generalizó el uso del pago telemático del salario para los trabajadores formales con la intención de incentivar la inclusión financiera. Este proyecto pretendía intentivar el acceso a la banca múltiple por parte de la población con menores ingresos, pero sus reducidos salarios hieron difícil o imposible acceder al financiamiento en estas entidades.

El pago fraccionado, utilizado principalmente en las tiendas departamentales de Coppel y Elektra ${ }^{4}$, es el sistema financiero formal con mayor uso en la región. Aunque está destinado principalmente al consumo en el propio establecimiento, y los intereses y condiciones de pago pueden resultar abusivos, este tipo de comercios tiene mucho éxito en la región por ofertar ciertos productos que difícilmente se encuentran en otros establecimientos, principalmente aparatos tecnológicos y electrodomésticos.

El cuarto subcapítulo de este bloque se encuentra enfocado en la presentación de las cajas populares presentes en los dos municipios principales. Todas ellas ofrecen la posibilidad de acceso a crédito para las personas que conforman la caja, aunque su ingreso en la misma precisa de poseer ciertos requisitos, tanto económicos como de carácter social o incluso religioso.

Las casas de empeño ocupan el último subcapítulo de este bloque, presentándose como último recurso de financiamiento en muchos casos. Aunque el empeño o venta de un bien no es una opción deseada por los consumidores de este tipo de servicios, la crisis

\footnotetext{
3 Conjunto de entidades o instituciones reguladas por el Estado que presta servicios bancarios.

4 Tiendas departamentales mexicanas de venta que ofrecen créditos con pocos requisitos para el consumo en sus establecimientos.
} 
económica y la reducción de ingresos de muchas familias han provocado que este tipo de establecimientos sean muy numerosos en la región.

El segundo capítulo expone las modalidades de financiamientos que operan desde la informalidad. Este tipo de modalidades tendrán una amplia descripción dentro de la etnografía, por lo que en esta sección solo se presentan de manera generalizada, realizando una descripción del funcionamiento de cada una y las variantes existentes. En este tipo de financiamiento se encuentran:

1- Los apartados, destinados a fomentar el consumo y ofrecidos por los comerciantes

2- Las kermeses, celebraciones destinadas a recaudar fondos, ya sea para un objetico colectivo y el beneficio individual del organizador

3- Las tandas o asociaciones rotativas de crédito, estudiadas desde la disciplina antropológica desde la década de 1960, destinadas a coordinar grupos de individuos que ahorran conjuntamente para ofrecer la oportunidad a los poseedores de los primeros turnos de obtener un crédito basado en la confiabilidad de todos los integrantes

4- Los prestamistas locales que ofrecen crédito bajo diferentes condiciones que se inscriben en dos vertientes, aquellos que realizan esta labor entendiendo su actividad como una ayuda a la comunidad, y los que pretenden conseguir el máximo beneficio posible del préstamo con altos intereses. 
La presentación de los sistemas financieros, formales e informales, tanto en sus características como en su funcionamiento, selección de participantes y penalizaciones, sirve de introducción para la exposición de los datos etnográficos del bloque 4.

Este bloque, dividido en cuatro capítulos, presenta las historias de vida, la cotidianeidad de cada uno de los sujetos participantes y su interacción con uno a varios de estos sistemas.

El primer capítulo, enfocado en la persona de $\operatorname{Karen}^{5}$, comerciante que precisa de dinero para realizar la compra de nuevos productos para su establecimiento, sirve de eje vertebral para presentar el pago fraccionado y una modalidad de tanda no encontrada en la literatura anteriormente presentada. Su necesidad de financiamiento es resuelta a través de la organización de una tanda de carácter retroactivo, en la cual, las participantes formarán parte de su entorno social más cercano, familiares y amigos. A través de esta historia se presentan diferentes sujetos, cada uno con sus motivaciones personales para la participación en la tanda, y la resolución de la misma, tanto desde una perspectiva económica, como social. El desarrollo y finalización de la tanda pone de manifiesto la presencia indispensable del capital social para la participación, así como las diferentes penalizaciones dependiendo de si el participante es considerado parte integrada o no del grupo social mayoritario.

Elena es la protagonista del segundo capítulo. Organizadora de una tanda periódica y mujer importante en la comunidad, mantiene una tanda activa con el propósito de servir de ayuda a los vecinos de su comunidad con más bajos recursos. Además de su papel en la tanda, también forma parte de una comunidad en torno a la parroquia de San

\footnotetext{
${ }^{5}$ Los nombres presentados en la etnografía son ficticios en aras de garantizar el anonimato de los sujetos participantes.
} 
Cayetano en Jiquilpan, preparando kermés y actividades con la intención de recaudar dinero para la comunidad.

El tercer apartado está centrado en Humberto, marido de Elena, quien también, con la intención de servir de apoyo a la comunidad, ofrece préstamos a sus vecinos. En este capítulo también se incluyen la aportación de su hijo y la pareja de este realizan a través de organizaciones de migrantes. Para finalizar con la familia, el hijo pequeño de Humberto completa el último subcapítulo, ofreciendo un testimonio clarificador de los problemas y falta de oportunidades que encuentra la generación más joven en la región.

El empeño de bienes y una tanda muerta ${ }^{6}$ completan la etnografía con el testimonio de Gustavo, trabajador de una casa de empeño y participante en una tanda familiar. A través de Gustavo y las entrevistas realizadas a usuarios de la casa de empeño se ponen de manifiesto los condicionantes principales para recurrir a este tipo de financiamiento. De igual modo, las experiencias, discursos y conductas de los usuarios se ven reflejadas en estas entrevistas, intentado con ellas ofrecer un abanico de fenómenos que son dependientes del uso de este tipo de establecimientos.

La tanda muerta en la que participa Gustavo tiene como característica ser íntegramente familiar, por lo que las relaciones de dominación y confianza están asentadas en los lazos filiares.

La investigación presentada a continuación busca como objetivo último la explicación e interpretación de las pautas sociales que hacen posible el funcionamiento de los sistemas financieros alternativos. Para ello, se han seleccionado sujetos de

\footnotetext{
${ }^{6}$ Asociación rotativa de crédito en la que el organizador no participa. Dentro de las modalidades de este tipo de tandas podemos encontrar aquellas en las que el organizador no recibe ninguna contribución por su trabajo, otras en la que se acuerda una cantidad al inicio de la rotación, y por último, aquellas tandas en las que el organizador recibe el número 0 , una contribución igual a la asignación de la tanda para un participante.
} 
diferentes niveles socioeconómicos e inmersos en diferentes roles sociales, con la finalidad de entender cómo la exclusión o inclusión a este tipo de sistemas está condicionada por la posesión del capital social, el respeto a las normas morales de la comunidad, y la similitud ideológica entre los participantes en tanto garantía de reciprocidad entre semejantes. Esta atmósfera social es capaz de generar un paisaje financiero que situa el grueso de las transferencias en la informalidad, donde los postulados de la teoría económica son invalidados en pos de la conformación de grupos que actúan dentro de sus propios valores y discursos. La obligación del don como capaz de generar una obligación moral puede ser entendido como algo exento de materialidad, pudiendo comprender algunas dinámicas de estos tipos de financiamientos inmersas en la misma lógica, la obligación de dar, recibir y devolver se encuentra en un nivel de incrustamiento semejante al propio sistema financiero. En el desarrollo de esta investigación se verán ampliadas estas cuestiones, así como la presentación de debates secundarios en torno al crédito y deuda. 


\section{BLOQUE I. ASPECTOS TEÓRICOS Y METODOLÓGICOS}

\section{Líneas de trabajo (hipótesis y objetivos)}

El objeto de estudio se ha ido perfilando en torno al interrogante que se presenta en el título de la tesis "Micro-créditos o macro-deudas". Este interrogante se formuló por primera vez a mediados de 2012 cuando comenzaba el quehacer etnográfico. La utilización de los prefijos micro y macro no tienen la intención de analizar ni los microcréditos, entiéndase con ellos los créditos fomentados desde las políticas al desarrollo, ni las macro-deudas, como deudas presentes en la macroeconomía. Los prefijos buscan significar la ambivalencia, por un lado, del tamaño del importe que se maneja en estas transacciones, apuntando a un crecimiento de la deuda con respecto al crédito, y un enfoque social en el que los créditos de carácter individual se convierten en deudas colectivas.

Con el avance del trabajo etnográfico y el estudio teórico que ayudó a configurar el marco teórico que péndula entre la antropología economía y la teoría económica se fueron configurando tanto las hipótesis como los objetivos de la investigación, tanto la formulación de las mismas como las derivadas.

\section{Hipótesis principal:}

Los sistemas financieros alternativos (informales) utilizados por los habitantes de la región de la Ciénaga de Chapala, DDR 089, desempeñan funciones financieras 
incrustadas en el tejido social para atender las necesidades de la población en riesgo de exclusión de los sistemas financieros formales. Los sistemas financieros alternativos, incrustados en el tejido social realizan una labor dependiente del capital social del sujeto.

Por "sistemas financieros alternativos" entendemos los sistemas financieros no regulados por leyes gubernamentales que operan dentro de la informalidad (préstamos, apartados, tandas, empeños); entendemos por "funciones financieras incrustadas en el tejido social" las operaciones financieras que se desarrollan en el sector informal y para las cuales el capital social del solicitante y de su entorno es determinante para su participación; "la población en riesgo de exclusión" engloba desde trabajadores informales, personas sin recursos económicos e individuos que carecen de salario o ingresos y son dependientes económicos de terceras personas.

\section{Sub-hipótesis vinculadas:}

1-Los sistemas financieros alternativos no son formas tradicionales de financiamiento en el mundo rural. Por el contrario, son sistemas que han irrumpido en el mundo rural junto con otras dinámicas capitalistas para posibilitar el consumo

2- El funcionamiento de los sistemas financieros alternativos es posible por la confluencia de tres dinámicas sociales articuladas entre sí, el don como obligación moral, la posesión de capital social como facultad que permite la confiabilidad, y la intervención de las economías afectivas.

La confluencia entre las tres dinámicas no está presente en todo momento, sino que la articulación de algunas de ellas hace posible el funcionamiento de diferentes tipos de sistema financiero. Entendemos que "las obligaciones relacionadas con el don" son aquellas formuladas por Mauss (2010), la obligación de dar, recibir y devolver; será 
estudiada en esta investigación por su capacidad generadora de reciprocidad entre individuos. El capital social se analizará como cualidad individual y social que posibilita la participación, así como elemento sensible de sufrir un desgaste cuando se incumple las expectativas que el mismo capital social condiciona. Por economías del afecto entendemos el concepto tal como lo define Ahmed (2004,) emociones capaces de unir a los sujetos en colectividades. Sin embargo, analizaremos los condicionantes y consecuencias de la economía del afecto desde una perspectiva más cercana a la de Richard y Rudnyckyj (2009) en la cual el afecto es un medio para conducir la conducta y facilitar la transformación neoliberal.

\section{Objetivos:}

Los objetivos fijados en esta investigación se enmarcan dentro de dos categorías. En primer lugar, se pretende describir el "paisaje financiero" (Bouman y Horpes, 1994), otorgando un papel importante a los cambios históricos, relaciones sociales, normas y procesos internos de la comunidad. En segundo lugar, se pretende explicar su proceso teniendo en cuenta el papel que el capital social desempeña en el la selección y participación de sujetos en los sistemas financieros que ofrecen una alternativa al sistema regulado por la legislación gubernamental. Por último, se presentan dos interrogantes a los que esta investigación intentará dar respuesta a través de los datos recabados en el trabajo de campo teniendo en cuenta que la hipótesis principal no pueda ser validada.

$1^{\circ}$ Describir y analizar los sistemas financieros formales e informales que se encuentran presentes en la región de la Ciénaga de Chapala, DDR 089, a partir de las interacciones sociales de sus participantes, normas y procesos internos generados. 
-Analizar cuáles son los factores que intervienen en la selección de un sistema financiero.

-Exponer los mecanismos de selección para la participación en cada uno de los sistemas financieros y su patrón de exclusión.

-Analizar el funcionamiento y proceso de financiación de los sistemas informales a través de los diferentes roles sociales, prestamistas, prestatarios y avalistas.

$2^{\circ}$ Señalar cuáles son las pautas sociales que intervienen en la conformación de grupos de individuos que usan los sistemas financieros informales y las penalizaciones sociales que produce el incumplimiento de los acuerdos.

-Explicar los diferentes tipos de penalización que sufren los morosos, sus factores, repercusiones y el desgaste del capital social que producen.

-Exponer cómo se articulan los diferentes sistemas financieros informales y como se produce el encadenamiento de deudas.

Por último, se contemplarán dos interrogantes que pretenden servir de guía en la investigación etnográfica y completar las conclusiones finales.

- ¿Son los sistemas financieros informales una respuesta a la exclusión que los Sistemas financieros formales ejercen sobre la población o, al contrario, es la población la que decide excluir a los sistemas financieros formales de algunos ámbitos de sus interacciones económicas?

-En el caso de que la población deliberadamente esté excluyendo en ciertos ámbitos a los sistemas financieros formales, ¿cuáles son los beneficios 
individuales y colectivos generados por la utilización de los sistemas financieros informales?

\subsection{Horizonte teórico y discusión conceptual sobre la teoría económica}

Los sistemas financieros alternativos objeto de estudio de esta investigación se encuentran operando en un sistema mucho más amplio en el que la formalidad y la informalidad conforman un todo en el que se inscribe el sistema capitalista. Dado que la antropología económica se ha desarrollado en un principio analizando sistemas económicos externos al capitalismo se ha considerado necesario contextualizar esta investigación a través de un recorrido en la historia tanto de la teoría económica, que ha creado el sistema capitalista, como de la antropología económica. Para ello, en un primer lugar, se realizará una exposición y discusión de las escuelas de pensamiento y modelos de sistema económico que han configurado la teoría económica actual en la que se inscribe la comunidad estudiada. Este repaso tiene como objetivo definir el estado actual de la cuestión a través de la ciencia económica señalando las escuelas y autores que han influido en la investigación.

\subsubsection{Las tres escuelas que fundamentaron el capitalismo: Mercantilismo,}

\section{Fisiocracia y Liberalismo}

La fundamentación de un sistema económico es imposible de entender fuera del contexto histórico, la estructura del Estado y la aparición de la burguesía. Aunque el debate sigue vigente a día de hoy, gran parte de los economistas consideran como primer germen del sistema económico actual las transformaciones originadas por la expansión del comercio exterior derivado de las rutas comerciales hacia América, África y Asia. 
Adam Smith denominó mercantilismo al conjunto de prácticas desarrolladas entre la primera mitad del siglo XVI y el siglo XVIII. Podemos considerar al mercantilismo la primera escuela económica independiente de la moral religiosa, cuya finalidad principal es el enriquecimiento del Estado. Desarrollada durante el período colonial, centra su importancia en el comercio exterior, la figura del Estado como eje principal de las actividades, y convierte la acumulación de metales preciosos en el propósito principal del intercambio.

Mientras en Inglaterra la escuela mercantilista expandía el comercio a través de su potencial naval en el siglo XVIII, en Francia surgía una escuela de pensamiento más relacionada con los valores de Contrato Social y la producción interna. La Fisiocracia presentaba las actividades agrícolas y los recursos naturales de la nación como los únicos en producir beneficio económico. El fisiocratismo intentaba superar el feudalismo europeo y el mercantilismo que había surgido de él defendiendo la existencia de una ley natural y negaba la validez de monopolios, impuestos y burgueses parasitarios. Su principal defensor, François Quesnay, se opuso firmemente al control de la economía por parte del estado y defendió la no intervención y la libertad económica. Su conocida frase “Laissez-faire, laissez-passer" (dejar hacer- dejar pasar) se convirtió en el mantra oficial de los fisiócratas que pretendían superar la época feudal y dar paso a una etapa ilustrada, con libertad económica.

El debate emprendido por estas dos escuelas, y también su fusión selectiva, dio origen a la tercera, el liberalismo económico. Presentado por Adam Smith en su obra " $L a$ riqueza de las naciones" (2009), publicada en 1776, presentaba el origen de la riqueza como un proceso individual en el que el ser humano busca obtener el máximo beneficio. El principal protagonista de la economía deja de ser el Estado produciéndose un cambio en el plano epistemológico similar al ocurrido durante el renacimiento. Si bien durante el 
renacimiento el cambio partió del teocentrismo hacia el antropocentrismo (en el caso de la ciencia económica el Dios feudal había sido el Estado), a partir del liberalismo, el antropocentrismo económico tomaría el control de las escuelas de pensamiento. El único modo de enriquecer a una nación sería enriquecer al individuo, y el éxito individual solo llegaría con la libre actividad y la no intervención. La ley natural que defendían los fisiócratas fue perfeccionada a través de los postulados que afirmaban que la interacción entre individuos que buscan su propio beneficio era capaz de regular automáticamente la economía manteniendo un equilibrio en el caos: los liberales la denominaron "La mano invisible". El hombre como agente emprendedor, libre y en continuo desarrollo buscando el máximo beneficio era legitimado por la ciencia económica y, al igual que en el Renacimiento, el cambio de plano epistemológico cuestionó si el cambio real era de Dios al hombre, o de Dios a convertir al hombre en un Dios, la ciencia económica pasó del Estado, al hombre-Estado o como se denominó el Homo Oeconomicus.

Aunque el liberalismo económico promulgaba el equilibrio en el caos a través de las múltiples interacciones entre individuos, eso no significa que dejase de ser político, y por tanto moral, del mismo modo que esa oda a la libertad no eliminaba la estratificación social de la época. En "Ensayo sobre el principio de la población" (1951), Malthus enlaza la libertad individual con el concepto de meritocracia convirtiendo a las clases bajas de la sociedad en responsables directos de sus carencias. Inglaterra decide eliminar las Poor $\operatorname{Laws}^{7}$ y todo aquel programa social o de caridad afirmando que la libertad económica hace que la responsabilidad de enriquecimiento sea una obligación individual, por tanto, el no enriquecimiento también pasa a ser un fracaso individual.

\footnotetext{
${ }^{7}$ Sistema de ayudas destinadas a la población de bajos recursos que durante la Edad Media se mantuvo vigente en Inglaterra y Gales. Los ciudadanos beneficiados por las Poor Laws eran principalmente vagabundos y mendigos, aunque parte de su influencia desapareció durante los siglos XIX y principios del XX, su abolición formal no llegaría hasta la instauración del estado de bienestar y las políticas sociales posteriores a la Segunda Guerra Mundial.
} 
La búsqueda de la lógica de ese equilibrio económico llevo a Ricardo en 1817 a desarrollar la "Teoría del Valor" (1959), argumentando que las mercancías obtienen su precio del trabajo y los beneficios, haciendo desaparecer la renta de terratenientes de la economía clásica. Al centrar su análisis en el trabajo y los beneficios, el autor desarrolla los conceptos necesarios para la posterior teoría de la plusvalía marxista, ya que el equilibrio económico debe instalarse entre el precio de producción y el precio de venta. Influenciado por Malthus y concibiendo que la economía regula múltiples esferas de la sociedad, se desarrolla en esta época la ley de bronce de los salarios ${ }^{8}$, la teoría económica capaz de regular la sociedad, los gastos de producción y mantener los beneficios a través del poder de la mano invisible. El liberalismo económico se convirtió en la herramienta ideológica de la burguesía contra la aristocracia, haciendo prevalecer el poder del comercio y la industria por encima de los privilegios de clase.

La lucha de clases que se estaba produciendo entre las clases dominantes solo llevó a una nueva explotación de la fuerza de trabajo, problemática que abordo Marx (1867) en "El Capital" (2007; 2009). La aparición de la escuela socialista es una respuesta a las teorías del liberalismo económico y la expansión del capitalismo. Para ello, Marx realizó un estudio histórico a través del materialismo, considerando el régimen económico la base de la sociedad. Esbozó la teoría de la plusvalía, ejemplificando con ella cómo la sociedad se estratificaba al convertir la fuerza de trabajo en una mercancía y presentar a la mano invisible como un régimen condicionante de desigualdades y no como la panacea del equilibrio que los burgueses pretendían.

\footnotetext{
${ }^{8}$ Teoría característica de la economía clásica. Promulga que los salarios tienen tendencia a mantenerse en el nivel mínimo para cubrir las necesidades de subsistencia de los trabajadores y garantizar la reproducción de la fuerza de trabajo. La teoría afirma que cualquier aumento del salario provoca el aumento en el número de hijos, generando un desequilibrio que se traduce en una mayor competencia por el empleo por lo que los salarios descienden nuevamente al mínimo.
} 
Posteriormente, Lenin utilizaría los supuestos desarrollados por Marx para analizar el nuevo imperialismo, afirmando que el capitalismo había creado nuevos monopolios cuya función principal era aumentar el capital financiero y crear una oligarquía financiera internacional.

Hasta el momento, hemos presentado teorías económicas ortodoxas que se complementan siguiendo una evolución lineal en el pensamiento económico. El objetivo de este análisis es generar una base para abordar la antropología económica desde una menor distancia a la ciencia económica por lo que no debemos conformarnos con la economía ortodoxa y cuidar de otorgar la atención necesaria a las teorías heterodoxas, en muchos casos, influenciadas por las ciencias sociales, que también intentaron salvar el espacio entre las dos disciplinas.

El institucionalismo se implantó en la economía estadounidense durante el período de entreguerras a partir de 1919, aunque posteriormente fue marginado por la economía ortodoxa durante la posguerra, con el ascenso de la economía neoclásica. Los institucionalistas generan una diferenciación entre el valor y el precio. Thorstein Veblen, fundador de la escuela, utilizó a Marx, Morgan y la etnografía para desarrollar una teoría económica que comprende la economía como una entidad sociopolítica y culturalmente condicionada en la que las elecciones económicas y el consumo no son posibles de catalogar sin las ciencias sociales. "El institucionalismo distingue netamente entre los determinantes universales de lo que es económicamente posible y los determinantes culturales limitados de lo que al fin y al cabo decidimos hacer" (Klein, 1994: 36). La escuela institucionalista comparte con la antropología el objeto de estudio, intereses y metodología, pero no han llegado a participar conjuntamente, desarrollándose de manera individual. 
Edificar una teoría de las instituciones sobre el fundamento de elecciones individuales es un paso hacia la reconciliación de diferencias entre las ciencias económicas y las otras ciencias sociales. La elección del enfoque teórico es esencial debido a que es preciso construir un conjunto de hipótesis consistente lógicamente, y potencialmente comprobable sobre una teoría de la conducta humana (North, 1994: 14).

En la década de 1980 reaparecerá esta corriente bautizada como nuevo institucionalismo, que mantendrá los rasgos principales de su predecesora al incorporar al análisis económico las ciencias sociales. Sus líneas principales están desarrolladas en torno al capital social y a la génesis social del valor (North, 1986). La escuela economía institucional tomará el relevo de los formalistas en el debate emprendido en torno al estudio de la esfera económica en las ciencias sociales. Sus aportaciones les hicieron merecedores del premio Nobel de economía a Douglass North y Robert Fogel en 1993.

Aunque muchos problemas en esta reconciliación no están todavía solventados, durante las últimas décadas se ha construido un aparato conceptual capaz de operar conjuntamente. Posteriormente, analizaremos las herramientas desarrolladas y cómo pueden ser utilizadas.

Volviendo a la economía ortodoxa, presentaremos la escuela de pensamiento económico todavía vigente, aunque con sus variaciones. La escuela neoclásica, gran triunfadora en los años posteriores a la Segunda Guerra Mundial, presentará a la economía como una esfera totalmente separada y con sus propias leyes. Los economistas neoclásicos, también llamados marginalistas, harán desaparecer las clases sociales del análisis económico, poniendo el énfasis en los individuos. El individuo percibido como 
el nuevo Homo Oeconomicus amplía su interacción económica más allá de la producción y acumulación convirtiéndose también en consumidor. Nótese la influencia que en la concepción del nuevo individuo económico tiene el Fordismo y el americanway para analizar la esfera económica como una serie de interacciones complejas. Jevons (1875) anticipó la respuesta a la complejidad económica postulando la necesidad de reducir los asuntos económicos a fórmulas matemáticas y entendiendo que el hombre guía sus deseos en busca del placer y evita el dolor. Promulgó una serie de leyes que pretendían estructurar la complejidad económica a través de la idea de la utilidad mermada, en la que la satisfacción del consumidor crece hasta alcanzar la saciedad, lo que dará origen a que los sistemas de producción implementen la obsolescencia planificada. En 1870 el marginalismo estaba desplazando a la economía clásica, nutriéndose de la revolución industrial y el desarrollo de nueva infraestructura. os neoclásicos crearán la teoría de valor-utilidad, correlacionando gracias a ella conceptos que hasta ahora se habían mantenido inconexos como Producción, salario y maximización del beneficio. Las necesidades humanas serán para los marginalistas infinitas y los bienes escasos, asumiendo como natural y axiomático el concepto de necesidad, una necesidad que solo el proceso económico puede satisfacer.

La economía se convierte en la ciencia de la escasez y su unidad de análisis es el individuo que busca incansablemente satisfacer sus necesidades y maximizar sus medios escasos, la decisión racional maximizadora. Muchas de estas afirmaciones fueron adoptadas por los antropólogos formalistas de la década de los 60; en contra se opusieron los sustantivistas y marxistas franceses. Posteriormente analizaremos este debate.

Para terminar este breve análisis de las escuelas económicas volveremos a las teorías heterodoxas y sus aportaciones, no tanto en el campo de la antropología como en la percepción social que se tiene de la economía. La escuela austriaca después de la 
Segunda Guerra Mundial fue criticada por la mayoría de los economistas porque rechazaba los métodos matemáticos y estadísticos en el estudio de la economía. Murray Rothbard afirmaba que las raíces de la escuela procedían de la Escuela de Salamanca del siglo XV y de los fisiócratas del siglo XVIII. La economía es concebida como la forma en la que se organiza la sociedad para llevar a cabo los procesos de producción, distribución y consumo de mercancías, siendo los individuos actores que cooperan para el desarrollo de dichas actividades. En la década de los 40 la escuela se divide en dos tendencias. La primera encabezada por Ludwing von Mises critica la metodología neoclásica; en su contra, Hayek acepta la metodología en su mayoría. La diferencia principal que encuentran estas tendencias frente a la teoría neoclásica es que mientras los neoclásicos analizan los ciclos económicos (especialmente los de producción y consumo), los austriacos centran su interés en los ciclos crediticos considerándolos la causa primordial que pone en funcionamiento la economía.

Dentro de las dos tendencias de la escuela austriaca, haremos hincapié en la encabezada por Mises al acercarse más al resto de ciencias sociales e intentar alejar a la economía de las ciencias exactas. La teoría económica de Mises realiza una importante distinción entre dos facetas de la economía, la teoría económica (cataláctica) y la teoría de la acción humana (praxeología) señalando como importante el estudio de la relación entre ambas. La variable introducida con Mises, e imposible de cuantificar como función matemática, es la empresarialidad, definida como la capacidad humana de descubrir nuevos fines y medios (von Mises, 2001). Lo que Mises presenta como una variante económica de carácter cuantitativo acerca notablemente la economía a la actividad antropológica. Hasta este momento, la economía había sido un campo que buscaba regularidades y leyes en los fenómenos de mercado, pretendiendo tener validez universal. Mises considera que la catalaxia económica opera con conceptos vacíos de contenido 
material, solo capaz de generar un sustrato objetivo a la comprensión de la economía en su faceta más amplia, dependiente para su aplicación y funcionamiento de la acción humana.

En contraposición a las teorías de Mises, Hayek se convertirá en el defensor del liberalismo y en un crítico ferviente de la economía planificada y del socialismo. Desarrolló la Teoría Austriaca del ciclo económico influenciado por la Teoría del dinero y el Crédito de Mises. Hayek analiza el ciclo económico a partir de los créditos concedidos a los bancos centrales con tipos de interés artificialmente bajos. Estos tipos de interés generan una bola de nieve que empuja a los empresarios a aventurarse a proyectos con un alto riesgo, provocando un desequilibrio entre producción, consumo e inflación. La intervención del Estado en la mejora de la economía solo genera para Hayek burbujas financieras que reinician el ciclo económico, como argumento en su libro “Camino a la servidumbre" (2005).

Posteriormente se desarrollarían otras escuelas de pensamiento económico como el Keynesianismo, el Monetarismo y el Neoinstitucionalismo que han ayudado a abrir debates sobre el papel del Estado y las instituciones en la economía desde una perspectiva macro.

Este resumido recorrido por algunas teorías económicas pretende contextualizar el desarrollo de la antropología económica y la creación de nuevas herramientas y conceptos analíticos que serán utilizados en esta investigación para abordar la vida económica de una región desde el consumo, el préstamo y la deuda. 


\subsubsection{Catalaxia, Economía Neoclásica y Microeconomía}

La teoría economía se ha desarrollado históricamente a través de los estudios económicos de los países occidentales. Esto ha provocado que su valor resida en el estudio de sociedades industrializadas, teniendo un desarrollo paralelo la economía y el capitalismo. La escuela austriaca intentó entender la fractura que se presentaba cuando la teoría económica neoclásica no confluía con los actores sociales, sintiéndose como un modelo impuesto que transgredía el comportamiento social de los individuos. Para ello, von Mises presentó la esfera económica dividida en dos vertientes. El primer lugar presentó una esfera económica cataláctica ${ }^{9}$, utilizando el término de Whately, en el que los intercambios siempre están condicionados por la búsqueda del deseo de maximizar su utilidad o beneficio. La catalaxia o economía crematística serán términos utilizados tanto por von Mises como por Commons para explicar el comportamiento colectivo. Hayek (1976) presentará la catalaxia como el concepto necesario para entender el funcionamiento de los mercados, entendiendo que los intercambios son espontáneos y se rigen por la búsqueda de beneficio individual. Para Hayek, la catalaxia encerraba las bases de la inteligencia colectiva, considerando que esta producía una mayor especialización, un comercio sano basado en la competencia perfecta, el progreso de ideas y estructuras sociales y el desarrollo de la innovación y la tecnología. La catalaxia es a la sociedad, lo que la mano invisible a la economía, un concepto abstracto sobre el que se asienta la defensa de la individualización y la libre competencia.

Sin embargo, von Mises ya advirtió que no se podía abordar los estudios económicos solo desde una perspectiva matemática, entendiendo que bajo la sociedad cataláctica en la que todas las elecciones eran racionales, y estas las fuentes del equilibrio

\footnotetext{
${ }^{9}$ Catalaxia proviene del término griego katallasso "pasar de enemigo a amigo". 
y la libre competencia, también residía la acción humana impredecible. Para el estudio de la acción humana presentó la segunda vertiente de los estudios económicos, la praxeología. La economía praxeológica estaáfuera de cualquier dogma y es imposible de predecir a través de valores matemáticos, por lo que presenta una fractura en la teoría económica, posicionándose más cerca de las ciencias sociales y en especial de la antropología económica.

Inscrita dentro de la lógica de la teoría económica, y bajo la óptica de una sociedad cataláctica se ha desarrollado el discurso de la teoría microeconómica. La microeconomía estudia el comportamiento económico de individuos o mercados generando diferentes subdisciplinas como la teoría del consumidor, de la demanda, la del equilibrio general y la de los mercados de activos financieros. Lo que propone la microeconomía es la generación de una teoría capaz de explicar a través de modelos matemáticos (como la teoría de juegos) el comportamiento social y económico de los individuos.

Como podemos observar, la teoría económica parte del estudio de la elección racional para entender el comportamiento humano relacionado con los intercambios económicos. Sin embargo, esta teoría ha suscitado la aparición de numerosas críticas que cuestionan la capacidad de los modelos matemáticos para entender el comportamiento humano en toda su complejidad. Entre ellas cabe destacar a Amartya Sen quien, en "Los tontos racionales: Una crítica de los fundamentos conductivistas de la teoría económica" (1986), sostiene que los principios del homo oeconomicus son los de un imbécil social, un individuo sin sentimientos ni lazos sociales que carece de moral, dignidad y compromisos. 
No debe verse el comportamiento en términos de la dicotomía tradicional existente entre el egoísmo y los sistemas morales universalizados (como el utilitarismo). Los grupos intermedios entre el individuo y los demás, como la clase y la comunidad, proveen el foco de muchas acciones que implican el compromiso. Por tanto, el rechazo del egoísmo como una descripción de la motivación no implica la aceptación de cierta moral universalizada como la base del comportamiento efectivo. Tampoco vuelve a los seres humanos excesivamente nobles (Sen, 1986: 216).

\subsubsection{La hegemonía del equilibrio general de la competencia perfecta. La} economía convertida en ideología.

A través de los análisis de "El príncipe" de Maquiavelo, Gramsci (1980) elaboró la teoría de la Hegemonía que posteriormente sería reformulada por Ernesto Laclau y Chantal Mouffe. Gramsci utilizó el concepto de hegemonía para reflexionar acerca de la dominación de la burguesía en Europa que hacía irrepetible la Revolución bolchevique en los países capitalistas más desarrollados del resto del continente. Los mecanismos de control del capitalismo se aplicaban, según Gramsci, a través de instituciones culturales como escuelas, iglesia, partidos políticos y asociaciones, que manipulaban a la población aplicando un conjunto de ideologías transmitidas por los intelectuales que generaba una subordinación pasiva. Para superar esa subordinación, considera necesario crear una cultura reflexiva capaz de proporcionar las herramientas para transformar el "sentido común" de la experiencia histórica concreta en un "bloque histórico" que pueda confrontar el discurso hegemónico (Gramsci, 1998). Uno de los principales problemas que Gramsci presenta es la creación de una “filosofía de la praxis", llevar un movimiento 
abstracto a uno concreto produciendo un discurso coherente que sea capaz de convertir a las clases subalternas en agentes de la historia. La ideología es para el autor un todo orgánico y relacional encarnado en aparatos e instituciones, un cemento orgánico productor de un "bloque histórico".

Gramsci realiza una distinción entre ideología intelectual (ideología como doctrina) y la ideología moral. En esta investigación indagaremos en este segundo concepto para entender la participación de los sujetos en la economía dentro de una perspectiva ideológica. La ideología como moral es presentada como un conjunto de valores, prácticas y representaciones sociales compartidos dentro de una cultura. Cabe precisar que no todos los elementos de una cultura son parte de la ideología, sino solo los que permiten una operación de legitimación de una relación de dominación.

Aunque abordaremos posteriormente este tema con más detenimiento, es necesario señalar el componente ideológico que los sistemas financieros precisan para su funcionamiento, y como estos desarrollan un discurso hegemónico en torno a la economía. En este punto nos permitimos cuestionarnos el desarrollo de una economía articulada en la que diferentes ideologías morales convivan. Más adelante presentaremos un debate sobre esto, apoyándonos en datos etnográficos.

La finalidad de este epígrafe es recapacitar en torno a la noción de hegemonía realizada por Gramsci y presentar el discurso ideológico hegemónico en la economía identificado con la escuela neoclásica. A través de las instituciones culturales, la economía se presenta en la actualidad como una ciencia matemática, en su mayoría incomprensible para el ciudadano medio. El origen de este discurso se encuentra en la economía neoclásica y, más concretamente, en uno de sus fundadores, León Walras, precursor de lo que hoy conocemos como la economía matemática. Walras (1986) fue el primero en analizar y describir la economía como un problema matemático, lo que él 
llamo "El equilibrio general de la competencia perfecta". A través de ecuaciones, se pretendía explicar la fluctuación de los precios considerando que estos se encuentran determinados por las interacciones entre los mercados. La teoría del equilibrio general presenta un patrón para comprender la interacción entre todas las subdisciplinas de la microeconomía. El desarrollo de esta teoría es considerado una rama de la microeconomía que explica el fenómeno económico dando una explicación de lo particular a lo general $\left(\right.$ bottom-up ${ }^{10}$ ) a través de ejercicios matemáticos. La competencia perfecta es una constante de carácter utópico en la cual los mercados donde interactúan las empresas carecen de poder para manipular el precio, originando una maximización del bienestar. Lo que Walras presenta con esta teoría es la forma matemática en la que los precios solo son condicionados por la ley de la oferta y la demanda.

El discurso ideológico que ha generado la implantación de la teoría de Walras ha provocado que la economía sea percibida como una ciencia compleja solo dependiente del mantra de oferta y demanda sin analizar detenidamente otros factores que entran en juego al hablar de los precios en la microeconomía, como el apalancamiento ${ }^{11}$, la financiación y la especulación. Mientras el análisis económico continúo manteniendo la lógica de la oferta y la demanda como teoría útil para el análisis, los países periféricos poseen una variada articulación de sistemas económicos que posibilitan el mantenimiento del tejido social y mejoran la capacidad de estos para soportar crisis de producción y consumo. La investigación de los sistemas financieros informales nos llevará a debatir si el discurso hegemónico de la economía neoclásica es extrapolable al entorno rural, o ha

\footnotetext{
${ }^{10}$ De abajo hacia arriba.

${ }^{11}$ Relación entre crédito y capital propio invertido en una inversión financiera. El crédito, observado como expectativa futura de capital. En este caso, cuanto mayor es el porcentaje de expectativa y menor el porcentaje de capital invertido, los riesgos en la operación aumentan dando lugar a la insolvencia del sujeto solicitante de crédito, incapaz de devolver el préstamo. El aumento de apalancamiento en operaciones financieras da lugar a burbujas financieras, en las que el total invertido es en su mayoría fruto de unas expectativas futuras no cumplidas, llevando a la bancarrota.
} 
desarrollado modalidades paralelas que les permiten prácticas financieras externas a los sistemas percibidos por ellos como de dominación (Scott, 1990). Para poder analizar el mundo rural debemos tener en cuenta estas articulaciones, así como cuestionar el discurso ideológico de la escuela neoclásica.

\subsubsection{La periferia, dependencia y subdesarrollo que promueven la} generación de una resistencia

Hasta el momento hemos planteado algunas teorías económicas y cómo estas se han convertido en ideología intelectual para evidenciar el complejo debate que subyace en las investigaciones antropologías que pretenden realizar un estudio de comunidades inmersas en el sistema capitalista. Aunque los estudios económicos fluyan en torno a una corriente principal, la cataláctica, que centra su interés en el cálculo matemático, esto no significa que los números carezcan de ideología, ya que la teoría de juegos y la maximización de beneficios se asienta en la defensa de la individualización y la exaltación del Homo Oeconomicus.

El objetivo principal de esta investigación es otro, con sus referentes en la praxeología y la ideología moral. Para ello, y tomando estas bases para el estudio en una comunidad asentada en el Occidente Mexicano, se ha considerado necesario revisar algunas teorías que puedan aportar mayor nitidez al tema antes de presentar la etnografía. La primera de estas teorías es la Teoría de la dependencia, presentada aquí por su valor para inscribir el acontecer económico de una comunidad, no como un espacio social aislado, sino inmerso en una estructura mayor.

Con el fin de analizar la diferenciación global, se desarrollaron los conceptos Centro-Periferia, propuestos inicialmente por Raul Presbich (1950), dentro de la teoría de 
la Dependencia. Las regiones periféricas tenían sus economías dirigidas a la exportación, mientras el flujo de recursos se estaba direccionado hacia las regiones del centro. El centro poseía el desarrollo industrial y producían manufacturas elaboradas gracias a las materias primas de la periferia y el monopolio tecnológico que ostentan. El subdesarrollo será entendido entonces como una relación de dependencia y subordinación capitalista de unas regiones a otras.

Magnus Blomströn y Bjorn Hettne, economistas suecos, desarrollarán su actividad investigadora como historiadores de la teoría de la dependencia. En Blomström y Hettne (1990:15) afirman la existencia de un "conflicto de paradigmas" entre el paradigma modernizante y el enfoque de la dependencia. La teoría de la dependencia choca con el discurso de organismos oficiales internacionales y los países del centro, por lo que los autores identifican dos antecedentes principales para la aparición de la teoría de la dependencia. En primer lugar, la creación de una tradición crítica al eurocentrismo relacionado con la teoría del desarrollo. Criticas nacionalistas al imperio euronorteamericano y a la política neoclásica, siendo sus precursores Raúl Prebisch y la CEPAL. En segundo lugar, encontramos el debate latinoamericano en torno al subdesarrollo, influenciado por el debate anterior entre el marxismo clásico y el neomarxismo con Paul Baran y Paul Sweezy como representantes.

Las ideas centrales de la Teoría de la Dependencia, tal y como apuntan Blomströn y Hettne, defienden que el subdesarrollo está relacionado con la expansión de los países industrializados, siendo el desarrollo y el subdesarrollo aspectos diferentes de un mismo proceso. De igual modo, afirman que el subdesarrollo no puede ser considerado como una etapa en el proceso evolucionista, y la dependencia no debe ser entendida como un proceso externo y de carácter económico, sino que se manifiesta de diferentes formas en la estructura a través de las esferas de lo social, ideológico y político. 
Los autores distinguen cuatro corrientes principales en la escuela de la dependencia. La primera se engloba en torno a la crítica o autocrítica estructuralista de los científicos sociales que trabajan o colaboran en la CEPAL. Estos trabajos hacen hincapié en los límites de los proyectos de desarrollo nacionales y cuestionan la autonomía que estos países puedan tener. Entre los investigadores más destacados de esta corriente se encuentran Oswaldo Sunkel, Celso Furtado y el propio Raul Prebisch.

La segunda corriente, de carácter neo-marxista, se basa en los trabajos realizados por Theotonio Dos Santos, Ruy Mauto Marini y Vania Bambirra, investigadores del Centro de Estudios Socioeconómicos de la Universidad de Chile (CESO).

Otra corriente diferenciada por Blomström y Hettne es la marxista más ortodoxa, la cual acepta el papel positivo del desarrollo capitalista y que considera el socialismo inútil para alcanzar el desarrollo. En esta corriente destacan los trabajos de Cardoso y Faletto (1969).

La última está caracterizada por su oposición con el marxismo y su propuesta de un esquema de expropiación internacional, en el que se inscriben los trabajos de Gunder Frank. Este autor $(1967 ; 1976)$ presentó las relaciones de dependencia económica como un reflejo de las relaciones de dependencia estructural internas en los Estados y entre las comunidades. La Teoría de la Dependencia explica la pobreza como el resultado de las circunstancias particulares de la estructura social, en las que intervienen el mercado laboral, la explotación de la fuerza de trabajo y la concentración del ingreso. En la historia de América Latina se pueden identificar distintas etapas que determinan las relaciones de producción dominantes (Sunkel y Paz, 1975) y las conectan con la proporción de pobreza. Cardoso y Faletto (1969) puntualizan que la estructura de tenencia de la tierra permite explicar las etapas de servidumbre y esclavitud, así como la pobreza rural de los países una vez conseguida la independencia en los siglos XIX y XX. Otros investigadores han 
relacionado la dependencia con la importancia creciente del capital extranjero, la acumulación del mismo en pocas manos y el aumento de la desigualdad, empobreciendo a gran parte de la población. Marini (1977) relaciona la dependencia con la sobreexplotación del trabajo y la carencia de derechos laborales.

El concepto de economías mundo fue desarrollado por Wallerstein en el libro "The Modern World System" (1991), publicado en 1974 convirtiéndose en una aportación significativa para la Teoría de la Dependencia. Para el autor, el capitalismo en su desarrollo (siglo XVI) instauró un sistema económico mundial en el cual los países emergentes se posicionan en una estructura de intercambio desigual, denominando a los estados industrializados como "fuertes" o "centrales", y los demás como estados “débiles" o "periféricos". Es importante remarcar que, para Wallerstein, no estamos ante un nuevo desarrollo de la época de los imperios dado que la economía mundo carece de unidad política centralizada. Concretamente, el autor analiza el capitalismo (1979) como un sistema basado en una relación económica, social, política y cultural que dará lugar a un sistema mundial y a una economía mundial estructurada en torno a regiones centrales, semiperiféricas y periféricas. Las economías centrales poseerán el rol hegemónico en la organización del sistema, existiendo una conexión entre pobreza global y polarización social y desigualdad.

A diferencia de Wallerstein, quien no consideraba lícito calificar este sistema como imperialista debido a la ausencia de una unidad política centraliza, Harvey hablará abiertamente de un "Imperialismo capitalista". Para ello descarta la Teoría de la Dependencia como una relación centro-periferia, prefiriendo centrar su análisis en la acumulación por desposesión, teniendo como protagonista de su análisis a las clases sociales. El nuevo imperialismo presentado por Harvey (2004) se estructura a través de los cambios neoliberales emprendidos por los países occidentales a partir de la década de 
1970 hasta la actualidad, caracterizándose por poner en práctica la privatización, la financiarización, la gestión y manipulación de las crisis y redistribuciones estatales de la renta. El objetivo principal del nuevo imperialismo es privatizar la propiedad comunal, entendiendo por esta las empresas y servicios públicos. A través de la privatización se persigue mantener las relaciones asimétricas de intercambio y desposeer a las clases sociales más vulnerables de sus bienes y derechos, haciendo que estos se vuelvan una responsabilidad individual y no del Estado. Harvey hace especial hincapié en el papel que el Estado tiene en el Imperialismo capitalista ya que, realizando las privatizaciones de bienes y servicios públicos, respalda y en muchos casos promueve la acumulación por desposesión.

Una de las reflexiones más críticas en torno al concepto del desarrollo fue presentada por Arturo Escobar, para quien el desarrollo:

Conlleva simultáneamente el reconocimiento y la negación de la diferencia; mientras que a los habitantes del Tercer Mundo, se les considera diferentes, el desarrollo es precisamente este mecanismo a través del cual esta diferencia deberá ser eliminada. El hecho de que esta dinámica de reconocimiento y desaprobación de esta diferencia se repita inacabablemente en cada nuevo plan o en cada nueva estrategia de desarrollo no es solo un reflejo del fracaso del desarrollo de cumplir sus promesas sino un rasgo esencial de todo el concepto de desarrollo en sí mismo (Escobar, 2006: 2). 


\subsubsection{El sistema financiero, el molino satánico y la crisis}

El sistema financiero dentro del sistema económico capitalista tiene como principal función canalizar los recursos obtenidos por el ahorro o el superávit hacia los hogares que quieran consumir por encima de sus propios recursos y las empresas que quieran realizar una inversión. Los bancos se convierten en los intermediarios financieros, recogiendo fondos y destinándolos a la inversión y el consumo en forma de préstamos. A parir de los acuerdos de Bretton Woods, se establecerían las reglas de estas relaciones comerciales y financieras entre los países industrializados. Estos acuerdos perseguían el propósito de acabar con la etapa de proteccionismo económico (1914-1945), intentando mantener la paz entre naciones a través de una política librecambista y una economía globalizada que hiciera inviable un nuevo resurgimiento de los nacionalismos. En los acuerdos de Bretton Woods también se decidirá la creación de dos organismos internacionales, el Banco Mundial (BM) y el Fondo Monetario Internacional (FMI), con el objetivo de regular las relaciones económicas internacionales usando el dólar como moneda de referencia internacional. Estos acuerdos dieron inicio a un nuevo contexto internacional en el cual el sistema financiero comenzó a dominar y determinar el funcionamiento de la producción. Este proceso se conoce como la Financiarización, desarrollado gracias a la ideología neoliberal y reafirmando el dominio de las naciones ganadoras de la Segunda Guerra Mundial, y se ha consolidado gracias a las políticas económicas y monetarias llevadas a cabo por los distintos gobiernos. A partir de la década de los sesenta, y condicionado por la crisis de inflación, las reformas políticas, económicas y monetarias han estado enfocadas en reproducir este modelo en todos los países dando mayor poder al sistema financiero y arrebatándoselo al sistema productivo de los estados. 
El proceso de financiarización ha ocasionado que la liquidez en el sistema financiero produzca burbujas financieras, provocando una vez que estallan, crisis mundiales. Hyman Minsky $(1986,1992)$ presentó el proceso de financiarización como el culpable de las crisis por su fragilidad. Para él, la expansión económica continua genera prestatarios y prestamistas que están dispuestos a adquirir mayores riesgos y así las empresas con perfiles de financiamiento "cubierto" se transforman en empresas de financiamiento "especulativo", que caen fácilmente en lo que se conoce en teoría económica como el financiamiento Ponzi. Las finanzas Ponzi tienen como característica principal que el valor neto de la inversión se vuelve negativo para el prestamista, se presta un dinero que en realidad no existe, siendo muy semejante a un fraude piramidal. Los resultados de la contracción del crédito más acuciantes son la recesión y la pérdida de patrimonio de aquellos hogares o empresas que no pueden hacer frente al pago del préstamo.

La crisis de 2008 posee todas las características de lo que se denomina un "momento Minsky", en el que existe más valor en el sistema financiero del que en realidad puede recuperarse a través de los pagos de los préstamos, por lo que los problemas de liquidez hacen que el sistema se repliegue sobre sí mismo absorbiendo patrimonio, empresas, ahorros y dinero de las arcas públicas.

Con cada crisis económica, un número considerable de individuos descienden a la base de la estratificación social. Aunque quiebren grandes empresas y el sistema de mercado pueda perder liquidez, los últimos damnificados por estos acontecimientos son siempre la población que se encuentra desprotegida y dependiente de los servicios sociales y forman parte de la fuerza de trabajo.

Durante las últimas décadas, el aumento del sector informal se ha acelerado, especialmente en América Latina. Como apunto Polanyi en su obra "La Gran 
Transformación" publicada originalmente en 1944 (2011), la sociedad ha llegado a estar completamente subordinada al sistema de libre mercado. La dislocación que sufrió la vida rural durante la primera Revolución Industrial se ejemplifica en el éxodo de la población a las ciudades para trabajar como asalariados. Para ejemplificar este proceso, Polanyi utiliza la propuesta de un molino, lo que él llama "satanic mill", el molino satánico, que aplasto a los hombres para convertirlos en masas.

\subsubsection{El momento Minsky de 2008 y el canibalismo financiero}

Durante los últimos meses de 2007 se produjo en Estados Unidos la crisis de las hipotecas subprime, hipotecas de alto riesgo que habían sido objeto de especulación en la bolsa norteamericana. A inicios de 2008, la crisis hipotecaria empezó a mostrar sus efectos en el sistema financiero produciendo una crisis de liquidez y el derrumbe bursátil de aseguradoras, bancos e inmobiliarias. No tardaría mucho en tornarse en una crisis mundial porque los desfalcos financieros producidos se habían mantenido con una excesiva confianza en la autorregulación de los mercados. El exceso de confianza se apoya en el ámbito ideológico, en la hegemonía de la doctrina del libre mercado de Milton Friedman (1962). Los fraudes en el sistema de créditos hipotecarios dieron origen a una recesión que impregnaría otros sectores económicos, primero en Estados Unidos y luego a nivel internacional (Barth, 2009).

Durante los siguientes años, los debates económicos y la aparición de corrientes críticas con las ideas de Friedman y, especialmente, con la "mano invisible" de Adam Smith, llenarían gran parte de los noticieros y la producción académica. Un ejemplo de esta producción es la serie de textos recogidos en el volumen "Time for a Visible Hand. Lessons from the 2008 World Financial Crisis", editado por Joseph Stiglitz entre otros en 2010. En apartados posteriores haremos especial mención a la producción académica de 
la antropología en estos años en relación a la crisis de 2008. Si algo comparten todas estas publicaciones es la crítica a la teoría económica neoliberal, aunque también, en cierta medida, un tono de autocomplacencia, un reproche del que se sabe en lo cierto y precisa reafirmarlo con hechos, que había permanecido esperando desde la etapa de triunfalismo de la economía neoliberal después de 1989.

Aunque durante los primeros años de la crisis, el modelo económico neoliberal fue presentado como un fracaso, incapaz de no provocar crisis, existe otra interpretación que ha ido adquiriendo más fuerza según pasan los años y se aprecian los efectos de esta produjo. La crisis de 2008 fue el inicio de una nueva victoria neoliberal. Como señala Fabricio Cabrera, "en muchos casos estas crisis logran ser aprovechadas por algunos sectores, en otros son incluso creadas por sectores estratégicamente situados con miras a administrarlas" (2011: 17). La crisis de 2008 provocó el derrumbe bursátil, la desaparición de grandes compañías aseguradoras y la nacionalización de bancos, pero los rescates multimillonarios que realizaron la Reserva Federal en Estados Unidos, así como el Banco Central Europeo, junto con los recortes en gasto social y, en muchos casos, las pérdidas de soberanía de los estados, se tradujeron en las medidas características de la economía neoliberal. Años después de la crisis, los derechos laborales siguen siendo mermados, gran parte de la población ha perdido sus trabajos, otros han visto reducido su salario o han pasado al sector informal. Las empresas han acelerado la deslocalización de sus fábricas y se han privatizado servicios básicos debido a los recortes que los gobiernos produjeron en las políticas sociales. Casi una década después del inicio de la crisis, el mundo se parece más al ideal neoliberal que Smith y Friedman tenían en mente.

El aumento de la informalidad que parecía haberse estancado en los últimos años ha ocasionado la revitalización de nuevos sistemas financieros que operan en la informalidad, o sistemas de obtención de crédito enfocados en el empeño de bienes o la 
contratación de deudas por cantidades muy bajas. El alto porcentaje de la población que vive o realiza parte de sus actividades en el sector informal precisa para su desarrollo de financiamiento que pueden obtener dentro de la misma informalidad. Aunque posteriormente analizaremos con detalle las modalidades encontradas en el trabajo de campo, cabe destacar que la financiarización del sector informal contiene numerosos peligros. Al igual que está sucediendo en el sistema formal de las finanzas, la crisis económica está disminuyendo notablemente los lugares donde poder invertir, por lo que la lucha por el mercado no produce un crecimiento, sino una destrucción de la competencia. En otras palabras, el sistema financiero, tanto el formal como el informal, está fagocitando negocios, consumidores y modos de producción para su mantenimiento. Quizá este proceso sea más evidente en el sector formal por manejar operaciones con grandes sumas de dinero, pero como se verá en los datos obtenidos en la etnografía, el proceso de canibalismo que emprende la economía en una crisis económica también afecta a la economía informal.

\subsection{Horizonte teórico y discusión conceptual sobre la antropología económica}

Una vez fijados algunos referentes teóricos en torno a la ciencia económica, es necesario realizar un repaso histórico a la antropología económica desde los debates iniciales que configuraron su campo de estudio hasta el estado actual de la misma.

Las diferentes escuelas económicas habían abordado la esfera económica como ciencia capaz de entender los sistemas de producción, intercambio y consumo de Occidente. Solo los institucionalistas habían introducido en sus análisis intereses y métodos de la antropología. Sin embargo, las dos disciplinas tardarían décadas en 
encontrarse y siempre de manera frontal. La antropología económica se planteó en un inicio como una herramienta para el estudio de sociedades externas a la Occidental. Es habitual encontrar como el primer caso etnográfico que analiza los intercambios económicos "The Primitive Economics of the Trobriand Islanders" de Malinowski (1921). Un año después, Malinowski publicaría "Los argonautas del Pacífico Occidental" (1922), pero en su artículo precedente ya podemos encontrar una matización importante en los análisis económicos de sociedad primitivas cuando afirma que es imposible hablar del "salvaje" individualista, sino que era necesario hablar del "comunista" en una sociedad organizada. De igual modo, "Primitive Economics of the New Zealand Maori” (Firth, 1929) y "Economics in Primitive Communities" (Thurnwald, 1932) presentan sociedades primitivas bajo un enfoque organizado de intercambio. Estas obras señalan la necesidad de definir el campo de estudio de la antropología económica. Estos análisis están influenciados por la economía neoclásica, hasta el punto en el que cualquier característica contraria a los postulados neoclásicos es enmarcada dentro de las categorías de la escuela antagónica a esta, como apunta Malinowski al calificar a los individuos de su estudio en Melanesia como comunistas. En esta etapa se empieza a fraguar las controversias generadas por la enorme influencia que las teorías económicas tendrán en el resto de ciencias sociales y, especialmente, en el estudio de sociedades primitivas. Goodfellow presentará sus investigaciones desde la perspectiva más ortodoxa centrando el análisis en documentar los medios de subsistencia y la tecnología empleada, mientras Herskovits y Firth optarán una visión más positivista. Thurnwald y Malinowski serán los más interesados en desarrollar el discurso sustantivista de la antropología económica que centrará sus esfuerzos en recoger datos económicos cuantificables como horas de trabajo, cantidad de excedentes y cantidades intercambiadas. 
La antropología económica, en sus inicios, investiga los procesos de decisión y asignación de recursos, utilizando para ello el análisis de instituciones o identificando los intereses de individuos o grupos. El enfoque microeconómico todavía no está presente en estos estudios. Aunque la antropología centra su lugar de estudio en comunidades relativamente pequeñas, los elementos estructurados buscan presentar la macroeconomía primitiva como un elemento central. La influencia de la economía ortodoxa en la antropología económica se mantendrá vigente durante toda su trayectoria, aunque se generará un aparato conceptual capaz de analizar la esfera económica desde una metodología cuantitativa utilizando algunas herramientas de la economía heterodoxa y el propio carácter metodológico de la disciplina antropológica.

Los comienzos de la disciplina están enmarcados en dos temáticas, la circulación de bienes, haciendo especial atención a los bienes preciosos o aquellos capaces de otorgar prestigio, y el debate en torno a la reciprocidad. En torno a la reciprocidad hay de destacar "Essai sur le don", publicado por primera vez en 1924 (Mauss, 2010) en el cual ya se introducen elementos de análisis como el avance del capitalismo en las sociedades primitivas. Para Mauss el Kula y el Potlatch son ejemplos etnográficos de lo que denominará "economías del don" en las cuales la reciprocidad será más importante que las lógicas neoclásicas basadas en la eficacia, maximización y plusvalía. Con la aparición de Ensayo sobre el don la antropología económica perfila la esfera económica como un espacio social donde se produce un valor social al intercambio de acuerdo con premisas morales impuestas por la colectividad y sujetos en posiciones sociales específicas. Mauss apunta que, en las sociedades primitivas, no son los individuos (como afirma la teoría neoclásica) sino las colectividades las que se obligan mutuamente. Los sujetos son personas morales que de enfrentan, entran en conflicto, pero también negocian y crean alianzas a través del intercambio, no solo buscando la maximización del beneficio, sino 
la adquisición de valores sociales bajo reglas morales. Mauss utiliza el Kula y el Potlach para representar lo que él denomina el principio humano fundamental: la obligación de dar, recibir y devolver. Esta es la formulación clásica del don, en la cual el valor no se encuentra solo en el valor del objeto de intercambio, sino en el valor del intercambio en sí como actividad creadora de sociedad. La alianza, la solidaridad y la sociabilidad ocupan gracias a Mauss un papel protagonista en la antropología económica.

El Don es analizado como un acto que genera una doble relación entre el que da y el que recibe, siempre de manera voluntaria. Se trata de la creación de una relación en la que el donante y el receptor crean una deuda vista como un compromiso, en la que se articula la obligación de recibir y de devolver. La relación estructura una interacción asimétrica, una jerarquía en la que el donante adquiere un estatus benefactor y el receptor una obligación de restaurar la relación entre iguales devolviendo. El vínculo creado por el don es percibido por Mauss como un "vínculo entre almas" de orden espiritual ya que los objetos están habitados por dos espíritus. El de la persona que lo posee y luego lo dona, y el espíritu mismo del objeto. "Mauss quería demostrar que el objeto dado no estaba alienado, que seguía unido a su propietario y, por tanto, era a la vez inalienable y alienado" (Godelier, 2000: 178).

Las prestaciones totales son catalogadas por Mauss dentro de dos variantes, agonísticas y no agonísticas. Él se ocupa principalmente de las agonísticas en donde se inscribe el Potlatch. Para Mauss, el Potlatch es una guerra de riquezas para conseguir estatus y poder, en la que la generosidad pasa a un segundo plazo para perseguir como objetivo final la rivalidad y la victoria sobre el oponente.

La antropología económica tomará la iniciativa en los estudios de campo gracias a Mauss. Su definición del intercambio como "hecho social total" en el que entran en 
juego las transferencias, la idea de justicia distributiva y la cooperación social ocupará durante los siguientes años gran parte de las investigaciones antropológicas.

Aunque las teorías expuestas por Mauss contradicen las premisas principales de la economía neoclásica, el posterior desarrollo que ha experimentado el concepto de reciprocidad hace la distancia entre las dos disciplinas sea pendulante, dependiendo del poder hegemónico que la ciencia económica reproduzca en ciertas perspectivas de análisis. Como ejemplo, encontramos las contradicciones que expone Anette Weiner (1992) al realizar una crítica de la teoría antropológica como búsqueda de universales a través del enfoque positivista y, al mismo tiempo, aventurar la esfera económica dentro de la paradoja universal de como "guardar mientras se da". Wiener amplia una teorización de la reciprocidad en la que la obligación social de dar va en contra del deseo individual de guardar.

Weiner menciona algunos datos etnográficos de la obra de Lévi-Strauss (como el sueño expresado en un mito de una isla andamanesa) (1981), para ejemplificar como el "hecho social total" de Mauss no deja de ser una obligación impuesta culturalmente, mientras el mercado y las acciones de comprar y vender se convierten en una utopía liberadora de los entramados sociales que bajo la ley de intercambio no permiten la libertad económica. Este mundo utópico reproducido por el mito de la isla andamanesa puede llevar, sin embargo, a dos respuestas. La primera es considerar comprar y vender más natural que el acto de dar, recibir y devolver, cargado de elementos simbólicos y normas sociales. La segunda conclusión es que la única manera de escapar a la ley de intercambio y poder guardarse lo suyo es un mundo utópico en el que el individuo deje de vivir en sociedad, y en el que ni el intercambio ni el mercado son necesarios. Esta segunda conclusión vuelve más utópico el razonamiento, aunque encierra una deducción 
interesante afirmando que el fin de la economía es posible solo con el fin del individuo como ser social.

\subsubsection{El debate entre Formalistas y Sustantivistas}

El debate emprendido por la confrontación de la escuela neoclásica y los institucionalistas en las ciencias económicas, y la literatura sobre la circulación de objetos en Melanesia, así como el desarrollo de la teoría antropológica relacionada con el don y la reciprocidad son los precedentes que originaran el debate entre formalistas y sustantivistas. La división entre "formal" y "sustantiva" es tomada de "Economía y sociedad" (1969), obra de Max Weber publicada en 1922, en su capítulo dedicado a las categorías sociológicas de la vida. Para Weber existen dos maneras de actuar económicamente: la primera, individual, cercana a los postulados neoclásicos y al cálculo marginal, en la cual el precio de obtiene por una evaluación subjetiva de la utilidad. La segunda manera, material o sustantiva, influenciada por los institucionalistas, analiza el abastecimiento de bienes enmarcados en un grupo social, en el que las instituciones otorgan el valor. Esta racionalidad económica es aplicable a la hora de analizar la acción de individuos dentro de instituciones sociales y, a diferencia de la primera, tiene en cuenta la existencia de éticas, políticas y obligaciones morales dentro del grupo y no solo la interacción producida por el individuo como agente aislado que busca satisfacer sus necesidades.

El debate entre formalistas y sustantivistas se desarrolló en dos etapas; la primera tuvo lugar en la década de los 40 del siglo pasado con las discusiones de Herskovits y Firth frente a Thurnwald y Malinowski; la segunda tuvo lugar en la década de los 60 entre los formalistas que predicaban el universalismo (Lecrair, Schneider y Burling) frente al sustantivismo que defendía el relativismo cultural representado por Polanyi, Dalton y 
Sahlins. En 1957, Polanyi, Arensberg y Pearson publicarán “Comercio y mercado en los imperios antiguos" (1976), donde presentaran el dilema al que se enfrentan los antropólogos al estudiar sociedades desde una perspectiva económica.

A la mayoría de nosotros se nos ha acostumbrado a pensar que la piedra de toque de la economía es el mercado (...). ¿Qué hacer, pues cuando topamos con economías que operan sobre bases totalmente distintas, sin ningún rastro de mercado o de ganancia obtenida comprando o vendiendo? Es Entonces cuando hemos de revisar nuestra concepción de economía (1976: 47).

Polanyi fue el primero en señalar el análisis económico como una falacia económica en la que la economía humana era presentada como una economía organizada alrededor de la institución del mercado, concretada en el mecanismo "oferta-demandaprecios fluctuantes". Para Polanyi, reducir el fenómeno de "lo económico" a la lógica del mercado era perder de vista la mayor parte de la esfera económica. Igualmente, ampliar el concepto de mercado a cualquier fenómeno económico era atribuir cualidades artificiales a las cuestiones económicas y entorpecer la construcción de un aparato conceptual necesario para abordar en su plenitud la esfera económica en todas sus variantes. Para evitar esta falacia, Polanyi elaboró conceptos teóricos alternativos. Gracias a su trabajo se desarrollaron algunas de las herramientas conceptuales necesarias para comprender la existencia de formas y estructuras económicas fuera del discurso hegemónico de la escuela neoclásica y la economía de mercado. Como bien aventuraba Polanyi en la década de los 50, la existencia de formas sociales capaces de construir el orden social a través de la economía serían encontradas en el campo. De este modo, los sustantivistas entienden que los individuos precisan del entorno físico y del resto de seres 
humanos para lograr su sustento y reproducción a través de la interacción institucionalizada. Para ellos, la economía es el proceso que permite obtener los medios necesarios para satisfacer necesidades materiales, pero también generadora de integración social (Polanyi, Arensberg y Pearsonl, 1976).

Los formalistas entienden que la teoría económica es aplicable a todas las sociedades por lo que realizan una proyección etnocéntrica al universalizar los principios y la lógica capitalista en realidades socioculturales externas. Apoyan que la economía es el campo que estudia la asignación de medios escasos a objetos múltiples, la ciencia que estudia las interacciones entre fines y medios escasos que tienen usos alternativos. La concepción formalista pretende demostrar la universalidad de los principios de escasez y elección. De igual modo, el formalismo centra su elemento de análisis en el comportamiento individual, tomando como fuente de inspiración el Homo Oeconomicus.

Polanyi y Sahlins se convierten en los más acérrimos críticos a los postulados formalistas. Polanyi niega que el principio de escasez pueda ser universal, considerando que los modelos de integración económicos válidos se reducen a la reciprocidad, la redistribución y el intercambio de mercado. La racionalidad económica se encuentra en la búsqueda por satisfacer las necesidades materiales según los requerimientos institucionales y no en la búsqueda de maximizar los beneficios individuales. Debido a la singularidad de las instituciones económicas, estas deben ser estudiadas particularmente. La teoría económica ortodoxa no puede ser aplicada de manera general, sino únicamente para la sociedad Occidental. Sahlins va más allá en su crítica a los formalistas aventurándose a afirmar que la economía, como es entendida por ellos, no existe, sino que se limita a supuestos teóricos no relacionados con la realidad.

Hablar de 'la economía' de una sociedad primitiva es un ejercicio de irrealidad. Estructuralmente 'la economía 'no existe. Más que 
una organización delimitada y especializada, 'la economía 'es algo que generaliza la función de los grupos sociales y de las relaciones, especialmente los grupos y las relaciones de parentesco. La economía es más bien una función de la sociedad que una estructura, porque el armazón del proceso económico, la proporcionan los grupos concebidos clásicamente como "no económicos" (Sahlins, 1987: 91).

Los aportes de Polanyi al debate entre formalistas y sustantivistas serán ampliados por Dalton, quien afirma que las diferencias entre la economía primitiva y la neoclásica no son de grado, sino cualitativas. En las economías primitivas, las transacciones económicas no pueden entenderse fuera de las obligaciones sociales.

\subsubsection{La Gran Transformación}

Además de rebatir las teorías formalistas, Polanyi formuló las premisas básicas del sustantivismo en el capítulo IV de su libro "The Great Transformation", en el cual presenta los principios de integración económica: reciprocidad, redistribución e intercambio. Las formas de integración no son exclusivas de tipos evolutivos, sino que se pueden observar en todas las sociedades. Las propuestas de Polanyi supondrán la configuración de la antropología económica. Para el autor, la economía es una construcción social históricamente determinada. De este modo, mientras la cultura occidental ha separado la economía como ciencia independiente, en las sociedades primitivas y los imperios antiguos la economía está incrustada (imbricada) en el resto de instituciones sociales. 
El hombre no actúa para salvaguardar sus intereses individuales en la posesión de bienes materiales, sino para salvaguardar su posición social, sus derechos sociales, sus activos sociales. El hombre evalúa los bienes materiales solo en la medida en que sirvan a este fin (Polanyi, 2011: 56).

La economía como esfera social entendida desde el enfoque sustantivista es un proceso que tiene como finalidad asegurar la subsistencia del grupo humano, en donde "lo necesario" estará condicionado por las pautas culturales y las relaciones sociales que estructuran la organización del grupo. La problemática que encuentra la antropología económica a la hora de abordar la investigación de sociedades ajenas a la occidental es buscar nuevas herramientas conceptuales, propias de la comunidad estudiada. Las herramientas disponibles en la sociedad occidental para entender el funcionamiento de nuestra economía están condicionadas por el capitalismo y el libre mercado. Es en el análisis del libre mercado donde la antropología económica solo puede encontrar instituciones que tienen como objetivo principal fortalecer el poder del Estado y la destrucción de la retícula social mediante el individualismo, no pareciendo válido este enfoque para analizar economías externas que no persiguen los mismos objetivos.

Polanyi realiza una distinción con el termino de reciprocidad (2009; 2011), considerando la reciprocidad como un modo de institucionalización de los procesos económicos dentro de un contexto social cuyo orden moral produce una serie de obligaciones que no se extinguen con su cumplimiento, sino que se perpetuán formando parte del orden social y cultural de la sociedad. Sin embargo, Polanyi apunta que la reciprocidad convive con la ayuda mutua, de similar funcionamiento, pero en la que se 
establecen entre las partes unos objetivos concretos. Al obtener estos objetivos, la obligación termina. Para Polanyi, la ayuda mutua es la esencia de un contrato implícito.

Dentro de la obra de Polanyi el concepto que mayor repercusión ha tenido para la historia de la antropología posterior ha sido el "incrustamiento" (embeddedness) de la economía. Con ella, pretende mostrar que la esfera económica no se encuentra aislada, sino que es dependiente y elemento participante de la realidad social. Aunque su perspectiva está condicionada a la crítica del discurso formalista y el pensamiento hegemónico de que la economía capitalista posee una dinámica propia, considerar la economía como incrustada dentro de la sociedad será el punto de partida para el desarrollo de una antropología económica más holista.

Entre las críticas a la obra de Polanyi podemos destacar a Dumont (1983), Moreno (1994) y Narotzky (1997), que puntualizan una incongruencia en su discurso al distinguir una esfera de lo económico mientras al mismo tiempo señala la imposibilidad de entender lo económico como separado. Por su parte, Clammer (1985) advierte que el debate entre formalistas y sustantivistas llevó a las dos corrientes a radicalizar su discurso: los sustantivistas acentuaron en exceso la socialización de la economía mientras los formalistas economizaron de manera radical la sociedad. Gudeman (2001) intenta superar el debate llevando a los dos oponentes a un empate técnico. Para él, la economía consta de dos racionalidades que conviven y se combinan, la social y la maximizadora de la ganancia individual, conviviendo las dos en todos los sistemas sociales, incluido el capitalismo.

El debate entre formalistas y sustantivistas agotó su interés mayoritario con el ascenso de la antropología simbólica y la etnografía reflexiva, con el ascenso de la antropología culturalista. La antropología económica permaneció durante décadas relegada a pocas escuelas sin que transcendiesen en muchos casos sus avances. Entre las 
corrientes que intentaron sobrevivir cabe destacar el marxismo francés encabezado por Maurice Godelier y Claude Meillasoux.

\subsubsection{Las estructuras de Althusser}

La obra de Althusser se ha situado en muchas ocasiones en el estructuralismo, y otras tantas dentro de la corriente marxista. Lo que sí es incuestionable es que fue una gran influencia para la escuela francesa siendo autor de referencia para Godelier y Meillasoux. La obra de Althusser gira en torno a dos conceptos principales: toda sociedad está determinada por su nivel económico, y la lucha de clases es el motor de la Historia.

Inspirado por el desarrollo del concepto de hegemonía emprendido de Gramsci, Althusser (2003) presenta la ideología como la representación de una relación imaginaria de las condiciones reales. Se desmarca de Gramsci en la medida que no considera la ideología como mecanismo capaz de generar una falsedad, sino más bien productora de relaciones entre las representaciones imaginarias del sujeto y su entorno. La heterogeneidad de la estructura, a la que hace referencia Althusser, se encuentra articulada y en una variedad de planos, por lo que considera necesario definir un nuevo tipo de causalidad (causalidad estructural) y distinguir entre una estructura estructurante y una estructura estructurada. La estructura solo puede ser percibida por entero a través de sus determinaciones, $\mathrm{y}$ estos son en la medida en la cual la estructura los produce como efectos porque ella es la premisa necesaria para pensar su existencia. Esta manifestaciónocultación de la estructura en sus efectos está inspirada, aunque en este caso con un mayor desarrollo, en el "fetichismo" (Althusser y Balibar, 1978) que ya indicó Marx. El discípulo de Althusser, Jacques-Alain Miller definirá la causalidad estructural como "causalidad metonímica" justificándolo a través de la no existencia de la causa sino en su efecto, el efecto es tomado como causa. 
En esta investigación se presentarán en la etnografía efectos de una estructura articulada en diversos planos (en este caso, diferentes sistemas de financiamiento). Para explicar parte del sistema, utilizaremos la causalidad, así como los dos tipos de estructura distinguidos por el autor.

Si bien Marx entendía que la única manera de entender el conocimiento científico del sistema capitalista era descubrir su estructura interna oculta, Lévi-Strauss afirmaba:

Las estructuras no se confunden con las relaciones sociales visibles, sino que constituyen un nivel de la realidad invisible. La lógica de estas, y más generalmente las leyes de la práctica social, dependen del funcionamiento de esas estructuras ocultas, cuyo descubrimiento debería permitir informar sobre todos los hechos observados (Godelier, 1967: 52).

\subsubsection{La Escuela de la Articulación}

En la década de los 60 surge la escuela marxista-estructuralista francesa, también conocida como la Escuela de la articulación. Entre los autores más destacados se encuentran Claude Meillassoux, Maurice Godelier, Emmanuel Terray, Pierre-Philippe Rey, George Dupré o Marc Augé. Casi todos comparten el conocimiento etnográfico de África central, occidental y Madagascar con una tendencia estructuralista influenciada por Lévi-Strauss y la corriente marxista de Althusser, Balibar y Bettelheim. Sus investigaciones y trabajos teóricos abordaron la aplicación del materialismo histórico en el estudio de la sociedad "tradicional" a través del análisis de los modos de producción y 
la formación social entendida como entidad geográfica que posee particularidades en el desarrollo histórico de su estructura económica y su superestructura.

Sus aportaciones avanzarían en el planteamiento de un problema al que la antropología se enfrentaría en las próximas décadas: los efectos ideológicos que la expansión del capitalismo estaba produciendo en las comunidades que hasta ese momento se habían considerado aisladas de la cultura occidental. El capitalismo oculta la explotación bajo el proceso de producción, a través de la compra de la fuerza de trabajo y la posesión de la plusvalía haciendo aparecer nuevos medios económicos como el salario, los precios, los créditos y las deudas. En el proceso de globalización, la ideología y la cultura serian la columna vertebral necesaria para expandir el capitalismo, siendo esto solo posible intentando mantener un equilibrio social en el que las premisas principales del libre mercado y la acción individualista se enfrentaban a los modos tradicionales de entender la economía en las regiones. El surgimiento de nuevos interrogantes metodológicos relacionados con el cambio de paradigma que la antropología va a experimentar en este proceso permitirá una Economía Política de la cultura, en la cual conceptos como fetichismo de la mercancía (Marx), discurso y poder (Foucault) y hegemonía (Gramsci), se volverán imprescindibles para explicar los procesos derivados de la implantación del capitalismo. La Economía Política, la Sociología y la Historia centrarán sus investigaciones en el "mundo civilizado", generando dualidades como macro-micro, mundo civilizado-mundo primitivo, modernotradicional, urbano-folk. Aunque estos nuevos conceptos pretendían presentar el proceso de modernización como novedoso, no dejaban de ser el desarrollo de las construcciones polares de Tonnies (Gemeinschaft-Gesellschaft) o Durkheim (Solidaridad orgánicaSolidaridad mecánica). 
Dentro de las aportaciones teóricas más importantes de la escuela francesa cabe destacar la noción de articulación de los modos de producción. Meillassoux (1999) realizó una investigación entre los guro de la Costa de Marfil. Allí encuentra que los modos de producción de la población se encuentran combinados, presentando dos categorías, el modo de producción tradicional y característico del linaje convive con el modo de producción colonial. La categorización de los modos de producción llevará a Terray (1972) a afirmar que el modo de producción tradicional está compuesto en realidad por la articulación del modo de producción de los miembros de la aldea, por una parte, y el trabajo del linaje por otra. Según la afirmación de Terray, un sistema de producción puede consistir en más de un modo de producción, operando las diferentes modalidades articuladas entre sí. El estudio de los modos de producción articulados es uno de los objetivos de esta investigación, por lo que se extenderá este planteamiento más adelante. Cabe destacar que, cuando la escuela francesa desarrolló la noción de articulación de los modos de producción, la influencia que ejercían las teorías de Marx, Gramsci y Foucault sobre ella les llevaron a puntualizar que la articulación presentaba un modo de producción como dominante.

Rey (1971) analiza la articulación de los modos de producción capitalistas y como estos conviven con modos de producción tradicional o precapitalista, presentando la articulación como un proceso en el que se pueden distinguir tres estadios. El primero sería el caracterizado por la llegada del capitalismo a las sociedades tradicionales, implantándose la articulación a través del intercambio de mercancías, en concreto el intercambio entre materias primas por productos industriales. El segundo estadio presenta la convivencia del capitalismo con otros modos de producción, pero siendo el capitalismo el dominante y los modos tradicionales necesarios todavía. Al llegar al tercer estadio, el 
desarrollo del capitalismo ha marginado a los otros modos de producción convirtiéndolos en modalidades regionales utilizadas para la subsistencia.

\subsubsection{El marxismo estructuralista de Godelier}

La obra de Maurice Godelier se desarrolló a partir de la unión y crítica de algunos aspectos del materialismo histórico de Marx y la antropología estructural de Lévi-Strauss. En "Sistemas, estructura y contradicción en El Capital" (1966) encuentra las raíces del estructuralismo en Marx y el puente que une "El Capital" con "Las estructuras elementales del parentesco" (1949) de Lévi-Strauss. También presenta una lectura crítica de las dos obras al cuestionar la primacía de la infraestructura y de lo simbólico, junto con la refutación de ciertos asertos presentados por la antropología clásica mientras elabora una teoría sobre la producción de las relaciones sociales y sus prácticas simbólicas.

Tal y como afirma Godelier (1976), la antropología económica no debe limitarse al estudio del presente etnográfico, sino que, a través de la teoría, debe analizar la lógica aparente y mostrar al mismo tiempo las condiciones históricas y estructurales de su aparición y reproducción. Partiendo de las teorías de Lévi-Strauss, mantiene la idea de la existencia de una estructura, aunque esta no sea inmediatamente visible. Para Godelier los hombres no solo viven en sociedad, sino que son ellos quienes producen sociedad para vivir en ella. En su trabajo de investigación con los mbuti, Godelier presenta tres principios estructurales básicos para la conformación de la sociedad. El primero sería el principio de dispersión que atiende a facetas como las relaciones de propiedad y de cohabitabilidad del grupo social. La cooperación, tanto de grupos como de individuos, es el segundo principio, en el que engloba las relaciones de parentesco y linaje, así como las relaciones con otros grupos externos. El tercer principio estructural es la fluidez, 
permitiendo la adaptación a posibles cambios. Cada uno de los rasgos de la sociedad mbuti puede ser explicado, según Godelier, a partir de la participación de uno o más principios estructurales.

Otro de los aportes más significativos de la obra de Godelier a la antropología económica se encuentra en el desarrollo que realiza a partir de la obra de Mauss del concepto de don (1998). Aunque Godelier no desarrolla extensamente el término de reciprocidad, sí analiza el don como forma ceremonial de la reciprocidad, categorizando los objetos que se donan. Para él, los objetos se pueden englobar en alguna de estas tres categorías, objetos sagrados (inalienables), objetos preciosos (que se donan) y objetos corrientes (que se intercambian).

Será Alvin Goulder quien realizará un desarrollo mayor del término reciprocidad. Para Goulder (1960) es un valor moral universal comprendido como una norma en la cual estás obligado a ayudar a quien te ayuda, con carácter indefinido. La formulación de Goulder implica que la reciprocidad posee una doble naturaleza, abarcando lo material y lo ideológico dentro del concepto de reciprocidad.

Aunque no pertenece a la escuela francesa, Sahlins siguió la línea de investigación y desarrolló el concepto de reciprocidad bajo las mismas premisas. Con la publicación de "Stone Age Economics" en 1972, Sahlins (1987) definirá la reciprocidad como una relación inversa a las relaciones de parentesco. Genera para ello tres categorías de análisis que atienden a su ratio de influencia y a su función. La reciprocidad generalizada se presenta como propia de la unidad doméstica y el linaje; la reciprocidad equilibrada está inscrita dentro de la unidad política o la tribu; y la negativa como propia de otros grupos políticos. La reciprocidad equilibrada está enmarcada dentro del concepto de intercambio igualitario, en el que los bienes y favores tienen un valor preciso. Actos como el rapto y la guerra son interpretados por Sahlins como formas de reciprocidad negativa, afirmando 
con ello que presentan una función que debe ser considerada en la investigación económica.

La reciprocidad es comprendida como un entramado ideológico en el que las desigualdades y competencia operan dentro de una misma unidad moral. El don, sin embargo, es un acto ideológico que se materializa en un regalo. La reciprocidad es capaz de inscribirse en operaciones de supervivencia o cotidianas, mientras que el don posee una excepcionalidad al ser utilizado para generar alianzas o vencer a enemigos.

\subsubsection{La escuela de la Economía Política}

El estructuralismo de Althusser fue criticado por E.P. Thompson (1978), señalando que la epistemología althusseriana muestra una total indiferencia por la realidad empírica, solo aplicable bajo un planteamiento idealista de la realidad. Mientras el método histórico de Marx está fundamentado en hechos, las estructuras de Althusser solo pueden reconocerse teóricamente $\mathrm{y}$, por ello, hace imposible que puedan ser desveladas por la investigación empírica. También señala la distinción entre Marx y Althusser, al considerar el primero que el sujeto es el generador de la historia, mientras el segundo considera a los "verdaderos sujetos" las relaciones de producción (sociales, políticas e ideológicas) y no a los agentes. La polémica emprendida con las posiciones de Althusser acerca de la Historia puede ser resumida a través de la calificación que realiza Thompson (1992) de ella como "teoricista".

Thompson se ocupará de las formas de representación y manifestación de los contenidos de clase desde el marxismo cultural. Considera necesario enfocar el análisis de clase a través de la lucha de clases y no reducirlo directamente a una estructura. Es en esta lucha de clases en la que se inscribe el proceso en el que se crean formas culturales 
específicas. La clase es presentada como una formación económica y cultural. El enfoque culturalista implicó una renovación conceptual, siendo necesario una Historia desde abajo.

Frente a los marxistas estructuralistas y los marxistas culturales se desarrollará la escuela de la Economía Política durante las décadas de 1970 y 1980. Se basa en las teorías de la dependencia y del sistema-mundo. Está influenciada por la sociología política, especialmente las teorías del sistema mundial de Wallerstein y la teoría del subdesarrollo de Gunder Frank, centrando su unidad de análisis en los sistemas políticos económicos regionales a gran escala. La combinación de este enfoque con el trabajo de campo en comunidades específicas llevó a que sus estudios presentasen los efectos de la penetración del capitalismo en estas regiones.

Anteriormente al trabajo de la escuela de la Economía Política ya se había planteado este enfoque de la mano de Eric Wolf. En su libro "Europa y la gente sin historia" (2005) publicado en 1982, presentaba el mundo como una totalidad de procesos múltiples interconectados en el que se hacía necesario analizarlos conjuntamente. "Historia en el sentido de exposición analítica del desarrollo de las relaciones materiales que se mueven simultáneamente en el nivel del sistema general circundante y en el micro nivel" (Wolf, 1990: 39).

\subsubsection{La Economía Moral}

La economía moral se desarrolló a partir del trabajo etnográfico que investigaba la reciprocidad y el don a través de los estudios sobre el campesinado. La problemática abordada eran los modos de subsistencia y las normas morales de reciprocidad y derecho a la subsistencia. A través del campesinado se va a desarrollar una línea de investigación 
en la antropología económica que presenta los componentes morales genuinos de la cultura campesina. El concepto de economía moral fue popularizado por Thompson (1971) aunque, en la antropología, su máximo representante es James Scott. Es en “The Moral Economy of the Peasant" (1976) donde Scott desarrolla el planteamiento de Thompson junto con la idea de comunidad cerrada de Wolf y el incrustamiento de Polanyi. A través de las instituciones sociales locales Scott presenta los procesos económicos como imbricados en un universo moral en el que la justicia y la equidad son premisas preponderantes. Scott insiste en que el marco social y cultural de la obligación moral se encuentra en la realidad, y esta debía explicarse en sus propios términos. Para ello, propone como base de la economía moral dos principios universales, garantizar la subsistencia y reclamar la reciprocidad.

La economía moral está conformada por un conjunto de teorías de carácter político y social, y también de un tipo de comportamiento económico propio de una comunidad campesina. Los economistas morales consideran que la comunidad campesina se perpetúa a través del principio de mutualismo y los valores costumbristas que permiten la supervivencia e impiden la acumulación de riqueza, manteniendo una relativa igualdad entre sus componentes. Este mantenimiento de la igualdad, así como evitar "el problema de los gorrones" (Harris, 1998), es posible gracias a la presión social ejercida por el grupo. De este modo, la economía moral permite equilibrar el poder económico a través de normas éticas que aseguran la justicia social (Powelson, 1991).

Aunque la economía moral puede estar presente mayoritariamente en las relaciones entre los habitantes de una comunidad campesina, estos grupos no se encuentran aislados, por lo que es necesario analizar la economía moral y cómo esta interactúa dentro y fuera de la comunidad. Popkin (1979) presenta la problemática a través de dos premisas. Afirma que el capitalismo transforma las instituciones 
tradicionales anteriores y que las instituciones tradicionales perseguían fines más morales frente a la lógica capitalista. Por otro lado, será el propio Popkin quien critique las interpretaciones realizadas por los economistas morales. Si bien él afirma que el capitalismo transforma, considera a los campesinos actores racionales que se ajustan a la economía de mercado según su propio interés.

El estudio del campesinado y la economía moral fueron criticados por demonizar el capitalismo y la economía de mercado, presentando al campesino como una víctima y negando que ellos puedan tener un comportamiento maximizador del beneficio. Algunos estudios que se desarrollaron en torno a la economía moral presentan una visión paternalista del campesinado que se explica por la tendencia de idealizar al sujeto antropológico. Tampoco presentaban fielmente las relaciones de explotación y desigualdad dentro de la comunidad, y minimizaban los conflictos internos para acentuar los procesos de explotación derivados del capitalismo. Los economistas morales veían el capitalismo como responsable de la destrucción de las instituciones tradicionales, siguiendo las ideas que Marx y Lenin habían augurado. Sin embargo, estas instituciones se mantuvieron operativas. La coexistencia de instituciones tradicionales e instituciones capitalistas se encuentra más cercana a los postulados de articulación presentados por el marxismo francés, que no la destrucción de la economía tradicional.

En la actualidad, la antropología económica investiga los mecanismos que permiten el sustento de hombre y los medios de vida (Narotzky, 1997; 2004), como ya aventuro Polanyi en "The livelihood of Man" (2009) publicado originalmente en 1977. Estas premisas se aplican al investigar tanto las sociedades primitivas, las economías étnicas y las sociedades capitalistas. La acción económica se entiende como integrada con el resto de facetas sociales, como el parentesco, las relaciones sociales o la religión. 
La investigación de los modos de vida permite analizar los procesos de circulación y consumo de bienes en toda la variedad de sociedades.

\subsection{Conceptos clave para la investigación cualitativa de los sistemas financieros alternativos}

Para abordar los sistemas financieros, es necesario realizar un repaso a los conceptos que posteriormente utilizaremos, tanto a la hora de diseñar metodológicamente la investigación, como para su posterior análisis. Aunque ya hemos desarrollado algunos de ellos en el marco teórico que hace referencia al desarrollo de la antropología económica, volveremos a ellos para completar su análisis a través de las investigaciones más recientes. Por otro lado, el crédito y la deuda serán completados en el apartado dedicado a definir y explicar cada sistema financiero encontrado en el campo.

\subsubsection{La reciprocidad, el intercambio y el consumo como estrategias} económicas

Para que la reciprocidad sea posible deben presentarse tres características básicas:

-La transferencia de recursos, sean estos materiales o simbólicos.

-Que dicha transferencia esté condicionada por valores morales que la hacen posible y la creación de relaciones sociales producidas por la actividad de estas transferencias. Cabe señalar que la reciprocidad es generadora de obligaciones mutuas y estas, a su vez, pueden generar conflictos, negociaciones o incluso imposición. 
-Los valores morales que entran en juego para hacer posible la reciprocidad no necesitan ser compartidos por los participantes, en muchos casos, son impuestos y construidos para la diferenciación u homogeneidad social.

Mauss (2010) presentó el don como un proceso de transferencias que forma parte de las prestaciones totales. También realizó una diferenciación entre lo que él consideraba transferencias condicionadas por su carácter moral, en las que participan relaciones sociales que se mantiene en el tiempo, y el contrato, de carácter individual y con una obligación delimitada, por lo que las relaciones emprendidas pueden terminar una vez cumplido el proceso. Al llevar la teoría del Don al trabajo de campo, nos encontramos varios problemas. El primero de ellos es que la prestación total es un concepto experto (etic) que nos puede llevar a falsear la realidad a través de los parámetros analíticos de la antropología. El contrato establecido por los individuos puede ser un concepto que abarque las dos visiones, etic y emic, pero presenta múltiples variantes que no tienen un carácter individual, sino colectivo. Aunque presente una delimitación de la obligación, puede ser productor de nuevas obligaciones residuales en el futuro dentro de la colectividad, asi como permitir la asignación de roles sociales. Posteriormente desarrollaremos, ayudándonos de los datos etnográficos, las obligaciones residuales. En el caso del Don, también presenta el doble componente etic y emic, pero la obligación de dar, recibir y devolver puede atender a intereses individuales o a la moral, por lo que sería necesario analizar las motivaciones personales y patrones culturales que lo hacen posible. Como afirma Terradas (2002), la "reciprocidad estricta" de Mauss no es suficiente para la comprensión de la realidad etnográfica, pudiendo presentarse solo en algunas sociedades no capitalistas. La moral de la reciprocidad como fenómeno universal falla en la medida en la que no considera contextos particulares en los que existen obligaciones morales concretas, obligaciones morales futuras e incluso comportamientos cercanos al 
chantaje o la extorsión. Para entender cómo la reciprocidad se hace presente en el trabajo etnográfico y en el discurso de los propios actores (emic) es necesario, tal y como apunta Algazi (2002), atender a la negociación de la producción de relaciones de dominación y explotación. En el discurso de la reciprocidad encontramos presentes las relaciones de interdependencia social, las imposiciones y la configuración de relaciones desiguales y depredadoras. Como ya señalaron Bourdieu (1980) y Gouldner (1960), el concepto de reciprocidad encierra un desequilibrio de poder dentro de las transferencias y obligaciones mutuas.

El discurso de la reciprocidad se ha inscrito dentro de la construcción histórica occidental tanto para explicar estados prístinos como para catalogar relaciones económicas externas a Occidente bajo la certeza de estudiar una sociedad igualitaria. Según Algazi (2002), esta noción de reciprocidad ha llevado a no primar el estudio de las estrategias de los actores sociales y a la imposición por parte de los investigadores de una "reciprocidad estricta" (don-contra don) falseando sociedades desiguales, llegando a presuponer contra-servicios para así poder justificar la noción de reciprocidad. Levi (2002) propone entender la reciprocidad como instrumento de mediación en las relaciones verticales entre niveles diferentes de estatus, analizando a través de la desigualdad una negociación entre los actores que persigue un intercambio equitativo.

Para comprender más ampliamente el tipo de relaciones que abarca la reciprocidad, realizaremos una breve matización en torno al intercambio. Peter Blau (1964) realiza una distinción entre dos tipologías de intercambio, el intercambio social y el intercambio económico. El intercambio social opera con un valor no específico en el cual se genera la expectativa de una posible retribución, aunque esta no está estipulada. Blau entiende que el intercambio económico, al contrario que el anterior, sí tiene inscrito una obligación definida. El intercambio social posee las características primordiales de lo 
que anteriormente presentábamos bajo el concepto de reciprocidad, obligación personal, confianza y gratitud. Aunque Blau pretende con la presentación de estas dos tipologías de intercambio separar la reciprocidad de los intercambios económicos, vistos por él más en relación al contrato, hasta en las transacciones comerciales podemos encontrar una cualidad atribuida al intercambio estrictamente económico. Las relaciones sociales presentes en el intercambio, que se pretende equitativo, la adquisición de un producto o servicio considerado confiable, desdibujan la supuesta línea que nos puede permitir hablar de intercambios estrictamente económicos.

Aunque la reciprocidad y el intercambio son los conceptos primordiales para poder abordar el estudio de los sistemas financieros y de las relaciones económicas de la región, se hace necesario completar el conjunto de conceptos empleados con el consumo. Debemos tener en cuenta que el uso que realizan los pobladores está muchas veces enfocado a permitir el consumo, y que el propio uso de sistemas de financiamiento alternativo es percibido como un tipo de consumo.

Durante las décadas de 1970, y especialmente en 1980, se formó una subdisciplina en la antropología económica enfocada al estudio del consumo. En la antropología del consumo destacan los trabajos de Mary Douglass y Baron Isherwood (1990), Arjun Appadurai (1991) y Daniel Miller (1987). Sus investigaciones se centraron en analizar las prácticas de consumo. Se realizó con estas investigaciones una transición desde el estudio de los sistemas de producción e intercambio hacia los sistemas de consumo. El enfoque culturalista que había relegado durante unos años a la antropología económica a un segundo plano también permitió afianzar las teorías sustantivistas introduciendo el concepto de consumo como una formación en la que participa el valor económico y las dinámicas culturales. A partir de estos años se presentarán diferentes aproximaciones para el estudio del consumo. 
La aproximación culturalista considera los bienes como poseedores de una función comunicativa o simbólica, capaces de definir identidades y, de esta forma, generar diferencias o similitudes entre grupos sociales. Esta aproximación está influenciada por la semiología y el estructuralismo francés, considerando los bienes de consumo por su significado cultural implícito (Baudrillard, 2010). Las mercancías o servicios son entendidos como signos que codifican ideologías, y la actividad de consumir presenta información sobre la identidad y pertenencia del individuo (Campbell, 1995). No solo la actividad de consumo, sino las necesidades y deseos son considerados parte de una ideología.

En segundo lugar, tenemos la aproximación estructuralista, muy cercana a la culturalista, pero que se diferencia en la medida que opta por analizar la diversidad simbólica en los modos de vestir, o las preferencias en ciertos productos y su capacidad de reproducir oposiciones estructurales y categorías (Sahlins, 1987). En "Culture and Consumption", McCracken (1990) presenta la moda como un proceso de imitación por parte de los grupos subordinados de las clases más adineradas, que intentan diferenciarse de las primeras generando un nuevo ciclo.

Frente al consumo abordado desde una perspectiva culturalista o estructuralista se presentará como alternativa a estas un análisis procesual del consumo, que relaciona el consumo con la economía política, la desigualdad y el conflicto. Las teorías socioeconómicas desarrolladas por Marx, Weber y Veblen estarán presentes en la corriente que considera el consumo como proceso social. Weber y Veblen analizaron cómo la identidad burguesa se proyectó sobre los bienes y servicios generando prácticas de emulación y emprendiendo un carácter competitivo en torno al consumo para determinar la posición económica. La aproximación social considera el consumo como parte fundamental en la competencia de clases. Si bien durante la expansión del 
capitalismo apareció el consumo de masas, no siempre ha estado asociado con el consumo ostensible. Max Weber, en "La ética protestante y el espíritu del capitalismo" (1979), publicada entre los años 1904-05, presenta al hombre de negocios calvinista como trabajador y austero que contrasta notablemente con las ideas que presentaría después el capitalismo, enfocado en mantener la productividad a través del consumo de las masas.

El precursor de lo que hoy conocemos como consumo ostensible, Thorstein Veblen, relató en su obra "Theory of the Leisure Class" (1992), publicada en 1899, las condiciones históricas y sociales que permitieron la creación de la clase ociosa. A través de un enfoque evolucionista, considera que la aparición de la propiedad privada dio paso a la creación de una clase social con suficiente patrimonio para conseguir su bienestar sin la necesidad de desempeñar ningún tipo de trabajo. Esta clase social consta de riqueza y poder, pero la posesión de bienes no es suficiente para identificarse dentro de esta clase ociosa. La riqueza y poder no pueden exhibirse y, por tanto, no pueden ponerse de manifiesto para diferenciarse frente a la clase que, poseyendo las mismas características, precisan de realizar alguna labor para mantenerlas. Por ello, Veblen habla de una clase ociosa, en la que el ocio se hace un elemento ostensible, ya sea a través de modales sofisticados, luciendo lujosos vestidos o participando en actividades en las que el derroche es parte principal de la actividad. Veblen desarrolló el concepto de clase ociosa durante la época Victoriana, por lo que hace especial hincapié en los gustos de la moda victoriana y cómo el uso de vestimentas que impidiese la realización de cualquier tarea (corsé, faldas, tacones) evidenciaban el carácter ocioso de sus portadoras, al igual que las apuestas excéntricas y la compra de animales exóticos. Si bien las actividades de ocio ostensible dieron lugar a lo que hoy conocemos como el sector turístico, el consumo ostensible también permanece presente en el siglo XXI. El consumo de estas características no se encuentra fundamentado en la satisfacción racional de las 
necesidades, sino en principios psicológicos de la emulación. Veblen lo denomina como la comparación envidiosa. Los individuos consideran que deben consumir en la medida que marca su clase social, por lo que nos encontramos ante un consumo como identificador de clase, y una emulación a través del consumo para poder ser aceptado dentro de esa misma clase.

Casi un siglo después de las teorías de Veblen sobre el consumo ostensible, Pierre Bourdieu publicará "Distinction: A social Critique of the Judgement of Taste" (1979). En esta obra, el autor relaciona los estilos de vida y el gusto con las diferentes clases sociales. Entiende que el mundo social está compuesto por estructuras objetivas, independientes de la percepción y de la voluntad que determinan o, por lo menos, orientan las acciones de los individuos. Sin embargo, al mismo tiempo, defiende la existencia paralela de esquemas de percepción, de pensamiento y de acción social. Estos esquemas serán denominados por él como habitus. Con esta perspectiva, Bourdieu intenta superar el debate entre las posturas objetivistas y subjetivistas, a través de su Teoría de la distinción. Los sistemas por los que se presentan las preferencias de consumo están intrínsecamente relacionados con la clase social que ocupa el consumidor. Su hipótesis principal es que existe una relación directa entre el estilo de vida y la clase social, y que la relación entre ambos existe en la medida en la que componen la manifestación más clara del proceso de estructuración de las sociedades, la tensión entre campo y habitus. El trabajo de investigación llevado a cabo por Bourdieu muestra que la clasificación social se percibe a través del consumo de los agentes sociales, y son los propios agentes sociales los que realizan sus propias clasificaciones. En su estudio, presenta tres dimensiones de la vida social: la económica, el habitus y el capital cultural, las tres interrelacionadas. El capital cultural es definido como el habitus de prácticas, conocimientos y conductas aprendidos 
dentro del grupo social que determinará la clasificación que el propio individuo realice correlacionando el consumo con la clase social.

En relación con el consumo de masas, como bien apunta Miller (1998), es necesario cuestionar ciertos lineamientos que se han perpetuado en múltiples estudios críticos hacia este consumo. El principal es cuestionar que el consumo de masas genere una homogeneización global y un ser social particular. Si bien es cierto que en los estudios urbanos es posible encontrar procesos de homogeneización y de diferenciación de grupos, es muy difícil aplicar estos parámetros en el entorno rural. Para Miller, el consumo es un modo de integración de las prácticas sociales por lo que se hace necesario encontrar un equilibrio entre la percepción de los bienes como fetiches o marcadores sociales, y la visión romántica en la que el consumo es presentado como una respuesta de resistencia de los grupos subalternos (Miller, 1995: 271-272).

\subsubsection{El sector informal}

La primera constancia que se tiene en antropología de la utilización del concepto sector informal aparece de la mano de K. Hart (1973) al describir los ingresos obtenidos en el sector informal de la población en Republica de Ghana. Hasta la década de 1970, las actividades realizadas en el sector informal no habían atraído la atención de los antropólogos, pero será durante esta década cuando se presente una primera visión sobre el sector.

El concepto de informalidad abrirá en América Latina un debate sobre los diversos modos de entender el sector y sus actividades. El primero de ellos surge inspirado por el Programa Regional de Empleo para América Latina y el Caribe (PREALC) de la Organización Internacional del Trabajo (OIT) en 1978. Este programa divide el mercado 
de trabajo en dos sectores, el formal y el informal, teniendo como referente el modelo de Arthur Lewis (1955) sobre crecimiento económico. Lewis plantea una teoría dual en la que se presenta un sector basado en la subsistencia y otro en el capitalismo. Las críticas principales a esta teoría, descritas por Portes (1995), se centran en destacar que la visión sectorial ignora las vinculaciones y relaciones mutuas que existen entre lo formal e informal. Simplificar el sector informal, no teniendo presente su gran heterogeneidad impide entender como muchas personas realizan actividades al mismo tiempo en los dos sectores.

Durante la década de 1980, la informalidad será concebida como un producto derivado de la mucha o poca regulación que exista por parte del Estado tanto de las políticas laborales como especialmente de las pequeñas empresas. Este segundo enfoque es desarrollado por de Soto (1987). En su libro presenta la informalidad desde una perspectiva liberal, abogando por el libre mercado y la desregulación de las actividades económicas por parte del Estado. Con este discurso califica el sector informal como necesario y justifica su origen en el exceso de regulación estatal. La informalidad para de Soto es producto de la revolución popular frente al Estado y la producción de este es producto de una legislación que no hace posible el enriquecimiento de las clases pobres, además de reproducir con dicha legislación los beneficios de los grupos privilegiados.

Serán Castells y Portes (1989) quienes realizarán un análisis más pormenorizado sobre el concepto de informalidad planteándolo como un proceso difícilmente definible. La informalidad es entendida como un rasgo característico de las sociedades capitalistas actuales que busca como objetivo flexibilizar la mano de obra. En la definición que uso la OIT, convirtiendo la informalidad en sinónimo de pobreza, podemos apreciar que la informalidad se inscribe para ellos en el mundo urbano, hablando específicamente de 
fuerza de trabajo marginal que usa tecnologías anticuadas y, por lo general, inscrita en el ámbito familiar (Portes y Haller, 2004).

En la actualidad, la informalidad es concebida como un concepto utilizado para determinar asociaciones económicas que ocurren en redes familiares, amigos, vecinos, y que no está regulada, por lo que no obedece a ninguna obligación burocrática, no paga impuestos, ni afilia a sus empleados. La economía informal es un sector heterogéneo de individuos que desarrollan su actividad en muy diversos ámbitos y persiguiendo objetivos distintos. Lo único que tienen en común es que su actividad es realizada fuera del control estatal, ya sea comercio, trabajo, habitación o financiación.

Castells y Portes realizaron una clasificación de las actividades informales según los objetivos que perseguían. En esta clasificación encontramos las economías de supervivencia, en las que las actividades emprendidas buscan mantener a una persona o familia que se encuentra en situación de pobreza. También forma parte de esta clasificación la economía informal de explotación dependiente, actividad que tiene como objetivo mejorar la gestión o reducir el gasto de contratación de las empresas formales, a través de contrataciones no declaradas. Un tercer tipo de actividad informal es la economía de crecimiento, red de pequeñas empresas que tienen como objetivo acumular capital a través de la ayuda mutua.

Comprendiendo lo informal como externo a cualquier tipo de normativa o regulación estatal, hay que señalar un matiz importante. Dentro del sector existe un nivel de ilegalidad a nivel político, y también ilegalidad que cumple distintos grados de delitos. Existe dentro del concepto de informalidad un discurso que intenta no estigmatizar a las clases populares, aunque no debemos olvidar que dentro del sector informal se maneja dinero y se realizan actividades que comprenden actividades delictivas. Portes y Castells abordan la informalidad en México desde una perspectiva moral, incrustada en la política, 
moral y jurídica mexicana. Afirman que la Nación se ha conformado centrándose en la sociedad, y no en el Estado, haciendo o fomentando que los mexicanos no crean en la legitimidad del Estado, sino en las reglas tradicionales de la familia, grupos social o lugar de origen. La informalidad es un elemento presente en la lógica mexicana y latinoamericana, en los límites de la legalidad donde el gobierno estatal no posee el control de todo. La tradición de trabajar en familia no es algo característico solo del sector informal, de hecho, es la preexistencia de estas relaciones sociales las que han favorecido la expansión del sector informal. Adler Lomnitz (1975) y Lewis (1961) ya habían presentado investigaciones en las que la asociación familiar era elemento indispensable para la empleabilidad y mantenimiento de sus miembros. La participación en el sector informal también condiciona la manera de relacionarse, de organizarse, donde la confianza, el honor y el capital social se convierten en suplentes de las leyes, los contratos y la justicia.

Mientras desde el mundo académico es muy habitual enfocar la informalidad como implícito en los sectores más desfavorecidos, influenciados por la definición realizada por la OIT del sector, las actividades informales pueden estar presentes en todas las clases sociales como veremos en esta investigación. La OIT y la CEPAL han desarrollado discursos neoliberales o marxistas respectivamente. Por una parte, la OIT ve la informalidad como una necesidad para evitar las exigencias burocráticas que entorpecen o hacen inviable la formación de algunos sectores como el comercio o la vivienda. Por otro laod, la CEPAL presenta la generación de este sector como una etapa del desarrollo para las economías tercermundistas. Sin embargo, dentro del sector informal, las dos organizaciones han enfocado su análisis dando preeminencia a asuntos laborales o al comercio. 


\subsubsection{Solidaridad circunscrita y Capital Social}

El capital social es un concepto sociológico que centra su atención en las consecuencias positivas de la sociabilidad y en la manera en la que estas interacciones no monetarias pueden ser fuente de influencia y poder. Se entiende por capital social las relaciones, redes y obligaciones existentes que producen valor social y son formadoras de la identidad del poseedor.

A diferencia del capital económico, que se encuentra en las cuentas bancarias y el capital patrimonial, en los bienes, el capital social es inherente a la estructura de sus relaciones. Para tener capital social es necesario que el individuo se relacione con otras personas, y el beneficio que consigue es la captación de una red de relaciones. La ciencia económica moderna considera el capital social como la acumulación de obligación de otros hacia el poseedor del capital social, de acuerdo con la norma de reciprocidad.

La fuente del capital social es la denominada solidaridad circunscripta. Este tipo de solidaridad deriva de la teoría de la integración social de Durkheim (1982). Como ya vimos al hablar de reciprocidad, las expectativas de retribución no se basan únicamente en el conocimiento del receptor, sino en la pertenencia del receptor a un grupo más amplio y a la pertenencia de ambos, dador y receptor, de una estructura social común. La imbricación del intercambio en una estructura social tiene como consecuencia que la recompensa del dador se origina en la colectividad, no únicamente en el receptor, adquiriendo prestigio, estatus o poder por dicha actividad. Es la colectividad la que actúa como testigo y garantía de la transacción por lo que la posible deuda que se pueda producir en el futuro, también será retribuida de algún modo por la colectividad.

Pierre Bordieu explica el capital social como "el agregado de los recursos reales o potenciales que se vinculan con la posesión de una red duradera de relaciones más o 
menos institucionalizadas de conocimiento o reconocimiento mutuo" (1985: 248). Su comprensión de capital social es como concepto instrumental y se inscribe dentro de los beneficios que captan los individuos gracias a formar parte de grupos sociales y en la construcción de la sociabilidad como objetivo para generar estos recursos. Bourdieu divide el capital social en dos elementos principales: el primero es la relación establecida; el segundo, la cantidad y calidad de los recursos. A través del capital social, los individuos pueden obtener acceso a recursos económicos, incrementar su capital cultural o asociarse con otro tipo de grupos o instituciones que permitan el aumento de su capital cultural institucionalizado. En el caso del capital social destinado a obtener recursos económicos, las obligaciones derivadas del uso del capital social para obtener estos recursos no son específicas, los tiempos no están definidos y existe mayor incertidumbre. Como apunta Bourdieu $(1979 ; 1980)$, la falta de claridad en las transacciones derivadas del uso del capital social pueden llegar a disfrazar intercambios mercantiles en una atmósfera de reciprocidad donde los valores morales y el prestigio se hacen presentes junto con los intereses económicos.

Granovetter (1974) no llega a utilizar el concepto de capital social en sus investigaciones, sino que presenta "la fortaleza de los lazos débiles" como concepto. A través de él, se presenta la capacidad que las influencias indirectas del círculo de la familia y los amigos más cercanos puedan ejercen para obtener servicios dentro del sector informal.

Mientras tanto, Glen Loury $(1977 ; 1981)$ desarrollaba su crítica a la teoría económica neoclásica y presentó varias de las características que explican la influencia del capital social en la trayectoria individual de los actores. Loury critica las teorías económicas ortodoxas por ser excesivamente individualistas y concentrarse únicamente en el capital humano individual. Sin embargo, defiende que el ascenso social en base a la 
meritocracia es falso, ya que los individuos no llegan a una posición social como individuos aislados, sino que la trayectoria se realiza acompañada del bagaje familiar, social y cultural desde el origen.

Influenciado por el desarrollo emprendido por Granovetter en torno a "la fortaleza de los lazos débiles", Coleman (1988) desarrollará el término capital social y los mecanismos generadores del mismo. Entre ellos, el autor destaca las expectativas de reciprocidad, la imposición grupal de las normas, las consecuencias de su posesión (como una situación privilegiada), y la posible apropiación de la organización social. Para Coleman, los recursos obtenidos a través de la influencia del capital social son percibidos por el receptor como un tipo de don. El autor (1990) apunta que el uso del concepto capital social debe distinguir siempre tres elementos que forman parte del mismo. En primer lugar, están los individuos o grupos que poseen el capital social, quienes hacen los reclamos; en segundo lugar, las personas o grupos que atienden estas demandas, las fuentes de capital social; y finalmente, los recursos.

Ya en la década de los noventa, Baker define el capital social como "un recurso que los actores deducen de estructuras sociales específicas y luego usan en la búsqueda de sus intereses; se genera debido a cambios en la relación entre los actores" (Baker, 1990: 619). Burt entenderá el termino como el compendio de relaciones entre "amigos, colegas y contactos más generales a través de los cuales uno tiene oportunidades de usar su capital financiero y humano" (Burt, 1992: 9). Sera Burt quien señale que la relativa ausencia de lazos, denominada por él como "huecos estructurales", permite la movilidad individual. El motivo principal que apunta el autor es que las redes densas transmiten información redundante, mientras que los vínculos más débiles pueden ser implementados con mayor facilidad y su uso conllevar acceso a nuevos recursos. 
El capital social, para Putman (1994), es de carácter limitado y se inscribe dentro de una red de relaciones de carácter horizontal formando redes con normas asociadas. Estas normas y redes tienen como función facilitar la coordinación y cooperación, relacionando de este modo el capital social con la capacidad de desarrollo de los participantes en la red.

Como hemos podido comprobar, el concepto de capital social se ha desarrollado en gran medida como un concepto positivo que permite o facilita el acceso a recursos a través de las relaciones sociales. Sin embargo, existen numerosos estudios que presentan el enfoque opuesto, presentando el capital social desde un enfoque negativo con datos etnográficos que así lo atestiguan.

El análisis más detallado del capital social como elemento capaz de crear exclusión, asimetría y desigualdad fue realizado por Portes y Landolt (1996). La investigación parte del análisis crítico de estudios recientes en el que apuntan cuatro consecuencias negativas del capital social. La primera de ellas es la exclusión de los extraños. Ccomo apunta Waldinger (1995: 557), “las mismas relaciones sociales que (...) mejoran la desenvoltura y la eficiencia de los intercambios económicos entre los miembros de la comunidad restringen implícitamente a los extraños de ella". En segundo término, encontramos una dinámica que hemos podido observar en el campo múltiples veces en referencia al cobro de remesas: los reclamos excesivos a los integrantes del grupo. Geertz (1963) ya había señalado esta problemática cuando describió cómo los empresarios exitosos sufrían los reclamos continuos de sus familiares y de los miembros de la comunidad en general. Una tercera consecuencia, muy habitual cuando analizamos las relaciones sociales del entorno rural, son las restricciones a la libertad individual. En las redes familiares o vecinales, el control social es restrictivo con las libertades individuales, existiendo unas normas morales que son consideradas de obligatoriedad 
para todos los componentes del grupo. En el caso de la presente etnografía, se recogió varias veces la expresión "Pueblo chico, infierno grande" para hacer referencia a esta situación de imposición moral y control social. Boissevain (1974) presenta una situación semejante en la vida rural de Malta. La densidad de las redes genera una intensa vida comunitaria en donde se practica una imposición de las normas locales, y la privacidad y autonomía de los individuos está penalizada. La cuarta consecuencia deriva directamente de la anterior, ya que la restricción de la libertad individual tiene como objetivo homogeneizar a la comunidad. Por eso, la imposición de las normas niveladoras hacia abajo es determinante para alcanzar este objetivo. Como podemos observar, las consecuencias negativas del capital social fomentan que aquellos individuos de la comunidad que quieran optar a mayor libertad individual o no quieran verse obligados a la asistencia de ayuda mutua hacia sus vecinos suelan optar por abandonar la comunidad. Este es el caso de muchos individuos que emigran a la ciudad, donde se ha podido encontrar que uno de los factores que repiten para presentar su satisfacción en la vida urbana es la independencia y libertad que consiguen emigrando a las grandes ciudades.

En las investigaciones sociales que se realizan actualmente se presenta la reciprocidad como asociada a formas grupales de relación social. La reciprocidad es considerada dependiente de la sumisión por parte de los actores, a la razón social de la comunidad. El estudio de la reciprocidad y las relaciones sociales que la hacen posible es el causante de la influencia que el concepto de capital social está teniendo en la actualidad en los estudios sociales (Bagnasco, 1994; Piore y Sabel, 1984; Putman, 1993; Woolcock, 1998). En estas investigaciones se presenta la reciprocidad como un modo de justicia que persigue el bien común. Cuando analizamos minuciosamente el tipo de relaciones que se encuentran inscritas dentro del concepto de capital social (Fine, 1999), encontramos que la base común de todas ellas se encuentra en la reciprocidad. La dependencia de la 
confianza que condiciona las relaciones económicas entre individuos pertenecientes a un mismo grupo social es el factor clave para hacer posible este tipo de relaciones. Como señala Narotzky (2002: 26), "esta sustancia de relaciones sociales de intercambio duraderas y presuntamente equitativas situadas más allá o más acá de los incentivos de mercado, es lo que se entiende generalmente como reciprocidad".

Narotzky (2002) se pregunta cuál es el motivo por el cual el modelo de capital social adquiere tanta notoriedad en las ciencias sociales al proponer la re-incrustación de las relaciones económicas y cómo este modelo se desarrolla en contraposición al individualismo capitalista. Para responder a estas preguntas utiliza el concepto de mercancías ficticias desarrollado por Polanyi (2011) con el que se refiere a la naturaleza y la vida humana. La aportación del capital social a los estudios sociales está representada en su nuevo modelo orgánico jerárquico que pone en duda el modelo liberal igualitario del capitalismo.

Nos encontramos con una ambivalencia tal que lo económico ni siquiera debe entenderse como incrustado en relaciones sociales previas (por ejemplo, de parentesco, o de comunidad), lo económico no está en lo otro sino que lo económico es lo otro, hay inmediatez y simultaneidad en la producción de relaciones sociales que posibilitan la reproducción de interdependencias humanas particulares (Narotzky, 2002: 18-19). 


\subsubsection{La antropología económica durante la crisis de 2008}

La crisis de 2008 provocó la venta y desmantelamiento de empresas para su venta o especulación. Estos movimientos de destrucción del tejido productivo son el primer daño provocado por una crisis que tiene su origen en el sistema financiero global (Harvey, 2010). No obstante, las crisis logran ser aprovechadas por algunos sectores, o incluso creadas por ellos, siendo los mayores beneficiarios a largo plazo. Debemos entender que el sector financiero, responsable de la crisis de 2008, fue el mayor beneficiario de esta, y aunque el sector informal del mismo, opere en cantidades menores, también vivió durante este periodo un momento de esplendor.

Durante los años anteriores a la crisis, la antropología económica se había mantenido en un segundo plano, no formando parte del "mainstream" académico. Uno de los libros más destacados de este periodo es un handbook de antropología económica publicado en 2005 y dirigido por James Carrier en el que están incluidos textos de Hann y Hart, Graeber, Gudeman, Narotzky y Robotham. En 2007, Wilk y Cligget presentarán "Economies and Cultures: Foundations of Economic Anthropology", pero no será hasta 2008 y la irrupción de la crisis cuando la antropología económica empiece a recuperar la atención que anteriormente tuvo. Será a partir de este año cuando los editores del handbook prepararán una segunda edición que verá la luz en 2012, ampliada y actualizada, incluyendo una sección completa llamada "The crisis". El propio Carrier (2012) afirmó durante la publicación de esta segunda edición que la crisis había dado un impulso a la antropología económica. También aparecerán etnografías interesadas en las prácticas culturales del mundo financiero, influidas por el trabajo de Hertz (1998) sobre la bolsa de Shanghái. Karen Ho (2009) publicó una etnografía sobre la cultura institucional de Wall Street y Emil Royrvik (2011) presentó su investigación sobre los modos de operar de las corporaciones multinacionales. 
Las consecuencias de la crisis serán el impulsor de movimientos como "Occupy Wall Street", al que se unieron públicamente varios intelectuales, entre ellos, una de las caras más visibles de las manifestaciones, David Graeber. Es en este periodo cuando ve la luz el handbook (2012). La reseña realizada por Maurer (2012) titulada “Occupy economic anthropology" señala acertadamente uno de los problemas que se ha mantenido en este proceso de resurgimiento de la antropología económica. Maurer remarca que el handbook en su segunda edición es más un trabajo político que académico, y hace especial mención al capítulo de Hann y Hart en el que realizan una reflexión sobre la alternativa socialista en el mundo contemporáneo, señalando "Hann y Hart han sido influidos por 1968, más que por 2008" (2012).

La antropología económica siempre ha estado influenciada en mayor o menor medida por escuelas económicas o tendencias políticas y seguramente este trabajo no esté exento de ellas. En esta investigación se intentará dar la mayor importancia a los datos recopilados en la etnografía, por encima de análisis críticos que puedan viciar las conclusiones finales. Para ello, tanto la metodología utilizada, como la selección de sujetos participantes se han realizado con la mayor riguridad, buscando presentar la región en su heterogeneidad y no buscar ideales utópicos en la economía informal.

\subsection{El trabajo de campo: observaciones, metodología y técnicas empleadas}

En el siguiente apartado se pretende poner de manifiesto algunos datos sociodemográficos que puedan ser de utilidad para perfilar al sujeto investigador, así como la metodología, desarrollo de la etnografía y las técnicas empleadas para la 
selección de los sujetos participantes y la compilación de los datos expuestos en la etnografía.

\subsubsection{Conocimiento situado. Reflexiones epistemológicas y compromiso con}

\section{la realidad}

La etnografía que se presenta en esta tesis doctoral se realizó entre agosto de 2012 y mayo de 2016. La estancia de investigación inicial fue posible gracias a la Beca con Universidades Extranjeras de la Universidad de Salamanca que posibilitó una estancia de un curso lectivo en una de las sedes de la Universidad Nacional Autónoma de México, UNAM. La selección de la sede, bajo el asesoramiento de Iñigo González de la Fuente, fue consensuada buscando el lugar idóneo para realizar la investigación. Entre los factores que se tuvieron en cuenta para la selección destacan que la región está inserta en una zona rural que ha experimentado virulentamente las transformaciones neoliberales, la desagrarización del campo y un proceso migratorio que se extiende durante todo el siglo XX. Además, la región de la Ciénaga de Chapala cuenta con un centro urbano (los municipios de Jiquilpan y Sahuayo) que, a través de un proceso de diferenciación motivado por su rivalidad histórica, han generado particularismos que permiten investigar la dualidad del campo mexicano. Esta dualidad se reproduce en la diferenciación entre Jiquilpan y Sahuayo, mostrando en el caso del primero una identidad agraria, ejidal, socialista y con un fuerte arraigo a la historia nacional y al pasado revolucionario. En el caso de Sahuayo, esta identidad se muestra como comercial, competitiva, neoliberal e influenciada por la religión católica y la guerra cristera.

Aunque la estancia en Jiquilpan, donde se sitúa la Unidad Académica de Estudios Regionales (UAER) fue mi primer contacto con México, el haber pasado parte de mi infancia en la comarca de la Bureba (de donde es originaria mi familia paterna), me 
facilitó adaptarme sin problemas al ritmo de una localidad pequeña. Además del propio ritmo que poseen los municipios del ámbito rural, el quehacer cotidiano, los conflictos sociales originados hace dos o tres generaciones y la rivalidad entre municipios no son algo novedoso para una persona del norte de Burgos (España).

La gestación del proyecto se configuró años antes de mi llegada a la Ciénaga de Chapala. Este proyecto se fraguó gracias a experiencias pasadas que quizá, ante una mirada externa, no guarden relación entre sí, pero que a nivel individual configuraron la inquietud intelectual que me llevó a realizar esta investigación. Para entender esta inquietud y justificar esta etnografía a nivel personal, debo remontarme más de una década, cuando cursaba estudios de Bellas Artes en la Universidad de Salamanca. Las clases de pintura de los últimos años de licenciatura no pretendían tanto mejorar la técnica de los alumnos como definir su estilo, por lo que nos solicitaron que seleccionásemos una obra del amplio repertorio de la Historia del Arte para realizar interpretaciones de la misma. La acción de seleccionar, fuera de los cánones establecidos y con la libertad de ignorar el discurso oficial en torno a la importancia de ciertas obras sobre otras, nos permitía convertirnos en jueces independientes a los que la elección les define. Relato este momento porque, aunque pudiese haber sido otra de las muchas actividades por las que debe pasar un estudiante de Bellas Artes, mi elección me devolvió como reflejo preguntas que deseaba realizar. El cuadro seleccionado que reinterpretaría durante los siguientes meses fue El Niño de Vallecas, realizado en el siglo XVII por Velázquez. La obra representa a un enano de la corte de Felipe IV. El cuadro, más allá de su valor artístico o histórico, me interesó por la temática. Ante las grandes obras pintadas por Velázquez, en las que se representa la vida en palacio, la familia real y la vida cortesana, este retrato realizado de manera brusca y con aspecto de inacabado representaba a "los otros". Estos "otros" convivían con las figuras prominentes del Estado, compartían 
espacio, pero permanecían en un segundo plano como algo anodino, dedicado al divertimento, una rareza de la realidad que se contemplaba como un elemento peculiar digno de extrañeza.

Durante el proceso de realización de la serie de retratos tuve la oportunidad de configurar una idea de estos "otros", no enmarcada por las ciencias sociales, sino a través de la Historia del Arte. Aunque la distancia entre las dos disciplinas puede ser tan grande o pequeña como el experto en alguna de ellas quiera considerar, en mi caso la conexión de una con la otra fue fácil y rápida, entendiendo la producción artística como una actividad antropológica y la producción antropológica como una actividad artística, en la cual el otro, o mejor dicho, el sentimiento de otredad debía permanecer consciente.

Años después tuve la oportunidad de residir en Fortaleza, Brasil durante varios meses. Fue en la ciudad de Fortaleza donde pude conocer la iniciativa que había puesto en funcionamiento el Banco Palmas, un banco local que ofrecía acceso financiero a la población con bajos recursos del Conjunto Palmeiras. El Conjunto Palmeiras es un barrio periférico, creado en 1973 para trasladar a la población que estaba asentada en la línea de costa. Los planes urbanísticos de la ciudad de Fortaleza, que se centraban en la construcción de hoteles y restaurantes en las playas para atraer el turismo, expulsaron de su residencia a numerosas familias que se vieron abocadas a trasladarse al interior, en una zona sin servicios básicos, donde tuvieron que empezar desde cero. A diferencia de los programas de desarrollo y el por entonces aplaudido proyecto de microfinanzas para los pobres, la comunidad del Conjunto Palmeiras con Joaquim Melo como coordinador del Banco Palmas, comenzaron a trabajar con base en la propia capacidad de sus habitantes, reconociendo que la organización de la comunidad era la característica principal para encontrar solución a los problemas comunitarios. Esta iniciativa se concretó en el proyecto, realizar un banco comunitario, semejante a una caja popular mexicana, pero 
con la diferencia de que ellos empezaron a imprimir su propio dinero para favorecer el movimiento de capitales dentro de su comunidad. En el trascurso del tiempo que estuve en Fortaleza tuve oportunidad de conocer diferentes estrategias que utilizaban los habitantes de la ciudad $\mathrm{y}$, en especial, aquellos que permanecían fuera del sistema financiero formal.

Estas dos experiencias motivaron años después la elección de la temática para constituir la tesis doctoral que aquí se presenta. La primera como precedente de mi posterior interés en la antropología, y la segunda como iniciadora de mis investigaciones en torno a la economía informal. Espero que este relato sirva para describir brevemente la voz que escribe esta etnografía y aporte algún conocimiento que permita evaluar esta investigación tomando como referencia mis motivaciones y limitaciones. El camino reflexivo que me ha llevado a investigar los sistemas financieros que presentan una alternativa a los sistemas formales, y mi particular interés en el conocimiento del otro como participante de la realidad humana, son las piedras angulares que conforman esta tesis doctoral. He intentado a través de este relato realizar un ejercicio de objetivación propia que me permita entender mis motivaciones e intereses. Entiendo que no existe ningún método capaz de explicar e interpretar la realidad humana que sea neutro, asumiendo como inevitable que la identidad del etnógrafo contamine, en mayor o menor medida, el conocimiento antropológico. Mi compromiso en describir etnográficamente lo mejor posible la realidad humana de la Ciénaga de Chapala pasa por la obligatoriedad de reconocer mis limitaciones, tanto teóricas como económicas, las circunstancias que pudieron condicionar el acceso a los informantes y los acontecimientos que transcurrieron durante aquellos años.

Para tales fines, se presentarán los fenómenos, experiencias, discursos y relaciones etnográficas acontecidas durante el desarrollo del trabajo de campo. También se relatará 
los condicionantes y problemas a los que tuvo que enfrentarse el proyecto, así como las soluciones que se aplicaron en cada caso. Estas reflexiones no buscan la crítica o generalización de las experiencias vividas durante el desarrollo del trabajo etnográfico, ni presentar una descripción idealizada de tal experiencia, sino realizar una reflexión socio biográfica, o en palabras de Bourdieu, un autoanálisis, que me permita objetivar mi desempeño en el campo en cuanto sujeto investigador.

(...) La objetivación científica no está completa si no incluye el punto de vista del sujeto que la opera y los intereses que él puede tener por la objetivación (especialmente cuando él objetiva su propio universo), pero también el inconsciente histórico que él compromete inevitablemente en su trabajo. Por inconsciente (o trascendental) histórico, o más precisamente, académico, hay que entender el conjunto de estructuras cognitivas que es imputable a las experiencias propiamente escolares, y que es común en gran parte al conjunto de productos de un mismo sistema escolar nacional- o, bajo una forma específica, a todos los miembros de una misma disciplina en un momento dado (Bourdieu, 2006: 91).

Añadir a esta investigación las experiencias vividas en primera persona me permiten incorporar al yo investigador “...al campo de análisis y poner en cuestión su mundo académico, cultural y social, que es su condicionamiento, a la vez que su posibilidad de conceptualizar la objetividad social" (Guber, 2005: 77). Espero que esta descripción de mi experiencia permita situar la voz que escribe esta etnografía, así como los hándicap y limitaciones a los que tuve que hacer frente. 


\subsubsection{Desarrollo del trabajo de campo}

Llegué a Jiquilpan a finales de julio de 2012, pasando unos días en el departamento de la UAER hasta encontrar una habitación en renta. Una vez encontrada residencia en el municipio dediqué los siguientes meses a conocer las dos localidades principales del DDR 089, recopilar información de carácter histórico sobre la región y empezar a entablar amistades. El espacio que me brindó la UAER para estudiar me fue de gran utilidad, ya que me sirvió para organizar los días entre el despacho, el campo y la casa. En una localidad pequeña como Jiquilpan es fácil ir conociendo a la gente de forma natural, y como comprobaría durante los primeros meses, es aún más fácil que la gente te conozca a ti. La llegada de alguien nuevo siempre es cuestión de conversación y mi metro ochenta de estatura me impedían confundirme con alguien de allí. En realidad, viendo aquellos primeros meses en perspectiva, la entrada a campo consistió en una presentación, yo hacía pocas preguntas, pero respondía muchas y cuando hube apaciguado la curiosidad de la gente pude empezar la etnografía; antes hubiera sido imposible.

Aunque las personas que trabajaban en la UAER me habían indicado que presentarme bajo las siglas de la UNAM me facilitaría la confianza necesaria para encontrar sujetos participantes con la investigación, rápidamente pude darme cuenta que eso era una verdad a medias. Si bien es cierto que la UNAM posee esa aura de prestigio y legitimad que consigue que te hablen de usted e intenten responder de la manera más educada y pomposa posible, esa misma aura produce un distanciamiento, una jerarquía que considere perjudicial para la tarea etnográfica.

La falta de recursos económicos y becas con aporte monetario hizo que después de las navidades mis ahorros empezasen a disminuir. Por mi experiencia vital sé que una buena manera de conocer gente y de ganarse la confianza de una comunidad es trabajar 
dentro de la comunidad, por lo que empecé a trabajar en la Casa de Cultura de Jiquilpan en febrero de 2012. Mi trabajo consistía en impartir clase de dibujo y pintura a niños de entre 4 a 10 años dos días a la semana, una actividad que al principio pensé que me evadiría de mi trabajo etnográfico por unas horas y que, posteriormente, supuso un avance significativo en el mismo. El desprenderme del aura de la UNAM y pasar a ser la maestra de dibujo supuso un cambio significativo en la manera en la que los habitantes de la región se relacionaban conmigo.

Gracias a este cambio de rol dentro de la comunidad y a mis limitaciones económicas, las personas empezaron a integrarme dentro de su comunidad. Con la residencia fijada en Jiquilpan y mis visitas habituales a Sahuayo, pronto pude seleccionar a algunos sujetos participantes en la investigación que, por su diferencia de edad y nivel socioeconómico, consideré que podían aportarme una visión holística de las actividades económicas. Además de las personas que participaron en el estudio, conocí a varias personas con las que todavía mantengo amistad, que fueron de gran ayuda para sentir la región como mi nueva casa. Por motivos éticos no he incluido en esta etnografía ningún dato aportado por los segundos, ya que considero que esa información es de ámbito personal y porque nunca fueron considerados como sujetos participantes de la etnografía. Los primeros, los participantes, a los que se les ofreció la posibilidad de colaborar en esta investigación y estuvieron de acuerdo en participar, aparecen con diferentes nombres para mantener su anonimato, y se han eliminado datos que puedan facilitar su identificación. Entre los motivos del anonimato, se encuentran los problemas de inseguridad y violencia en la región. También porque esta investigación abarca una esfera económica ante la que muchos sujetos no deseaban identificarse con sus nombres originales, hablamos de deudas, préstamos y confianza, motivo por el cual muchas personas me pidieron que presentarse "el pecado, pero no el pecador". Por último, el anonimato me ofreció la 
posibilidad de no coartar el discurso de los sujetos, considerando que gracias a su no identificación tenía una mayor oportunidad de conseguir información veraz sobre asuntos económicos.

Los sujetos entrevistados principales de esta primera etapa fueron cuatro, originarios de diferentes municipios de la región. A lo largo de la etnografía se realizará una descripción de cada uno de ellos, así como su historia de vida. Además de estos cinco informantes, se recogen entrevistas e información recogida en el campo de las personas que interactuaron con ellas, intentando mostrar los mismos acontecimientos desde diferentes puntos de vista, uno principal y varios secundarios. Con este ejercicio se pretende representar el acontecer económico bajo el efecto Rashomon, tal como hiciera Lewis en “Los Hijos de Sánchez” (1961).

Cuando estaba próximo el fin de mi visado en México, Julio de 2013, decidí alargar mi estancia buscando un trabajo que me permitiese renovar el visado y disponer del dinero suficiente para seguir adelante con la investigación. Ante la imposibilidad de conseguir un trabajo en la región que me permitiese cambiar mi visado y alargar mi estancia opté por trasladarme a Zamora e impartir clases en la Universidad del Valle de Atemajac. Zamora se encuentra a 59 kilómetros de distancia de Jiquilpan, una hora de viaje en autobús, lo que me permitió ir asiduamente a la Ciénaga y continuar con la etnografía durante los fines de semana y las vacaciones. En la Universidad del Valle de Atemajac trabajé impartiendo clases en las licenciaturas de Diseño Gráfico e Ingeniero Arquitecto, gracias a mi licenciatura en Bellas Artes, entre septiembre de 2013 y abril de 2016. El último año de mi estancia también pude impartir docencia en la Universidad de Zamora, desde septiembre de 2015 a junio de 2016, lo que me otorgó la posibilidad de residir durante cuatro años en la zona, realizar visitas frecuentes, mantener un contacto 
asiduo con los sujetos participantes y poder presentar una etnografía que recopila cuatro años de datos etnográficos.

\subsubsection{Técnicas y recursos utilizados}

Esta tesis doctoral se fundamenta en el método etnográfico apoyado en la convivencia y la observación directa de la cotidianeidad a través de sus discursos, prácticas y relaciones durante cuatro años. Esta co-temporalidad (Fabián, 1983) permitió compartir el espacio de vida y de relación durante el periodo de investigación, facilitando la comprensión de las razones que motivan a las personas a tomar decisiones de tipo económico. La estancia de un año en Jiquilpan y de otros tres años en Zamora con visitas periódicas a la Ciénaga de Chapala posibilitó que las relaciones con los informantes se fortaleciesen hasta permitir realizar un trabajo etnográfico capaz de abarcar procesos de larga duración, como la rotación completa de las tandas, el encadenamiento de deudas y la observación de resultados. El campo de trabajo constituyó otro elemento de observación debido a que los dos municipios principales de la investigación, Jiquilpan y Sahuayo, experimentaron cambios sustanciales tanto en sus modelos productivos, como el caso de Jiquilpan una vez fue nombrado Pueblo Mágico, y las repercusiones que la inseguridad y los conflictos relacionados con la violencia han generado en la región.

El ocupar un rol en la comunidad, más allá del rol de investigador, me concedió la oportunidad de superar la observación distante, permitiéndome participar en celebraciones y acontecimientos familiares y personales. Los discursos, conductas y prácticas recopiladas durante la investigación fueron posibles gracias a la confianza que depositaron en mí. Esta confianza hubiera sido imposible de no ser recíproca, por lo que tuve que externalizar mis sentimientos y sufrimientos para llegar al nivel de intimidad que desea mantener con los sujetos. 
Retrospectivamente considero que el choque cultural se fundamentó en tres elementos que yo tenía normalizados pero que eran elementos disruptivos para la comunidad. El primer hándicap al que tuve que enfrentarme fue ocasionado por mi nacionalidad y apariencia. Este hándicap se configura como algo ambivalente. Por un lado, pude constatar el malinchismo ${ }^{12}$ de parte de la población, en cuanto dentro de sus discursos alababan o señalaban como virtud mi fenotipo o apariencia. En contraposición a esto, también se presentó la oportunidad de corroborar el efecto contrario, encontrando casos en los que estas características hacían florecer discursos nacionalistas de odio o desprecio hacia los españoles, así como desconfianza y recelo. El segundo y tercer hándicap están correlacionados aunque realizo una separación de ellos para presentar estas dos características como creadoras de dos confrontaciones con la comunidad diferentes aunque paralelas. Por un lado, y sin pretender realizar un análisis pormenorizado de la teoría feminista, el ser mujer e irrumpir en una sociedad patriarcal como la mexicana originó mi inscripción en nuevos roles que hasta ahora no había experimentado. Aunque si bien es cierto que una etnógrafa puede tener mayor facilidad para acceder a informantes femeninas, también pude comprobar que la rivalidad entre mujeres y el sentimiento de pertenencia hacia sus maridos y viceversa, se interponían en la configuración de relaciones no sexualizadas. Si bien en un primer acercamiento me sorprendió el interés que mostraron muchas mujeres en entablar conversación conmigo, pronto pude comprobar que este proceso estaba condicionado por un ejercicio de calibración que ciertas mujeres consideraban necesario. Desarrollaré más este proceso a través del tercer hándicap. En el caso de las relaciones con el género masculino se reprodujeron roles diferentes, desde el paternalismo y proteccionismo de alguno de los

\footnotetext{
12 Término peyorativo. Su origen parte de la figura de La Malinche, mujer mexicana que acompaño a Hernán Cortes durante la invasión de México. Se entiende por una persona malinchista aquella que prefiere lo extranjero frente a lo nacional o considera que lo extranjero posee virtudes o beneficios solo por el hecho de ser extranjero.
} 
hombres participantes en la investigación, hasta situaciones de acoso y pretendida dominación. Mi negativa a participar en cualquier tipo de ritual de cortejo o simplemente externalizar mis preferencias sexuales desembocó en dos resultados. Uno de ellos dio como resultado que me identificasen como una mujer altiva, malinchista y prepotente, lo que califique como una respuesta agresiva originada por mis negativas que habían provocado una herida en su orgullo. El segundo resultado, de generación más común entre las mujeres, fue el catalogarme como homosexual. Este calificativo, aunque nunca fue afirmado o desmentido, consiguió que parte de los sujetos me catalogasen como asexual, facilitando parte de mi investigación. El tercer hándicap, correlacionado con el segundo y, por tanto, también productor de los resultados anteriores, fue el estar soltera y no tener hijos. La soltería como tal no fue un elemento perturbador en la comunidad, pero el no tener hijos y no externalizar mi necesidad de tenerlos fue algo que chocaba directamente con los roles culturales de parte de la comunidad. Gran parte de mis relaciones en la Ciénaga de Chapala se realizaron a través de unidades familiares a las que podía acceder en calidad de investigadora, pero también de maestra, en principio como maestra de la Casa de Cultura y posteriormente como docente universitaria. En este caso, mi nomaternidad fue entendía más como una imposibilidad física que como una carencia elegida, por lo que el hándicap se equiparó a una discapacidad. La estancia en el campo conllevó un proceso interno de aprendizaje y adaptación, en la que los roles ocupados y la percepción que los habitantes adquirían sobre mí no pudo ser controlada, aunque sí amortiguada gracias a los consejos y apoyo moral de parte de los participantes y mis amigos. Como señalan Velasco y Díaz de Rada, la incursión en el campo y su adaptación a él en cuanto individuo externo y como investigador requirió "un aprendizaje controlado, una socialización con retorno previsto, una socialización reversible" (2009: 27). Comparto con estos autores la idea de que la tarea del investigador va más allá de su 
propio quehacer etnográfico y considero que "la superación del shock cultural ha requerido en ocasiones de una potente fuerza de voluntad, una enorme capacidad de sufrimiento, largas dosis de paciencia, y algo de suerte" (2009: 30).

En cuanto a las técnicas utilizadas para la obtención de datos etnográficos, me decanté en un inicio por la observación no-participante frente a la observación participante. Esto se debió a que el mantenerme como agente externo a los intercambios económicos fue considerado una mejor forma de acercarme al campo. Además, esta decisión fue motivada por mi rechazo hacia la práctica etnográfica de la observación participante en el inicio de una investigación, ya que considero que puede ocasionar que el antropólogo se convierta de este modo en un turista de la realidad cultural, en la que participa como consumidor ocioso de la misma. Mis reticencias iniciales a participar activamente en los sistemas financieros informales fueron eliminadas cuando tuve que hacer uso de los mismos por problemas económicos. Los gastos derivados del cambio de domicilio a Zamora y, posteriormente, el pago de las tasas para cambiar mi forma migratoria me llevó a contraer deudas, y aunque barajé en primera instancia el empeño de mi cámara de fotos para solventar este problema, decidí por pedir un préstamo informal, lo que me hizo partícipe del funcionamiento de cada modalidad de financiamiento. Aunque mi experiencia personal no ha sido recogida en esta etnografía, esta actividad ofreció la oportunidad de tener un mayor acceso a ciertos sujetos. La recolección de datos se hizo gracias a entrevistas abiertas en situaciones informales, así como la recopilación de historias de vida y la convivencia con los informantes. El método etnográfico permitió articular diferentes técnicas a través de un proceso de aprendizaje y adaptabilidad continua. Además de las técnicas de observación, entrevistas abiertas e historias de vida, la obtención de información se completó con entrevistas semiestructuradas, historias familiares y el análisis de materiales documentales y estadísticos, 
a lo que se suma el estudio y discusión de los materiales bibliográficos que sirven de apoyo teórico a la investigación. Las historias de familia fueron una herramienta fundamental para trazar las conexiones existentes entre relaciones personales y su posicionamiento en la comunidad, entendiendo la familia como epicentro del análisis de clase (Wolf, 1980). Cabe mencionar que las historias y experiencias recabadas en esta investigación son difícilmente comprensibles si no se contextualizan dentro de los procesos regionales, estatales y nacionales a los que se hace mención durante la etnografía.

La recogida de datos se realizó a través de diferentes recursos. Aunque en un inicio se consideró grabar el audio de las entrevistas, la experiencia no fue del todo fructífera al comprobar que cuando los informantes iban a dar algún dato que consideraban comprometedor miraban la grabadora con desconfianza y modificaban su discurso ante la posibilidad de dejar un testimonio grabado del mismo. El único caso en el que la grabación de audio sí fue posible fue con Karen, debido en parte a que nuestras conversaciones se realizaban en su tienda. Por ello se tomó como la opción más idónea tomar apuntes escritos de los datos en el diario de campo. El mero hecho de tomar apuntes generaba una atmosfera más cómoda para los sujetos participantes, ya que se sentían en la libertad de indicar cuáles de las cosas que estaban diciendo eran las más importantes, para que las señalase en el diario de campo como tal, y la conversación se ralentizaba generando un espacio de reflexión que los informantes aprovechaban para comentar ciertos detalles o indicarme algunos factores consecuentes con la historia. En otras ocasiones resultaba imposible tomar notas, ya que las conversaciones se realizaban de manera informal mientras caminábamos por la calle o en algún establecimiento. Debido a esto intenté encontrar siempre unas horas al final del día para escribir la información en el diario de campo, así como apuntes en torno a otras facetas de la conversación. 


\subsubsection{Reflexiones sobre las técnicas utilizadas}

Al extenderse la etnografía durante cuatro años, los testimonios, historias y entrevistas que se presentan en esta investigación están en la medida de lo posible contextualizados con hechos que sucedieron durante este periodo. En total se realizaron más de 40 entrevistas, haciendo un seguimiento a lo largo de los años de diferentes sujetos para obtener datos del proceso financiero, así como cambios discursivos y en las relaciones forjadas en torno a los sistemas financieros.

Para ello, se seleccionaron clientes y usuarios de los sistemas financieros informales, pero también empleados que trabajaban en este sector, dueños de establecimiento que ofrecían financiación, organizadores y participantes en tandas, prestamistas, deudores y organizadores y participantes en kermes. La selección de los cuatro sujetos participantes principales se realizó buscando representar la diversidad, tanto por edad y género, como por nivel socioeconómico y residencia. A partir de estas personas se seleccionaron otras para triangular informaciones y presentar más puntos de vista sobre el mismo fenómeno.

Por efectos prácticos se ha elegido redactar la etnografía con base en estos cuatro testimonios, para vertebrar a través de ellos las informaciones obtenidas. Además de los testimonios principales, a estos se sumarán dentro del hilo narrativo los participantes secundarios, aportando otras perspectivas y completando la etnografía. La articulación de estos fragmentos etnográficos me permite presentar una aproximación multifocal, aplicando el efecto Rashomon a la redacción etnográfica. El método aplicado no persigue realizar generalizaciones a partir de casos particulares, sino el de presentar estas experiencias particulares como elementos susceptibles de incorporar dentro de su significado individual configuraciones de poder estructural articulado. Con esta 
investigación se pretende contribuir al estudio antropológico de la economía informal, presentando hechos concretos difícilmente generalizables ya que se encuentran condicionados por el contexto en el que se producen. 


\section{BLOQUE II. LA CIÉNAGA DE CHAPALA. \\ CONTEXTUALIZACIÓN HISTÓRICA Y DESCRIPCIÓN \\ DE LAS COMUNIDADES}

"El capitalismo mexicano nació mucho antes que la Revolución pero maduró y se extendió hasta llegar a ser lo que es gracias a la acción y a la protección de los gobiernos revolucionarios. Al mismo tiempo, el Estado estimuló y favoreció a las organizaciones obreras y campesinas (...) El Estado posrevolucionario completó su evolución con la creación de dos burocracias paralelas. La primera está compuesta por administradores y tecnócratas; constituye el personal gubernamental y es heredera histórica de la burocracia novohispana y de la porfirista. Es la mente y el brazo de la modernización. La segunda está formada por profesionales de la política (...) Las dos burocracias viven en continua ósmosis y pasan incesantemente del partido al gobierno y viceversa (...) Como en la Rusia de principios del siglo, el proyecto histórico de los intelectuales mexicanos y, asimismo, el de los grupos dirigentes y el de la burguesía, puede condensarse en la palabra modernización”

El Ogro Filantrópico (Paz, 1990: 15-16) 


\subsection{México: economía, sistema financiero y sector informal. Desde el sexenio de Salinas de Gortari hasta Peña Nieto (1988-2012)}

Durante las últimas décadas, México ha experimentado cambios profundos, crisis económicas y un aumento de la desigualdad, siempre en la búsqueda de la modernización que es percibida por los mexicanos como una simulación deficiente. El neoliberalismo llegó a México en el periodo presidencial de Salinas de Gortari (1988-1994). Salinas comenzó su mandato encarcelando a dirigentes petroleros, capturando a narcotraficantes y apoyando la condena norteamericana al dictador panameño General Manuel Noriega, haciendo que el grupo Contadora y la intervención mexicana en asuntos centroamericanos cesasen, dando paso a la intervención estadounidense y provocando que México mirase hacia el norte.

Estados Unidos de América premió a su nuevo mejor compañero presionando a los bancos para la renegociación de la deuda externa, haciendo más llevadera la crisis económica del país cuando llegó Salinas. En 1989 se presentó el Plan Nacional de Desarrollo 1989-1994, convirtiendo a México en un país no intervencionista y nacionalizador que se abría totalmente al mercado internacional y que buscaba la inversión extranjera. Las primeras negociaciones se realizaron en 1989, firmando acuerdos con el Fondo Monetario Internacional (FMI), el Banco Mundial (BM) y el Club de París. Posteriormente, con la puesta en marcha del Plan Brady por parte del gobierno estadounidense, México fue el primer país en renegociar su deuda externa con los bancos comerciales.

Un año antes, 1988, se había creado el Programa Nacional de Solidaridad (PRONASOL), en un inicio como programa adscrito a la Secretaria de Programación y Presupuesto. Tiempo después comenzó a operar la Secretaria de Desarrollo Social 
(SEDESOL) para la administración y aplicación del programa. PRONASOL nació con la intención de reforzar el gasto social. Su objetivo principal era combatir la pobreza utilizando el método de focalización, dirigiendo las acciones a una población o territorios definidos. El gobierno transfirió recursos fiscales a las familias más vulnerables, pero sin alterar las condiciones estructurales. De esta manera, convertía a los pobres en consumidores potenciales (como forma de subsidio a la demanda), con la intención de incluirlos en el sistema educativo formal para satisfacer la demanda del mercado laboral.

Al inicio de la década de los 1990 México se está convirtiendo en la "novia" perfecta para los Estados Unidos de América. La banca comercial nacionalizada en 1982 por Miguel de la Madrid es privatizada, igual que el negocio de las telecomunicaciones con Telmex. Este proceso de privatización se produce al mismo tiempo en el que se crea la Comisión Nacional de Derechos Humanos y se modifica el artículo $4^{\text {o }}$ constitucional, donde por fin se reconocía a los indígenas como mexicanos y la composición pluricultural de la nación.

Durante el año 1991, el gobierno adoptó el denominado liberalismo social, abriéndose al pluralismo, fortaleciendo el ejercicio de las libertades y la tolerancia religiosa y anteponiendo como uno de sus puntos principales en la agenda la defensa de los derechos humanos. Estas políticas fueron acogidas con entusiasmo por la población, aunque con el paso del tiempo fueron consideradas una simulación que pretendía hacer México más atractivo para acuerdos internacionales, especialmente para la opinión pública estadounidense.

La reforma constitucional del ejido realizada en 1992 supondrá un cambio radical para la población rural. La modificación del artículo $27^{\circ}$ constitucional otorga a los ejidatarios y comuneros derechos de propiedad privada sobre sus tierras, lo que supondrá la venta de un buen número de tierras y el inicio de la decadencia para el mundo rural. 
Con la intención de amortiguar este proceso se estableció el Programa de Apoyos al Campo (PROCAMPO), para otorgar subsidios directos a los productores, pero la inversión extranjera y el monocultivo, al igual que el éxodo que se llevaba años produciendo del campo a la ciudad, hicieron que el mundo rural sufriese una gran transformación.

Las relaciones exteriores de México habían mejorado notablemente desde que Miguel de la Madrid abriese el país al comercio exterior con el ingreso de la nación al Acuerdo General sobre Aranceles Aduaneros y Comercio (GATT). En 1990, con la instauración de la organización que sustituye este acuerdo, Organización Mundial del Comercio (OMC), y su posterior puesta en marcha, convertirá a México en un claro exponente de las políticas neoliberales en América Latina. Con Salinas, México ingresa en la Organización para la Cooperación y Desarrollo Económicos (OCDE) en 1993 con la finalidad de expandir la economía y el empleo generando una clase media fuerte.

Durante este periodo también se llevarán a cabo las negociaciones para la firma del Tratado de Libre Comercio. El presidente estadounidense George Bush había sentado las bases del acuerdo, que buscaba formar en el continente americano un mercado común capaz de competir con la Comunidad Europea. Para conseguir la firma del Tratado de Libre Comercio de América del Norte (TLCAN), la propuesta se complementó con la llamada Iniciática de las Américas que pretendía impulsar la ayuda económica a través de tres programas, reducción de la deuda, inversión y libre comercio. México se sumaría a Estados Unidos y Canadá y tras las negociaciones realizadas durante 1991 y 1992, entraría en vigor en 1994.

Antes de que empezase a operar el TLCAN, México tuvo que realizar reformas económicas y financieras que impactarían en la población. Los cambios estructurales emprendidos durante el periodo de la presidencia de Salinas transformaron el país, 
haciendo aumentar el trabajo informal e incrementando la maquila. Las privatizaciones favorecieron la concentración de capital de las grandes corporaciones y la privatización de la banca, sumado a la caída de los precios internacionales del petróleo que fulminó el poder adquisitivo de la población. El 1 de enero del 93 se eliminaron tres ceros del peso mexicano, pasando de 3000 a 3n\$13 1 dólar.

La economía informal, que había sido un sector marginal y periférico antes de 1980, se convirtió en una actividad común, y la desconfianza de la población hacia su gobierno y los nuevos rumbos que estaba tomando la economía se tradujo en una población que modificó sus pautas culturales y de consumo.

El final del mandato de Salinas fue protagonizado por los movimientos de insurrección que se organizaron en Chiapas. El 1 de enero de 1994, coincidiendo con la toma de posesión del nuevo presidente, Ernesto Zedillo, el Ejercito Zapatista de Liberación Nacional (EZLN) tomo las armas en San Cristóbal de las Casas y las poblaciones de Altamirano, Las Margaritas, Ocosingo y Chanal de Chiapas. Al día siguiente se hizo pública la Declaración de la Selva Lacandona, que constituía una declaración de guerra contra del gobierno y especialmente de las medidas tomadas por este para la modernización del país.

Ernesto Zedillo, 1994-2000, encontraría un país con un clima político inestable y con una notable fuga de capitales. El 21 de diciembre de 1993 se produjo una masiva fuga de capitales y al día siguiente el peso mexicano se había devaluado un $20 \%$. Estados Unidos y el FMI saldrían a su rescate, pero lo que se denominó el "error de diciembre" provocaría que muchas familias perdiesen sus ahorros. Zedillo identificó a Salinas como máximo responsable de la crisis, abriendo un proceso penal contra el ex presidente. La

\footnotetext{
${ }^{13} \mathrm{~N} \$$, Nuevos pesos.
} 
crisis de 1994, conocida como "El Efecto Tequila", fue alimentada por el desajuste presupuestario y la utilización de los $\operatorname{Tesobonos}^{14}$ para financiar el gobierno. La preocupación de los inversionistas en los movimientos insurgentes como EZLN, las prácticas bancarias no reguladas y el coste económico del año electoral hundirían la economía mexicana.

En abril de 1995 se aprobó la ley de la Comisión Nacional Bancaria y de Valores, convirtiendo al sistema financiero mexicano en uno de los más concentrados del mundo. Los 5 principales bancos de México poseerán el 74\% de los activos, para 2001 ya concentraban el $88 \%$. Zedillo opto por privatizar sectores estratégicos como puertos, aeropuertos, minas, electricidad, gas, etc.; modificó leyes para favorecer la explotación y dominio extranjero sobre inmuebles, recursos mineros y aguas nacionales. No solo siguió con las reformas emprendidas por Salinas, sino que las acentuó con medidas en las que el país perdía soberanía y dejaba en manos privadas sectores necesarios para mantener la seguridad nacional.

El crecimiento de las exportaciones durante los siguientes años provocaría que en 1996 México empezase a crecer, y al año siguiente fuese posible adelantar el pago de todos los préstamos con Estados Unidos. Sin embargo, las altas tasas de interés provocaron que muchas familias no puedan hacer frente a los préstamos contraídos o hipotecas, perdiendo sus propiedades, mientras el gobierno federal realizaba un rescate financiero a los Bancos Mexicanos conocido como Fondo Bancario de Protección al Ahorro (FOBAPROA).

El periodo que comprende entre 1995-2005 fue vital para el futuro de México, al convertirse en el país con menor crecimiento económico de América y acumulando un

14 Emisión de deuda a corto plazo. Se compraba y vendía en pesos, pero estaban protegidos contra una posible devaluación al cotizar en dólares. 
retraso tecnológico en algunos sectores de 30-40 años. La nación se transformó en un país de maquiladoras y exportador de materias primas, mientras la clase media desaparecía y las pequeñas empresas no podían hacer frente a la entrada de multinacionales que producían a unos precios más bajos. La apertura al libre mercado y la puesta en marcha del TLCAN convirtieron a México en el patio trasero de Estados Unidos y aumentaron las tensiones del país con sus vecinos latinoamericanos.

En las elecciones de 2000 el Partido Revolucionario Institucional (PRI) perdería su primera elección para presidente de la Republica desde 1929. El candidato ganador, Vicente Fox 2000-06, del Partido Acción Nacional (PAN), adoptó la iniciativa de imponer una política pro cíclica, evitando el crecimiento. Esta medida estuvo condicionada por la recesión en 2001 de Estados Unidos. Fox decidió que México debía crecer al mismo ritmo que su vecino para no poner en riesgo sus cuentas con el exterior. La política pro cíclica se expresó en la contracción del gasto público y la tasa de desempleo casi se duplicó entre 2000 y 2006. La calidad del empleo se vio resentida y la tasa de cotización se contrajo debido al aumento del sector informal y la migración de la población hacia los Estados Unidos. A costa de los trabajadores se ampliaron los márgenes de beneficios y se profundizó la dependencia de la economía mexicana con su vecino del norte.

En las zonas rurales la migración aumentó considerablemente. Durante el anterior sexenio se había sustituido la producción agrícola y ganadera nacional por la importada, y los precios de la producción nacional habían caído hasta llegar a perder su rentabilidad. La inversión pública en el mundo rural se reduce, y se traslada a los productores la responsabilidad de obtener beneficios. Fox reduciría los recursos públicos hacia el campo y muchos pequeños productores se verían forzados a negociar su producción con intermediarios o directamente ser dependientes de empresas dedicadas al monocultivo y 
la exportación. En 2003 desaparece BANRURAL y es sustituida por Financiera Rural. La entidad acumuló pérdidas durante los primeros años y, al contrario que su predecesora BANRURAL, se dedicó al ámbito financiero para utilizar sus recursos en inversiones bursátiles de deuda del propio gobierno federal. El crédito otorgado a los productores agropecuarios disminuyó y muchos de ellos abandonaron el campo. El despoblamiento rural y el proceso de feminización del campo se aceleraron notablemente, mientras los hombres emigraban a Estados Unidos para trabajar como asalariados agrícolas.

Fox centró los recursos federales en impulsar la exportación y la implantación de industrias agroalimentarias. Como respuesta, el movimiento "El Campo no aguanta más" reivindico una renegociación del TLCAN. La renegociación no fue llevada a cabo y el sexenio de Fox supondría el declive de muchas poblaciones rurales. La fuerza de trabajo rural se convirtió en el segundo recurso de exportación del país después del petróleo, y ya para 2016 se convertiría en el primero.

Mientras el campo mexicano agonizaba y el mundo rural se despoblaba rápidamente, se implementó el Programa Pueblos Mágicos, el cual perseguía un cambio de modelo productivo en ciertas regiones, pasando de la producción al sector servicios, especialmente aquellos dependientes del turismo y la promoción cultural. Más adelante analizaremos este programa de manera más exhaustiva.

Las elecciones presidenciales de 2006 estuvieron enmarcadas por la sospecha de fraude electoral al ganar el candidato Felipe Calderón por solo medio punto porcentual después de una campaña de desprestigio al segundo candidato López Obrador. Con Calderón, el PAN se mantenía en el poder continuando con el proyecto iniciado por Fox.

Durante el sexenio de Felipe Calderón, 2006-12, la población en edad de trabajar se incrementó en 6.9 millones. De ellos, 4 de cada 10 consiguieron un trabajo en el sector 
formal, mientras los otros 6 pasaron a engrosar la población que obtenía el sustento en el sector informal ${ }^{15}$. El Plan Nacional de Desarrollo 2007-2012 centraba sus esfuerzos en el empleo, la seguridad, igualdad de oportunidades, sustentabilidad ambiental, democracia efectiva y política exterior responsable. Sin embargo, según datos de la Comisión Económica para América Latina y el Caribe (CEPAL, 2000), el 36,3\% de la población mexicana vivía en situación de pobreza. El problema se acrecentaría con la crisis económica de 2008, cuando el salario mínimo acumuló un crecimiento durante el sexenio del 1.64\%, mientras la inflación llegaba al 28.22\%. El empleo formal no llegaba para satisfacer las necesidades y la informalidad se generalizó en gran parte del país.

Uno de los mayores problemas a los que se enfrentó Felipe Calderón durante su sexenio fue la creciente influencia del narcotráfico en el territorio nacional. Durante la década de los 90 habían florecido 4 cárteles gracias al desmantelamiento de los cárteles de Medellín y Cali en Colombia. El Cartel de Juárez, el de Tijuana, Sinaloa y el Golfo se repartían el territorio y empezaron a aumentar los índices delictivos con la llegada de la crisis de 1994. Fue en este periodo cuando el gobierno mexicano empezó a recurrir al ejército para apoyar los operativos y consiguieron arrestar a varios líderes del narcotráfico. El procurador general de la república, general Rafael Macedo de la Concha, facilitó la coordinación entre la Procuraduría General de la Republica (PGR) y el ejército. Se capturaron a líderes importantes como Osiel Cárdenas del Cartel del Golfo, Benjamín Arellano Félix del Cartel de Tijuana, Adán Amezcua del Cartel de Colima y Gilberto García Mena del Cartel del Golfo pero no se consiguió desarticular la estructura operacional de mercadeo y financiera, los cárteles siguieron operativos. El descabezamiento de los cárteles supuso nuevas tensiones entre ellos al romper los equilibrios mantenidos por sus antiguos líderes, lo que provocó múltiples

\footnotetext{
${ }^{15}$ Instituto Nacional de Estadística y Geografía, INEGI, 2012.
} 
enfrentamientos, especialmente entre el Cartel de Sinaloa y el Cartel del Golfo por el control de la plaza de Nuevo Laredo. La guerra se extendió rápidamente a otros estados como Guerrero y Michoacán. Cuando Felipe Calderón llega a la presidencia de la Republica, los cárteles del narcotráfico tenían el control territorial de parte del país, la violencia empezaba a ser endémica y los conflictos fronterizos por el narcotráfico comenzaban a ser habituales. El flujo de droga, en su mayoría marihuana y cristal, hacia los Estados Unidos se mantuvo constante y el consumo dentro de México aumentó, dando origen a un mayor número de violencia por la venta al menudeo. Cuando Felipe Calderón llego al poder tardó pocos días en declarar la guerra al narcotráfico, especialmente en Michoacán, de donde él es originario. En 2007 continúo con los operativos policiacomilitares en otros estados provocando lo que se denominó "el efecto cucaracha"16, trasladando la narcoviolencia de un estado a otro. El procurador Medina Mora, así como Carpenter (2012) señalaron la estrategia del nuevo presidente como un combate frontal al narco, intentando con ello convertir el narcotráfico en un problema de seguridad pública y posteriormente en un asunto de seguridad nacional. Se perseguía convertir a los cárteles en enemigos nacionales que atentaban contra la soberanía e integridad nacional para justificar con ello la intervención de las fuerzas armadas. La nueva percepción de los cárteles como enemigos internos ya fue aventurada por Kaldor (2001) cuando hablaba de la nueva estrategia para militarizar la guerra contra las drogas.

La guerra contra las drogas ha desestabilizado el país, ha hundido el turismo en muchos estados, y ha llegado a convertirse en algo con lo que la población está obligada a vivir, con toques de queda, luchas entre cárteles en las zonas urbanas e inseguridad. El descontento entre la población ha ido creciendo durante los últimos años del sexenio de

\footnotetext{
${ }^{16}$ El efecto cucaracha consiste en el desplazamiento de redes criminales de una ciudad, estado o región a otra cercana, en búsqueda de lugares más seguros y autoridades estatales más débiles (Bagley, 2011).
} 
Calderón y cuando llegaron las siguientes elecciones, el PAN perdió el poder para retornar a manos del PRI.

Con la llegada de Enrique Peña Nieto, 2012-2018, México reduciría notablemente su inversión pública, debido mayormente en la bajada del precio del petróleo lo que limitaba la recaudación del estado. Peña Nieto se propuso realizar las reformas necesarias para que el sector informal menguase a través de obligaciones fiscales y la modificación de muchas reformas emprendidas por gobiernos anteriores que habían creado vacíos legales de regulación discutible, como sucedió en el caso de las Sociedades Financieras de Objeto Múltiple (SOFOM).

Durante las últimas décadas la economía mexicana había crecido con una visión gradual de informalidad. Hoy en México el 60\% de los empleos se encuentran en el sector informal con un crecimiento de la productividad del $45 \%$ inferior al sector formal. La economía en México crece gracias a contener el costo de la mano de obra, convirtiendo a México en el país miembro de la OCDE con mayor porcentaje de pobres, 18.2\%, mientras la media de la OCDE es del $8 \%$.

Las instituciones mexicanas han sufrido la guerra emprendida contra el narcotráfico y, aunque no podemos hablar de un Estado Fallido, la guerra de baja intensidad ha generado "un Estado solo parcialmente fallido, en la medida en que el fracaso se concentra en las estructuras de seguridad, inteligencia, policiales y de justicia para combatir al narcotráfico" (Benítez, 2009: 174).

\subsection{La sociedad rural del siglo XXI, reconversión productiva}

La concepción tradicional que consideraba como opuestos la ciudad y el campo ha dejado de ser funcional como herramienta explicativa. El mundo rural ha 
experimentado durante las últimas décadas una reconversión productiva y esta transformación lo ha convertido en portador de nuevas características que definen el mundo rural en la actualidad. El éxodo a las ciudades y la consecuente despoblación, el aumento de las actividades no agrícolas y la pluriactividad han hecho difuminarse la línea que separaba la dualidad campo-ciudad. Las transformaciones que han modificado el mundo rural han generado que varios autores presenten nuevas propuestas para definir una "nueva ruralidad" (Aparicio, Giarracca y Teubal, 1992; Graziano Da Silva, 1996, 1999; Carneiro, 2006; Schneider, 1994, 2003, 2006; Neiman y Bardomás, 2001).

Miguel Teubal (2001) enumera algunas de las modificaciones que la nueva ruralidad en América Latina presentaba a principios del siglo XXI.

La precarización del empleo rural; la multiocupación; la expulsión de medianos y pequeños productores del sector; las continuas migraciones campo-ciudad; la creciente orientación de la producción agropecuaria hacia los mercados; la articulación de los productores agrarios a complejos agroindustriales en los que predominan las decisiones de núcleos de poder a grandes empresas transnacionales (2001: 47).

Entre las investigaciones realizadas en torno a definir el concepto de "nueva ruralidad" encontramos un compendio de modificaciones que han transformado el espacio rural. Entre estas modificaciones, destacaremos aquellas que se han desarrollado en los trabajos de Graziano Da Silva (2002), Klein (1992) y Weller (1997).

En el ámbito rural, el agricultor tradicional ha sufrido la irrupción de los modos de producción capitalistas, como el monocultivo, la agricultura extensiva y el uso de químicos para maximizar las cosechas. Han sido los productores tradicionales del ámbito 
rural los que han tenido que generar nuevas estrategias, redirigiendo su productividad a otro tipo de mercados, como la producción ecológica, o desarrollando parte de su actividad en otros sectores, lo que ha desembocado en un aumento de la pluriactividad por parte de la población rural. El informe emitido por la CEPAL en el año 2000 ya recogía el auge que el desarrollo de actividades no agrícolas había adquirido en América Latina, donde muchas poblaciones rurales habían visto desaparecer los ingresos derivados de la actividad agrícola. Las actividades no agrícolas generadas a través del autoempleo o como asalariado se han convertido durante las últimas décadas en el generador de un nuevo sistema productivo, entre ellas destacan la venta ambulante, el empleo en el sector turístico y el sector comercial.

En segundo lugar, encontramos la reinvención de la cultura campesina que había arrastrado durante años calificativos que la relacionaban con una cultura estática. La nueva ruralidad ha puesto de manifiesto que la cultura rural tiene capacidad adaptativa. Como señala Pongratz (1990), existe una integración entre la tradición campesina y la sociedad moderna que se puede percibir especialmente en las nuevas generaciones rurales. Por estos motivos, la nueva ruralidad no puede ser definida dentro de los parámetros que caracterizaban el mundo rural anterior, basado únicamente en actividades agropecuarias.

Una de las modificaciones más notorias, e impensable hace tan solo unas décadas en las que el éxodo a la ciudad se convirtió en una necesidad para participar en la sociedad moderna, es la llegada de urbanitas al campo buscando una mejora de su calidad de vida y una convivencia en comunidad. Las crisis ambientales que sufren gran número de ciudades en América Latina han favorecido este éxodo ciudad-campo en el cual la naturaleza se revaloriza. 
Por último, dentro de las modificaciones que ha experimentado el campo se destaca su modificación espacial. Ha dejado de ser un espacio donde la producción agropecuaria ocupaba gran parte de la extensión de terreno, para ver el surgimiento de nuevas tipologías de espacio destinados a hoteles, cabañas y espacios destinados a actividades de ocio.

La disminución de las actividades agropecuarias y el aumento de la pluriactividad han transformado el medio rural. Si bien, como apunta Van der Ploeg (1992), la combinación de actividades productivas siempre estuvo presente en el campo, en la actualidad la pluriactividad ha dejado de ser ocasional o temporal para convertirse en generalizada.

La transformación del mundo rural ha provocado mayor desigualdad, "con el nuevo modelo económico, la pobreza rural ha aumentado y se ha acentuado en ciertos sectores de la población como indígenas, mayores de edad y mujeres cabezas de familia" (Pérez Correa, 2002: 17). Desde comienzos de la década de 1970 el gobierno mexicano ha puesto en marcha numerosos programas que intentaban fomentar el desarrollo rural y disminuir la desigualdad y falta de recursos, entre ellos destacan la Coordinación General del Plan Nacional de Zonas Deprimidas y Grupos Marginados (COPLAMAR) y el Sistema Alimentario Mexicano (SAM) que comenzaron en 1977. Posteriormente, se sustituyeron por diferentes programas enfocados a erradicar la pobreza y desarrollar zonas rurales. Le siguieron programas como Solidaridad, Progresa, Oportunidades, la Cruzada Nacional contra el Hambre y Prospera (Gutiérrez, 2016). El Estado mexicano al igual que otros países de América Latina, ha emprendido numerosos programas para combatir o paliar la situación de marginalidad o falta de infraestructuras en el espacio rural pero, como señalan Salas y Velasco 
no tienen el poder ni la posición global para asegurarle una sobrevivencia a sus productores agrícolas y a la mayoría de las poblaciones rurales. Su papel es el de allanar el camino para la continuación de las políticas y discursos neoliberales beneficiando a las elites dominantes, dejando a su paso personas y lugares “desechables” (Salas y Velasco, 2013: 9).

La irrupción del modelo neoliberal en el campo ha provocado el aumento del sector informal, llevando a los pobladores a obtener trabajos temporales y precarios (Kay, 2007). Los procesos de transformación, abordados por Salas y González (2013), se inscriben en la articulación entre lo local y lo global. Como apuntan los autores, "los elementos globales adquieren significados que atañen a la 'relocalización', al resurgimiento de compromisos locales y a la 'reinvención' de formas sociales que emergen como parte del proceso de globalización" (Salas y González, 2013: 7). Esta reinvención, provocada por una necesidad de adaptación al nuevo modelo neoliberal, también implica la renovación o importación de instituciones que puedan permitir la sobrevivencia económica. Es en este tipo de instituciones en las que se centra el análisis de esta investigación.

\subsection{Michoacán como experimento: ruralidad, desaparición de los poderes del Estado y aumento de la desigualdad}

El estado de Michoacán colinda al norte con Jalisco, Guanajuato y Querétaro, al este con Querétaro, México y Guerrero, al sur con Guerrero y el Océano Pacifico y al oeste con el Océano Pacífico, Colima y Jalisco. Sus coordenadas geográficas extremas 
son, al norte $20^{\circ} 23^{\prime} 40^{\prime \prime}$, al sur $17^{\circ} 54^{\prime} 54^{\prime \prime}$ de latitud norte; al este $100^{\circ} 03^{\prime} 47^{\prime \prime}$, al oeste $103^{\circ} 44^{\prime} 17^{\prime \prime}$ de longitud oeste ${ }^{17}$. Michoacán tiene una población de 4.351 .037 habitantes $^{18}$.

En 2010 se posicionaba en séptimo lugar a nivel nacional en informalidad nacional. Esta tendencia se mantendrá constante entre 2007 y 2014, teniendo un pequeño repunte durante el año 2011.

Gráfico 1, Ocupación y Empleo, Michoacán, 2007-2014

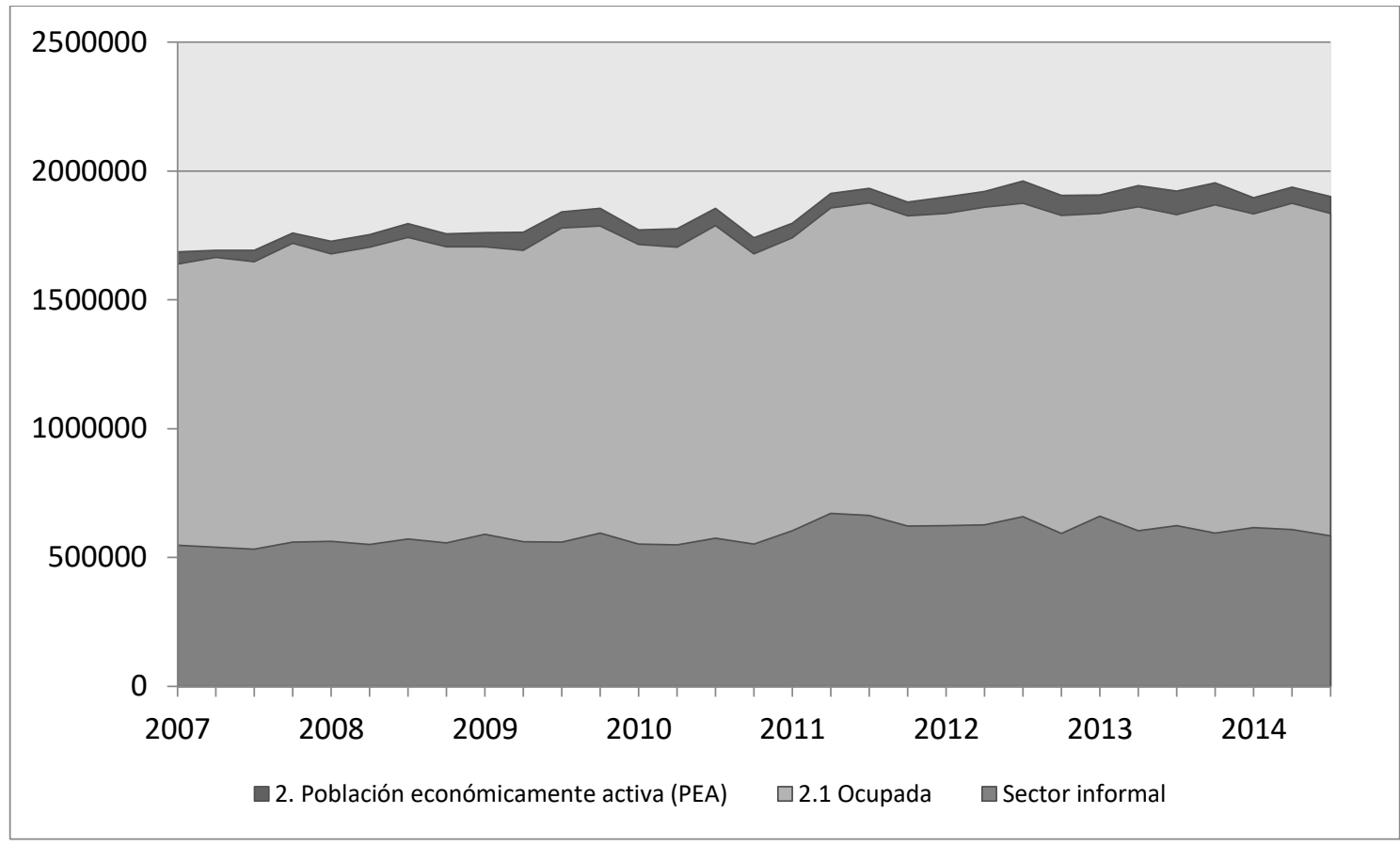

Fuente: Elaboración propia, Encuesta Nacional de Ocupación y Empleo (ENOE). STPS-INEGI

\footnotetext{
${ }^{17}$ INEGI. Marco Geoestadístico Nacional 2013, versión 6.0.

${ }^{18}$ Datos de INEGI, X Censo general de Población y Vivienda 1980. XIII Censo General de población y vivienda 2010.
} 
Tabla 1, Ocupación y Empleo, Michoacán

\begin{tabular}{|c|c|c|c|c|c|c|c|}
\hline \multicolumn{2}{|c|}{$\begin{array}{l}\text { MICHOACAN } \\
\text { DE OCAMPO }\end{array}$} & $\begin{array}{l}\text { I. Población } \\
\text { total }\end{array}$ & $\begin{array}{l}\text { 2. Población } \\
\text { económicamente } \\
\text { activa (PEA) }\end{array}$ & 2.1 Ocupada & $\begin{array}{c}\text { Sector } \\
\text { informal }{ }^{19}\end{array}$ & $\begin{array}{c}\text { Tasa de } \\
\text { ocupación en } \\
\text { el sector } \\
\text { informal \% }\end{array}$ & $\begin{array}{c}2.2 \\
\text { Desocupada }\end{array}$ \\
\hline \multirow{4}{*}{2007} & I & 4277419 & 1686138 & 1639227 & 547131 & 33,38 & 46911 \\
\hline & II & 4285757 & 1691879 & 1664186 & 539737 & 32,43 & 27693 \\
\hline & III & 4295085 & 1692764 & 1648273 & 532556 & 32,31 & 44491 \\
\hline & IV & 4305270 & 1759634 & 1719451 & 560129 & 32,58 & 40183 \\
\hline \multirow{4}{*}{2008} & 1 & 4316253 & 1726762 & 1677735 & 563089 & 33,56 & 49027 \\
\hline & II & 4327710 & 1752493 & 1704572 & 550149 & 32,27 & 47921 \\
\hline & III & 4339843 & 1796229 & 1742583 & 571693 & 32,81 & 53646 \\
\hline & IV & 4352099 & 1755681 & 1705092 & 556626 & 32,64 & $5058 s$ \\
\hline \multirow{4}{*}{2009} & 1 & 4364248 & 1760968 & 1705157 & 589654 & 34,58 & 55811 \\
\hline & II & 4375990 & 1762757 & 1691275 & 561162 & 33,18 & 71482 \\
\hline & III & 4387131 & 1841087 & 1779427 & 559833 & 31,46 & 61660 \\
\hline & IV & 4397534 & 1854211 & 1786373 & 594116 & 33,26 & 67838 \\
\hline \multirow{4}{*}{2010} & 1 & 4407239 & 1770549 & 1715505 & 551721 & 32,16 & 55044 \\
\hline & II & 4416596 & 1775611 & 1703662 & 548672 & 32,21 & 71945 \\
\hline & III & 4425920 & 1854863 & 1787217 & 574350 & 32,14 & 67646 \\
\hline & IV & 4435189 & 1741331 & 1678507 & 552698 & 32,93 & 62824 \\
\hline \multirow{4}{*}{2011} & 1 & 4444538 & 1796419 & 1740803 & 603518 & 34,67 & 55616 \\
\hline & II & 4453584 & 1912453 & 1856749 & 671256 & 36,15 & 5570 \\
\hline & III & 4462754 & 1931712 & 1876044 & 663910 & 35,39 & 55668 \\
\hline & IV & 4471933 & 1878620 & 1825323 & 621575 & 34,05 & 53297 \\
\hline \multirow{4}{*}{2012} & 1 & 4481167 & 1898864 & 1835555 & 623813 & 33,98 & 63305 \\
\hline & II & 4490220 & 1920199 & 1860040 & 627396 & 33,73 & $6015 s$ \\
\hline & III & 4499292 & 1960843 & 1874143 & 658420 & 35,13 & 86700 \\
\hline & IV & 4508246 & 1905822 & 1827867 & 593018 & 32,44 & 77955 \\
\hline \multirow{4}{*}{2013} & 1 & 4516953 & 1906420 & 1835715 & 660929 & 36 & 70705 \\
\hline & II & 4525607 & 1942726 & 1860481 & 603626 & 32,44 & 82245 \\
\hline & III & 4534280 & 1921386 & 1830154 & 624366 & 34,12 & 91232 \\
\hline & IV & 4542882 & 1954026 & 1869174 & 594743 & 31,82 & 84852 \\
\hline \multirow{3}{*}{2014} & 1 & 4551347 & 1896026 & 1833849 & 615341 & 33,55 & 62177 \\
\hline & II & 4559695 & 1936478 & 1874698 & 608233 & 32,44 & 61780 \\
\hline & III & 4568096 & 1900188 & 1835678 & 584447 & 31,84 & 64510 \\
\hline
\end{tabular}

Fuente: Elaboración propia, Encuesta Nacional de Ocupación y Empleo (ENOE). STPS-INEGI

\footnotetext{
${ }^{19} \mathrm{El}$ sector informal forma parte de la población ocupada
} 
El sector informal en Michoacán se mantiene en una media del $33.27 \%$ de la población ocupada, indicando la existencia de un gran número de familias que desempeñan su actividad económica fuera de sistemas formales. El mercado laboral de la región es muy reducido, con salarios muy bajos y una gran estratificación con informalidad laboral y el desempleo juvenil.

Así mismo, la tradición migratoria que se extiende más de 100 años en el Estado, ha supuesto un importante flujo de dinero en forma de remesas que durante la última década se ha estancado.

Tabla 2, Ingresos por remesas familiares, Michoacán. Serie trimestral de 2008 a 2014 en millones de dólares

\begin{tabular}{lcccc} 
AÑO & ENERO-MARZO & ABRIL-JUNIO & $\begin{array}{c}\text { JULIO- } \\
\text { SEPTIEMBRE }\end{array}$ & $\begin{array}{c}\text { OCTUBRE- } \\
\text { DICIEMBRE }\end{array}$ \\
\cline { 2 - 5 } 2008 & 568 & 656 & 612 & 613 \\
\cline { 2 - 5 } 2009 & 564 & 559 & 530 & 479 \\
2010 & 497 & 585 & 550 & 513 \\
2011 & 518 & 585 & 591 & 552 \\
2012 & 540 & 636 & 520 & 514 \\
2013 & 472 & 554 & 506 & 510 \\
2014 & 516 & 561 & 560 & 607
\end{tabular}

Fuente: Elaboración propia, Banco de México

Debemos tener en cuenta que la migración en el estado de Michoacán es de larga data, por lo que los migrantes asentados en Estados Unidos ya son en muchos casos de segunda o tercera generación, lo que ha llevado a una reducción paulatina del dinero de las remesas. El Estado ha sufrido durante las últimas décadas la descomposición del tejido rural y la implantación del monocultivo y la agricultura intensiva. Buen ejemplo de esta transformación es el valle de Zamora, productor de fresa y berrys, en su mayoría 
destinadas a la exportación, y especialmente la región de Uruapan una de las mayores exportadoras de aguacate a Estados Unidos y Apatzingan, primera productora de limón a nivel nacional.

Las zonas rurales del Estado han sufrido el éxodo a las grandes ciudades y la migración (especialmente de varones para desempeñar trabajos agrícolas) hacia los Estados Unidos. Esto ha generado grandes extensiones de terreno en las ciudades del Estado donde existen numerosos asentamientos de paracaidistas ${ }^{20}$. Esta nueva ruralidad ha hecho que el trabajo informal, como veíamos anteriormente, suponga un tercio de la tasa total de ocupación, y los índices de pobreza lleguen a una tasa del 59.2\% en 2014. Si bien los programas promovidos por el Gobierno Federal han disminuido la pobreza extrema hasta el $14 \%$ en 2014 , la pobreza moderada y la carencia de acceso a servicios sociales se sitúa en el $45.2 \%$.

Tabla 3, Indicadores seleccionados de pobreza, Michoacán, 2014

\begin{tabular}{|c|c|c|}
\hline & PERSONAS & $\begin{array}{l}\text { ORCENTAJE DE } \\
\text { PERSONAS }\end{array}$ \\
\hline EN SITUACION DE POBREZA & 2708631 & 59.2 \\
\hline MODERADA & 2066780 & 45.2 \\
\hline EXTREMA & 641851 & 14 \\
\hline VULNERABLES & & \\
\hline SOCIALES & 1142440 & 25 \\
\hline VULNERABLES POR INGRESOS & 186424 & 4.1 \\
\hline NO POBRES Y NO VULNERABLES & 534240 & 11.7 \\
\hline
\end{tabular}

Fuente: Elaboración propia, Consejo Nacional de Evaluación de la Política de Desarrollo Social (CONEVAL).

\footnotetext{
${ }^{20}$ Personas generalmente de origen rural, que se asientan ilegalmente en el extrarradio de ciudades o centros de producción buscando empleo.
} 
La sustitución del trabajo agrícola por el de asalariado, el alto índice de pobreza y la falta de industrialización del Estado han sido elementos clave para una nueva reconversión productiva. Además de la implantación de una industria agropecuaria de monocultivo, también se han dirigido esfuerzos hacia el sector turístico y de servicios. La declaración en 2012 de 4 nuevos pueblos mágicos, Anganguero, Tacambaro, Tzintzuntzan y Jiquilpan, que se suman a otros cuatro ya declarados, hace que Michoacán posea un gran número de pueblos mágicos, intentando con ellos fomentar el sector turístico y el comercio.

Considerado durante muchos años como un Estado "tranquilo" caracterizado por su historia y tradiciones, durante la última década ha sido uno de los lugares más castigados por la violencia del crimen organizado y el aumento de poder de los narcotraficantes. Michoacán es un lugar estratégico, tanto por sus grandes extensiones dedicadas al cultivo como por el Puerto de Lázaro Cárdenas. El puerto, uno de los puntos principales en la entrada de droga al país, permite la llegada de droga proveniente de Sudamérica y los químicos necesarios para la producción de droga sintética. La escalada de violencia que ha experimentado el estado ha generado, tal y como apunta Carpenter, que "prominentes líderes de negocios hayan abandonado regiones peligrosas del país debido a amenazas de secuestro" (2012: 125). La fuga del Estado no ha sido únicamente protagonizada por comerciantes, también oficiales de policía y políticos han visto amenazadas sus vidas. En diciembre de 2009 ocho funcionarios públicos de Tancítaro renunciaron a sus puestos alegando haber sido amenazados por los narcotraficantes después de que Gonzalo Paz, funcionario de la ciudad, fuese secuestrado, torturado y asesinado a principios de ese año.

El 6 de septiembre de 2006, el cartel de la Familia Michoacana se da a conocer cuando un grupo armado lanza cinco cabezas humanas a la pista de baile de un club 
nocturno en la ciudad de Uruapan. El acto supuso la presentación ante las autoridades y población de un nuevo cartel que reclamaba la legitimidad de sus acciones calificándolas de "justicia divina". Con las cabezas se adjuntaba una nota que remarcaba: "La Familia no mata por deudas, no mata mujeres, no mata inocentes. Quien debe morir, muere". Los últimos meses del año eran también los últimos de la presidencia de Vicente Fox, cuya cónyuge es originaria de la ciudad de Zamora.

En diciembre de 2006, Felipe Calderón se convierte en presidente de la Republica. Originario de Morelia, capital de Michoacán, en pocas semanas comenzará su “Guerra contra el narco". El 11 de diciembre manda a 7000 soldados a su estado natal para iniciar lo que él califica como una guerra militar contra los carteles. En 2007 las operaciones del cartel se habían extendido por gran parte del Estado. El 11 de noviembre se celebrarían las elecciones a la presidencia municipal de los municipios. Unos días después serían convocados 14 de los nuevos alcaldes por parte de La Familia para exigir la devolución, en dinero y en favores, del apoyo que habían recibido los alcaldes durante la campaña por parte del cartel. El apoyo a políticos garantizaría la protección oficial para el cartel durante los siguientes cuatro años.

El cargo de gobernador del Estado es ocupado por Leonel Godoy en febrero de 2008. Posteriormente se conocerá que miembros del cartel habían avisado a las autoridades durante las primeras semanas de septiembre de un ataque el día de la celebración de la Independencia Mexicana. En ningún momento se informó a la población o se tomaron medidas extraordinarias para evitar el ataque que se produjo el 15 de septiembre en el zócalo de Morelia. El lanzamiento de varias granadas en una plaza abarrotada de gente dejaría el saldo de ocho muertos, más de cien heridos y el desconcierto y miedo la población del Estado. 
Después de los acontecimientos del 15 de septiembre, la cooperación entre políticos y narcotraficantes se hace más patente. En mayo de 2009 las autoridades federales arrestan a diez alcaldes y a dieciocho oficiales, entre ellos un juez, acusados de vinculación con actividades del crimen organizado. El arresto será considerado como un éxito sin precedentes por la administración de Felipe Calderón. Sin embargo, pocos días después, todos los detenidos salvo uno serán liberados por falta de pruebas. El presidente Felipe Calderón y el procurador General de la República, Eduardo Medina Mora evidenciarán la incapacidad del gobierno para hacer frente al problema del narcotráfico y la impunidad de las actividades delictivas de estas organizaciones. El 13 de julio de ese mismo años doce oficiales de la policía federal serían encontrados muertos al lado de una carretera con un mensaje de advertencia de La Familia.

En los siguientes años La Familia se separaría del cartel de los Zetas (según la Administración para el control de las Drogas, DEA), desatando con ellos la guerra entre carteles por el control de la metanfetamina michoacana, su producción y distribución. En 2011 dos exjefes de la Familia, "La Tuta” y “El Kike” también se separan de La Familia formando el grupo de "Los Caballeros Templarios". Con la colocación de "narcomantas" en las plazas de los principales municipios del Estado pretenden darse a conocer y garantizar las "actividades altruistas" que anteriormente realizaba La Familia Michoacana. Organizados como un grupo pseudo-religioso bajo el código de honor de la Caballería del Temple alegan que la guerra por el dominio del territorio está fundamentada en una batalla ideológica en la cual, ellos defienden los valores de la sociedad michoacana. Una de las actividades más visibles de este grupo será la persecución y ejecución de aquellos que vendan o distribuyan droga entre la población del Estado. 
La guerra entre diferentes Cárteles se prolongará hasta la actualidad, produciéndose numerosos toques de queda en los municipios, la desconfianza hacia las autoridades, extorsión y pago de cuotas a los comerciantes. En este clima de tensión se producirá un primer levantamiento de la sociedad civil en contra de los carteles. El primer caso documentado se produce en el municipio de Cherán, en la meseta Purépecha el 15 de abril de 2011. La población, cansada de secuestros, homicidios y extorsiones se levantará en armas contra los madereros, policía y políticos de la localidad. Las organizaciones criminales habían diversificado el negocio, entrando en el negocio de la venta de madera, talando parte del bosque. Cherán expulsará tanto a estas organizaciones como a funcionarios públicos, autogobernándose de manera independiente. Bajo este precedente, en los primeros meses de 2013 nacerá el primer grupo de autodefensas (Fuentes Díaz y Paleta, 2015) de Michoacán en las localidades de La Ruana, Tepalcatepec y Buenavista, en territorio de Tierra Caliente. Las milicias civiles emprenderán una lucha armada contra los Caballeros Templarios que dejará numerosos muertos en ambos bandos. Aunque posteriormente las autodefensas michoacanas serán reconocidas por parte de las autoridades, la corrupción de las milicias, el encarcelamiento de su mayor dirigente en extrañas circunstancias, y los esfuerzos del gobierno por mantener un status quo, permitirán a las organizaciones criminales seguir operando con impunidad y dejará a la población exhausta y desmoralizada.

La connivencia de las organizaciones criminales con los poderes del Estado es una de las características principales de lo que se ha llamado los estados fallidos. " $L a$ incapacidad de los Estados para proteger a sus ciudadanos de la violencia e incluso de la destrucción" y el que Michoacán tenga "un déficit democrático que carece de instituciones democráticas formales de substancia real" (Chomsky, 2007: 1-2). Si bien no es posible calificar a todo el Estado dentro de estos parámetros, sí es posible hablar de 
regiones del Estado que se encuentran en posiciones de ser calificadas como Estado fallido. Los cárteles del narcotráfico se han apoderado de las rutas de tráfico terrestres, afectando a la población civil, que sumado a la impunidad, corrupción, instituciones débiles y la connivencia entre narcos y gobernantes, ha derivado en una espiral de inseguridad y violencia en la que la población se encuentra secuestrada dentro de sus localidades. La violencia generada no solo afecta a los criminales, sino que cualquier ciudadano puede sufrir la violencia generada por esta guerra. Aunque no existen cifras fiables sobre las víctimas del conflicto, solo en 2013, el año que surgieron las autodefensas, más de mil personas habían sido asesinadas, cuatrocientas secuestradas, trescientas desaparecidas, tres mil familias fueron desplazadas $\mathrm{y}$ mil doscientas despojadas de sus tierras. A estas cifras habría que añadir el masivo cobro de cuotas o cobro de piso $^{21}$ de comerciantes locales, violaciones, amenazas y el sentimiento generalizado de desamparo de la población civil.

\subsection{La Ciénaga de Chapala y el Distrito de Desarrollo Rural 089}

La región de la Ciénaga de Chapala se ubica en el oriente de la Laguna de Chapala, un área compartida por los estados de Jalisco y Michoacán. Aunque el territorio de la Ciénaga está compuesto por los municipios de Jamay, Ocotlán, Poncitlán, Chapala, Jocotepec, Tuxcueca y Tizapán en el estado de Jalisco y Cojumatlán de Régules, Venustiano Carranza, Briseñas, Jiquilpan, Sahuayo, Venustiano Carranza y Villamar en Michoacán (Sandoval y Ochoa 2010), la investigación se centrará especialmente en los municipios del territorio michoacano y especialmente en las dos localidades con mayor población, Jiquilpan y Sahuayo. El motivo de esta decisión es facilitar el trabajo

\footnotetext{
${ }^{21}$ Reclamo de pago por ocupar un espacio, ya sea en la venta ambulante, mercados de abastos, pequeños comercios o tianguis.
} 
etnográfico utilizando para ello la demarcación del Distrito de desarrollo rural (DDR) $089^{22}$ con una población de 200.602 habitantes, compuesto por las localidades michoacanas anteriormente mencionadas.

Tabla 4, Población y Edad Media por género, DDR-089

\begin{tabular}{|c|c|c|c|c|c|c|c|}
\hline \multirow{2}{*}{ MUNICIPIO } & \multicolumn{3}{|c|}{ POBLACION TOTAL } & \multicolumn{3}{|c|}{ EDAD MEDIA } & \multirow{2}{*}{$\begin{array}{c}\text { RELACION } \\
\text { HOMBRES-MUJERES }\end{array}$} \\
\hline & TOTAL & HOMBRES & MUJERES & TOTAL & HOMBRES & MUJERES & \\
\hline BRISEÑAS & 10653 & 5138 & 5515 & 25 & 24 & 27 & 93.16 \\
\hline COJUMATLAN & 9980 & 4863 & 5117 & 25 & 25 & 26 & 95.04 \\
\hline JIQUILPAN & 34199 & 16134 & 18065 & 28 & 27 & 29 & 89.31 \\
\hline MARCOS CASTELLANOS & 13031 & 6309 & 6722 & 26 & 25 & 27 & 93.86 \\
\hline PAJACUARAN & 19450 & 9430 & 10020 & 24 & 23 & 25 & 94.11 \\
\hline SAHUAYO & 72841 & 35298 & 37543 & 25 & 24 & 26 & 94.02 \\
\hline VENUSTIANO CARRANZA & 23457 & 11527 & 11930 & 27 & 25 & 28 & 96.62 \\
\hline VILLAMAR & 16991 & 8063 & 8928 & 29 & 27 & 28 & 90.31 \\
\hline
\end{tabular}

Fuente: Elaboración propia, Censo de Población y Vivienda 2010. INEGI.

En este apartado haremos referencia a la Ciénaga de Chapala en su conjunto porque, aunque el trabajo etnográfico se centre en el distrito 089, la región tiene un pasado común.

Durante las últimas décadas del siglo XIX y la primera del siglo XX, el porfiriato hizo resurgir el protagonismo de la hacienda como el centro, no solo de la producción agropecuaria, sino también como centro de la organización socioeconómica y política. Porfirio Díaz convirtió a la hacienda en una empresa capitalista con las intenciones de modernizar y europeizar el país. La hacienda de Guaracha, que dominaba todo el territorio

\footnotetext{
${ }^{22}$ La Ley de Distritos de Desarrollo Rural del 28 de Enero de 1988, pág. 35 bajo la Presidencia de Miguel de la Madrid reconoce como Distrito de Sahuayo "la circunscripción territorial establecida por los municipios de Jiquilpan, Marcos Castellanos, Villamar, Venustiano Carranza, Sahuayo, Cojumatlán de Regules, Briseñas, Pajacuarán y parte del municipio de Vista Hermosa, del Estado de Michoacán, que ocupa la zona de riego del Distrito de Riego de Ciénaga de Chapala que inicio su operación en el año de 1936. Además, este distrito queda conformado con los Centros de Apoyo de Jiquilpan y Venustiano Carranza".
} 
en el que con posterioridad se encontraría la Ciénaga de Chapala, "fue el ejemplo más claro de este prototipo, pues se constituyó como el principal núcleo agroganadero, industrial y comercial de la región" (Covarrubias y Ojeda, 2009: 123-124). Durante estos años, el proceso de modernización emprendido por el presidente, quien realizó una importante inversión en vías de comunicación, permitiría el transporte eficiente de mercancías, aunque también provocaría la expropiación de tierras que se encontraban en manos de la población indígena. En torno a estas grandes inversiones en infraestructura y la centralización del poder y la producción en las haciendas se generaría una cultura política asentada en las lealtades patrimoniales, la ejecución de políticas paternalistas y una corrupción sistematizada. Estos años de esplendor económico provocarían que la Ciénaga se convirtiera en un espacio atractivo para la inversión de diferentes terratenientes. Entre ellos destaca Manuel Cuesta Gallardo, futuro Gobernador del Estado de Jalisco que propuso a Porfirio Díaz desecar una gran parte de la zona sureste del lago, construyendo un bordo que impidiese la inundación de la zona. Las obras comenzarían en 1904 y se extenderían cuatro años más para la construcción del bordo de contención de Maltaraña que tenía como función desecar 560 km2 entre los límites de Michoacán y Jalisco. Con la consecución de esta obra civil se formaría lo que hoy se conoce como la Ciénaga de Chapala, una planicie de tierra fértil de aproximadamente 80.000 hectáreas (Guzmán, 2001; Boehm, 2002). El proceso de desecación, así como la administración y dirección de las obras fue asignada por el Gobierno Federal a empresarios de Jalisco y Michoacán ligados a la Hacienda de Guaracha. Esto supuso un apoyo por parte del gobierno al dominio de hacendados y terratenientes que consolidaban de este modo su dominio sobre la región. La influencia de los hacendados llegó a abarcar todos los negocios derivados del proceso modernizador de esta etapa, así como la mitad de la producción agrícola del distrito de Jiquilpan. Su poder llegó a controlar casi por completo 
la región, hasta el punto que impidió que el ferrocarril, que estaba en proceso de construcción, fragmentara sus tierras, desviando las líneas férreas hacia el exterior de sus dominios (Covarrubias y Ojeda, 2009: 28). En este periodo, Jiquilpan se convirtió en el centro político y administrativo de la región con una importante producción ganadera, manufacturera y rebocera. Ante el domino de Jiquilpan, Sahuayo se especializó en actividades comerciales y manufacturas, logrando un rápido crecimiento gracias a su cercanía con el lago.

Durante los años que siguieron a la Revolución Mexicana, el reparto de tierras se mantuvo sin cambios importantes, algo que cambiará notablemente con la llegada al gobierno de Lázaro Cárdenas del Rio $^{23}$ (1934-1940). El reparto masivo de tierras que la reforma agraria de Cárdenas propicio en la región permitió a los campesinos cultivar sus tierras con el financiamiento y asesoría del estado (Covarrubias y Ojeda, 2009: 38) El proyecto del gobierno se centró en la expropiación de las haciendas. En la región se expropió la hacienda de Guaracha, y se formaron ejidos como alternativa productora para una agricultura capitalista a gran escala. También se realizó la expropiación de las haciendas de Cumuato, Buenavista y San Simón entre 1936 y 1938 que, sumadas a la expropiación de Guaracha también durante estos años, cambiaron la tenencia de la tierra en la región. El ejido se convirtió en el eje principal del desarrollo rural, y para apoyar su producción se crearon entidades como el Banco Nacional de Crédito Ejidal (BNCE), la Aseguradora Nacional Agrícola y Ganadera S.A. (ANAGSA), el Comité Regulador de los Precios del Trigo, el Comité Regulador del Mercado de las Subsistencias y la carretera México-Guadalajara (Covarrubias, Cruz y Ojeda, 2012: 5; Tetreault, 2007: 185-186).

\footnotetext{
${ }^{23}$ Originario de Jiquilpan.
} 
La figura del cacique se extendería por todo el territorio mexicano en esta época. El cacique será generador de una institucionalidad distorsionada y ambigua que obtendrá reconocimiento y poder en la sociedad en su conjunto y especialmente en la economía. El cacique se convertirá en el centro del poder durante el periodo de la presidencia de Cárdenas, caracterizado por ser

intermediario obligado entre la sociedad tradicional y el estado moderno: si su autoridad se funda en la sociedad antigua, pertenece, por su cultura política, al pueblo moderno. Mediación indispensable, pero poder ilegal, oculto, vergonzante; en él es donde se manifiesta mejor la ficción política (Guerra, 1988: 334).

En la Ciénaga de Chapala, el hermano de Lázaro Cárdenas, Damasco Cárdenas, levantó un aparato caciquil de poder centralizado en su persona. Construyó una red de relaciones con subalternos que ostentaban el poder de las cabeceras municipales de la región, controlando de esta forma todo el territorio (Vargas, 1993).

Cuando el gobierno cardenista finalizó, las relaciones sociales, políticas y económicas estaban dominadas por nuevos grupos de poder compuestos por dirigentes ejidatarios, caciques y funcionarios del gobierno. Los ejidatarios solo recibían crédito para la siembra de ciertos cultivos, especialmente para el sorgo, maíz y trigo, y la entrega selectiva de estos créditos provocó una alta expulsión de migrantes campesinos al interior del país y al extranjero (Boehm, 1994). El que muchos ejidatarios hubieran contraído 
deudas con el Estado, y otros con los agiotistas, provocó que muchos de ellos buscaran trabajo en los programas de braceros ${ }^{24}$ (Boehm, 1985: 98-99).

Derivado de un periodo de crecimiento sostenido de la economía mexicana (19401970), conocido como "el milagro mexicano", en la Ciénaga de Chapala el proceso de institucionalización del poder permitió la decadencia del dominio de los caciques tradicionales en la región. La tecnificación de las actividades agrícolas fue generadora de cambios estructurales en el poder local y fomentó la aparición de nuevas organizaciones y sindicatos que se confrontaron contra el régimen anterior (Vargas, 1993). Sin embargo, la hegemonía del PRI se había mantenido en las zonas rurales gracias al apoyo de los caciques que aseguraban el voto de los ejidatarios al partido. La década de los 70 llevó nuevas inversiones a la región como la planta procesadora de fresa y estrategias para mejorar y expandir el ganado lechero de alta calidad. Los funcionarios y promotores públicos habían tejido sus redes personales hasta la capital federal y nacional por lo que los campesinos de La Ciénaga empezaron a sentirse víctimas de una mafia y llegaban hasta los comisarios ejidales. No obstante, el ejido se había convertido en la forma de propiedad de la tierra más habitual en la Ciénaga, los campesinos habían obtenido tierras y el gobierno había invertido entre las décadas de 1960-70 una importante suma en infraestructuras de riego. Mientras en otros lugares de la nación los campesinos habían sido abandonados por el gobierno y se mantenían con una agricultura de subsistencia, en La Ciénaga de Chapala la modernización del campo intentaba impulsar el modelo productivo capitalista. La Ciénaga se perfilo como un lugar estratégico para la producción agrícola destinada al mercado nacional e internacional, pero cuando comenzó la crisis de

\footnotetext{
${ }^{24}$ Acuerdo laboral temporal entre Estados Unidos y México iniciado en agosto de 1942. El programa fue promovido por la demanda de mano de obra durante la Segunda Guerra Mundial de campesinos mexicanos para cultivar y cosechar inicialmente en ingenios azucareros ubicados en la región de Stockton, California. Posteriormente se extendería a otras regiones de Estados Unidos y abarcaría también labores de mantenimiento de las vías férreas del país. Al final de la Segunda Guerra Mundial se calcula que 50000 braceros estaban empleados en la producción agrícola y 75000 en el programa ferroviario.
} 
la década de 1980 los apoyos financieros fueron retirados y los ejidatarios abandonaron la producción. El colapso económico que acompañó el final del periodo de López Portillo y el cambio hacia políticas neoliberales emprendido por Miguel de la Madrid supuso un nuevo auge de la migración hacia los Estados Unidos.

\subsubsection{La llegada de la economía neoliberal. Salinas de Gortari (1988-1994)}

La llegada de Salinas de Gortari a la presidencia de la nación (1988-1994) supondría una nueva reforma en el modelo de producción agrícola, incentivando profundas reformas en el sistema ejidal. El modelo neoliberal eliminó los subsidios, liquidó empresas gubernamentales y abrió la agricultura mexicana al libre mercado internacional. También se modificó la ley agraria, permitiendo la compra y venta de tierras ejidales, lo que cambiaría rápidamente la organización ejidal, agilizaría la regulación de la propiedad rustica y elevaría el valor de la tierra atrayendo la inversión.

Las instituciones que se habían creado para apoyar la modernización de la producción agrícola cambiaron su función. El Banco Nacional de Crédito Rural (BANRURAL), creado en 1975 con la fusión del BNCE y el Banco Nacional Agropecuario, dejó de ser el promotor y modernizador de la agricultura ejidal para constituirse como una institución que ofrecía recursos a una población empobrecida, llevándolo a un déficit crónico. La privatización de la mejor tierra y su concentración en unos pocos inversores originó el surgimiento del neolatifundismo y la aparición de una burguesía agrícola, acentuando la desigualdad económica. Los campesinos trasladaron su actividad agrícola a las peores tierras, laderas y ciénagas, donde los subsidios no llegaban y la producción de las familias más pobres se vio mermada. 
El modelo económico neoliberal y la "revolución verde" provocó la desaparición de la agricultura endógena y mucha población campesina se vio abocada a abandonar sus tierras para buscar trabajo en las zonas urbanas. La expansión urbana se extendió anárquicamente por la periferia de las ciudades con los asentamientos de paracaidistas.

Durante la década de 1990, la Ciénaga de Chapala era una región atrapada entre distintas reformas y políticas públicas que habían llevado a la región al agotamiento productivo y social. La decadencia del proyecto de reforma agraria que estaba ligado al mantenimiento de la hegemonía del PRI en la región y era dependiente del poder ostentado por los caudillos urbanos convivía con las políticas neoliberales y la influencia de una clase transnacional con su centro de poder económico en los Estados Unidos gracias a la migración.

Las políticas neoliberales y el abandono por parte del gobierno a los problemas del campo han hecho que resurjan formas de "resistencia" practicadas desde el periodo de las haciendas. Como señala Gledhill (1997), las respuestas individuales al sistema impuesto por BANRURAL se tradujeron en desviación de recursos públicos hacia proyectos que los propios campesinos consideraban de mayor rendimiento como vender en el mercado negro y pagar mordidas a los inspectores de ANAGSA. Gran parte del aparato legal ha sido ignorado o manipulado porque la gente considera una solución justa llegar a acuerdos informales.

En la actualidad, la Cuenca de Lerma-Chapala, en la cual se inscribe La Ciénaga, ha sido calificada como "river basin clousure" o como dentro del proceso de cierre de cuenca. Esto significa que ha dejado de existir disponibilidad de agua para nuevas demandas (Keller, Keller y Davids, 1998). La cuenca se encuentra en una situación de déficit desde hace décadas, generando el enfrentamiento entre usuarios, tal como analiza Wester (2008). El lago de Chapala es el mayor abastecimiento con el que cuenta la 
segunda área metropolitana del país, Guadalajara, cubriendo el 70\% de las necesidades de la urbe. La Ciénaga experimenta el deterioro y agotamiento de los recursos naturales junto con la incorporación de su producción al mercado global y el proceso de privatización de la tierra que ha llevado a muchas familias campesinas a abandonar las parcelas y la actividad agrícola. Entre estas familias, muchas se asentaron en ciudades cercanas como Jiquilpan y Sahuayo donde realizan actividades dentro del sector informal, mientras algunos individuos de la familia, o incluso la familia completa emigraban hacia los Estados Unidos.

\subsubsection{La tradición migratoria en la Ciénaga de Chapala y su organización}

La migración en la Ciénaga de Chapala se ha venido produciendo desde las primeras décadas del siglo XX por lo que ha participado en las cinco etapas identificadas por Durand y Massey (2003). La primera fase, la fase de enganche, se produjo entre 1900 y 1920 continuada por una etapa de deportaciones entre 1921 y 1939. El programa bracero, del cual ya hablamos anteriormente se extendió entre 1942 y 1964 nutriéndose de campesinos y personal no cualificado. Entre 1965 y 1986 se produjo la era de los indocumentados en la que un gran número de mexicanos atravesó el desierto. La posterior legalización de parte de estos indocumentados y la continuación de la migración clandestina son los factores que caracterizan el periodo entre 1987 y 2001 para Durand y Massey. Los autores publican la investigación en 2003 por lo que es comprensible que al calificar la última etapa la daten hasta 2001. Aunque México forme parte del TLCAN, la libre circulación de personas nunca se ha llevado a cabo, por lo que la migración clandestina se ha mantenido hasta la fecha actual, 2017.

Las fases de emigración que ha experimentado la Ciénaga de Chapala tienen un largo historial en los pueblos de la región que abarca a todas las generaciones vivas en la 
actualidad. Después de la crisis de la década de 1980 y, especialmente durante la década de 1990, se produjo una mejora en las condiciones de vida de la población de La Ciénaga. Muchas familias pudieron adquirir televisores, electrodomésticos, estufas y construir baños modernos en sus casas. También la inversión de PRONASOL ha permitido la pavimentación de las calles y la instalación de alumbrado público en los municipios. Sin embargo, este desarrollo sería imposible de entender sin el impacto que las remesas de dinero de los migrantes tuvieron en la región. Muchos de esos migrantes ya no están de forma estacional en los Estados Unidos, sino que tienen allí su residencia permanente y, en muchos casos, son hijos o nietos de migrantes. Estos migrantes conservan lazos sociales y realizan visitas regulares a sus comunidades de origen, especialmente en fechas señaladas como las festividades locales, conformando los "circuitos migrantes transnacionales" (Rouse, 1992).

El 6 de julio de 2002 se inauguró la iniciativa ciudadana 3X1 en Jiquilpan. Este tipo de iniciativas se extiende a gran parte del territorio michoacano. Durante el 2002, los migrantes originarios de Michoacán enviaron a través de estas iniciativas 10 millones cien mil pesos destinados a 66 proyectos entre los que destacan el mejoramiento de los sistemas de agua potable, carreteras, reparación o embellecimiento de las iglesias y el establecimiento de microempresas a través de apoyos y créditos (Bada, 2003: 262). Muchos de estos recursos se movilizaron gracias a la Federación Californiana de Michoacanos (FECADEMICH).

La migración en la Ciénaga de Chapala ha dado origen a comunidades transnacionales en las cuales las remesas colectivas y las organizaciones migrantes apoyan proyectos de desarrollo local para su comunidad de origen. Tal y como acuñó Moctezuma (1999), el migrante colectivo se hace patente a partir de las organizaciones. También se ha utilizado el nombre de desarrollo participativo transnacional (Márquez, 
2006) para analizar la intervención de la colectividad transnacional en obras públicas e infraestructura, a través de organizaciones binacionales.

Estas organizaciones han sido posibles ya que los migrantes de una localidad han tendido a trasladarse a las mismas localidades, formando comunidades que trascienden las fronteras del Estado-Nación mexicano. Como ejemplos, podemos ubicar a la gente de Aguililla en Redwood City, la de Cheran en Watson Wille, la de Parritas en Petaluma y Planada, la de Pruándiro y Chilchota en Fresno, la de Tarímbaro en Chicago, la de Tacámbaro en Oregón y Carolina del Norte. En el caso de esta etnografía, las comunidades más numerosas de migrantes de La Ciénaga son las de Santa Ana, Riverside y Puerto de San Pedro en California, formadas en gran parte por originarios de Sahuayo y la comunidad de Inglewood, también en California, integrada por originarios de Jiquilpan y las comunidades de Los Remedios y San Martin Totolán.

En Jiquilpan podemos encontrar la formación de organizaciones transnacionales como el "Comité los Remedios", "Comité Totolán”, "Club San Cayetano" y el "Club Jiquilpan-USA". Los clubes de migrantes en Sahuayo fueron algunos de los precursores de las organizaciones que actualmente operan como Federaciones de Clubes Michoacanos que ya cuentan con 58 organizaciones, agrupadas geográficamente por los estados donde se ubican los migrantes. Entre estas Federaciones, destacan por su actividad la Federación Californiana de Michoacanos (FECADEMICH) y especialmente la Federación de Clubes Michoacanos de Illinois (FEDECMI). La FEDECMI se fundó en 1996 y en el año 2004 se convierte en el centro educativo y cultural "Casa Michoacán "en donde se realizan actividades educativas, culturales y sociales dentro del contexto binacional. Las comunidades de origen mantienen los lazos sociales y económicos al igual que buscan generar una comunidad transnacional que facilite o ayude tanto a las 
personas que se mantienen en la comunidad de origen, como aquellos que emigran hacia los Estados Unidos.

"El lugar de origen se convierte en un centro ritual al que se regresa para festejar al santo patrono y otros aniversarios calendáricos como la pascua y la navidad (que mucho tienen que ver con el calendario oficial de vacaciones y días festivos). Allí se refuerzan los lazos familiares y se establecen nuevos vínculos: la provisión de mujeres, el hermano menor que va a emprender su primer viaje al terminar la fiesta, etc." (Boehm, 1985: 108).

Aunque el gran número de federaciones de migrantes y la participación de estos en el desarrollo de sus municipios de origen pueda llevar a percibir a los migrantes como elementos indispensables para el desarrollo comunitario, también debemos atender al proceso y las circunstancias que los migrantes han experimenta en Estados Unidos. Las zonas rurales de Estados Unidos, especialmente aquellas destinadas a la producción agrícola, han experimentado procesos de "huida blanca" hacia los suburbios de las ciudades. El trabajo poco remunerado que oferta la producción agrícola ha sido ocupado por migrantes mexicanos originando los conocidos "núcleos mexicanos", focos de pobreza rural. Salarios bajos y la carencia de servicios públicos adecuados han desplazado a la clase media estadounidense a los suburbios de las grandes ciudades, dejando estos empleos a inmigrantes ilegales (Palerm y Urquiola, 1993).

La tradición migratoria y el aumento del número de migrantes también han provocado numerosos conflictos entre la comunidad de migrantes ya que competían por 
los mismos trabajos. Los contratistas, en muchos casos personas que llevan más tiempo en Estados Unidos, pero que son originarios de las comunidades en México que muchos migrantes recién llegados, han experimentado la presión por contratar a vecinos y familiares. Algunos contratistas que mantenían lazos con sus comunidades de origen dejaron de viajar de vacaciones a ellas por sentirse presionados por sus vecinos que les reclaman en muchos casos facilidades para conseguir un trabajo o dinero. También se han producido casos de infidelidad, abuso, violencia u homicidio dentro de las comunidades de migrantes lo que ha repercutido en sus comunidades de origen. El aumento considerable durante las últimas décadas de indocumentados y la falta de empleos han sido percibidos por los migrantes que ya habían conseguido su Green Card $^{25}$ como una situación problemática que ponía en peligro su estilo de vida en Estados Unidos. Gledhill (1997) señala como factores clave de este rechazo a los nuevos migrantes, el acoso que la policía empezó a generalizar a todas aquellas personas de apariencia mexicana, así como la repulsa que la población estadounidense comenzaba a tener hacia la migración mexicana.

Las entrevistas realizadas a migrantes durante sus visitas a La Ciénaga de Chapala evidenciaron que especialmente los migrantes que ya habían obtenido su Green Card no deseaban que se siguiese manteniendo el flujo migratorio. Apuntaban a la crisis económica y la falta de trabajo como los factores principales que estaban originando tensión en sus comunidades estadounidenses y muchos repitieron en sus explicaciones la frase que a continuación se reproduce: "El mayor enemigo de un mexicano en el gabacho $^{26}$ es otro mexicano". Aunque al término de la etnografía, mayo de 2016, la participación de Donald Trump en la candidatura republicana no era tomada en serio, un

\footnotetext{
25 Documento de identidad expedido por el Gobierno de los Estados Unidos a las personas de otras nacionalidades que permite la residencia permanente y el derecho a trabajar en el país.

${ }^{26}$ Forma coloquial con la que se refieren a Estados Unidos de América.
} 
número considerable de las personas entrevistadas durante la investigación que residían de manera permanente en los Estados Unidos apoyaban al candidato, principalmente por las intervenciones que estaba realizando Trump en los medios de comunicación sobre la construcción del muro y frenar la migración.

Aun con la falta de trabajos en los Estados Unidos y la feroz competencia que existe entre los migrantes para conseguir un salario que los permita permanecer allí, la emigración ha ido en aumento durante los últimos años en La Ciénaga de Chapala. El motivo principal de esta fuga de habitantes, algunos migrados al norte, y otros que han trasladado su residencia en ciudades como Guadalajara y Ciudad de México, es la falta de empleos en la región y el clima de inseguridad derivado del narcotráfico. Ya presentamos una panorámica de la violencia e inseguridad que el narcotráfico estaba ocasionando en Michoacán, a la que hay que añadir la situación fronteriza y estratégica que tiene La Ciénaga de Chapala, ubicada entre dos estados, y con la carretera Guadalajara-Ciudad de México. Esto ha ocasionado que los toques de queda derivados por las disputas por el dominio de la plaza entre diferentes carteles, especialmente entre La Familia Michoacana y el Cartel de Jalisco hayan provocado el cierre de negocios y la falta de inversiones. Estos factores han acrecentado el proceso de abandono y despoblación de la región, en la que las nuevas generaciones optan por migrar y las tierras agrícolas son rentadas a grandes productores de grano. Las actividades productivas han sido invadidas por el capital generado por la narcoeconomía, ya sea por el financiamiento y la extorsión. La sociedad ha aprendido a convivir con el crimen organizado, ya que distribuye ingresos, sobornos, lavado de dinero, aporta a las fiestas patronales, construye o rehabilita iglesias, y es precursora en muchas ocasiones de infraestructura destinada a políticas sociales (Aguilar, 2012). La articulación entre la sociedad civil y el narcotráfico 
es fácilmente perceptible gracias a elementos culturales característicos de la narcocultura que ya generan una fuerte influencia en la comunidad.

\subsection{Jiquilpan "pueblo mágico" y Sahuayo "ciudad comercial".}

\section{Cardenismo Souvenir vs. Santiago, Joselito y los negocios}

Las diferencias que particularizan los municipios de Jiquilpan y Sahuayo son fruto de una rivalidad histórica y de un desarrollo e identidad que se han forjado a través de la diferenciación con su vecino, convirtiendo al eje Jiquilpan-Sahuayo en la mayor zona urbana del distrito 089 y de la región de la Ciénaga de Chapala.

Los dos municipios principales de la Ciénaga de Chapala se encuentran distanciados por $7.4 \mathrm{~km}$, algo que para el observador externo sería una nimiedad ya que la carretera que separa los dos municipios está plagada de concesionarios de coches, lonjas con comercios, hoteles y un centro de convenciones. Este aglutinamiento de comercios y edificios entre las dos ciudades demuestra que la conurbación es un proceso imparable, y que la frontera territorial y las disputas sobre ella están apoyadas por la confrontación ideológica, donde colocar una estaca que determine la demarcación es mucho más difícil.

La entrada a los municipios ya remarca las diferencias de cada uno, evidenciando las diferencias desde el acercamiento por carretera. Cuando los viajeros llegan a Jiquilpan desde Morelia atraviesan primero una serie de comunidades de aspecto rural. Al pasar por los Remedios y Totolán pueden ver a gente haciendo su vida en la puerta de su casa, una jaula con dos gallos y algún perro vagando tranquilo, sin collar ni correa, mientras algún paisano a caballo se dirige a sus quehaceres con la atmosfera de tranquilidad que un pueblo otorga a sus habitantes. Una vez llegado el momento, una gran calle con más 
árboles que personas da la bienvenida al visitante, mientras el despliegue institucional hace imposible pensar que ese es un pueblo cualquiera. La Unidad Deportiva Lázaro Cárdenas, el Instituto Tecnológico, el Cuartel Militar, el Centro de Bachillerato Tecnológico, Industrial y de Servicios (CBTIS) nº 12, la Unidad de Estudios Regionales (UAER) dependiente de la UNAM (Universidad Nacional Autónoma de México), el cartel indicativo del Instituto Federal Electoral (IFE) y el monumento a Lázaro Cárdenas, presidido por la escultura del General, de pie, impasible, son la carta de presentación de un municipio de aspecto rural que fue favorecido por la Historia. No cabe duda que la Calle Lázaro Cárdenas es un escaparate de instituciones gubernamentales y educativas, un largo paseo a la sombra de los arboles puede hacer que cualquier visitante nostálgico sueñe con el éxito de un socialismo rural mexicano.

Una vez atravesado el puente, se llega al centro de Jiquilpan. Si el trayecto ha sido realizado en autobús, este se parará frente a la biblioteca Gabino Ortiz. Este edificio fue en un principio la capilla de la Virgen de Guadalupe. Durante la Guerra Cristera dejó de tener utilidad religiosa convirtiéndose posteriormente, durante la presidencia de Lázaro Cárdenas, en centro de educación socialista (Chavolla McEwen, 2014). Al final del periodo presidencial de Cárdenas se inician las labores de remodelación del edificio que tomará mayor notoriedad al pasar la carretera nacional frente a él. Las labores de remodelación incluirían diez murales sobre la nave y el ábside de la antigua capilla realizados por José Clemente Orozco con temática revolucionaria, sobre todos ellos destaca la "Alegoría a la mexicanidad". Un año después se añadirían las puertas de bronce encargadas a Guillermo Ruiz en la que se representan escritores, poetas, políticos y librepensadores de América. La Biblioteca Pública "Licenciado Gabino Ortiz" sería inaugurada en 1941, el día conmemorativo de la expropiación petrolera (18 de marzo) convirtiéndose en una joya artística, una infraestructura de carácter social y, 
principalmente, en una declaración de intenciones y emblema ideológico para los habitantes de Jiquilpan.

Si se cambia de perspectiva, y la llegada se realiza a Sahuayo desde Guadalajara las diferencias no se hacen esperar. El boulevard Lázaro Cárdenas es una carretera ancha con tres carriles en cada dirección separados por un camellón. La falta de árboles permite ver casas bajas, pero no de aspecto rural, sino unifamiliares más característicos de la periferia de una ciudad, organizados en cuidados fraccionamientos y un hipermercado Soriana con sus plazas de aparcamiento. La imagen se asemeja a la entrada a cualquier zona urbana de México, con pequeñas comunidades marginales, fraccionamientos y zonas comerciales. La carretera está plagada de grandes lonjas de distribución o compra, con grandes camiones aparcados en sus puertas, poco a poco las casas van dejando paso a un sinfín de comercios, vulcanizadoras y concesionarios de coches. La única referencia que nos puede indicar que hemos llegado al centro de la ciudad es la aparición de la presidencia municipal en uno de los laterales del Boulevard, así como el aumento del tráfico de motos de pequeña cilindrada, medio de transporte muy común en Sahuayo.

Mientras Jiquilpan tiene el poder de representar ese socialismo rural al que nos referíamos anteriormente, Sahuayo es fiel reflejo de la victoria del capitalismo, el triunfo de la ciudad que expande la mancha humana y crece a base de losas de cemento. El visitante de Sahuayo solo le queda preguntarse dónde se encuentra la entrada de metro más cercana que conecta este lugar con Tepito ${ }^{27}$.

Es oportuno señalar que, durante las entrevistas, muchos participantes han recalcado las diferencias de su municipio con el vecino: mientras en Jiquilpan se enorgullecían de su historia y patrimonio hasta el punto de entender su localidad como

\footnotetext{
${ }^{27}$ Barrio de la Ciudad de México conocido por su intenso comercio.
} 
una simulación de la utopía no conseguida, desprecian a Sahuayo por ser un municipio sin abolengo, sin patrimonio histórico y sin nada que aportar para la glorificación del país. Sin embargo, en la dirección inversa, Sahuayo se convierte en Sahuayork ${ }^{28}$, gran ciudad comercial, mientras el pueblo mágico de Jiquilpan se convierte en el "pueblo trágico", representante último de la decadencia de un proyecto fracasado. Sin embargo, esta rivalidad no es fruto de algún hecho acontecido hace algunos años ni siquiera del periodo del cardenismo que acrecentó la situación, sino que se remonta al periodo de las Haciendas (Shaffhauser, 2013), al porfiriato.

Durante el porfiriato, y con el dominio del territorio bajo la Hacienda de Guaracha y los caciques que anteriormente mencionamos, Jiquilpan se convierte en el centro político de la región, mientras que Sahuayo ocupa su actividad en el comercio y distribución (Zepeda, 1989). Es en esta época cuando el latifundio de Guaracha y el conflicto entre las dos ciudades provocan la definición productiva de las localidades, generando con ellos también una diferenciación cultural que se acrecentaría durante la Guerra cristera entre 1926 y 1929.

La guerra Cristera se inició a través del levantamiento en armas de un movimiento radical religioso católico. Como consecuencia de las políticas iniciadas durante la Revolución Mexicana y posteriormente por Plutarco Elías Calles, los cristeros se enfrentaron a las fuerzas federales. La guerra se cobró la vida de miles de personas a nivel nacional, siendo más cruenta en zonas rurales, que fueron principalmente los escenarios de batalla. El conflicto sembró los caminos, carreteras y plazas públicas de cadáveres que permanecían colgados como trofeo de guerra. En los pueblos se cancelaron los servicios religiosos y los sacerdotes dejaron las sotanas en el guardarropa para vestir como civiles

\footnotetext{
${ }^{28}$ Unión del nombre Sahuayo con York, haciendo con ellos un juego de palabras que indica que Sahuayork es el Nueva York de la región.
} 
y confundirse entre los parroquianos. Todas las costumbres y festividades religiosas pasaron a la clandestinidad hasta 1929. Será en este año cuando se pacte una tregua entre los dos bandos. Jiquilpan y Sahuayo sufrieron esta guerra viendo cómo sus iglesias eran utilizadas para fines más profanos y ejecutando a sacerdotes de manera pública. Pero mientras la población de Jiquilpan se mantuvo en un segundo plano y no hubo un enfrentamiento directo con las tropas de Plutarco, Sahuayo se levantó en armas y fue la población civil colaboradora de primer orden de las tropas cristeras. La participación de la población civil en Sahuayo se convirtió en un componente simbólico en la identidad de los sahuayenses reforzado por la película Cristiada ${ }^{29}$ y la figura de José Sánchez del $\operatorname{Rio}^{30}$.

Años después, el que fuera Gobernador de Michoacán durante la guerra y el cual se enfrentó a Plutarco durante esos años, se convertiría en el presidente de la República Mexicana durante el sexenio de 1934-40. Lázaro Cárdenas, originario de Jiquilpan, obligó a Plutarco a abandonar el país en 1936. Entre 1937 y 1938 nacionalizó los ferrocarriles y llevó a cabo la expropiación petrolera. La reforma agraria en este periodo será determinante para entender el cambio en la propiedad de la tierra a nivel nacional, y especialmente en Jiquilpan que se vio favorecida, adquiriendo mayor control político sobre la región y siendo ejemplo de la producción agrícola a través de los ejidos.

\footnotetext{
${ }^{29}$ Cristiada es una película mexicana estrenada en 2012 ambientada en la Guerra Cristera dirigida por Dean Wright. En ella se presenta la rebelión de los cristeros y la persecución del gobierno mexicano a la Iglesia Católica durante la década de 1920. Aunque comete varios errores históricos, en ella aparece la historia de José Sánchez del Rio, niño cristero originario de Sahuayo.

${ }^{30}$ San José Sánchez del Río (1913-1928) fue un joven sahuayense que participo en la guerra desde el bando cristero. Fue procesado, torturado y ejecutado por los oficiales del gobierno mexicano a la edad de 14 años. Aunque por su juventud no pudo alistarse oficialmente en las tropas cristeras, si participo en la batalla bajo el consentimiento de su madre a la que convenció con la frase que se ha convertido en lema "Nunca ha sido más fácil ganarse el cielo como ahora". El 10 de febrero de 1928 fue capturado y procesado, le desollaron las plantas de los pies y lo obligaron a caminar por las calles de Sahuayo hasta el panteón municipal. Durante todo el camino el niño iba gritando vivas a Cristo Rey y a la Virgen de Guadalupe hasta llegar al hoyo que sería su tumba. Posteriormente se convertiría en un símbolo de fe para el municipio de Sahuayo y alrededores, siendo beatificado el 20 de noviembre de 2005. El 22 de enero de 2016 será reconocido por la Santa Sede un milagro atribuido al Beato Sánchez del Rio, la canonización se realizó el 16 de octubre de 2016.
} 
Durante estos años se fortalecerá la diferenciación de los dos municipios y su desarrollo mantendrá una trayectoria divergente. Jiquilpan celebrará los éxitos de Cárdenas como propios, definiéndose a través de la figura del General y sus discursos, en los que el desarrollo de la nación pasa por un modelo socialista enfocado en el desarrollo institucional y la mejora de las condiciones de vida a través de la equidad, la justicia social, y el planeación urbana y agrícola. La expropiación de las haciendas para conformar los ejidos y el control que su hermano Dámaso Cárdenas ejerció en la región a través del aparato caciquil convirtieron a la localidad de Jiquilpan en algo más que el centro político, sino también en la encarnación de un eje ideológico que se definía por buscar una alternativa viable al capitalismo a través de un sistema caciquil. Este sistema estaba enfocado principalmente en la mejora de los campesinos de La Ciénaga, pero dejo de lado a los pobladores urbanos de Sahuayo.

Mientras Jiquilpan era la localidad que había visto nacer al presidente de la Republica que abogaba por un modelo keynesiano de la economía más cercano a una utopía socialista, las secuelas de la Guerra Cristera se traducirían en el movimiento sinarquista $^{31}$ (Meyer, 1994) que se extendería rápidamente en algunos lugares de La Ciénaga de Chapala y especialmente en Sahuayo (González y González, 1979: 195). En este periodo comenzará sus actividades en la región la Acción Católica Mexicana (ACM) y la Unión Nacional Sinarquista (UNS) ${ }^{32}$. En 1945 la UNS se dividió en dos ramas, una con orientación política que será la precursora de dos partidos políticos, Fuerza Popular

\footnotetext{
${ }^{31}$ El movimiento sinarquista está inspirado en los movimientos de tercera posición en Europa y principalmente en el falangismo español de José Antonio Primo de Rivera. La Unión Nacional Sinarquista (UNS) fue fundada en mayo de 1937 por jóvenes nacionalistas y católicos liderados por José Antonio Urquiza, quien sería asesinado en 1938, y Juan Ignacio Padilla. La UNS será una organización política de corte nacionalista, católica, anticomunista y nacionalsindicalista que nacerá bajo la determinación de defender a México de la amenaza comunista.

${ }^{32}$ La UNS fue un movimiento político que se oponía a la ideología de la postrevolución, en particular al gobierno de Lázaro Cárdenas. La Juventud Obrera Católica, asociación laica derivada del movimiento que llegó a México en 1960 se implantará en la Ciénaga de Chapala. En el municipio de Totolán llegarán a realizar reuniones de formación (Meyer, 2003).
} 
(FD) y el Partido Demócrata Mexicano (PDM) (Meyer,1980). La otra fracción de la UNS se mantendrá externa a los asuntos políticos y enfocará sus esfuerzos en la actividad comunitaria y social. La primera rama, ya constituida en partidos políticos, tendrá presencia en Jiquilpan, Sahuayo y Cojumatlan, siendo Sahuayo donde adquirirá más notoriedad. La introducción de las ideas sinarquistas en Sahuayo se debe en gran medida a que estas fueron enfocadas hacia la población pobre que estaban cansados de los conflictos entre ejidatarios (entre los que destaca los de La Hilacha) con los descendientes de los dueños de las haciendas (los Pájaros Prietos) (González y González, 1979). Además de la aparición de dos partidos políticos que defendían la ideología sinarquista, también se implementaron acciones sociales, por parte de la Iglesia, pero también de los laicos y organizaciones sociales. Entre estas últimas destaca la Unión Femenina Católica (UFC) con presencia en la parroquia de Sahuayo desde finales de 1940. Sus actividades se enfocaron a la catequesis y proyectos productivos, como granjas y talleres.

El sinarquismo en la Ciénaga de Chapala aglutinó a los cristeros como a otros ciudadanos que se oponían a las políticas de Cárdenas y a las políticas neoliberales que posteriormente empezarían a implantar con el gobierno de Salinas. Durante el trabajo de campo he encontrado que muchas organizaciones sociales, desde cajas populares de las que se hablará más adelante, a agrupaciones informales son las herederas directas de aquellas que bajo la UNS organizaron a la población a principios del siglo XX. También existe una relación entre el movimiento sinarquista de aquellos años y la ideología bajo la que teóricamente se rige el cartel de Narcotráfico más poderoso de la región. Cabe destacar que uno de sus líderes fue hace años profesor en Sahuayo y que el código pseudoreligioso que rige a los componentes de Los Caballeros Templarios guarda relación directa con la ideología sinarquista. Uno de los grupos precursores del 
sinarquismo en la región fue la formación del grupo Caballeros de Colon ${ }^{33}$ que cuenta con una de sus agrupaciones en el municipio de Sahuayo.

En el ámbito político Sahuayo "es panista, tanto como fue sinarquista” (González y González, 1979: 195), a diferencia de Jiquilpan donde el PRD y el PRI son los partidos más votados. El poder político en Jiquilpan está condicionado por el apego y cariño que sus habitantes mantienen a la figura de Lázaro Cárdenas, la herencia que el general dejó en la región, y la influencia que Cuauhtémoc Cárdenas Solórzano ${ }^{34}$ posee en el municipio, el cual visita asiduamente, son un referente político e ideológico que se mantiene en el municipio, más allá de ser solo un legado histórico.

\subsubsection{Las fiestas en la región, ejemplo de las particularidades de los}

\section{municipios}

Las festividades en la región son un reflejo fiel de los particularismos de los municipios. La fiesta principal de Jiquilpan es la celebración de la expropiación petrolera de 1938, realizada por Lázaro Cárdenas. Durante la celebración, uno de los puntos principales de reunión es el Estadio 18 de marzo, bautizado así por el día de conmemoración del acontecimiento histórico. En su entrada principal se reproducen dos frases del General, franqueando el arco de medio punto presidido por el águila con las alas abiertas. A su izquierda se lee "Los recursos naturales del país deben servir para su

\footnotetext{
${ }^{33}$ Los Caballeros de Colon es un grupo conservador antigubernamental y antimasónico fundado en 1925 en Zamora. En 1931 quedaría suspendida su actividad por el conflicto cristero pero el 29 de junio de 1958 se constituiría el consejo 4637 y volvería a su actividad. En él participaron 37 sahuayenses, precursores de la beatificación de José Sánchez del Río. Sus actividades se rigen por los principios básicos de "Caridad, Unidad, Fraternidad y Patriotismo", desarrollando sus actividades en parroquias, el asilo de ancianos, los hospitales y el reclusorio municipal. También cuentan con la Caja Popular Caballeros de Colon S.C., que ofrece financiamiento económico.

${ }^{34}$ Hijo de Lázaro Cárdenas.
} 
propia prosperidad", a la derecha "Entregarlos a intereses extraños es traicionar a la patria".

Fotografía 1, Estadio 18 de marzo

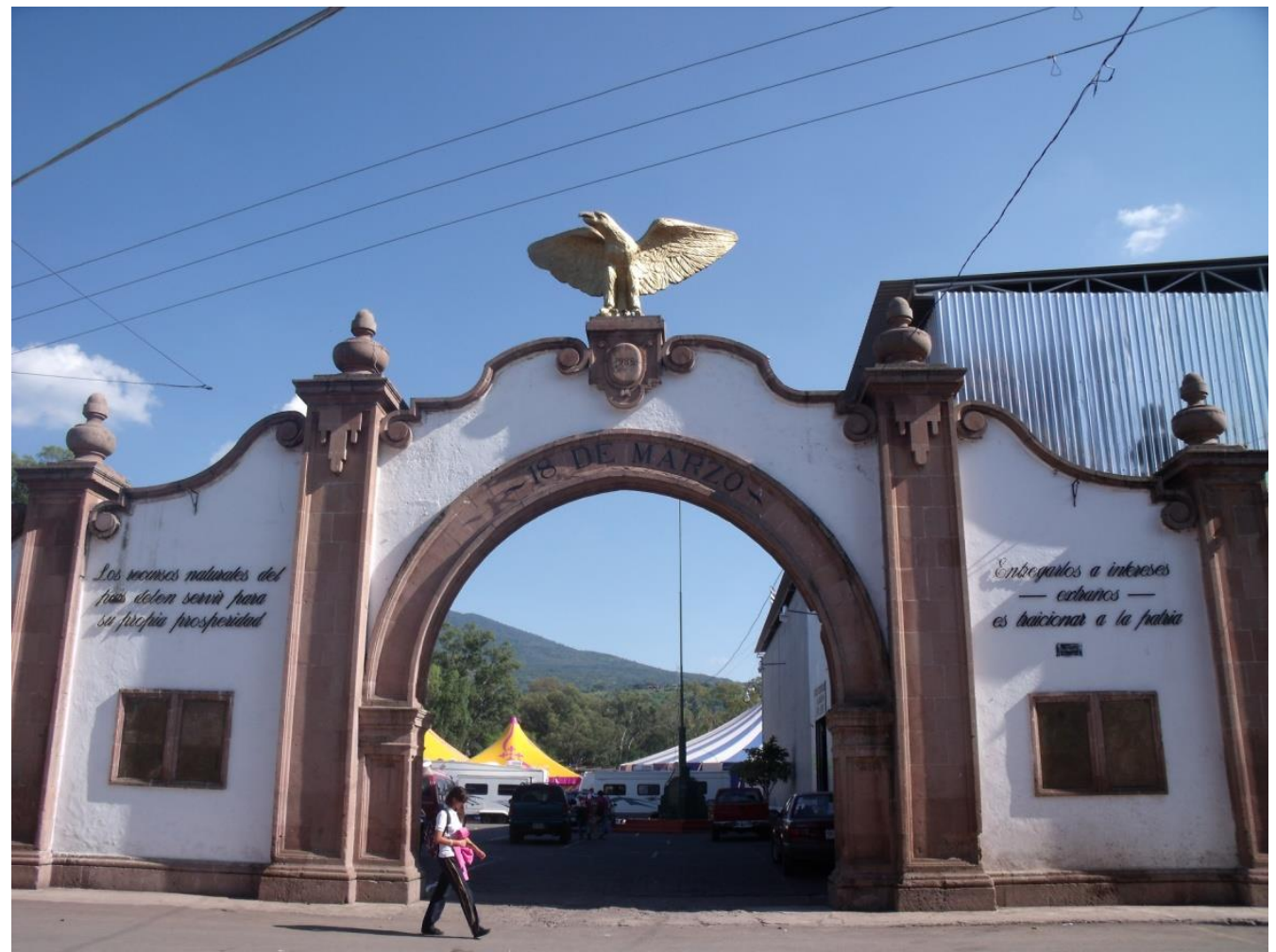

Fuente: Raquel Miranda, Año 2012. Jiquilpan

En el estadio se ubica durante varios días la feria, el palenque con las peleas de gallos y sus correspondientes apuestas que para el observador con conocimientos antropológicos se asemeja a un potlatch entre individuos de ranchos vecinos. La finalidad principal de las apuestas es ganar, aunque la satisfacción principal de los apostadores es hacer gala de la ostentación, en su vestimenta, la de sus mujeres, y los automóviles, así como apostar grandes sumas de dinero. Durante una noche en el palenque acompañada por uno de las personas participantes en la investigación observé que las sumas de dinero aumentaban en función de la rivalidad implícita que existía entre los apostadores. El cónyuge de la persona participante aprovechó un momento en el que nos quedamos a 
solas para soltar el chisme que explicaba esta rivalidad. El hijo del señor que siempre subía la apuesta quería casarse con la hija de una familia que estaba allí presente, de tal manera que la ostentación y el aumento de la apuesta no solo servía a una utilidad lúdica, era una forma de indicar el poderío económico de la familia pretendiente.

Fotografía 2, Aniversario de la Revolución mexicana, 20 de noviembre

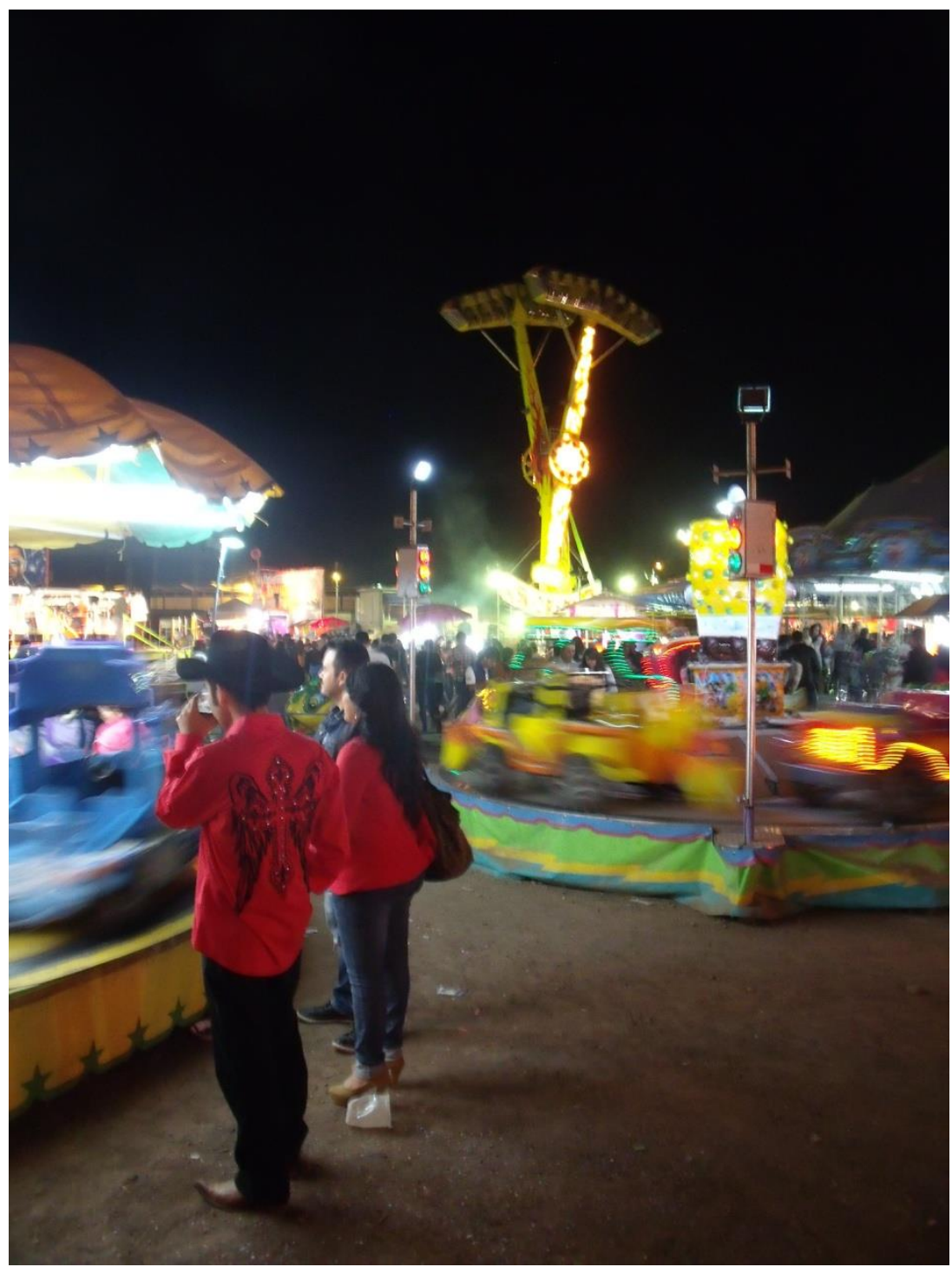

Fuente: Raquel Miranda, Año 2014. Estadio 18 de Marzo, Jiquilpan 
También se realiza todos los años el Certamen Señorita Expropiación Petrolera, eligiendo a "la muchacha más bella de la región". Este concurso tiene la misma estructura que cualquier certamen de belleza, pero con la particularidad de que las preguntas del jurado giran en torno a la expropiación del General Lázaro Cárdenas. Schaffhauser (2013) describe esta celebración denominando a los participantes "feligreses de la revolución santificada", señalando que en esta festividad se evidencian los etnocentrismos regionales. En Jiquilpan también es una fecha señalada el 20 de noviembre, festividad en honor de la Revolución Mexicana. Son durante estas dos fiestas cuando más personas de la región acuden a Jiquilpan, y concretamente al estadio 18 de marzo.

Fotografía 3, Procesión de los faroles

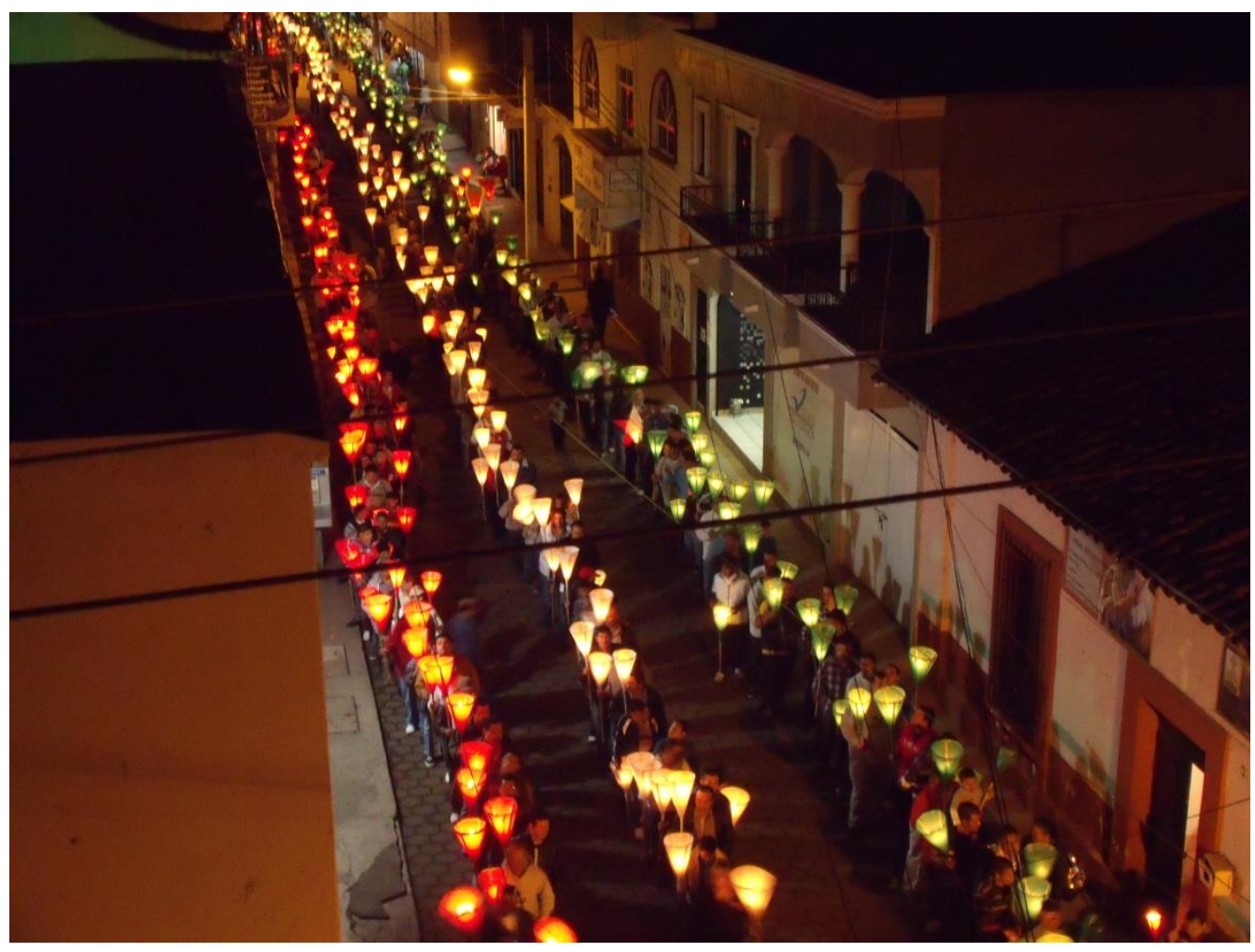

Fuente: Raquel Miranda. Año 2012, Jiquilpan 
La festividad religiosa por excelencia son las Fiestas Guadalupanas y, en especial, el día 12 de diciembre. En Jiquilpan el hecho más importante y que más personas congrega durante la festividad de la Virgen de Guadalupe es la procesión de los faroles. La procesión es multitudinaria en la que miles de hombres portando faroles con los colores de la bandera mexicana, desfilan por las calles de la ciudad. Se dividen en tres hileras, cada uno de un color (roja, blanca y verde) formando una gran bandera mexicana de luz que recorre las calles mientras se lanzan vivas a Cristo Rey, San Francisco y San Cayetano $^{35}$, el Papa y México Católico.

Como podemos observar, aunque la festividad principal es civil y de herencia cardenista, también convive con festividades católicas en las que existen referentes de la Guerra Cristera y demuestran el fervor religioso que también está presente en el municipio. Esta convivencia no significa que todo Jiquilpan participe en las festividades de igual modo. Mientras la expropiación petrolera tiene más participación institucional y, en general, los festejos son celebrados por personas de las zonas urbanas de Jiquilpan, en su mayoría funcionarios, clase media y empresarios, en las celebraciones religiosas tienen mayor participación las clases más desfavorecidas, familias y habitantes del entorno rural.

Mientras el Cardenismo marca la agenda de las festividades locales en Jiquilpan, Sahuayo marca su ritmo propio. La festividad principal de Sahuayo es Santiago Apóstol el 25 de julio. El municipio de Sahuayo no apoyó a los insurgentes durante la Independencia mexicana, al igual que luchó por la fe católica en la Guerra cristera. Esto ha desembocado en que la festividad de Santiago, de marcada herencia española, se convierta en la festividad más importante y en la que más se invierte. La fiesta cuenta con la participación de la figura de Santiago Apóstol, venerado en la región desde el siglo

\footnotetext{
${ }^{35}$ En referencia a los dos santos que tienen parroquia en Jiquilpan.
} 
XVI. Según la tradición oral la figura llegó gracias a unos arrieros que la dejaron en el Barrio del Pedregal bajo la promesa de volver a por ella. Eso nunca sucedió quedándose en el figurahasta el día de hoy. La devoción hacia la figura hizo que en 1717 se fundase la parroquia de Santiago Apóstol y su festividad se convirtiese en la fiesta patronal de Sahuayo.

Fotografía 4, Procesión Santiago Apóstol. Fiestas del Patrón Santiago

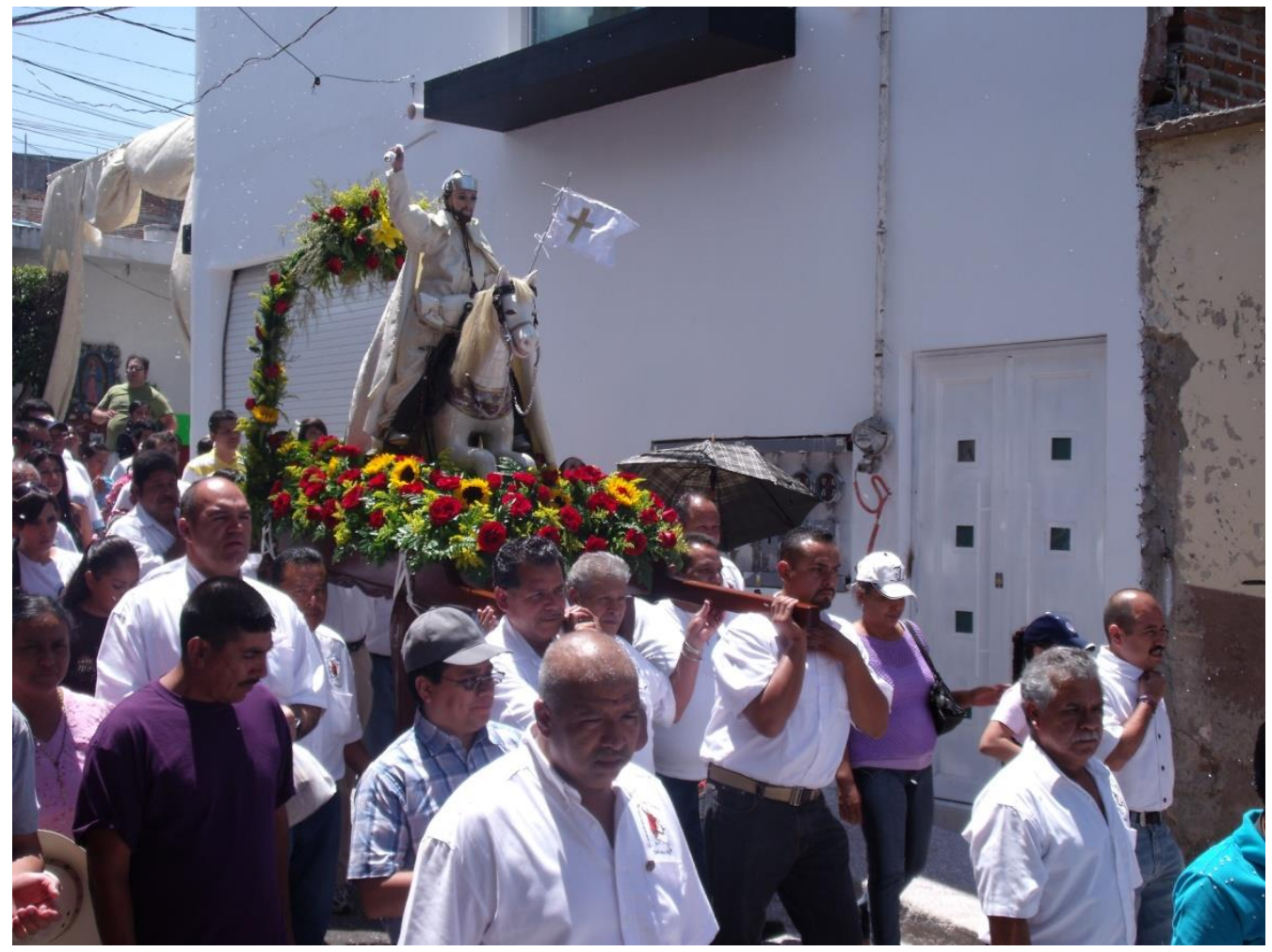

Fuente: Raquel Miranda. Año 2013, Sahuayo

En la festividad, de carácter sincrético, intervienen el Patrón, los moros y los caballeros de Santiago, de modo muy similar a la festividad celebrada en España, pero los protagonistas principales en el caso de Sahuayo son los Tlahualiles. Los Tlahualiles son guerreros prehispánicos vestidos con trajes que llevan carrutos de metal que, al caminar, producen el sonido que pretende imitar el de espadas chocando en la batalla. 
Este sonido, junto son los golpes de sables, hacen conmemoración a la Batalla mítica de Clavijo datada por la tradición oral en 844 entre el rey cristiano Ramiro I y Abderramán II, en la que los cristianos vencieron gracias a la intervención de Santiago Apóstol sobre su caballo blanco, ocasionando que los moros huyesen. Los elementos más característicos de los Tlahualiles son las máscaras que portan, de grandes dimensiones, y decoradas con elementos de herencia prehispánica en su frontal, y símbolos religiosos en la parte posterior. La realización de estas máscaras se realiza en grupos, a modo de cofradías, y el gasto monetario en la vestimenta se convierte en un motivo de orgullo por parte de los participantes. Las procesiones del Patrón seguido por los Tlahualiles se realizan durante los días anteriores y posteriores al 25 de julio, día grande de las fiestas, requiriendo por parte de las personas que portan las pesadas máscaras y trajes en un tipi de penitencia y de celebración que disfrutan realizando bailes y giros por las calles de los municipios. Los días de la festividad están marcados por la celebración de dos novenarios ${ }^{36}$ en honor a Santiago Apóstol, uno del 16 al 25 de julio, y el otro, seguido del primero hasta el 4 de agosto con recorridos diarios.

\footnotetext{
${ }^{36}$ Ejercicio de devoción que se realiza durante nueve días. Consiste en la celebración de una Misa de forma solemne cada día de los nueve que componen en novenario, seguida de una procesión.
} 
Fotografía 5, Desfile de los Tlahualiles. Fiestas del Patrón Santiago

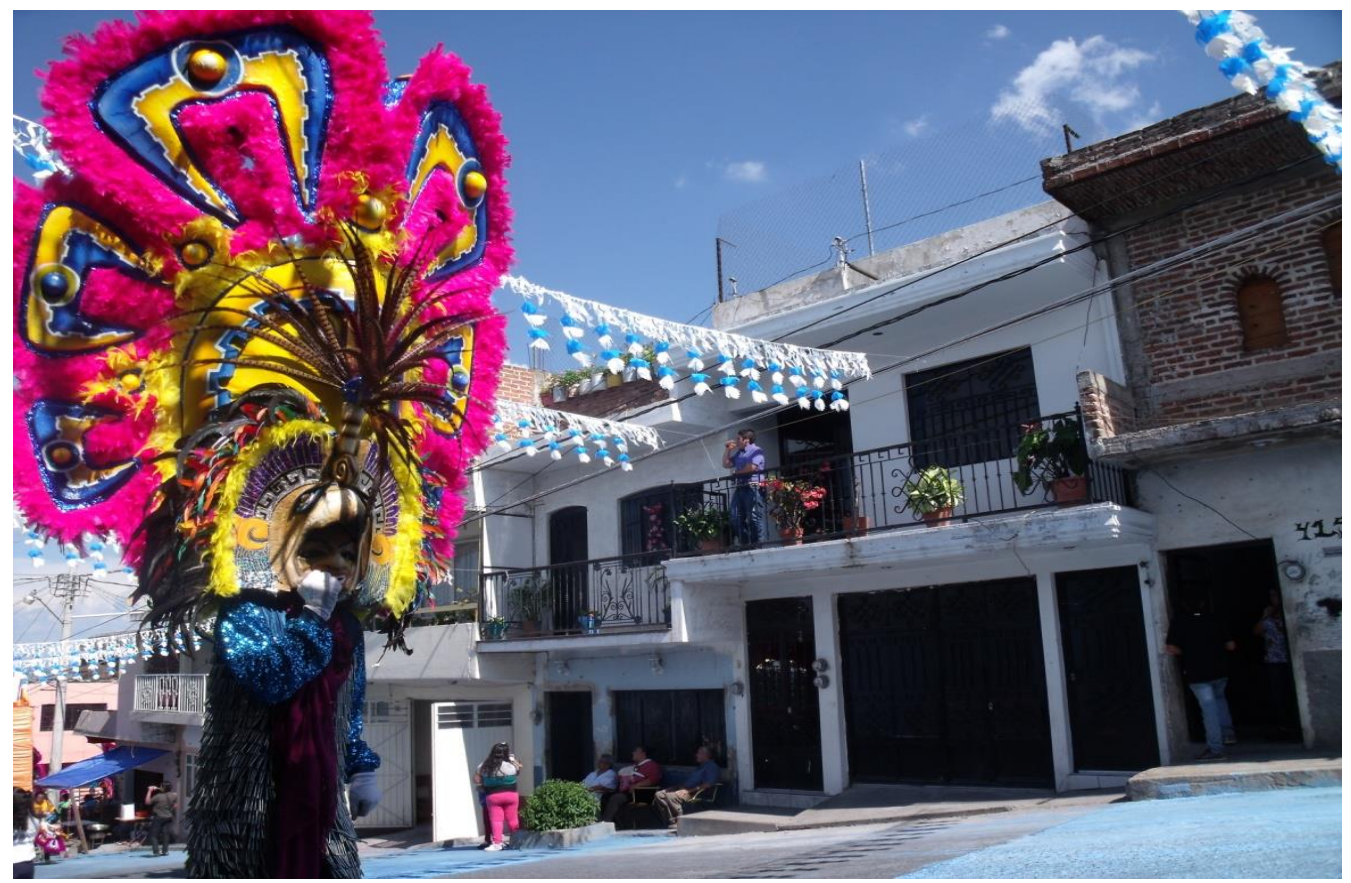

Fuente: Raquel Miranda. Año 2013, Sahuayo

Fotografía 6, Fiestas en Honor a la Virgen de Guadalupe

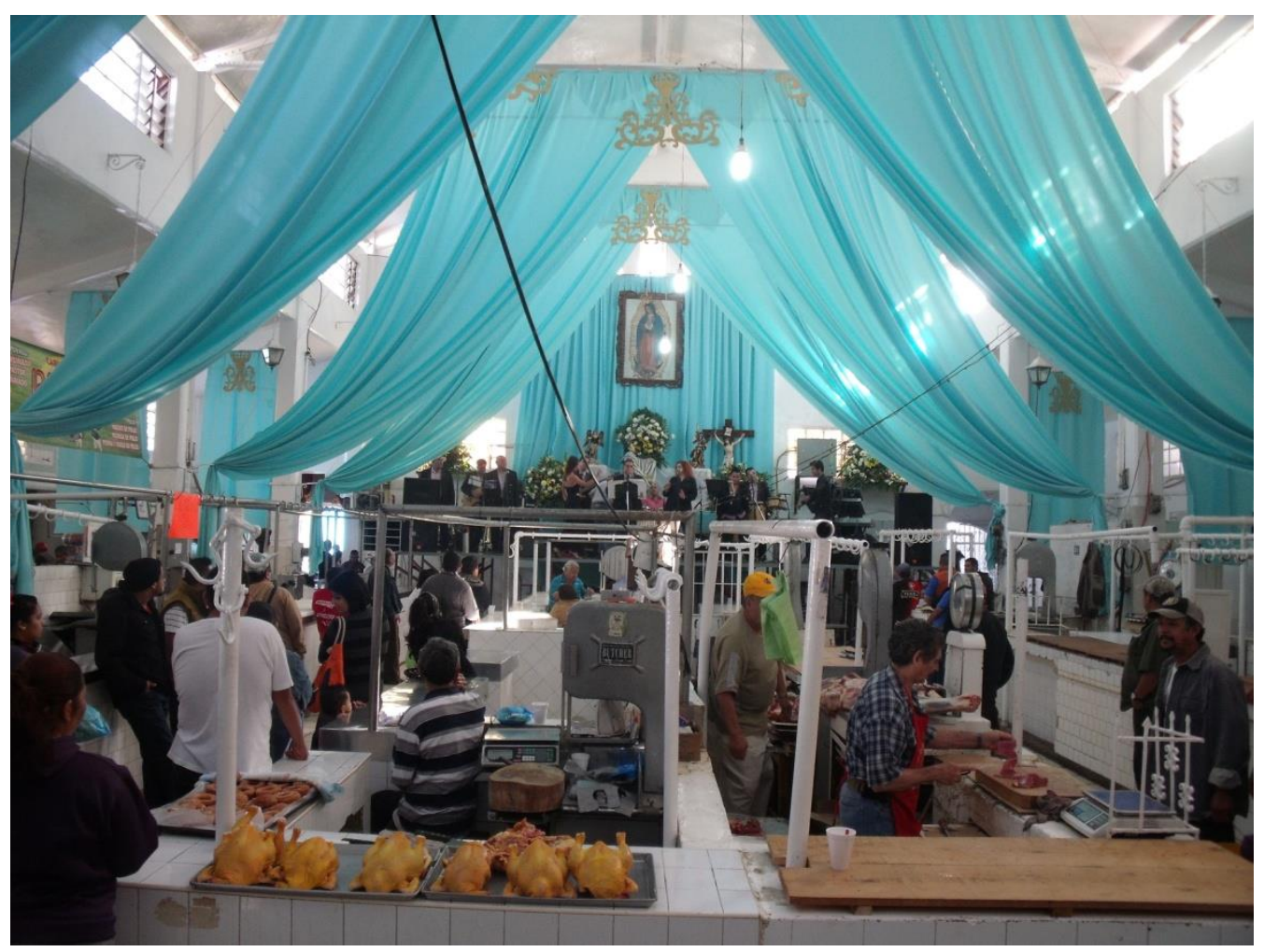

Fuente: Raquel Miranda. Año 2012, Sahuayo 
La otra festividad importante en Sahuayo son las Festividades Guadalupanas. Al igual que su vecino, Jiquilpan, la Virgen de Guadalupe tiene una gran devoción entre los habitantes de Sahuayo, aunque su festividad y los actos que se celebran son diferentes. La celebración se extiende desde el 1 de diciembre ${ }^{37}$ hasta el 12 del mismo mes, siendo esta la fecha de la fiesta grande. Durante los 12 días de celebración se realizan misas, conciertos y celebraciones patrocinados por particulares, gremios (entre los que destaca la contribución del comercio grande), personas acaudaladas del municipio y las asociaciones de migrantes bajo el gremio de la Colonia Sahuayense en Estados Unidos de América. Estas actividades se realizan principalmente en la plaza "Miguel Hidalgo" en el centro de la ciudad, aunque el día patrocinado por el Gremio del Comercio Grande también hay actuaciones dentro de las dependencias del Mercado de Abastos, convirtiéndose el edificio del mercado en un lugar lúdico donde múltiples bandas recorren los puestos caminando entre cajas de frutas y verduras en un mercado decorado para la ocasión.

Si bien en Jiquilpan habíamos hecho mención a la ostentación y derroche que suponían las apuestas en el palenque, en el caso de Sahuayo, ya sea por ser una ciudad comercial, o porque las clases sociales están legitimadas bajo la lógica neoliberal de libre mercado y competencia, las actitudes de ostentación y derroche son mucho más intensas y frecuentes. En las fiestas del patrón Santiago, la inversión monetaria principal gira en torno a la construcción de las máscaras de Tlahualiles, que se realizan por grupos. Aunque el diseño definitivo de cada grupo es un secreto hasta el primer día de la fiesta, durante meses se comenta el desembolso económico que realiza cada grupo en ellas,

\footnotetext{
${ }^{37}$ En el año 2015 y por la celebración de un proceso electoral extraordinario en Sahuayo, las festividades guadalupanas comenzaron el día 7, ya que el día 6 era el día de votación. Los vecinos se mostraron inconformes con esta fecha, principalmente porque el día 6 es el día señalado como aquel donde la festividad se realiza en el mercado, lo que se llama el Día del Comercio Mayor.
} 
especialmente en la compra de las plumas decorativas que son objeto de comentarios y competencia. En las fiestas de la Virgen de Guadalupe es el patronazgo de las actividades, varias de ellas patrocinadas por personas o familias, las que sirven como indiscutibles marcadores sociales. Durante las misas realizadas, y especialmente el día patrocinado por las familias y gremios más pudientes del municipio, la iglesia en palabras de los sahuayenses se convierte en "una pasarela de moda" donde las mujeres exhiben sus mejores vestimentas, maquillaje, peluquería $\mathrm{y}$, en muchas ocasiones, las mejoras producidas por operaciones de cirugía estética. El que Sahuayo y sus ranchos cercanos tenga un mayor número de población de descendencia europea y el cuidado e inversión que realizan las mujeres de la zona a su apariencia ha hecho que el mito de la belleza de las mujeres de Sahuayo sea reconocido en toda le región, motivo de orgullo para el municipio y exigencia para las mujeres sahuayenses.

\section{Fotografía 7, Fiestas en Honor a la Virgen de Guadalupe}

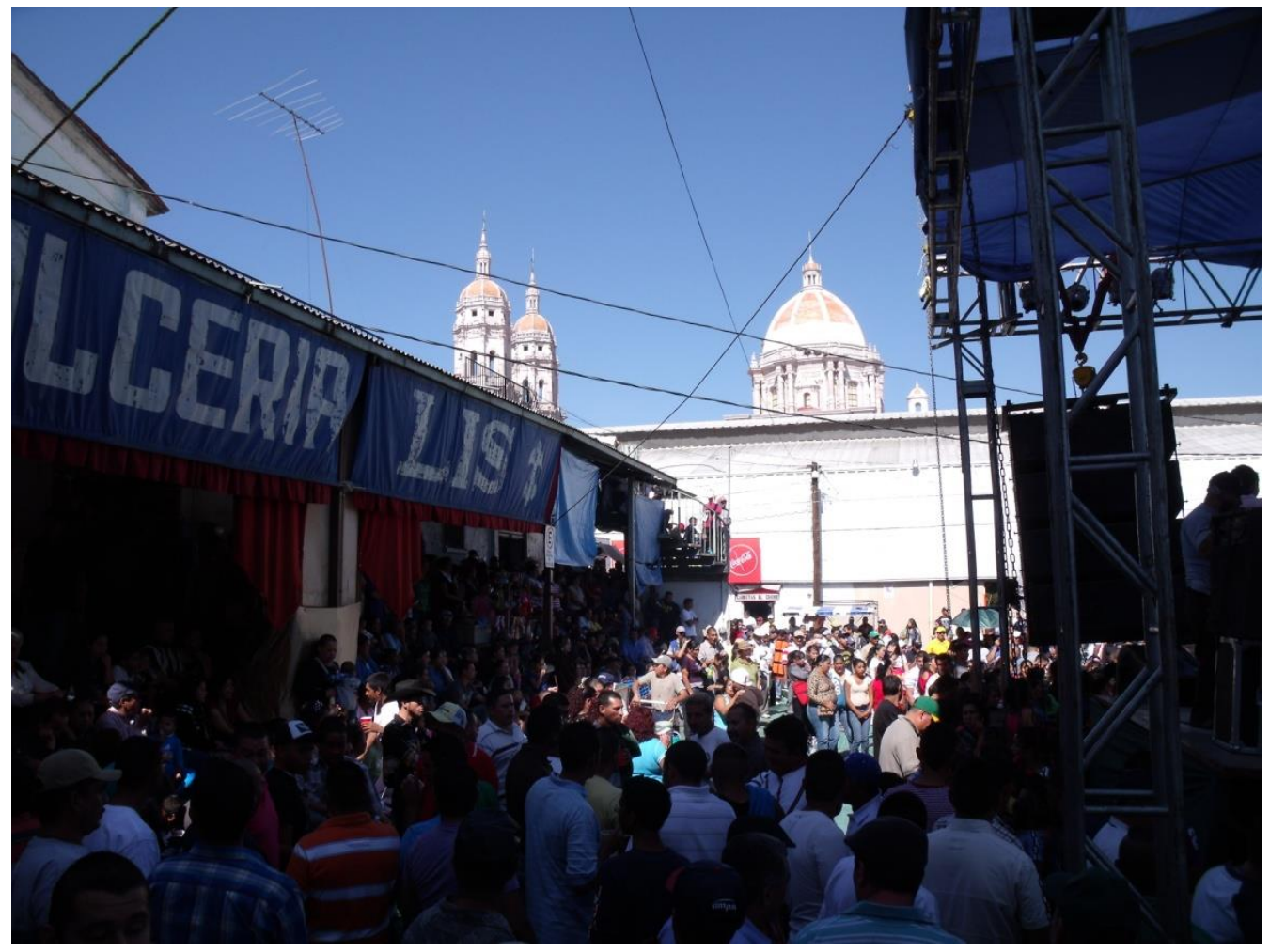

Fuente: Raquel Miranda. Año 2012, Sahuayo 
Como podemos observar, las dos localidades celebran las festividades a la Virgen de Guadalupe, pero mientras en Jiquilpan se convierte en una celebración donde se prima la colectividad en torno a la procesión de los faroles, en Sahuayo esta colectividad se divide en gremios que patrocinan, invierten en una actividad social de carácter religioso. Aunque la Virgen de Guadalupe tiene una gran devoción en los dos municipios, en Jiquilpan la fiesta principal es la expropiación petrolera reafirmando el carácter civil del municipio, su herencia cardenista y revolucionaria, emblema de la mexicanidad. Sahuayo es católico, de herencia europea, pero de tradiciones sincréticas, gremial y competitivo tanto en su pasado histórico como en tu contemporaneidad.

\subsubsection{Jiquilpan de Juárez}

El municipio tiene una población de 34.199 habitantes ${ }^{38}$, con una edad media de 28 años. Tiene una extensión de $242.81 \mathrm{~km} 2$ en la que se encuentran 32 comunidades y tres tenencias municipales. El 70\% de la población total del municipio se encuentra en la cabecera municipal, mientras el otro $30 \%$ se dispersa entre comunidades y tenencias. También existen en el municipio asentamientos irregulares, algunos de ellos fraccionamientos ilegales, otras rancherías o asentamientos informales.

Jiquilpan es un municipio de pequeño tamaño y gran extensión, con un gran patrimonio cultural e histórico que se ve reflejado en su arquitectura y el urbanismo de la ciudad. La gran extensión de terreno que comprende el municipio, junto con la construcción en general de casas de una o dos plantas y el gran número de árboles y jardines da una imagen rural de la localidad. El centro de la ciudad está formado por una fracción de la Calle Presidente Lázaro Cárdenas, el atrio de la Iglesia de San Francisco,

\footnotetext{
${ }^{38}$ Fuente: Censo de Población y Vivienda 2010. INEGI.
} 
la Plaza Principal y la plaza contigua donde se localizan el mercado y la Presidencia Municipal.

Tabla 5, Principales comunidades de Jiquilpan

\begin{tabular}{|c|c|c|c|c|}
\hline LOCALIDAD & TIPO & HABITANTES & HOMBRES & MUJERES \\
\hline JIQUILPAN DE JUAREZ & URBANA & 24233 & 11416 & 12817 \\
\hline ABADIANO LOS ALTOS & RURAL & 653 & 303 & 350 \\
\hline ABADIANO LOS BAJOS & RURAL & 880 & 431 & 449 \\
\hline LAS ANIMAS & RURAL & 127 & 51 & 76 \\
\hline SANTA BARBARA & RURAL & 359 & 157 & 202 \\
\hline LOS TABANOS & RURAL & 173 & 74 & 99 \\
\hline SAN MARTIN TOTOLAN & RURAL & 1662 & 773 & 889 \\
\hline LOS TRES RIOS & RURAL & 70 & 36 & 34 \\
\hline LA BRENA & RURAL & 34 & 15 & 19 \\
\hline LA CANTERA & RURAL & 38 & 18 & 20 \\
\hline EL CAPULIN & RURAL & 5 & 5 & - \\
\hline CERRO DE SAN FRANCISCO & RURAL & 29 & 14 & 15 \\
\hline FRANCISCO SARABIA & RURAL & 2056 & 1020 & 1036 \\
\hline EL FRESNO & RURAL & 237 & 101 & 136 \\
\hline LAS JARAS & RURAL & 55 & 25 & 30 \\
\hline LA LAGUNITA & RURAL & 297 & 145 & 152 \\
\hline LOS LAURELES & RURAL & 28 & 17 & 11 \\
\hline PAREDONES & RURAL & 284 & 123 & 161 \\
\hline PASO DEL BUEY & RURAL & 41 & 17 & 24 \\
\hline LA PURISIMA & RURAL & 35 & 22 & 13 \\
\hline LOS REMEDIOS & RURAL & 1854 & 868 & 986 \\
\hline EL SALTO & RURAL & 33 & 17 & 16 \\
\hline EL RINCON & RURAL & 33 & 15 & 18 \\
\hline OTERO & RURAL & 9 & 4 & 5 \\
\hline LA CASA BLANCA & RURAL & 1 & 1 & - \\
\hline LA LOBERA & RURAL & 6 & 6 & \\
\hline EL RAMIRENO & RURAL & 28 & 11 & 17 \\
\hline LA TACHICA & RURAL & 2 & 2 & \\
\hline RANCHO ALEGRE & RURAL & 1 & 1 & - \\
\hline ORDENA DE RODOLFO & RURAL & 5 & 5 & - \\
\hline COLONIA NIÑOS HEROES & RURAL & 860 & 417 & 443 \\
\hline PALOS ALTOS & RURAL & 43 & 19 & 24 \\
\hline LA BENEFICIENCIA & RURAL & 2 & 2 & \\
\hline LAS FUENTES & RURAL & 6 & 6 & - \\
\hline LA HUERTA & RURAL & 20 & 10 & 10 \\
\hline TOTAL, HABITANTES & RURAL & 34199 & 16147 & 18052 \\
\hline
\end{tabular}

Fuente: Elaboración propia. Plan de Desarrollo Municipal 2012-2015. H. Ayuntamiento de Jiquilpan, Michoacá 
Tabla 6, Comunidades con Tenencia de Jiquilpan

\begin{tabular}{|l|c|}
\hline \multicolumn{2}{|c|}{ COMUNIDADES CON TENENCIA } \\
\hline TENENCIA & CABECERA MUNICIPAL \\
\hline SAN MARTIN TOTOLAN & \multirow{2}{*}{ JIQUILPAN DE JUAREZ } \\
\hline LOS REMEDIOS & \\
\hline FRANCISCO SARABIA & \\
\hline
\end{tabular}

Fuente: Elaboración propia. Plan de Desarrollo Municipal 2012-2015. H. Ayuntamiento de Jiquilpan, Michoacán

Tabla 7, Asentamientos irregulares de Jiquilpan

\begin{tabular}{|l|}
\hline \multicolumn{1}{|c|}{ ASENTAMIENTOS IRREGULARES DE JIQUILPAN } \\
\hline CARLOTA LOZA \\
COL. PALOS ALTOS \\
EL SAUCILLO \\
EL ZALATE \\
LA CALERA \\
LA CAÑADA \\
LA CAÑADA TOTOLÁN \\
LA HUANIMBAN \\
LAS ORTIGAS \\
LÁZARO CÁRDENAS \\
LOMA DORADA \\
LOMAS DEL PASTOR \\
LOMAS DEL PASTOR \\
LOMAS DEL PASTOR 2 \\
MEZQUITE DE BREÑA \\
PUERTA DE LLAVE \\
RANCHO ALEGRE \\
\hline
\end{tabular}

Fuente: Elaboración propia. Plan de Desarrollo Municipal 2012-2015. H. Ayuntamiento de Jiquilpan, Michoacán

Entre estos lugares se encuentra la mayor actividad comercial del municipio. También es un lugar de esparcimiento, especialmente la plaza principal y calles aledañas donde se encuentran cafeterías y restaurantes. Es en esta plaza donde tradicional se realiza la vuelta, paseando alrededor de ella y dejándose ver. Las personas mayores del pueblo todavía recuerdan cómo estas vueltas a la plaza eran realizadas por jóvenes del municipio 
con la idea de buscar pareja, y hasta el día de hoy la actividad se sigue reproduciendo. Entre los portales de la plaza, las cafeterías y restaurantes disponen sus equipales ${ }^{39}$ donde sirven bebidas y comida a sus clientes. Aunque los jóvenes siguen participando en la actividad de la plaza, es mucho más habitual encontrarlos en el Bosque Cuauhtémoc. Este Bosque, comúnmente conocido como el Bosque de Jiquilpan, pertenece a la familia Cárdenas, aunque está abierto al público. Se encuentra detrás del Estadio 18 de marzo y, con los años, se ha convertido en el centro de reunión de la población de la zona. Con una hermosa alameda y una extensión de 20 hectáreas es el lugar preferido para pasar las tardes de los fines de semana con la familia y los amigos, y cuando cae la noche se convierte en el lugar de recreo de la juventud de la región, acudiendo jóvenes de diferentes municipios a dar allí su particular vuelta subidos a los coches que llegan a congestionar el tráfico en el recinto. Si el bosque tiene tanto éxito el sábado por la noche es por el gran número de jóvenes en edad universitaria que se congregan en Jiquilpan. El municipio cubre todo el itinerario educativo desde preescolar hasta la educación superior donde destaca el Instituto Tecnológico con una matrícula de hasta 1.700 alumnos. También se reparte con su vecino Sahuayo la población universitaria de la Universidad de la Ciénaga, además de contar con dos unidades de investigación en ciencias sociales, el Centro Interdisciplinario de Investigación para el Desarrollo Integral Regional (CIIDIR) Michoacán, dependiente del Instituto Politécnico Nacional (IPN), y la Unidad Académica de Estudios Regionales (UAER) que pertenece a la Universidad Autónoma de México (UNAM). Todas ellas son de carácter público, atraen a estudiantes de todo el estado creando una población flotante de universitarios.

\footnotetext{
${ }^{39}$ Sillas artesanales mexicanas realizadas de cuero de cerdo y palo de rosa. Característica de Jalisco muchos bares y restaurantes de la región utilizan este mobiliario.
} 
El patrimonio arquitectónico e histórico del municipio, sumado a la relevancia institucional que sigue poseyendo, hizo posible que el 27 de noviembre de 2012 Jiquilpan fuese nombrado "Pueblo Mágico ${ }^{40 "}$ en una ceremonia realizada en el centro del municipio. Aunque no todos los jiquilpenses celebraron por igual el nombramiento, sí hubo un periodo de revaloración de la identidad colectiva, así como un nuevo interés por las costumbres y tradiciones. Esto llevo a una relectura de la Historia, intentando rescatar tradiciones y bailes ya en desuso, y la rehabilitación de edificios que se habían mantenido por décadas en situación de abandono.

Fotografía 8, Nombramiento de Pueblo Mágico

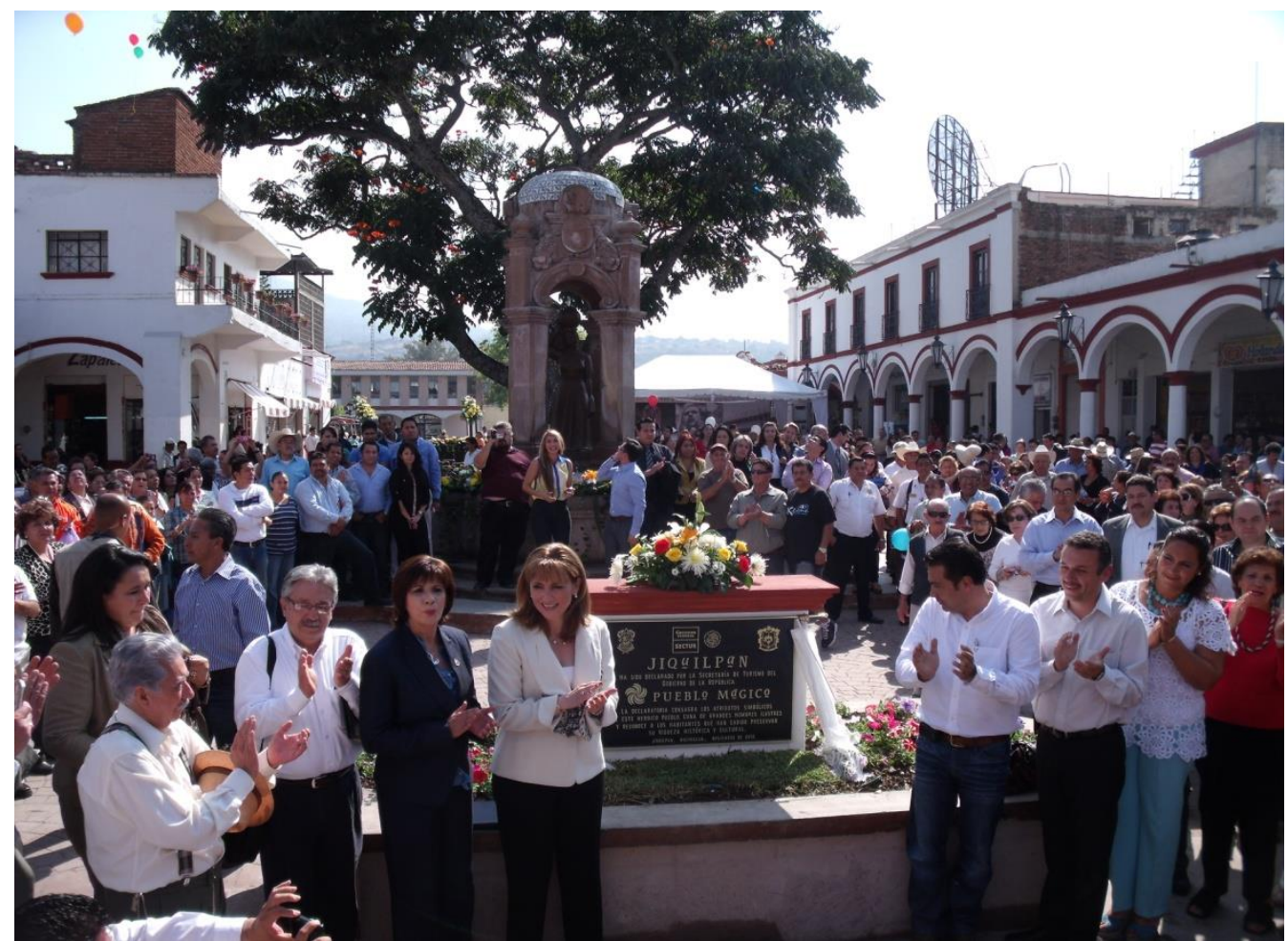

Fuente: Raquel Miranda. Año 2012. Jiquilpan

\footnotetext{
${ }^{40}$ El Programa Pueblos Mágicos es desarrollado por la Secretaria de Turismo (SECTUR) de México junto con diversas instancias gubernamentales creado en 2001. El reconocimiento de Pueblo Mágico ha sido otorgado a municipios de toda la geografía mexicana teniendo en cuenta cualidades como la influencia del pasado indígena, el legado del antiguo imperio español, la preservación de tradiciones seculares o ser un lugar donde se han producido importantes acontecimientos históricos. El programa Pueblos Mágicos tiene como objetivo estructurar una oferta turística complementaria hacia el interior del país y promocionar artesanías, festividades, tradiciones y gastronomía para lo que se destinan recursos estatales y municipales para la rehabilitación de edificios, desarrollo de infraestructuras y promoción turística y cultural.
} 
Fotografía 9, Nombramiento de Pueblo Mágico

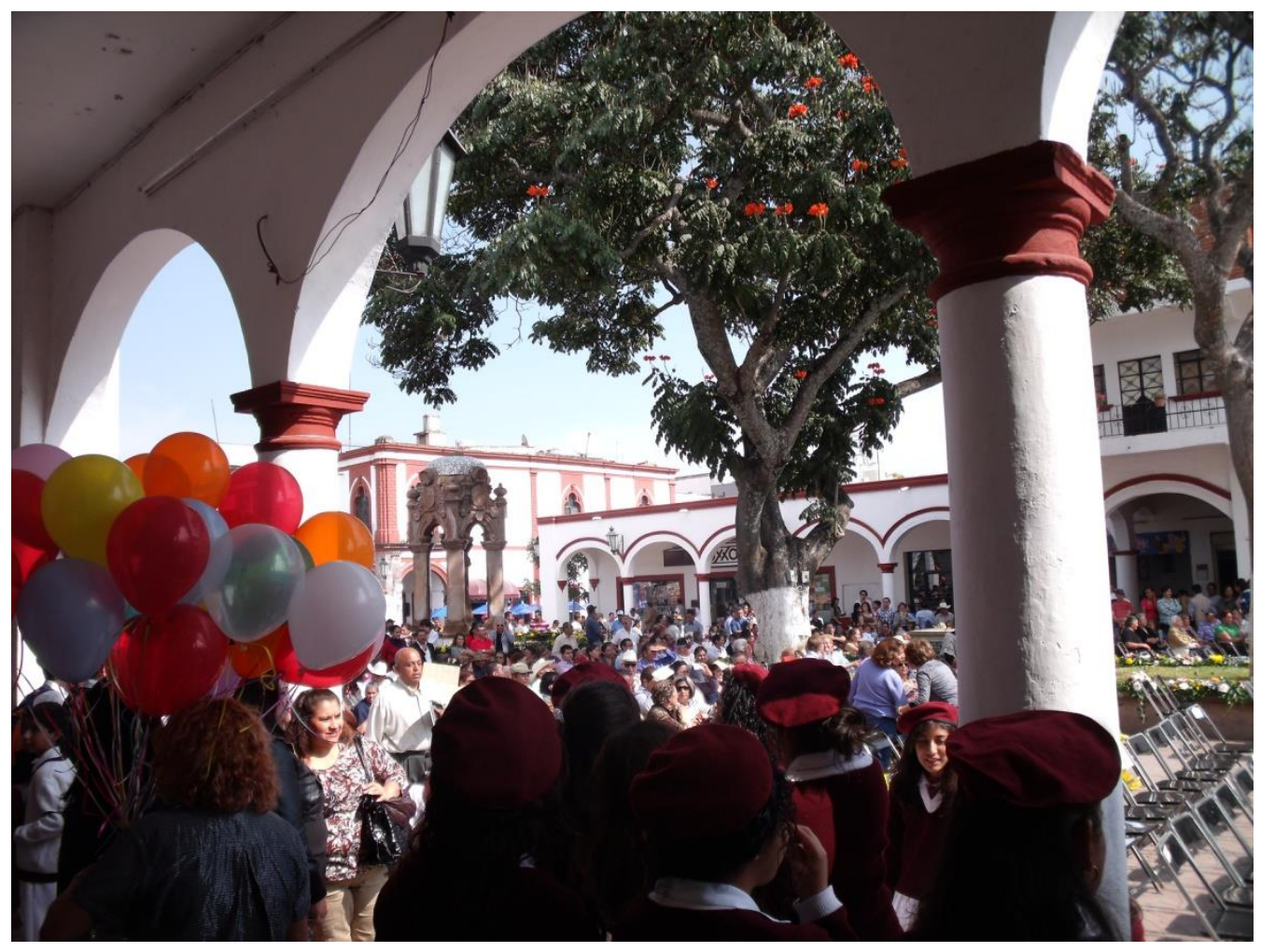

Fuente: Raquel Miranda. Año 2012. Jiquilpan

Durante los siguientes años a 2012, el municipio recibió una cantidad considerable de recursos para el mejoramiento de las calles del centro y el mejoramiento de fachadas y plazas. Este desembolso económico se destinó casi íntegramente para el centro del municipio y los lugares que eran considerados de interés turístico, por lo que el resto del municipio, así como las otras comunidades no experimentaron una mejora notable en el desarrollo. Aunque el programa tiene como finalidad el desarrollo económico del municipio a través de la promoción de las artesanías, festividades, tradiciones y gastronomía, en Jiquilpan, al igual que sucede en muchos Pueblos Mágicos de la geografía mexicana, el desarrollo se ha enfocado en generar patrimonio turístico que fomente las visitas nacionales e internacionales a través de una visión mercantilista del 
municipio que se transforma en un escenario de simulación histórica. La inseguridad y la violencia derivada del narcotráfico reducen significativamente el potencial turístico de la región.

Aunque Jiquilpan cuenta con un importante patrimonio arquitectónico e histórico, la falta de actividades que se puedan desarrollar en el municipio hace que muchos turistas hagan parada en el municipio durante unas pocas horas, sin pernoctar ni realizar un desembolso importante para el municipio. Otro de los factores que interfiere en el desarrollo turístico de Jiquilpan es fruto de la rivalidad entre Jiquilpan y su municipio más cercano, así como la percepción por parte de los ciudadanos jiquilpenses de que cualquier beneficio derivado del nombramiento de Pueblo Mágico debe mantenerse dentro de los límites municipales. Las asociaciones civiles que impulsaron el nombramiento y que posteriormente se ofrecieron al ayuntamiento para diseñar una estrategia turística para el municipio se mantuvieron reticentes a generar una promoción turística inclusiva con el resto de localidades sensibles de beneficiarse de la llegada de turistas. Así Sahuayo y Petatán ${ }^{41}$ y otros pueblos alrededor del Lago de Chapala no formaban parte de los planes con los que podemos mejorar la oferta turística.

\subsubsection{Sahuayo de Morelos}

El municipio de Sahuayo tiene una población de 72.841 habitantes ${ }^{42}$, con una edad media de 25 años. Tiene una extensión de $129 \mathrm{~km} 2$ en la que se encuentran 29 comunidades. El 86.1 \% de la población total del municipio se encuentra en la cabecera municipal. También existen en el municipio asentamientos irregulares.

\footnotetext{
${ }^{41}$ Municipio cercano a Jiquilpan donde se congregan todos los años entre noviembre y marzo un gran número de pelicanos borregones provenientes de Canadá y Estados Unidos por la migración anual.

${ }^{42}$ Fuente: Censo de Población y Vivienda 2010. INEGI
} 
Tabla 8, Principales comunidades de Sahuayo

\begin{tabular}{|c|c|c|c|c|}
\hline LOCALIDAD & TIPO & HABITANTES & HOMBRES & MUJERES \\
\hline SAHUAYO DE MORELOS & URBANA & 64431 & 31160 & 33271 \\
\hline EL AGUACATE (BARRANCA DEL AGUACATE) & RURAL & 112 & 51 & 61 \\
\hline LA BARRANCA (LA BARRANCA DE LA GLORIA) & RURAL & 14 & 6 & 8 \\
\hline $\begin{array}{lllll}\text { LAS GALLINAS } & \text { (EL POBLADO } & \text { DE } & \text { LAS } \\
\text { GALLINAS) } & & & & \\
\end{array}$ & RURAL & 118 & 60 & 58 \\
\hline EL GÜIRIO & RURAL & 227 & 116 & 111 \\
\hline LA PUNTITA & RURAL & 550 & 278 & 272 \\
\hline RINCÓN DE SAN ANDRÉS & RURAL & 705 & 342 & 363 \\
\hline TUNA MANZA & RURAL & 272 & 138 & 134 \\
\hline LA YERBABUENA & LOCALIDAD & 77 & 45 & 32 \\
\hline LA RAYA & RURAL & 40 & 19 & 21 \\
\hline LA FLOR DEL AGUA (EL MOLINO) & RURAL & 139 & 73 & 66 \\
\hline LA CHICHARRA & RURAL & 11 & * & * \\
\hline COLONIA CUAUHTÉMOC & LOCALIDAD & 522 & 262 & 260 \\
\hline EL AÑIL & RURAL & 25 & 16 & 9 \\
\hline LAS GALLINAS (LA HACIENDA) & RURAL & 12 & 5 & 7 \\
\hline LA CALZONUDA & RURAL & 135 & 69 & 66 \\
\hline BARRANCA DEL SOYATE & RURAL & 4 & $*$ & * \\
\hline EL MORAL & RURAL & 13 & 7 & 6 \\
\hline COLONIA INDEPENDENCIA (COYACHO) & LOCALIDAD & 473 & 233 & 240 \\
\hline LA CABAÑA & RURAL & 73 & 40 & 33 \\
\hline RANCHO ALEGRE & RURAL & 3 & $*$ & $*$ \\
\hline HUANIMBAN & RURAL & 5 & $*$ & $*$ \\
\hline KILÓMETRO 3.5 CARRETERA SAHUAYO & RURAL & 16 & 9 & 7 \\
\hline EL MONTE & RURAL & 14 & 8 & 6 \\
\hline $\begin{array}{l}\text { POTRERO HIGUERILLAS DE MARGARITO } \\
\text { (MILLONES) }\end{array}$ & RURAL & 4 & $*$ & $*$ \\
\hline COLONIA EL MOLINO (SALECIANO) & RURAL & 21 & 11 & 10 \\
\hline EL TENIENTE (LA ESPERANZA) & RURAL & 2 & $*$ & $*$ \\
\hline FRACCIONAMIENTO LOMAS DEL VALLE DOS & LOCALIDAD & 13 & 6 & 7 \\
\hline LOMAS DEL PEDREGAL & RURAL & 107 & 54 & 53 \\
\hline FRACCIONAMIENTO 18 DE MARZO & RURAL & 693 & 330 & 363 \\
\hline FRACCIONAMIENTO RANCHO DORADO & LOCALIDAD & 39 & 19 & 20 \\
\hline SAHUAYO (BALNEARIO) & LOCALIDAD & 2 & $*$ & $*$ \\
\hline FRACCIONAMIENTO LOMAS DEL BOSQUE & LOCALIDAD & 18 & 9 & 9 \\
\hline FRACCIONAMIENTO COLINAS UNIVERSIDAD & LOCALIDAD & 1152 & 544 & 608 \\
\hline FRACCIONAMIENTO SAN MIGUEL & LOCALIDAD & 2692 & 1319 & 1373 \\
\hline FLAMINGOS & LOCALIDAD & 107 & 59 & 48 \\
\hline
\end{tabular}

Fuente: Elaboración propia. Plan Municipal de Desarrollo 2012-2015. H. Ayuntamiento de Sahuayo. Michoacán 
Tabla 9, Asentamientos irregulares de Sahuayo

\begin{tabular}{|l|}
\hline \multicolumn{1}{|c|}{ ASENTAMIENTOS IRREGULARES SAHUAYO } \\
\hline LA MUDA \\
ENRIQUE MENDEZ 1 Y 2 \\
POLO \\
ADOBONEROS \\
LA PINERA \\
NIÑOS HEROES 2 \\
EL CAPULIN \\
GRIJALUA \\
LA BARRANQUILLA \\
JUAN PABLO II
\end{tabular}

Fuente: Elaboración propia. Plan Municipal de Desarrollo 2012-2015. H. Ayuntamiento de Sahuayo. Michoacán

Sahuayo es un municipio al que el comercio y el crecimiento de la población han otorgado el aspecto de una zona metropolitana. Aunque fuera de la cabecera municipal podamos encontrar espacios abiertos, la confluencia de edificaciones, calles estrechas con aceras angostas hacen que la percepción de la vida urbana sea bulliciosa y amontonada, como si se tratase de un fragmento de una ciudad más grande.

Sahuayo es atravesada de norte a sur por el Boulevard Lázaro Cárdenas. Esta vía es la continuación urbana de la Carretera Morelia- Guadalajara, que también atraviesa Jiquilpan bajo el nombre de Lázaro Cárdenas. A la mitad del Boulevard se encuentra la Presidencia Municipal frente al Instituto Sahuayense Marista, dos edificaciones levantadas en un lateral del Boulevard y que enmarcan el principio de la calle Constitución. Esta calle y sus adyacentes son la mayor zona comercial de toda la región. Al inicio de la calle, en la siguiente cuadra de la presidencia, se encuentra el Hotel Latino que entre finales de 2011 y 2012 fue donde se instalaron las fuerzas federales. Debido a la ausencia de un cuartel para dar alojamiento, y también por el punto estratégico que este hotel tiene en el centro del municipio, se ha convertido en un espacio improvisado donde 
la policía federal reside, patrulla y aparca sus vehículos. En la calle Constitución hay muy pocas casas, aunque su ausencia no significa la carencia de edificios. La falta de casas es reemplazada por un continuo número de lonjas, tiendas, grandes comercios y sucursales bancarias hasta llegar a la Plaza Principal Libertador Miguel Hidalgo.

\section{Fotografía 10, Calle Constitución}

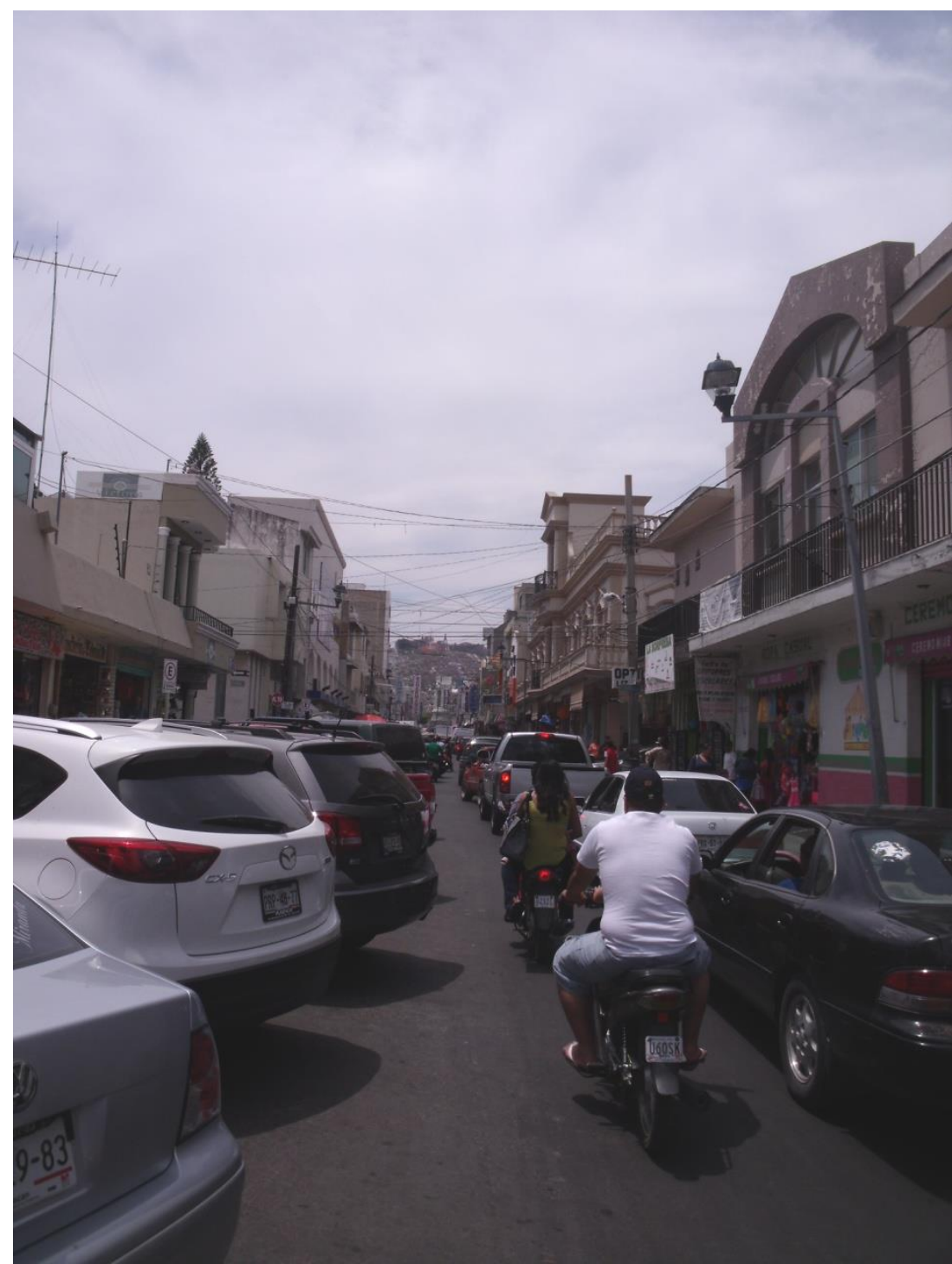

Fuente: Raquel Miranda. Año 2015, Sahuayo

La plaza tiene un kiosco de música en el centro y a uno de sus lados luce la escultura de un Tlahualil. En los portales de la plaza se instalan puestos de comida y vendedores de huaraches, una de las producciones artesanales más destacable de la 
localidad, tanto por el gran número de familias que se dedican a la fabricación del huarache $\mathrm{e}^{43}$ y calzado en general, como por la destreza en la fabricación y buena calidad del producto.

\section{Fotografía 11, Capilla de José Sánchez del Río}

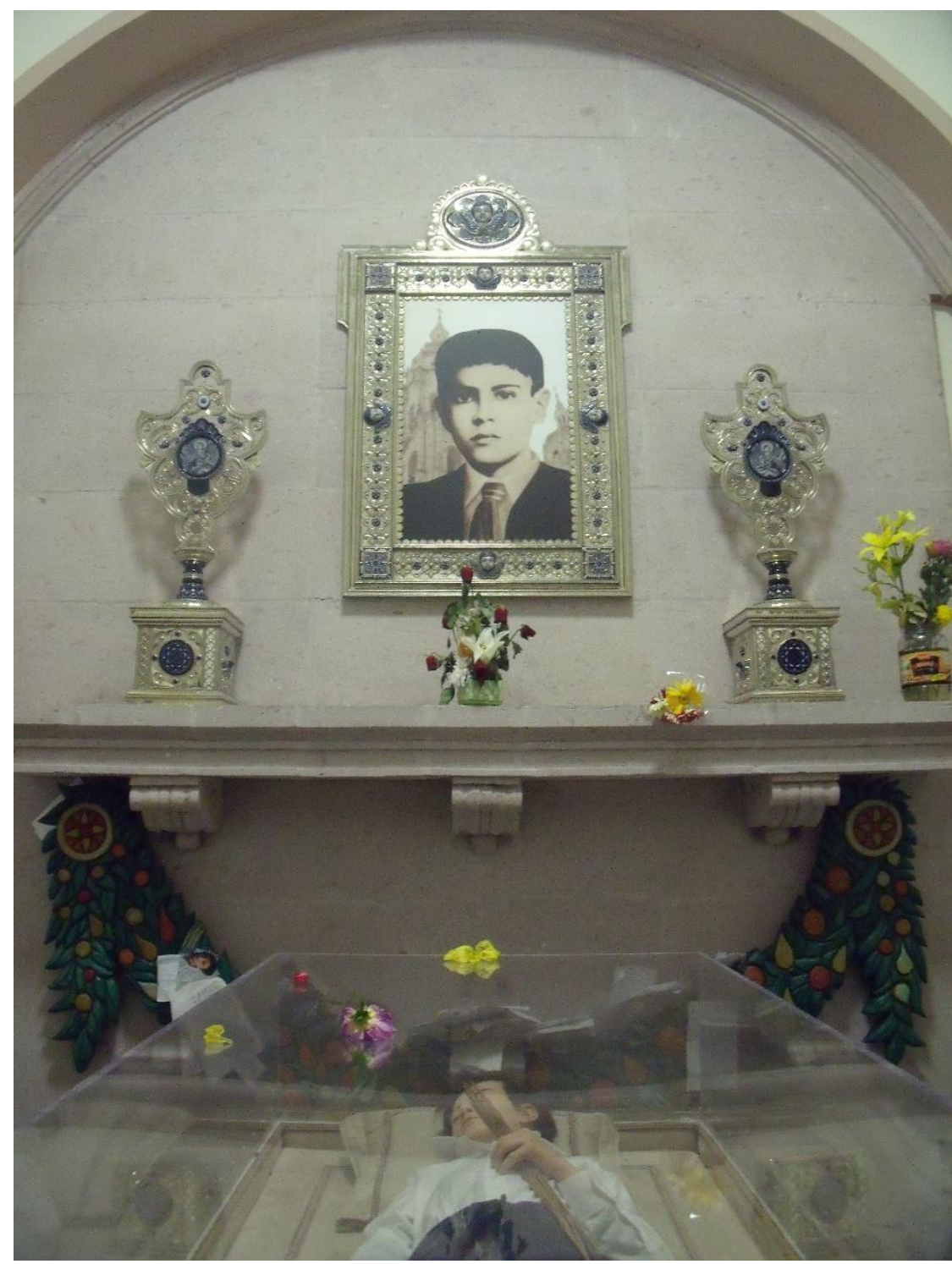

Fuente: Raquel Miranda: Año 2015, Sahuayo

\footnotetext{
${ }^{43}$ Nombre proveniente de la voz "Kwarachi" de la lengua purépecha que designa un tipo de sandalia hecha con tiras de cuero de ganado bovino, es un producto sincrético influido por el calzado de los frailes, especialmente de los franciscanos, y de los campesinos. Este calzado está asociado con la vida en el campo. Aunque su diseño original es sencillo, los productores de huarache en Sahuayo producen calzados con complejos trenzados y múltiples colores.
} 
En un lateral de la plaza, confluencia con la calle José María Morelos, se encuentra el templo principal de la localidad, la Parroquia de Santiago Apóstol, donde se encuentra la imagen de Santiago que sale en procesión todos los años durante su festividad. También en esta parroquia descansan los restos de Santo José Sánchez Del Rio.

A continuación, y en la misma calle, se encuentra el Mercado de Sahuayo, una de las zonas principales para la venta, compra y distribución de productos locales, especialmente de comestibles.

El municipio tiene un gran número de colonias y fraccionamientos, aunque es en la zona del centro donde está instalada gran parte de la actividad comercial. La arquitectura del municipio es muy variada, aunque las casas antiguas han dado paso a edificaciones habitacionales de varias plantas, o unifamiliares que poseen un estilo californiano. La influencia de la continuada migración hacia los Estados Unidos de América está presente en los edificios, pero también en la estética del propio municipio y de sus habitantes. En la calle Constitución hay comercios de huaraches y sombreros, pero también de ropa, maquillaje y casi cualquier cosa de importación. Entre los comerciantes de Sahuayo existe el dicho que afirma "Si no hay en Sahuayo, es que no existe", jactándose con ello de que la moda y las novedades llegan siempre a Sahuayo, incluso cuando todavía no se han comercializado.

Además de la zona comercial del centro del municipio, Sahuayo tiene un centro comercial ubicado en el Boulevard Lázaro Cárdenas en dirección a Jiquilpan. En este centro comercial, bautizado como Plaza Feria Sahuayo se encuentran los cines Cinepolis, únicos cines comerciales de la región, así como un hipermercado Aurrera y varias tiendas. Aunque la zona comercial no ha tenido el éxito esperado en un inicio, el cine, las 
cafeterías y el McDonald’s ubicados en el complejo lo han convertido en una zona de esparcimiento familiar y juvenil muy visitada durante los fines de semana.

Sahuayo cuenta con centros educativos de todos los niveles, tanto públicos como privados, sobre los que destaca la Universidad de la Ciénaga de Chapala por tener un gran número de matrículas y encontrarse en expansión. En el sector privado tienen sede la Univer, especializada en la formación de profesionales en diferentes campos y la Universidad Interamericana para el Desarrollo (UNID) con una filosofía institucional enfocada al humanismo cristiano. A diferencia de su vecino, ya sea por la falta de infraestructura educativa para satisfacer a toda la población, o por consideración por parte de la población sahuayense de que la educación privada es mejor, existen desde el nivel de preescolar hasta la universidad una oferta privada en la que parte de la población completa sus estudios. También hay que tener en cuenta que las familias que pueden permitirse el desembolso envían a sus hijos a estudiar a las universidades de Guadalajara y Morelia.

El municipio posee el aspecto de una ciudad de mediano tamaño, aunque las relaciones sociales y especialmente las interacciones entre sus habitantes demuestran que el entorno rural sobre el que se inscribe el municipio influye en la manera de ser y pensar de la ciudadanía. La influencia de Estados Unidos de América y el potencial económico y comercial de la ciudad no han hecho desaparecer las estructuras sociales derivadas de la ruralidad, sino más bien, han generado nuevas estructuras derivadas de las primeras, en las que la conciencia de clase y la posesión de capital social por parte de los individuos son las bases sobre las que se ha construido una nueva ciudadanía. 


\subsection{4. Área geográfica del trabajo de campo}

El desarrollo de la etnografía se ha desarrollado en el DDR 089, especialmente en los municipios de Jiquilpan y Sahuayo. Se ha tenido en cuenta el distrito porque las dos cabeceras municipales con mayor población poseen la mayoría de servicios, ya sea educativo, administrativo y social, como los bancarios. Por ello se consideró oportuno englobar el territorio al ser las comunidades rurales, los asentamientos irregulares y el resto de comunidades dependientes de estas dos ciudades. Además, las diferentes regiones del distrito son en algunos casos fracciones que pertenecieron en el pasado a alguna cabecera municipal, como en el caso de Venustiano Carranza que en 1935 fue creado fraccionando 238 km2 del municipio de Sahuayo (González, 1979: 180) y el caso similar ocurrido con San José de Gracia $^{44}$ y su separación de Jiquilpan en 1967 para conformar el municipio de Marcos Castellanos.

La fragmentación de los terrenos municipales de Sahuayo y Jiquilpan ha dado lugar a nuevos municipios que forman parte de lo que ahora se conoce como DDR089. La conformación del distrito y las todavía pendientes disputas territoriales ${ }^{45}$, especialmente el rechazo que presenta el municipio de Jiquilpan hacia Sahuayo, Venustiano Carranza, San José de Gracia (cabecera de Marcos Castellanos), entre otros (los jiquilpenses consideran que el desarrollo económico de las localidades vecinas ha supuesto una merma en el poderío histórico del municipio), hacen inviable un estudio etnográfico sin tener en cuenta las relaciones de poder, confrontación y rivalidad entre los municipios.

\footnotetext{
${ }^{44}$ Municipio originario de Luis González y González, historiador mexicano considerado el fundador de la microhistoria en México. Su obra, Pueblo en Vilo. Microhistoria de San José de Gracia (1968), se ha convertido en un referente internacional en los estudios históricos.

${ }^{45}$ Como el conflicto del Polígono Municipal que fue extraído de Jiquilpan por los Estudios más recientes del INEGI para ser otorgado a territorio sahuayense.
} 


\section{BLOQUE III. LOS SISTEMAS FINANCIEROS}

\section{PRESENTES EN LA CIÉNAGA DE CHAPALA, DDR 089}

Para entender la implantación y evolución de los diferentes sistemas financieros que operan en la región de la Ciénaga de Chapala, nos resulta necesario contextualizar estos cambios dentro de la política económica del país en las últimas décadas. La configuración de México como un país bajo las políticas neoliberales, dentro de un Tratado de Libre Comercio (TLCAN) pero interactuando como un país periférico han generado un sistema financiero estratificado donde gran parte de la población está excluida de su participación en estos sistemas. El proceso histórico que ha originado la situación actual se analizará a continuación con el fin de comprender la multitud de sistemas y cómo algunos han operado desde una función parasitaria.

La crisis de 1982 durante el gobierno de José López Portillo provocó la devaluación de la moneda lo que llevó a la cancelación de los créditos de la banca internacional a las instituciones bancarias mexicanas, y el consecuente colapso del sistema financiero. Ante esta situación, el presidente de la Republica decretó la expropiación de las instituciones bancarias ${ }^{46}$ y una inyección de capital de tres billones de pesos. La expropiación de la banca tuvo lugar el 1 de septiembre de 1982. Las instituciones privadas, mixtas y públicas que habían operado anteriormente pasaron a formar parte de un sistema financiero que estaba totalmente bajo el control del Estado. El sistema bancario funcionó bajo dos tipologías de entidades de crédito, las sociedades nacionales de crédito y las instituciones de crédito. Las primeras operarían bajo la Ley Reglamentaria del Servicio Público de Banca y Crédito; las segundas estarían reguladas

\footnotetext{
${ }^{46}$ Se calcula que la deuda de las instituciones bancarias ascendía a 25.000 millones de dólares
} 
por la Ley General de Instituciones de Crédito y Organizaciones Auxiliares, vigente desde 1941.

Durante los siguientes ocho años, el sistema bancario se estandarizó, aumentando el número de sucursales y emprendiendo la tarea de implantar el uso de tarjetas de crédito. También durante este periodo se comenzó a desarrollar una banca paralela que operaba mediante casas de bolsas, arrendadoras financieras, aseguradoras y sociedades de inversión. Posteriormente, cuando se inicia el proceso de reprivatización, serán los dueños de las entidades que operaban en la banca paralela quienes adquirirán los bancos.

La privatización se realizó durante la presidencia de Carlos Salinas de Gortari, dentro de su Programa de Modernización del Estado ${ }^{47}$ que pretendía preparar el sistema financiero mexicano para el comercio internacional y especialmente para el escenario económico que se presentaría con la entrada en vigor del TLCAN.

\subsection{Sistemas financieros formales}

La privatización parcial de las instituciones financieras, convirtiéndose en un sistema mixto, y la apertura al mercado internacional generaron la entrada de instituciones extranjeras, pero el proceso de nacionalización y la reducción necesaria de los costes de estas instituciones provocó el cierre de un gran número de sucursales, muchas de ellas en las zonas rurales. Cuando el sistema estaba estabilizado y se privatizó, muchas regiones de México no contaban con sucursales bancarias lo que provocaría la aparición de nuevas

\footnotetext{
${ }^{47}$ Como ya hemos avanzado en el capítulo en el que repasamos la trayectoria política del país, el gobierno de Salinas de Gortari implantó numerosas medidas que perseguían instaurar el neoliberalismo. Entre estas medidas se produjo un notable número de privatizaciones. La privatización de la banca se realizó gracias a la aprobación de la Ley de Instituciones de Crédito en Julio de 1990. Esta ley será revisada durante los años posteriores, sufriendo numerosos cambios. Aunque estos cambios se producen con asiduidad, en el año 2014 serán derogados varios artículos, otros reformados y secciones enteras adicionadas. Entre los cambios más notables estarán el cambio legislativo de las Sociedades Financieras de Objeto Múltiple (SOFOMES) y de la Banca para el desarrollo.
} 
modalidades financieras enfocadas a la población no urbana con pocos recursos. En 2011, según datos de la CNBV, México tenía 7'6 sucursales financieras por cada cien mil habitantes, mientras por ejemplo España contaba con 95'9. La CNVB advertía que la limitada presencia de entidades bancarias tenía como consecuencia el bajo nivel de ahorros y la dificultad de las familias para acceder a crédito. La limitada estructura del sistema bancario y la constitución de entidades bajo un régimen especial que podían operar sin control por parte de la CONDUSEF generó un sentimiento de desconfianza hacia las entidades bancarias que, sumado al rápido crecimiento del sector informal, desembocaría en la aparición de múltiples modalidades de sistemas financieros informales o Instituciones Microfinancieras (IMFs) dirigidas a pequeños ahorradores.

Las Instituciones Microfinancieras tendrán una rápida expansión durante la primera década del siglo XXI, apareciendo bajo diferentes figuras jurídicas: Sociedad Financiera de Objeto Múltiple (SOFOM), Sociedad Financiera de Objeto Limitado $\left(\mathrm{SOFOL}^{48}\right)$, Sociedad Financiera Popular (SOFIPO), Sociedad Financiera Comunitaria (SOFINCO) y Sociedad Cooperativa de Ahorro y Préstamo (SOCAP). Como señalan Cornejo y Galicia (2011), en México la mayoría de estas instituciones operaban sin estar registradas ante la Comisión Nacional Bancaria y de Valores (CNBV).

Durante 2007 varios cientos de empresas se inscribieron como SOFOM $^{49}$, convirtiéndose en la figura jurídica que mayor número de entidades aglutinaba. Bajo el término SOFOM se crearon entidades financieras que ofrecían crédito al consumo, como

\footnotetext{
${ }^{48}$ Figura jurídica creada en 1993 son entidades vigiladas directamente por el Estado. Esta figura ha sido utilizada por el Banco Compartamos y entidades especializadas en crédito hipotecario. En 2005 el Congreso aprobó la reforma que concedía a las sociedades comerciales la posibilidad de realizar las mismas operaciones que podían realizar las SOFOLES, creando la figura de las SOFOMES. Con la intención de aumentar el flujo financiero el Gobierno permitió que solo las entidades en propiedad de grupos financieros estuvieran por ley obligadas a la regulación. En julio de 2013 las SOFOL se desregularon, a excepción de aquellas vinculadas a bancos que pasaron a ser SOFOM.

49 Figura jurídica creada en 2007 para aglutinar a todas las empresas que quisieran otorgar créditos a cualquier sector de la economía, bajo la obligación de otorgar recursos propios.
} 
fue el caso de Bancoppel y Elektra. El rápido aumento de las SOFOMES género que para 2010 estuviesen registradas 1.704, de las cuales solo 23 estaban reguladas por la $\mathrm{CNBV}^{50}$. En 2011 el Gobierno Federal fortaleció el régimen de controles requeridos a estas entidades que se encontraban no reguladas, a través de disposiciones secundarias en materia de lavado de dinero. El 8 de mayo de 2013 el Ejecutivo Federal presentó una reforma integral del marco regulatorio de las SOFOMES con el fin de aumentar la regulación de las entidades y tener un mayor control de sus operaciones a través de la Comisión Nacional para la Protección y Defensa de Servicios Financieros (CONDUSEF). Para el año 2015, de las 3.012 SOFOM que operaban en México, solo 15 habían obtenido su renovación ante la CONDUSEF, trámite necesario para continuar funcionando. La CONDUSEF puso especial atención en la prevención del lavado de dinero, un problema que ya se había advertido durante años, señalado por organizaciones civiles y particulares.

\subsubsection{La Banca Múltiple}

Durante las entrevistas realizadas en la Ciénaga de Chapala, algunos habitantes que habían sido objeto de extorsión señalaban algunas de estas entidades como colaboradoras del crimen organizado. Las SOFOMES que operaban en la región desaparecieron progresivamente entre los años 2012 y 2015, manteniéndose únicamente aquellas ligadas a comercios y convirtiéndose en Instituciones de Banca Múltiple, como es el caso de BanCoppel, Banco Azteca y Banco Compartamos.

\footnotetext{
${ }^{50}$ Banco de México, 2010.
} 
Tabla 10, Sucursales de Banca Múltiple en DDR-089

\begin{tabular}{|c|c|c|c|}
\hline \multirow[b]{2}{*}{ BANAMEX } & JIQUILPAN & $\begin{array}{c}\text { MARCOS } \\
\text { CASTELLANOS }\end{array}$ & SAHUAYO \\
\hline & 1 & 0 & 1 \\
\hline BANCO AZTECA & 1 & 0 & 3 \\
\hline BANORTE & 0 & 0 & 1 \\
\hline BBVA & & & \\
\hline BANCOMER & 1 & 1 & 3 \\
\hline HSBC & 0 & 0 & 1 \\
\hline SANTANDER & 0 & 0 & 1 \\
\hline SCOTIABANK & 1 & 0 & 1 \\
\hline BANCOPPEL & 1 & 0 & 1 \\
\hline COMPARTAMOS & 0 & 0 & 1 \\
\hline TOTAL & 5 & 1 & 13 \\
\hline
\end{tabular}

Fuente: Elaboración propia. CNBV, 2014

De acuerdo con la CNBV, la región de la Ciénaga de Chapala posee en la actualidad una importante presencia de sucursales de la Banca Múltiple, en su mayoría presentes en la ciudad de Sahuayo.

Como apuntábamos anteriormente, el sistema financiero mexicano se convirtió durante el proceso de privatización en un sistema mixto, donde conviven las Instituciones de Banca Múltiple, de carácter privado, con una amplia infraestructura en el sistema financiero público. Estas entidades de carácter público operan bajo la figura jurídica de Banca de Desarrollo ${ }^{51}$. Aunque la Banca para el Desarrollo cubre muchos sectores y

\footnotetext{
${ }^{51}$ Las instituciones financieras de carácter público que se encuentran inscritas como bandos de desarrollo se encuentran:
} 
varios de ellos están enfocados a la población con bajos recursos, son Bancos de segundo piso $^{52}$. Además de las opciones de la Banca Múltiple y la Banca al Desarrollo existen numerosas secretarias e Institutos Nacionales que ofrecen créditos o ayudas. En el siguiente grafico podemos observar el uso que los habitantes de la Ciénaga de Chapala (se presentan solo los municipios pertenecientes al DDR 089) hicieron de la Banca al Desarrollo y secretarias e Institutos para obtener crédito hipotecario.

\footnotetext{
-Banobras- Banco Nacional de Obras y Servicios Públicos, su cometido es servir de instrumento para la financiación de servicios públicos como construcción de autopistas, infraestructura urbana y comunicaciones.

-Bancomext- Banco Nacional de Comercio Exterior, agencia de crédito para la exportación de bienes y servicios de la pequeña y mediana empresa.

-Banjercito, Banco Nacional del Ejército, Fuerza Aérea y Armada, ofrece créditos, pensiones e hipotecas a los trabajadores del ejército y fuerzas armadas. La sede en Michoacán se encuentra en Morelia

-Bansefi- Banco de Ahorro Nacional y Servicios Financieros, institución enfocada a incentivar el ahorro y la inclusión financiera de los mexicanos. Su creación en 2002 tuvo la finalidad de canalizar los apoyos económicos del Gobierno Federal para desarrollar el ahorro y crédito popular, con la intención de convertirse en la Caja de Ahorros más importante de México que opera en base a cubrir la demanda de segundo piso del sector. Aunque tuvo una rápida expansión, hacia 2012 se cerraron multitud de sucursales, como sucedió en el caso de Jiquilpan.

-Nafin- Nacional Financiera, institución especializada en otorgar recursos financieros y garantías como Banco Nacional y ser agente financiero del Gobierno Federal. Durante el gobierno de Miguel de la Madrid, Nafin apoyo el programa de saneamiento empresarial. Ya en el siglo XXI, la institución opera en los mercados financieros, especialmente en el mercado de cambio de divisa.

-SHF- Sociedad Hipotecaria Federal, la institución opera como banco de segundo piso, complementando el financiamiento para la obtención de vivienda. Trabaja junto con los bancos comerciales, una medida que ha posibilitado un gran número de hipotecas desde que entró en vigor en 2013.

${ }^{52} \mathrm{La}$ Banca de segundo piso es aquella institución financiera que no trata directamente con los usuarios, ya sea demandantes de crédito o ahorradores. Practica el papel de colaborador de los mismos, pero siempre es necesario que otra institución financiera realice los trámites y el seguimiento de los usuarios. Las instituciones financieras que sirven de puente entre la banca de segundo piso (figura común en las instituciones financieras públicas, Banca de Desarrollo) y los usuarios son aquellas que operan como instituciones financieras comerciales y privadas, con la figura jurídica de Banca Múltiple.
} 
Tabla 11, Créditos y Subsidios para vivienda por municipios y programas en el DDR-089

MUNICIPIO

TOTAL FONHAPO FOVISSSTE INFONAVIT SHF CONAVI SEDESOL BANJERCITO

BRISEÑAS

COJUMATLAN

JIQUILPAN

MARCOS CASTELLANOS

PAJACUARAN

SAHUAYO

VENUSTIANO

CARRANZA

VILLAMAR

\begin{tabular}{cccccccc}
\hline $\mathbf{1 1 2}$ & 100 & 2 & 4 & 6 & & & \\
\hline $\mathbf{2}$ & & & 1 & 1 & & & \\
\hline $\mathbf{3 4 5}$ & 50 & 19 & 80 & & 46 & 150 & \\
\hline $\mathbf{6}$ & 3 & 2 & 1 & & & 1 \\
\hline $\mathbf{3}$ & 13 & 86 & 3 & 23 & 150 & 100 \\
\hline $\mathbf{2 7 6}$ & 1 & 1 & & & & \\
\hline $\mathbf{1 0 2}$ & & & 1 & 2 & & & \\
\hline $\mathbf{1 4}$ & 5 & 8 & 1 & & & \\
\hline
\end{tabular}

Fuente: Elaboración propia. Programa Anual de Créditos y Subsidios para vivienda, 2013, CONAVI

\subsubsection{Tarjetas de crédito}

Las tarjetas de débito y crédito han experimentado durante la última década una gran expansión. Entre 2000 y 2011 las tarjetas de crédito se han convertido en el principal mecanismo de crédito al consumo en México ${ }^{53}$. Esta expansión se ha logrado ampliando los límites de crédito a clientes que ya contaban con tarjeta de crédito y emprendiendo campañas de captación de nuevos clientes. El gran número de nuevos clientes que han accedido a las tarjetas de crédito está justificado por la flexibilidad que ofrecen en cuanto al pago de la deuda y las posibilidades de retirar dinero o realizar pagos con ellas.

Desde los programas de desarrollo financiero y las estrategias bancarias de expansión, se ha utilizado el otorgamiento de tarjetas de crédito como un canal de inclusión financiera. Durante los dos primeros años de la investigación ${ }^{54}$, un gran número de jornaleros, trabajadores de comercios y en general los trabajadores asalariados, se

${ }^{53}$ Cuarto Reporte Nacional de Inclusión Financiera (RIF4).

54 2012-2013. 
congregaban cada quincena en los bancos para cobrar el salario a través de cheques. El acceso a disponer de una cuenta corriente en el banco era restrictivo para las personas de bajos ingresos ya que, en la mayoría de sucursales de la Banca Múltiple, la titularidad de cuenta estaba condicionada a un salario medio y los costes de mantenimiento de la cuenta eran elevados. La única manera de reducir los costes de mantenimiento de una cuenta bancaria era con el mantenimiento en la misma de un depósito que rondaba entre los 3000 y 5000 pesos dependiendo de la entidad. Debemos tener en cuenta que esa cantidad supone para el ciudadano medio una o dos quincenas de su salario, y en un país donde el salario mínimo ${ }^{55}$ y el costo de la cesta de la compra impiden el ahorro, el depósito era un condicionante que no permitía una fácil inclusión financiera de la población.

A partir de 2013, y en los años siguientes, se generalizará un nuevo producto bancario, dirigido a las empresas pero que resultará de una gran utilidad para alcanzar las metas de inclusión financiera: las cuentas bancarias (con su respectiva tarjeta de débito) generadas por las empresas para realizar el pago del salario del trabajador, usualmente llamadas las tarjetas de pago telemático. Las tarjetas telemáticas son solicitadas por la empresa contratadora al banco con el que opera. A través de los datos de contratación se genera una cuenta bancaria para el asalariado, con unos gastos mínimos de mantenimiento, en la cual la empresa ingresará el salario de forma quincenal o mensual. El asalariado recibirá, generalmente en su puesto de trabajo, la tarjeta con la que puede retirar su sueldo en oficinas o cajeros automáticos de la entidad.

La implantación del pago telemático logró que un gran número de trabajadores contase por primera vez con una cuenta bancaria. Los bancos vieron mejorar los índices

\footnotetext{
55 En enero de 2016 el salario mínimo se situaba en 73.4 pesos al día según la Secretaría de Trabajo y Previsión Social, mientras el precio del kilo de tortilla para el estado de Michoacán era de 12.14 pesos, dato del Sistema Nacional de Información e Integración de Mercados. Solo el consumo de tortilla abarca el $16.5 \%$ del salario diario.
} 
de ahorro de sus clientes, que empezaron a no retirar todo el salario y apartar parte del mismo en la cuenta vinculada al pago telemático. Y el Servicio de Administración Tributaria consiguió tener mayor control, tanto de los ingresos, como de todos los datos personales y fiscales de los trabajadores que ahora se encontraban vinculados a una cuenta bancaria.

La generalización del uso de las tarjetas telemáticas provocó que, cada quince días, se produjesen interminables colas en las entidades bancarias producidas por la masiva afluencia de aquellas personas que querían retirar el dinero de su quincena. El número de sucursales no era suficiente para el aumento de inclusión financiera producida por el uso de este nuevo método de pago, por lo que la saturación de las entidades en el día de cobro podía llegar a generar esperas de más de dos horas en ventanilla. Aunque las tarjetas de pago telemático estaban diseñadas para su uso en cajeros automáticos, muchas personas desconocían el funcionamiento de estas máquinas, ya sea por carencias en el conocimiento de las pantallas táctiles o por el bajo índice de alfabetización. En múltiples ocasiones, las mujeres que se disponían a retirar fondos del sueldo de sus maridos pedían ayuda para realizar la operación, bloqueando durante un tiempo la cola. Esta situación llevo a que muchos clientes optasen por retirar los fondos en las oficinas, lo que no solucionaba la situación, sino que solo la trasladaba al interior de la sucursal. El colapso de las sucursales durante los días de pago se convirtió en habitual y, aunque gracias a las tarjetas de pago telemático las personas disponían de una cuenta bancaria, desconocían la utilización de la misma, por lo que la inclusión financiera no provocó los efectos deseados en la población.

La posesión de una tarjeta telemática ofreció la oportunidad de conseguir una tarjeta de crédito dentro de la misma entidad a aquellas personas que disponían de un salario medio. De esta manera, el pago telemático es utilizado por la entidad bancaria 
como un primer paso de captación de clientes, ofreciendo a aquellos que tiene una nómica constante la posibilidad de obtener una tarjeta de crédito. El Buró de crédito ${ }^{56}$ ha revelado que la tarjeta de crédito bancaria es el punto de entrada más común en su base de datos de morosos, viendo como el aumento continuo de las deudas familiares está relacionado con la contratación de servicios financieros a través de estas tarjetas, de las que el consumidor desconoce los términos con los que operan.

Durante la investigación se observó este proceso de inclusión financiera y cómo las tarjetas telemáticas ofrecieron la oportunidad de acceso a programas de desarrollo gubernamentales (a través de la Banca al Desarrollo, secretarias e Instituciones). También se evidenció que este proceso de inclusión estaba provocando el sobreendeudamiento a través de la otorgación de tarjetas de crédito por parte de la Banca Múltiple. Aunque parte de la población participó y participa de este proceso de inclusión, también se advirtió que, pese a los esfuerzos de introducir a la población en el sistema financiero, parte de ella se mantenía cautelosa y prefería mantener parte de su actividad financiera fuera de los sistemas formales.

\subsubsection{La compra de bienes y servicios a través del pago fraccionado.}

\section{Bancoppel y Banco Azteca}

Ante la falta de financiamiento de la población, las empresas que vendían bienes de alto valor, como electrodomésticos, automóviles y tecnología tomaron la iniciativa de generar SOFOMES que permitiesen el financiamiento del consumo. Estas sociedades, en un inicio operando como SOFOMES y posteriormente como Banca Múltiple comenzaron con el financiamiento de productos que vendían en su establecimiento, pero en poco

\footnotetext{
${ }^{56}$ Empresa mexicana constituida como sociedad de información crediticia.
} 
tiempo también ofrecieron créditos externos a la posible compra. En la región de Chapala podemos encontrar dos de estos comercios, que tienen presencia en toda la República, Coppel y Elektra. En Jiquilpan los dos comercios se encuentran separados solo por unos metros, ubicados en la calle presidente Lázaro Cárdenas. En Sahuayo los comercios son de mayores proporciones, ubicados en la calle más comercial, calle Constitución. Estos comercios ofertan una amplia gama de productos. Coppel vende tecnología, electrodomésticos, muebles, ropa y calzado, publicando un folleto a nivel nacional donde anuncia sus productos y sus tipos de financiamiento. En el caso de Elektra, además de los electrodomésticos, tecnología y muebles, también ofrece la posibilidad de adquirir motos. Para los habitantes de la Ciénaga de Chapala la oferta para adquirir alguno de estos productos es muy limitada, por lo que se puede afirmar que existe un relativo monopolio en la venta de electrodomésticos y tecnología, como también sucede en otras zonas rurales del país. Los altos costes de estos productos los hacen objeto de requerir de alguna financiación, lo que llevó a la creación de instituciones financieras. En el caso de Coppel se creó Bancoppel en 2006 a nivel nacional, mientras Elektra tenía el Banco Azteca funcionando desde 2002.

Los dos comercios tienen un diseño similar a la hora de aprovechar el espacio. Poseen un espacio expositor para la mercancía donde los clientes pueden ver los productos. Este espacio se encuentra dividido por secciones que se reparten entre los empleados, estando cada uno de ellos especializado en una sección. Otra sección de la tienda presenta las características habituales de una sucursal bancaria en pequeña escala, hay un lugar donde los clientes pueden esperar su turno, ya sea sentado o de pie, ventanillas de atención brindadas y algunos despachos. Las sucursales, que operan desde hace poco como Banca Múltiple, se presentan como un servicio adicional a las tiendas, 
cuyo fin principal es el otorgar créditos para el consumo de bienes en su establecimiento (North, 1994).

En una entrevista concedida a CCNExpansión ${ }^{57}$, el presidente del Grupo Coppel, Agustín Coppel, señaló que la venta de teléfonos móviles era en la actualidad uno de los productos con mayor número de ventas. En relación al diseño de los comercios, y la preparación y disposición de los comerciales que trabajan en Coppel, Agustín reconoció que desde la directiva se perseguía la estandarización, tanto de productos como de servicios, intentando de este modo emular la efectividad de McDonald’s.

Banco Azteca y Grupo Elektra son parte de Grupo Salinas, teniendo en su poder medios de comunicación, telecomunicaciones ${ }^{58}$, negocios minoristas y servicios financieros. Elektra se ha convertido en la mayor cadena de electrodomésticos de Latinoamérica, estando presente en México, Estados Unidos, Guatemala, Honduras, Perú, Panamá y El Salvador.

Las dos tiendas departamentales con servicios financieros están teóricamente enfocadas al consumo del segmento $\mathrm{C}+{ }^{59}$, por ser los clientes considerados idóneos para los créditos de unos 3.000 pesos. Sin embargo, la realidad muestra que los servicios financieros ofertados por Coppel y Elektra cubren el vacío institucional que abarca a la población con menos recursos y al sector informal. La mayoría de los pagadores de "abonos chiquitos" suelen ser personas no bancarizadas, que acceden por primera vez a servicios financieros, o personas que realizan su actividad laboral en el sector informal y no pueden acceder a un crédito nómica ${ }^{60}$.

57 Entrevista realizada por Mónica Cruz el 2 de octubre de 2015.

${ }^{58}$ Televisión Azteca y las empresas de telecomunicación Totalplay y Enlace.

${ }^{59}$ Clase media alta mexicana.

${ }^{60}$ Prestamos vinculados únicamente al salario del trabajador. 
Estas dos compañías supieron tomar la iniciativa cuando hace décadas el microcrédito fue presentado como elemento indispensable para el éxito del desarrollo económico. Aunque en esos momentos el microcrédito, enfocado a la población de bajos recursos, se entendía como una política social sin fines de lucro que partía de ONG's y Programas gubernamentales, Coppel y Elektra enfocaron estos servicios financieros como una fuente de ganancias no explotadas. Estas ganancias eran posible porque la población con bajos recursos o excluida del sistema financiero de la Banca Múltiple pagan tasas de interés que la mayoría de la clase media consideraría usurarias. Estas condiciones abusivas hicieron que dentro del sistema financiero se conozcan estas entidades como "banca chatarra".

Las tasas de interés anuales varían entre el $50 \%$ y el $120 \%$, mientras en las instituciones sin fines de lucro el promedio mundial se sitúa en el 31\%. La diferencia es aún mayor cuando se compara con las tasas de interés de las tarjetas de crédito que se sitúa entre el $22 \%$ y $29 \%$ para aquellas personas con un mal historial crediticio. Coppel y Elektra, al tener como clientes una población que no suele tener otra opción de crédito ${ }^{61}$, puede cobrar a los clientes que carecen de crédito intereses abusivos. La estrategia que siguen estas dos entidades es remarcar los pagos semanales en lugar de las tasas a interés a largo plazo. Los pagos semanales sueles se muy bajos, pero lo que desconocen muchos de los clientes es que los intereses se cobran sobre la cantidad total prestada durante toda la vida del préstamo. La contratación del préstamo y el tiempo en el que se realizará el pago suele ser una de las actividades donde las entidades realizan mayores esfuerzos en formación de comerciales. En sus objetivos se encuentra vender a crédito para ganar más dinero, por lo que siempre persuaden al cliente que alargue el plazo el máximo tiempo posible, unas 104 semanas. Además de las tasas de interés sobre el préstamo, el pago se

\footnotetext{
${ }^{61}$ Posteriormente hablaremos del sistema financiero informal que sustituye o complementa esta opción.
} 
grava con un impuesto del $15 \%$ sobre los servicios financieros que, en muchos casos, no es informado a los clientes cuando contratan los servicios de financiación. La incapacidad de los clientes a cumplir con los pagos hace que se sume a la cantidad acordada intereses moratorios, pudiendo multiplicar el adeudo en pocos meses e inscribiendo al deudor en el buró de crédito durante años.

Durante la realización del trabajo de campo se recabó información del funcionamiento de estas entidades a través de clientes y trabajadores. En varios casos se comprobó que los créditos otorgados suelen estar vinculados a la compra de un producto del establecimiento, aunque existe la posibilidad de solicitar un crédito con pago en metálico para cubrir gastos externos al comercio.

Los requisitos necesarios para conseguir financiación varían notablemente dependiendo de la cantidad solicitada, siendo imprescindible en todos los casos la presentación de una identificación oficial del solicitante, su comprobante de domicilio y abonar en algunos casos un "enganche" de alrededor del 10\% de la cantidad total solicitada. A partir de estos documentos los requisitos pueden variar, desde avales de familiares o vecinos que deberán presentar también sus correspondientes identificaciones oficiales $^{62}$, comprobante de ingresos y comprobante de domicilio, o avalar el crédito a través de posesiones patrimoniales que pueden ser desde casas o terrenos a televisiones, refrigeradores, teléfonos móviles o muebles que en caso de impago serían vendidos en la sección de artículos usados del comercio ${ }^{63}$.

\footnotetext{
${ }^{62} \mathrm{Si}$ el solicitante no abona el pago del crédito, los avalistas estarán obligados a desembolsar la cantidad hasta liquidar la deuda, por lo que es complicado encontrar avalistas. En muchos casos, el exceso de confianza del avalista en la persona que le solicitó la ayuda ha llevado a fuertes disputas y conflictos.

${ }^{63}$ En el caso de avalar un crédito con bienes patrimoniales, la entidad opera de forma muy similar a una Casa de Empeño. En los comercios de Elektra, la compañía tiene una Casa de Empeño, PrestaPrenda, que se utiliza en el caso de solicitar un crédito en dinero en efectivo.
} 
La penalización por caer en mora, más allá de los intereses moratorios y la inscripción del deudor en el buró de crédito, activa un proceso de acoso. Según datos recabados en el campo, la entidad en muchas ocasiones vende la deuda a un despacho de cobranza que inicia un seguimiento continuo del deudor y sus avalistas a través de llamadas telefónicas y visitas a domicilio, en algunos casos con órdenes extrajudiciales de embargo que pretenden asustar a forzar la devolución del dinero más los intereses. Muchos deudores alegan que no entendieron los términos del contrato, se centraron en el pago semanal y no les advirtieron de la tasa de interés que se iba a aplicar a su préstamo. La entidad financiera considera que en caso de impago con la sustracción de los bienes que sirvieron de aval es suficiente para cubrir la deuda y considera que el préstamo esta pagado. La entidad colocará al deudor en una lista interna de morosos impidiendo que vuelva a solicitar un nuevo crédito, pero al considerar la deuda saldada el caso no formará parte de la tasa de incumplimiento de préstamos, que en el caso de Coppel y Elektra se sitúa por debajo del 2\% mientras la Banca Múltiple tiene un promedio de 5.3\% de tasa de morosidad en los préstamos al consumo (Epstein y Smith, 2007).

\subsubsection{Las Cajas Populares}

A la hora de solicitar un préstamo, los habitantes tienen otras opciones. Aparte de los sistemas informales de los que hablaremos más adelante, existen en la región varias Cajas Populares. El sector de las Cajas Populares nace con vocación de ayudar a obtener financiamiento a la población de bajos recursos, pero también para apoyar a la comunidad, independientemente de los ingresos, surgiendo de movimientos de carácter religioso y filantrópico. Las cooperativas de ahorro y préstamo, conocidas habitualmente como Cajas Populares, se definen como sociedades de capital variable en las cuales sus 
miembros se asocian para ahorrar en común y para obtener préstamos a un interés razonable.

Las actuales Cajas Populares tienen como referente histórico las Cajas Populares que a partir de 1954 se impulsaron desde el Secretariado Social Mexicano ${ }^{64}$. Una década después, las cajas populares habían experimentado una rápida expansión por el territorio mexicano lo que generó la creación de la Confederación Mexicana de Cajas Populares en 1964. Las Cajas Populares se desarrollaron sin contar con un marco legal que las regulase hasta 1991, cuando se aprobó un decreto con el que se reformo la Ley General de Organizaciones y Actividades Auxiliares del Crédito. La reforma supuso la desaparición de la mayoría de Cajas Populares o, en algunos casos, su paso hacia la informalidad. Debido a este fracaso a la hora de regular las Cajas, en 1994 una nueva Ley General de Sociedades Cooperativas (LGSC) reconoció que las cooperativas podían operar cualquier actividad económica lícita, incluido el ahorro y préstamo.

Aunque se reconoció la figura legal de las Sociedades Cooperativas de Ahorro y Préstamo (SCAP), la falta de normas administrativas para las mismas llevó a que la autorregulación fuese imprescindible. La figura de SCAP fue aprovechada por grupos empresariales privados para ingresar en el mercado de las finanzas populares, lo que llevó a una crisis del modelo que se evidenció con los múltiples casos de fraudes y desfalcos. Los escándalos relacionados con las Cajas Populares recibieron una amplia cobertura informativa que provocó una crisis de imagen que hasta hoy ha sido difícil de subsanar. La aprobación en 2001 de la Ley de Ahorro y Crédito Popular obligó a las cooperativas a operar bajo la premisa de que el interés único y principal debe ser la actividad económica, algo que coarta sus actividades ya que muchas de ellas también participan en

\footnotetext{
${ }^{64}$ Organismo de la Iglesia católica encargado de la pastoral social.
} 
actividades de educación financiera, apoyo social y, en el caso de las que están adscritas a iglesias, también actividades de carácter religioso.

En la actualidad, las cooperativas que están establecidas en la región de la Ciénaga de Chapala figuran dentro del marco legal de Sociedad Cooperativa (SC) de Ahorro y Préstamo (AP) de Responsabilidad Limitada (RL) ${ }^{65}$ de Capital Variable $(\mathrm{CV})^{66}$. En Jiquilpan está establecida Caja Popular Alianza, que tiene sucursales en gran parte del país. También se tuvo oportunidad de realizar entrevistas durante la investigación a personas que habían participado en la Caja La Palma que estuvo funcionando antes de 2014. En este caso, se recogieron en su mayoría quejas ya que la caja había sido un fracaso que había emprendido actividad judicial hacia varios clientes. En las entrevistas se señaló el carácter fraudulento con el que había operado.

En Sahuayo la presencia de Cajas Populares es más habitual, contando con tres sucursales de la anteriormente mencionada Caja Popular Alianza, además de Caja Popular Mexicana y Caja Morelia Valladolid, todas ellas con sucursales, a nivel nacional las primeras, y a nivel estatal la última. Además de las Cajas que poseen sucursales en Sahuayo, existen más cajas que son de carácter comunitario, entre ellas se encuentran la Caja Popular Sahuayo, Caja Popular del Sagrado Corazón y la Caja Popular Caballeros de Colon. Las dos últimas tienen un marcado carácter ideológico: la Caja Popular del Sagrado Corazón forma parte de la iglesia que lleva el mismo nombre, mientras la Caja Popular Caballeros de Colon realiza actividades a apoyo y desarrollo entre la comunidad católica. La existencia de varias cajas relacionadas con movimientos de carácter religioso evidenció cómo el pasado sinarquista del municipio de Sahuayo está todavía presente a

\footnotetext{
${ }^{65}$ La Responsabilidad de los socios se encuentra limitada por el monto de su aportación, por lo que no responden personalmente con su patrimonio por las deudas y obligaciones que haya podido contraer la cooperativa. El estatuto determina la forma y manera como se expresa la voluntad de los socios.

${ }^{66}$ Las siglas suelen aparecer de este modo: SC de AP de RL de CV.
} 
través de organizaciones y cajas populares que sirven como pilar para la actividad comunitaria $^{67}$.

Los participantes en estas Cajas Populares son en su mayoría personas excluidas del sistema financiero de la Banca Múltiple. Bajo esta premisa, las cajas operan como microfinancieras, enfocándose en personas de bajos recursos y el sector informal. El primer paso para optar a este tipo de sistemas financieros es formar parte del mismo inscribiéndose como socio de la cooperativa. En el caso de utilizar la entidad para el ahorro, la tasa de rendimiento suele oscilar entre el 0.5 y $4.5 \%$. Los escándalos que en el pasado posicionaron a las Cajas Populares en el punto de mira hicieron que desde la CONDUSEF se advirtiese que cualquier tasa de rendimiento que fuese por encima del 8\% debía encender las alarmas del cliente, ya que posiblemente fuese un fraude. En el caso de solicitar un préstamo, los intereses y el monto de la cantidad dependen del nivel de ahorro del socio. Cuanto mayor sea la cantidad solicitada en relación con el nivel de ahorro, mayor sea el interés aplicado al préstamo. El préstamo está condicionado al ahorro, pero también a las tasas que rara vez aumentan más del $24 \%$, un interés similar a entidades de la Banca Múltiple como HSBC y Bancomer. Los créditos siempre se otorgan en base a la capacidad económica y de endeudamiento del asociado, teniendo especial cuidado en que el asociado pueda devolver el préstamo.

Formadas como cooperativas enfocadas en la ayuda mutua, las Cajas Populares están formadas por personas que comparten un objetivo común, ahorrar en conjunto con el fin de ofrecer dentro de la asociación créditos competitivos para los socios. Los socios que conforman la cooperativa pueden retirar sus depósitos cuando ellos deseen (siempre que no los hayan presentado como garantía de algún préstamo), tienen voz y voto en la

\footnotetext{
${ }^{67}$ Para más información sobre las Cajas Populares y su actividad como cooperativas consultar Flores (2015)
} 
asamblea $^{68}$, y pueden proponer modificaciones, ampliaciones o matizaciones en los estatutos.

\subsubsection{Las Casas de Empeño}

Ante la imposibilidad de afrontar el pago de algún servicio o gastos, los habitantes de la Ciénaga de Chapala tienen como última opción el empeño de bienes para conseguir financiamiento. El recurso de las Casas de Empeño suele ser utilizado especialmente después de diciembre, en lo que se conoce la "cuesta de enero". Aunque las fiestas de Navidad suponen un gasto extra para las familias de muchos países, hay que tener en cuenta que en México esta festividad se prolonga en el tiempo en lo que se conoce como “el maratón Guadalupe-Reyes" que abarca desde el 1 de diciembre comenzando con las festividades de la Virgen de Guadalupe, Posadas, Navidad, Año Nuevo y la festividad de los Reyes Magos el 6 de enero. A este periodo de festividades hay que añadir las repercusiones del gasto extra que muchas familias realizan durante "El Buen Fin"69 que genera deudas a través de los créditos contraídos en noviembre.

Las casas de empeño ofrecen una solución rápida a la carencia de efectivo a través del empeño de algún bien. Según la Asociación Nacional de Casas de Empeño (ANACE), casi el $60 \%$ de los clientes de esta modalidad de financiamiento son mujeres, trabajadoras

\footnotetext{
${ }^{68}$ Dependiendo de la cooperativa, la presencia del socio en la asamblea, así como la votación puede ser opcional u obligatoria.

${ }^{69}$ Durante un fin de semana del mes de noviembre, y con ocasión del inicio de la campaña navideña, los comercios mexicanos ofrecen promociones de productos y servicios para fomentar el comercio. Durante estos días se pueden conseguir descuentos sobre el precio de productos y ofertas de créditos al consumo (en establecimientos como Coppel y Elektra) con menores intereses. La celebración del Buen Fin está inspirada en el Black Friday (Viernes Negro) estadounidense, siendo promovida por el Consejo Coordinador Empresarial en asociación con el Gobierno Federal, organizaciones comerciales del sector privado e instituciones bancarias. La primera edición del Buen Fin se celebró en 2011, habiéndose celebrado cada año ininterrumpidamente desde entonces. Aunque los objetivos iniciales del Buen Fin es incentivar al consumo a través de descuentos, en la actualidad los descuentos no son significativos para el consumidor, enfocándose más en las opciones de compra a crédito. Al incentivar el consumo a través de la opción del crédito, esta celebración ha sido criticada desde diferentes sectores como un incentivo al sobreendeudamiento.
} 
domésticas en su hogar, que tienen en muchos casos como única opción empeñar bienes. Aunque existen casas de empeño especializadas en ciertas mercancías, el bien empeñado más común en casi todas ellas suele ser alhajas, especialmente de oro, rondando una tasa del $80 \%$. El otro $20 \%$ son electrodomésticos, maquinaria o herramientas, aparatos electrónicos y automóviles. Siendo el empeño en muchos casos la única opción a la que pueden recurrir familias con bajos recursos, el destino del monto obtenido va destinado a cubrir gastos como el pago de servicios (electricidad, gas o teléfono), servicios médicos o pagos escolares.

El préstamo medio solicitado en las Casas de Empeño suele oscilar entre los 1.000 y 1.500 pesos, debido a que el préstamo depende del valor del bien empeñado y el plazo de devolución del crédito. El crédito prendario llega a alcanzar del 50 al $80 \%$ del valor total del bien empeñado dependiendo de la casa de empeño, ya que las condiciones del crédito varían notablemente dependiendo del establecimiento donde se realice. Entre la variedad de Casas de Empeño, la ANACE señala que, a nivel nacional, podemos encontrar grandes diferencias, tanto en el monto asignado a un bien, como en las tasas de interés. En relación con las tasas de interés aplicadas al préstamo, estas se sitúan desde el 42\% del Nacional Monte de Piedad hasta alcanzar más del 250\% en entidades privadas como Prendamex. La entidad que mayor tasa de interés anual aplica al empeño, Monte de la Republica, alcanzo en 2015 una tasa de $371.7 \%^{70}$. El plazo para realizar el pago del crédito prendario varía notablemente, pudiendo ser desde una semana a 18 meses dependiendo del bien empeñado y la cantidad solicitada. También existe la opción de realizar el pago a través de modalidades semanales, quincenales o mensuales. El crédito

\footnotetext{
${ }^{70}$ Datos administrados por CONDUSEF.
} 
prendario, los intereses aplicados y los gastos totales varían notablemente dependiendo del plazo de reintegro que se estipule en el contrato de empeño.

En la región de la Ciénaga de Chapala existen numerosas casas de empeño, algunas con una vida operacional relativamente corta (de unos pocos años) y otras afianzadas en la comunidad. Durante el tiempo de investigación (2012-2016) se presenció el establecimiento y desaparición de múltiples casas de empeño, siendo el periodo de 2012-2013 cuando mayor número de casas empeño aparecieron. Las Casas de Empeño tiene una amplia presencia en la región a lo que hay que añadir otros tipos de establecimiento que ofertan la posibilidad de empeño como joyerías (donde existe la posibilidad de empeñar oro) y centros cambiarios (que permiten el empeño de oro, monedas antiguas y plata). También Banco Azteca, dependiente de Elektra, ofrece la oportunidad de conseguir financiamiento a través de Prestaprenda.

El Jiquilpan existen o existieron durante el periodo de investigación un número reducido de Casas de Empeño entre las que se encontraban Casa Mazatlán, Montecash, La Casa, Casa de Empeño Jiquilpan, Prestamas y Monte Pio Líbano. Todas ellas se ubicaban en la zona centro de la ciudad repartidas entre las calles presidente Lázaro Cárdenas, Profesor Fajardo y Diego José Abad. El limitado número de Casas de Empeño en Jiquilpan estaba condicionado según algunos informantes con el mayor protagonismo que tiene Sahuayo en el comercio y actividad económica, aunque algunos informantes matizaron que conocían personas de Jiquilpan que preferían acudir a una Casa de Empeño de Sahuayo para evitar "la pena"71 de que un vecino los viese en esos apuros económicos.

En el municipio de Sahuayo la presencia de Casas de Empeño es mayor, tanto en número como en créditos prendarios, existiendo un gran número de centros cambiarios y

\footnotetext{
${ }^{71}$ Expresión coloquial que hace referencia a la vergüenza.
} 
joyerías que también ofertan esta opción. Entre ellas destacan por su volumen de negocio Casa Mazatlán, PrestaMex, Mundo Divisas, Empeño Fácil, Monte Pio Líbano, Alternativas Efectivas del Bajío, Servicios Don Vasco y Primesal, ubicadas en su mayoría en calle Constitución, el final de la calle Guadalupe Victoria y especialmente en las calles contiguas al mercado de abastos, como la calle Ignacio Zaragoza.

Debido a la fluctuación en las tasas de interés anual y el valor de la prenda, es imposible presentar una media que pueda abarcar a la mayoría de Casas de Empeño de la región. También hay que tener en cuenta que, aunque están obligadas por ley a hacer público el Costo Anual Total (CAT) que engloba todos los gastos involucrados en el préstamo, conseguir este dato resultó imposible en muchos casos, por lo que se desistió en el intento.

El proceso que debe seguir la persona ${ }^{72}$ que decide empeñar un bien con intención de conseguir un crédito prendario inicia con la presentación de una identificación oficial y la prenda (para su evaluación). El establecimiento, una vez evaluada la prenda, informa al solicitante de financiamiento del monto del préstamo y, si el solicitante está de acuerdo con el valor evaluado y los términos, se firmará el contrato con el que el solicitante recibirá el boleto de empeño ${ }^{73}$ y el dinero en efectivo.

Además del dinero en efectivo recibido por el empeño, hay que sumar a la cantidad solicitada para la devolución de la prenda el pago de los intereses (que han podido ser informados por la Casa de Empeño con carácter semanal o mensual), el cobro de almacenaje (que puede ser muy alto en el caso de bienes de grandes proporciones como automóviles o electrodomésticos), el seguro contra robo y en el caso de que la Casa de

\footnotetext{
${ }^{72}$ Denominada pignorante.

${ }^{73}$ En contrato suele aparecer en la parte trasera del propio boleto de empeño. En el contrato deben aparecer los datos relacionados con la prenda depositada, el CAT y las condiciones de recuperación (plazo e importe a pagar) así como otros gastos añadidos.
} 
Empeño esté regulada, el pago del Impuesto de Valor Añadido (IVA). También hay que tener en cuenta que el plazo para saldar la deuda puede variar considerablemente y, dependiendo del bien empeñado, el plazo puede sufrir modificaciones. En el caso del empeño de objetos de oro, el plazo puede alargarse o incluso permitir refrendos ${ }^{74}$ que aseguren que el bien no va a ser vendido. El aumento del plazo y la firma de nuevos contratos sobre un bien empeñado son habituales entre objetos de valor sentimental como joyas familiares o alianzas matrimoniales. Durante el trabajo de campo se encontraron varios casos en los que se había alargado el plazo de devolución porque el bien empeñado poseía más valor sentimental que monetario lo que llevo al endeudamiento de varios informantes por la necesidad que tenían que recuperar la prenda.

\subsection{Sistemas Financieros Informales}

Los sistemas financieros que operan en la informalidad escapan de los cálculos de la finanza oficial, siendo interpretados de múltiples formas. Desde los países desarrollados y, especialmente, desde los organismos internacionales, se han presentado este tipo de créditos como un recurso marginal, ligado a la pobreza y la marginalidad en el que el factor principal que lleva a las personas a la utilización de estos sistemas es la incapacidad de rebasar el mínimo nivel de subsistencia.

Este enfoque ha propiciado las políticas para el desarrollo y el auge de los microcréditos por parte de ONG's. Para los organismos oficiales, la alternativa a los microcréditos era la pobreza extrema, la usura y la violencia. Las políticas emprendidas por los gobiernos de las naciones que en mayor proporción tenían población que utilizaba este tipo de financiamiento no tomaron esta vía paternalista, sino que achacaron el modelo

\footnotetext{
${ }^{74}$ Renovaciones del contrato, ampliación del plazo con el aumento del dinero estipulado a devolver.
} 
informal a una falta de educación financiera en el que la inversión se centró en facilitar el acceso a sistemas financieros formales y legislar con la intención de flexibilizar el sistema bancario y financiero. Como ya hemos visto, esta fue la metodología utilizada por el Gobierno de México para facilitar la inclusión financiera, creó múltiples tipologías de entidad financiera, realizó múltiples reformas en las leyes que regulaban el sistema de crédito, y favoreció la implantación en el país de un sistema financiero socialmente estratificado.

Durante la década de 1990, desde la economía y la antropología hubo múltiples intentos que perseguían presentar las diferentes modalidades de sistemas financieros informales desde la perspectiva de los usuarios (Chamoux, Dehouve, Gouy-Gilbert y Pepin 1993; Espinosa y Villarreal 1999; Linck, 1982; Mansell-Carstens 1995; Villarreal 1997). Estos trabajos, enfocados en los créditos informales en territorio mexicano, definían un nuevo campo de estudio, que ya había sido estudiado con anterioridad desde la antropología, aunque ahora se inscribían en un nuevo contexto con la implantación del sistema neoliberal, las reformas en el sistema financiero mexicano, y el aumento del sector informal en todo el país. A través de estos trabajos se acuñaron diferentes términos para denominar este tipo de finanzas, desde las "finanzas populares" de Mansell-Carstens (1995) o el "crédito invisible" de Chamoux (1993).

El crédito invisible requiere, para funcionar, no solo de relaciones personales, individualizadas, como se dice a menudo, sino también de reglas impersonales y anónimas. Así pues, no es la individualización lo que lo diferencia del crédito oficial sino su nivel de regulación que es antes que todo local (Chamoux, 1993: 209). 
Siguiendo las palabras de Chamoux, no resultaría del todo lógico denominar a este tipo de créditos como no regulados, ya que la falta de regulación por parte de leyes federales no significa que carezcan de una regulación creada en el ámbito local. Bouman y Horpes (1994: 3) definen el ratio de acción de los sistemas financieros informales al hablar de "paisaje financiero" en donde es imprescindible atender a la diversidad regional, las relaciones y cambios históricos para contextualizar tanto el uso como el método de operar de estos sistemas. El paisaje financiero debe englobar las normas, acciones y procesos internos que configuran las transacciones entre ahorradores, solicitantes de crédito y prestamistas.

Los sistemas financieros informales que en esta investigación se presentan son una variedad de estrategias para solventar el ahorro y el crédito sin recurrir al sector formal de la economía. Por ello, se han presentado bajo el título de sistemas financieros alternativos, al ofrecer una alternativa, independientemente del nivel económico del usuario, intentando de este modo despojar a estos sistemas de convencionalismos que sugieren si operan únicamente para los trabajados informales, el ámbito urbano marginal o exclusivamente utilizado por mujeres trabajadoras domésticas no remuneradas en el hogar.

\subsubsection{Los apartados. La modalidad informal del pago fraccionado}

El método del apartado en los pequeños comercios guarda ciertas similitudes con el pago fraccionado de comercios como Coppel y Elektra, ya que ambas modalidades de comercios buscan facilitar la compra de sus productos y facilitar el consumo a través de posibilitar que el pago se realice en pequeñas cantidades durante un periodo alargado en el tiempo. Más allá de las similitudes, el apartado posee otros fines, principios y modos de proceder, tanto en el pago, como en el caso de que la deuda no sea saldada. 
El apartado es un acuerdo, por lo general verbal, aunque en algunas ocasiones se puede solicitar la firma de un recibo, que se realiza dentro de la informalidad. Su mecanismo consiste en "apartar", retirar de la venta un producto o servicio ofrecido por el comerciante. Aquí se presentan varias opciones en las que la confiabilidad del comprador y su capital social ${ }^{75}$ son los factores principales que pueden hacer que el apartado les permita llevarse el producto a su casa, o disfrutar del servicio, sin abonar todavía la cantidad, abonar parte de él a modo de fianza, o tener que esperar hasta abonar un porcentaje del valor total.

Al carecer de soporte legal, cualquier problema o duda sobre su funcionamiento entre las partes, como la decisión del comerciante de ofrecerlo o negarlo, pasan por una evaluación subjetiva de la confiabilidad de la persona a la que se le va a permitir acceder a este tipo de financiamiento. Si el comerciante no conoce suficiente a la persona, el elemento que decide su participación o exclusión está vinculado al capital social que esa persona tenga en la comunidad, o en su defecto, las personas de su entorno más directo, como familias o amigos, que juegan el papel de avalistas poniendo en juego su propio capital social.

El desembolso del valor total se realizará durante los días o semanas siguientes, siendo el plazo acordado con el comerciante. Al tratarse de un sistema financiero informal que depende para su funcionamiento de la confiabilidad y el capital social, las personas intentar saldar sus deudas con prontitud, siempre que eso es posible.

A través del apartado se financia el consumo de bienes y servicios que vende el comercio en el que se practica este financiamiento. En el caso de la Ciénaga de Chapala,

\footnotetext{
${ }^{75}$ Por decisión propia he considerado oportuno realizar la diferenciación entre confiabilidad y capital social. Esta decisión está sustentada en las observaciones de campo que posteriormente se relatan, en las que la confiabilidad puede ser independiente del capital social y viceversa.
} 
los comercios que ofertan esta modalidad de crédito son en su mayoría pequeños comercios de ropa, zapatos, maquillaje y joyas. Aunque se encuentran también ejemplos en comercios de útiles escolares, maquinaria y herramientas, aquellos productos que están ligados a la moda se presentan como más susceptibles de facilitar el apartado. El deseo de poseer los últimos productos relacionados con la apariencia física, ya sea en hombres o mujeres, se convierte en el motor de los apartados. La moda juega un papel importante en el funcionamiento de los apartados por las cualidades que ella misma posee como:

la imitación de un modelo dado que proporciona así satisfacción a la necesidad de apoyo social; conduce al individuo al mismo camino por el que todos transitan y facilita una pauta general que hace de la conducta de cada uno un mero ejemplo de ella. Pero no menos satisfacción da a la necesidad de distinguirse, a la tendencia a la diferenciación, a contrastar y destacarse (Simmel, 1988: 28).

Aunque se puedan encontrar compras realizadas a través del sistema de los apartados que no tienen vinculación directa con mercancías percibidas como condicionadas por la moda, en estos casos el sistema de financiamiento se parece más a un "fiado" 76 , semejante al que se produce en las tiendas de abarrotes. A diferencia del “fiado", los apartados no son artículos de primera necesidad, sino mercancías capaces de marcar un estatus, de simular una ostentación.

El pago de la deuda carece de suplementos como intereses o impuestos y, al tratarse de un sistema financiero informal, la amonestación por impago tiene sus consecuencias en el factor que permitió acceder a este tipo de financiamiento, el capital

\footnotetext{
76 Se denomina "fiado" a la compra realizada en la que no se puede pagar la cantidad en el momento de la compra, de tal modo que el comerciante confía en el pago futuro. Esta modalidad se puede aplicar a múltiples productos, aunque suele estar presente en mercancías de primera necesidad, como los productos de la cesta de la compra, o productos y servicios dependientes de la actividad laboral del comprador.
} 
social. El daño al capital social del deudor se produce a través de los llamados "carteles de malas pagas". Estos carteles son colocados en los escaparates o lugares más visibles de los comercios, indicando nombre y apellidos de los deudores, e incluso señas para su identificación más concreta como apodos o el nombre de la familia extensa a la que pertenece el moroso. Con la publicación de los datos se pretende avergonzar al deudor y hacer pública su deuda a la comunidad, intentando con ello que la presión social de la comunidad sea lo suficientemente efectiva como para que el deudor salde su préstamo. Los carteles de malas pagas han trascendido hasta las redes sociales, y los vendedores que promocionan sus artículos a través de ellas (utilizando para ellos redes como Facebook) también hacen público por esta vía quiénes son sus deudores.

\section{Fotografía 12, Cartel de Malas Pagas}

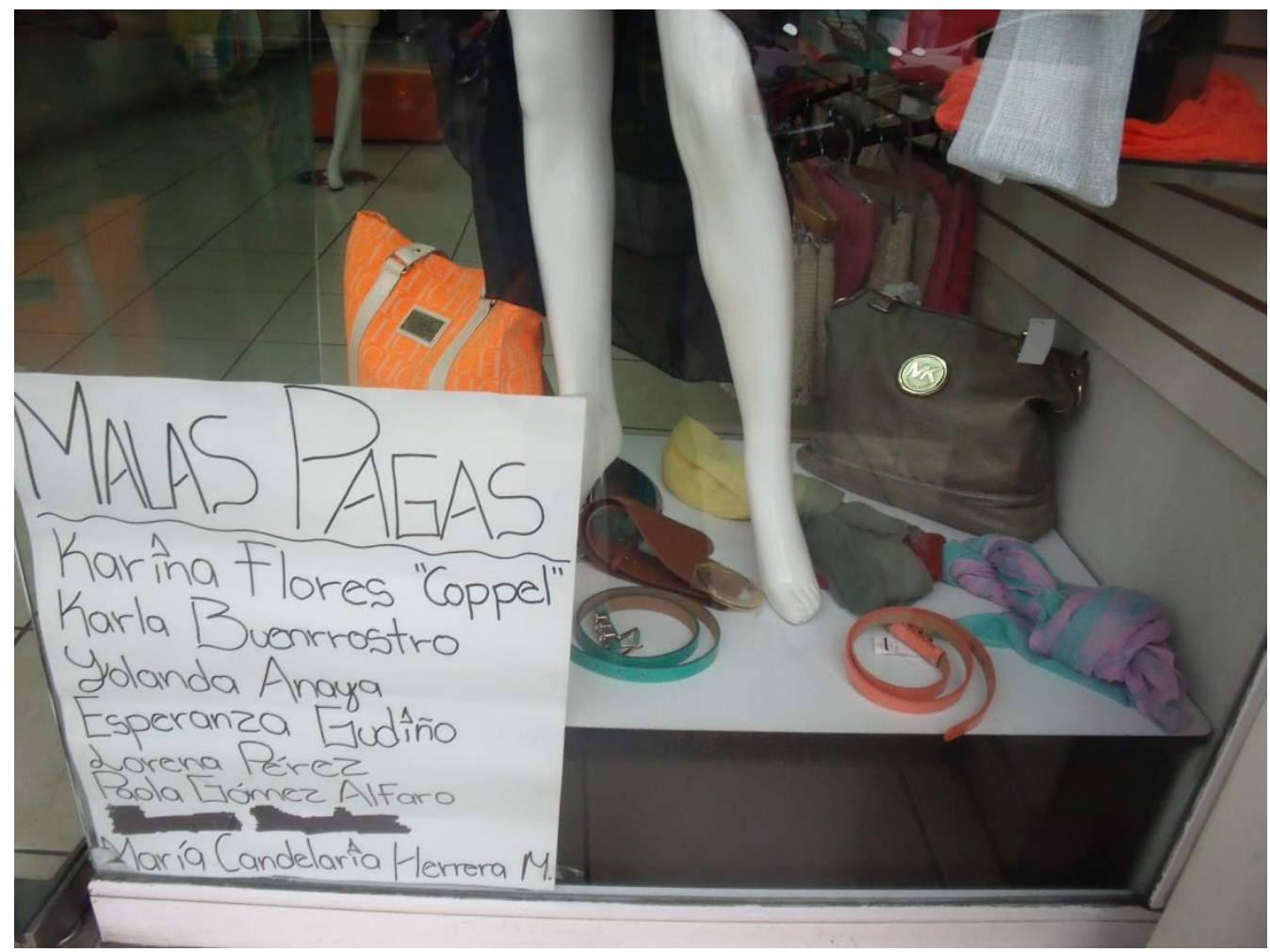

Fuente: Raquel Miranda. Año 2014, Sahuayo 


\subsubsection{Las kermeses}

Aunque las kermeses no pueden ser consideradas como un sistema financiero informal por sí mismo, realizaremos un breve resumen de su funcionamiento ya que, durante la etnografía, se documentaron algunas de ellas y se advirtió que la participación en estas fiestas es, en muchos casos, necesaria para el acceso a ciertos sistemas financieros informales, principalmente las tandas de las que hablaremos más adelante. Las kermeses son pequeñas celebraciones que se realizan, en un origen, durante festividades religiosas relacionadas con parroquias o pequeños municipios. También son un recurso utilizado por escuelas para recaudar fondos para causas benéficas. En la actualidad se producen kermeses residenciales, ocupacionales y familiares. Los motivos recaudatorios que persiguen las kermeses varían notablemente, desde realizar un fondo para una festividad posterior (como fiestas de 15 años, comuniones y bodas), hasta financiar viajes ${ }^{77} \mathrm{o}$ estudios.

La kermés es organizada de manera individual o grupal tanto por hombres como mujeres. Existen números tipologías de kermés, aunque las más comunes son en las que se ofrece comida y bebida, convirtiéndose en una reunión social a la que se asiste por invitación, aunque cualquier persona suele ser bienvenida siempre que acepte participar en la recolecta. Existen diferentes formas de participar. Los participantes que mantienen lazos más cercanos al organizador o destinatario del kermes suelen aportar mayor cantidad de dinero, ofreciéndoselo de manera informal como un regalo. En el caso de contrario, se abona la comida o bebida consumida (también se puede aumentar esa cantidad si el participante lo desea). El funcionamiento de esta reunión social posee una mecánica similar a las festividades relacionadas con la celebración de los sacramentos,

\footnotetext{
${ }^{77}$ En varias ocasiones, la realización de una kermés estaba destinada a financiar un viaje a los Estados Unidos para alguien de la comunidad, con la esperanza de que esa persona pudiese trabajar en el norte.
} 
especialmente con las bodas, en las que los invitados abonan una cantidad que guarda relación con el gasto realizado por los organizadores (generalmente los padres de los novios), o cuando parientes cercanos, amigos y compadres realizan un desembolso mayor considerando como una obligación el velar por el bienestar de la pareja.

En la Ciénaga de Chapala, DDR 089, la celebración de estas reuniones se realiza con motivo de viajes migratorios y para financiar futuras festividades. Durante la asistencia a varias de ellas, pude observar cómo estas reuniones pueden ser consideradas como un rito de paso para la participación posterior en otros sistemas financieros informales, especialmente aquellas de carácter colectivo como las tandas. La participación en una kermes hace posible el reconocimiento social que a su vez permite la generación de los lazos sociales necesarios para formar parte de un sistema financiero informal comunitario.

\subsubsection{Las tandas}

Las tandas, como popularmente se conoce a las Asociaciones Rotativas de Crédito (ARC), han sido abordadas por la antropología económica en múltiples ocasiones. Podemos encontrar el despegue de los estudios de la tanda durante las décadas de 1960 y 70, coincidiendo con la segunda etapa del debate entre formalistas y sustantivistas. Entre la bibliografía desarrollada durante este periodo encontramos investigaciones enfocadas a describir las funciones de estas prácticas económicas (Adler Lomnitz, 1977; Anderson, 1966; Ardener, 1964; Gamble, 1944; Geertz, 1962, Kerry, 1976; Kurtz y Showman, 1978). La aparición en la antropología de estas investigaciones también supuso un cuestionamiento de cuáles deberían ser los métodos y técnicas para realizar una etnografía sobre ellos, como analizó Ardener (1964) en la publicación "The Comparative Study of Rotating Credit Associations". 
Muchos de estos estudios centraron su atención en considerar a las tandas como sistemas que posibilitaban el desarrollo de la economía, entendiendo que funcionaban como un sistema intermedio entre la exclusión financiera y la participación en el sistema formal de la economía (Adler Lomnitz, 1977; Geertz, 1962; Light, 1972; Morton, 1978; Wu, 1974). Podemos considerar que el trabajo de Geertz es el precursor de la ideación de las ARC como elemento desarrollista. En su trabajo, presenta las tandas como prácticas que se originan durante "el giro de una sociedad agraria tradicionalista a una de flujo comercial creciente" (1962: 260). Las tandas serían estudiadas durante este periodo como una práctica de transición entre el mundo rural campesino y la implantación de sistemas bancarios formales, explicando su existencia como un proceso modernizador.

Entre la variedad de ARC estudiadas durante este periodo, destaca la diversidad de regiones donde se presenta este método. Light (1972) fue uno de los que presentó estudios de las tandas en Asia. En China estos créditos rotativos, denominados Hiu, forman parte del sistema económico tradicional, teniendo una antigüedad de más de 800 años. Esta modalidad china de las tandas se utiliza para la organización de festividades que, a través de una colecta con todos los miembros de la asociación, se financian los gastos derivados de la celebración posterior. En cada una de las celebraciones se sortea la cantidad recaudada durante la fiesta. El ganador del sorteo recibe todo el dinero y está obligado a realizar la siguiente fiesta en la que se repetirá el proceso. Las personas que ya fueron ganadores del sorteo con anterioridad y, por tanto, recibieron el dinero para costear la fiesta, no participan en los sorteos siguientes. Este tipo de tanda tiene la característica de permitir acceder a crédito ya que, entre el momento en el que se recibe el dinero, y aquel en el que se desembolsa el coste la fiesta, suele ser de un mes. Aunque los participantes no adquieren el ahorro de la cantidad invertida, sí pueden asegurarse disfrutar de una serie de fiestas durante el periodo de tiempo que dure la rotación hasta 
completar a todos los participantes en la asociación. Light presentó esta modalidad de ARC con dos variantes más, la primera en la que el sorteo del próximo organizador se sustituía por una serie de apuestas, una cantidad de dinero que se ofertaba para conseguir ser el siguiente organizador, y una segunda variante en la que el siguiente organizador era seleccionado a través de una subasta de la cantidad recaudada.

Otros ejemplos de créditos rotativos asiáticos fueron documentados en Japón donde existen variantes que se diferencian por la duración y el número de participantes. Aunque se desconoce si las modalidades japonesas son de influencia china o al contrario, en Japón existen variantes más cercanas a las que en la actualidad se presentan en México. Entre ellas, el tanomoshi se cree que ha existido en Japón desde el siglo XI. Cada miembro de la asociación contribuye con una suma fijada de antemano a intervalos regulares durante el periodo de tiempo necesario para que participante reciba en su turno la cantidad total de su inversión. De esta manera, en cada turno, uno de los miembros recibe de manera íntegra toda la recaudación, y este proceso se repite hasta que todos los miembros reciban esa cantidad. Durante el siglo XX, con la creación de sistemas financieros regulados por el Estado y la aparición de la Seguridad Social, este método de ahorro y crédito fue reemplazado. El Ko es la variedad menos común, aunque todavía se practica en comunidades con fuertes lazos sociales. Los participantes pueden ser cualquier persona de la comunidad, sin necesidad de que estén emparentados, por lo que los miembros suelen ser muy numerosos, entre 20 a 50. Las cantidades desembolsadas por cada individuo no varían notablemente del resto de tandas, pero al ser tantos miembros la cantidad recibida asciende considerablemente, lo que provoca que la duración de un ciclo completo pueda llegar hasta los 20 años.

Existen otros ejemplos de créditos rotativos en Asia, por lo que se considera que su origen se sitúa en este continente. La implantación de sistemas financieros formales y 
el acceso a ellos por parte de un gran porcentaje de la población, llevó a estas modalidades a casi desaparecer, pero se mantuvieron vigentes entre la población asiática que migró a los Estados Unidos. Ante la imposibilidad de obtener financiamiento en un nuevo país, estas modalidades tradicionales de financiamiento se practicaron entre la población migrante permitiendo que la comunidad alcanzase las metas económicas a través del financiamiento interno. Light destacó en su investigación de la población de inmigrantes asiáticos en los Estados Unidos que las ARC jugaban un papel importante en la capitalización de las comunidades de inmigrantes, destacando cómo la confianza que los participantes tenían en su comunidad era el elemento imprescindible para su supervivencia (Light, 1984; Light y Bonacich, 1988).

En contraposición a esta idealización de la tanda como practica de transición, Ardener (1964) expone que, aunque es posible encontrar estas asociaciones en sociedades que se encuentran en dicha transición, no podemos afirmar que esta sea la norma general, ya que también se producen estas asociaciones en otros contextos. En consecuencia, el análisis de Geertz está limitado a un contexto concreto, pero la utilización de este tipo de financiamiento abarca un complejo entramado de relaciones, contextos y tipologías que se presentaran en las siguientes décadas.

Las primeras investigaciones que mencionan el uso de tandas por parte de la población mexicana se remontan a la década de 1960 en los estudios de Oscar Lewis (1961; 1965). Estas versiones de las tandas fueron encontradas en la Ciudad de México, pero el análisis que realiza el autor de las mismas es muy limitado, por lo que desconocemos gran parte de la información. Sin embargo, años después, Kurtz (1973) informaría de la existencia de cundías $^{78}$ (versiones de las tandas) entre los mexicanos

\footnotetext{
${ }^{78}$ Nombres que reciben las tandas en Los Ángeles.
} 
inmigrantes de San Isidro, California y Tijuana. Estos primeros estudios mostrarían la aparición de las asociaciones de crédito rotativo en las grandes ciudades y en las comunidades mexicanas de Estados Unidos. Aunque es difícil trazar el origen y expansión de las tandas en América Latina, el trabajo de Kurtz es utilizado como referencia para afirmar que las comunidades asiáticas en Estados Unidos llevaron este sistema, que fue imitado por el resto de comunidades migrantes, especialmente en la región de California. Los inmigrantes mexicanos expandieron la utilización de las tandas al interior de México, primero a las grandes ciudades, como Ciudad de México y posteriormente en otras regiones del país.

Esta versión de la expansión de las asociaciones rotativas de crédito no es compartida por todos los investigadores, ya que muchos defienden que las tandas son instituciones económicas características de México. Larissa Adler Lomnitz (1975), defensora de esta idea, presenta su investigación en Cerrada del Cóndor, Ciudad de México, exponiendo el funcionamiento de la tanda.

La tanda es una especie de 'club', generalmente de cuatro a diez miembros, quienes contribuyen con cuotas de dinero a un fondo común. Por ejemplo, en una tanda mensual de seis miembros, cada miembro entrega mensualmente cien pesos a la tanda. Esta cantidad se entrega cada mes por turno a uno de los miembros, el turno se fijaba de una vez por todas, mediante sorteo. De esta manera, el participante en la tanda obtiene, cada sexto mes, una suma de quinientos pesos (1975: 241). 
La distribución geográfica de las tandas muestra que se encuentran más habitualmente en zonas urbanas y zonas periféricas de las zonas metropolitanas de México y sur de Estados Unidos. La presencia en zonas como la Ciénaga de Chapala se debe a la influencia cultural que la tradición migrante de la región ha tenido durante el siglo XX, exportando parte de sus conocimientos de sus regiones de origen.

En la investigación de Kurtz y Showman (1978: 67), los autores distinguen dos tipos de tandas, diferenciándose entre ellas por la utilización esporádica de la asociación o su instauración como asociación permanente.

Las tandas regulares (organizadas por una sola persona sobre una base repetitiva) se producen en comunidades donde los lazos sociales conforman una especie de cemento cultural (Elster, 1992) que genera confianza. En este tipo de tandas, la organización puede pasar a modo de herencia, de tal manera que la asociación se constituye como un elemento de la comunidad.

Las tandas episódicas o pequeñas se constituyen para alcanzar una meta a corto plazo. La contribución de cada miembro y el número de miembros son mucho menores, ya que los objetivos marcados se pretenden alcanzar en un plazo no demasiado extenso. Una vez finalizada la rotación completa de la tanda, la asociación desaparece, pudiéndose conformar en el futuro para alcanzar otra meta sin ser necesario que todos sus componentes anteriores vuelvan a participar y permitiendo la participación de nuevos miembros.

Aunque en esta investigación se abordan las tandas dentro de la característica de sistemas financieros informales, cabe mencionar que existen tandas formales y algunas que operan entre la formalidad e informalidad. 
Las tandas informales son asociaciones que dependen de la confianza para su funcionamiento y del capital social de cada individuo para su participación. Se encuentran en contextos residenciales, laborales o en comunidades con lazos sociales fuertes, como en zonas rurales. El organizador debe ser una persona que, por su capital social, pueda ser considerado una persona de confianza para llevar a cabo la contabilidad. Es común que la persona encargada de la tanda conozca a cada participante, seleccione los componentes de la asociación en base a su capital social, y mantenga contacto con ellos regularmente. En México es habitual que la figura del organizador sea ocupada por una mujer de media edad a la que se considere de una reputación intachable y ejerza una figura maternal sobre los participantes. Comúnmente se suele utilizar el término de "la señora de la tanda" o "la doña de la tanda" para referirse a esta figura.

Las tandas intermedias se presentan generalmente en ambientes laborales donde la tanda tiene un carácter informal entre empleados. El organizador suele ser la persona encargada de la contaduría de la empresa que realiza esta función informalmente.

Las tandas formales pueden ser llevadas a cabo por mutualistas comercializadoras o cooperativas de ahorro. También se realizaron asociación de crédito en la Banca de Desarrollo, como por ejemplo el Banco Compartamos.

Es habitual que la participación en una tanda no exija que los participantes compartan los mismos propósitos, salvo el caso de tandas informales episódicas en las que los participantes pueden organizarse para un objetivo común. En el caso de las tandas especializadas, Vélez-Ibáñez (1993) hace mención a la existencia de este tipo de asociaciones en el centro de México.

Las tandas especializadas se conforman en torno a un objetivo común que todos los participantes comparten. Este tipo de tandas suele contar con un amplio número de 
miembros, por lo que el periodo que necesita la asociación para completar la rotación es bastante amplio. Entre los objetivos de este tipo de asociaciones, los más comunes son la adquisición de viviendas o automóviles. Se documentaron las tandas de Volkswagen en Puebla $^{79}$ o las tandas de Datsun ${ }^{80}$. También existen ejemplos de cooperativas grupales de ahorros en la prisión de Lecumberri, donde las vaquitas (nombre de este tipo de cooperativas) eran organizadas con la finalidad de comprar marihuana dentro de la prisión. A diferencia de la tanda, la vaquita no obliga a que cada participante colabore con la misma cantidad de dinero, por lo que el reparto de la mercancía se realiza de manera proporcional a lo aportado.

También se encuentran ejemplos de tandas especializadas entre sectores de clase media y alta, como las tandas enfocadas a la compra de útiles escolares, de ropa, o las tandas de cumpleaños.

Entre la variedad de tandas que se pueden producir, existe una característica que condiciona de manera notable el funcionamiento interno de la misma. La motivación del organizador marca una pauta de funcionamiento entre los participantes que genera las variedades conocidas como "con número muerto" o "sin número muerto", también calificadas como tandas vivas o muertas.

La tanda viva o sin número muerto es aquella en la que el organizador participa en igualdad de condiciones a las de cualquier participante en la organización. Las expectativas son recíprocas entre los miembros de la asociación, dado que el organizador contribuye en la tanda y posee un turno como los demás.

\footnotetext{
79 En el Estado de Puebla se encuentra la fábrica principal de Volkswagen.

${ }^{80}$ Marca de coches perteneciente a la empresa Nissan que comercializó algunos modelos muy populares en México en las décadas de 1970-80.
} 
La tanda muerta o con número muerto está formada por una asociación desigual, en la que el organizador no participa de la rotación, recibiendo una cantidad estipulada por su actividad independiente de la tanda.

Dicha diferenciación aparece indudable para los participantes por la congruencia entre dicho significado y la simetría de las ARC en sí misma. Esto es, una tanda viva está viva porque equilibra equitativamente todo el esfuerzo, la credibilidad, las relaciones, la emoción, el sacrificio, la inversión y el dinero difícilmente ganado que constituyen las contribuciones individuales. El medio de intercambio es la prueba cierta e intangible de todos estos elementos encaminados hacia la construcción de un universo social simétrico. La tanda muerta por otra parte, esta desequilibrada, es asimétrica y, en último análisis indeterminada, fuera del control de los participantes. No es solo que la tanda se encuentre controlada exclusivamente por el organizador, sino que la amistad (el compañerismo), que es la base de determinación, también está muerta. (Vélez-Ibáñez, 1993: 83).

El no cumplimiento de la obligación con la asociación genera el rechazo social de esa persona en muchas actividades sociales no necesariamente relacionadas con la asociación, generando un desgaste del capital social. Al tener una obligación con todas las personas que intervienen en la asociación, el incumplimiento puede generar una acción en cadena en muchas facetas de la vida diaria, ya que el resto de participantes, decepcionados por dicho incumplimiento, no apoyarán en la comunidad al deudor. 
Durante el trabajo de campo en la Ciénaga de Chapala, DDR 089, se tuvo oportunidad de presenciar la creación y desarrollo de diferentes variedades de ARC. Algunas de ellas mostraron modificaciones en cuanto a las variantes de este capítulo que posteriormente se señalarán. En cuanto a las motivaciones individuales de los participantes y colectivas como asociación se expondrán la diversidad de objetivos que se persiguen con las mismas. Por último, cabe mencionar que el carácter rotativo de este tipo de asociaciones permite que los resultados sean diferentes dependiendo del turno ocupado por el participante ya que "los primeros en recibirlo obtienen un préstamo, el cual pagan a lo largo de los plazos establecidos. Los últimos, en cambio, ahorran, pues al final del ciclo reciben una cantidad que equivale nominalmente al total de todas sus aportaciones" (Campos, 1998: 199).

\subsubsection{Los prestamistas locales}

El préstamo informal a través de prestamistas suele ser uno de últimos recursos utilizados junto con las casas de empeño. Es habitual que los prestamistas formen parte de la comunidad o sean originarios de ella. El interés aplicado a este tipo de préstamos varía notablemente, dependiendo de la relación que tenga el solicitante de crédito con el prestamista. En casos de amistad o parentesco, el interés se mantiene bajo o incluso nulo, pero cuando la relación entre ambos no es muy cercana, los intereses pueden aumentar considerablemente. El tiempo acordado para la restitución del dinero también varía. Para la persona que presta dinero, la garantía de devolución se puede inscribir en diferentes modalidades, desde solicitar otras personas que avalen al solicitante, el empeño de un objeto de valor, o escrituras de propiedad. Al tratarse de un financiamiento informal no existe ningún contrato que establezca los términos de la relación, manteniéndose la palabra como contrato verbal. 
Entre los casos recogidos durante el trabajo de campo se ha podido comprobar que existen diferentes tipos de prestamista. El primero de ellos suele ser prestamista forzado por la necesidad de su entorno social. Son personas con liquidez económica, por disponer de ingresos constantes o recibir a remesa de algún familiar desde los Estados Unidos. Estas personas se convierten en prestamistas de sus vecinos, amigos y familiares cuando estos se encuentran en momento de necesidad. Los solicitantes del préstamo consideran que el prestamista es una persona comprensiva que mantendrá una actitud flexible y que entenderá en las dificultades en las que se encuentran. Entre este tipo de prestamistas destaca la percepción que ellos mismos tienen de su actividad, considerando que el dinero tiene una utilidad social que puede ayudar a su comunidad, por lo que ellos, al actuar como prestamistas, están colaborando al desarrollo de su comunidad, ejemplificando los valores morales deseables para la comunidad. En algunas entrevistas se constató cómo se presentaba la actividad de prestamista dentro de valores religiosos (caridad, piedad, misericordia).

Existen otro tipo de prestamistas a los que acuden las personas que no constan del suficiente capital social para hacer uso de él y acceder a prestamistas de la primera clase. En este caso, los prestamistas buscan la mayor rentabilidad de su dinero, imponiendo altos tipos de interés. También solicitan avales: en este caso, suelen ser únicamente objetos de valor. El acuerdo con este tipo de prestamistas no se considera que pueda ser flexible, por lo que los solicitantes de crédito intentan pagar la deuda con la mayor brevedad posible. En el caso de no poder hacer frente a la deuda, pierden el objeto de valor que avalaba el crédito y, en algunas ocasiones, se han visto obligados a realizar algún tipo de trabajo para el prestamista para saldar sus deudas, recibir amenazas y, como último recurso, utilizar la violencia para recuperar el préstamo o saldar la deuda. 


\section{BLOQUE IV. NINGUNO SOMOS MONEDITA DE ORO}

Los sistemas financieros alternativos presentes en las comunidades del DDR 089 son utilizados por la población bajo diferentes condicionantes, impulsados por fenómenos y dado lugar a conductas, prácticas y problemas diversos. Como ejemplo de esta heterogeneidad se presentan a continuación una serie de historias. Cada una de ellas intenta mostrar el complejo paisaje financiero de la región de la Ciénaga de Chapala.

\subsection{Karen la vendedora. Los pagos fraccionados y las tandas no son siempre un buen negocio}

Una vez finalizadas las fiestas en honor a Santiago Apóstol en Sahuayo que enmarcan el inicio de mi estancia en la región de la Ciénaga de Chapala, el primer acercamiento al trabajo etnográfico se realiza a través de las visitas a diferentes comerciantes de la zona. Un año antes, 2011, se había formado el cartel de los Cabellos Templarios, y el municipio de Sahuayo contaba desde hacía unos meses con mucha presencia de la policía federal. El ambiente político en el país se había tranquilizado una vez finalizadas las elecciones presidenciales, dando como ganador al PRI. Los grupos de protesta $^{81}$ que surgieron durante la campaña electoral habían propiciado la crítica y análisis político de la situación actual por la que México estaba atravesando.

A mediados de 2012 los retenes de la policía federal y los últimos casos de asaltos a vehículos particulares han provocado la disminución en las ventas. Sahuayo es el líder indiscutible en la región en cuanto comercio se refiere. La calle Constitución, repleta de

\footnotetext{
${ }^{81}$ Entre los grupos de protesta que emergieron durante el proceso electoral federal destacó "Yosoy132", grupo generado después de las protestas realizadas en la Universidad Iberoamericana que criticaba la actuación del candidato Enrique Peña Nieto como gobernador del Estado de México durante el caso Atenco.
} 
comercios, ofrece un amplio surtido de zapaterías, tiendas de ropa, farmacias y sucursales bancarias.

Karen es la dueña de una tienda de zapatos que cuenta con muchos clientes en la región. Su comercio tiene el aspecto de una tienda moderna, con espacio expositor, pequeños bancos para sentarse, probarse los zapatos y espejos.

Entre la mercancía que ofrece se pueden encontrar zapatos de vestir de hombre y mujer, calzado para niños, deportivo y algunos bolsos. Aunque cada variedad ocupa un espacio en la tienda, la zona más llamativa es la sección dedicada al zapato de mujer, donde se muestran zapatos con tacones y plataformas de diez centímetros más indicados para presentar un programa de televisión o desfilar en una pasarela que para caminar por las banquetas desiguales del municipio.

Karen presume de vender productos hechos en Sahuayo, de una alta calidad, aunque parte de sus productos son comprados al mayoreo en tiendas de Guadalajara. Los que se muestran en el expositor son copias o imitaciones de calzado de marcas conocidas como Chanel, Louis Vuitton, Hermes y Salvatore Ferragamo. Entre ellas, destaca la reproducción constante de las siglas de la marca Michael Kors, sus iniciales aparecen estampadas en casi todas las mercancías. Aunque estos productos no cumplen las características básicas para calificarlos como una imitación de un modelo concreto de la marca, el simple hecho de lucir el logotipo ${ }^{82}$ o isotipo ${ }^{83}$ ya es un elemento que revaloriza el producto.

En la parte trasera del comercio se guardan los que se califican como clones, reproducciones fieles de modelos originales de las marcas, realizadas con materiales de

\footnotetext{
${ }^{82}$ Las iniciales o nombre de la marca.

${ }^{83}$ Símbolo que identifica a la marca.
} 
calidad. Entre la aglomeración de bolsas de plástico con zapatos y bolsos, sorprende ver unos veinte bolsos del mismo modelo, el Cèline Boston Bag, el bolso de la temporada 2012. Esta mercancía adquirida en Guadalajara, pero recibida gracias al puerto de Lázaro Cárdenas y su continuo flujo de contenedores con Asia, hace posible que el mercado sahuayense cuente con imitaciones, copias y clones de zapatos, bolsos y vestimenta que hace unas pocas semanas se exhibieron en las pasarelas de New York, Paris o Milán.

Karen es una mujer de 32 años, güera ${ }^{84}$ que decidió invertir parte de los ahorros familiares en la tienda hace un par de años. El inicio de su aventura empresarial coincidió con el hecho de que su marido había conseguido un trabajo estable en California, trabajando para una empresa de paquetería. Armando dispone de Green card y el trabajo le permite enviar dinero a casa cada mes, así como visitar a la familia una vez al año. El marido ya se estableció en Estados Unidos (aunque ven este hecho como algo provisional mientras los niños crecen). Karen decidió volver a casa de sus padres y no residir sola en la casa que habían comprado cuando se casaron. La casa no tiene todavía muchos muebles.

Al principio pensé que mi hermana viniese con los niños a mi casa, ya que estábamos a la par, pero mi padre insistió que quería estar con los nietos y se veía feo las dos solas. Armando y Alfonso también estuvieron chinga y chinga con el tema, porque no se fían, y pues ahí le andamos, como Kardashian ${ }^{85}$ pero sin tanto varo ${ }^{86}$.

Grabación de audio, Sahuayo, 24 de septiembre 2012.

\footnotetext{
${ }^{84}$ Acepción mexicana que se utiliza para referirse a las personas de fenotipo blanco.

${ }^{85}$ Hace referencia al programa Keeping Up with the Kardashians, programa televisivo de telerrealidad que documenta la vida cotidiana de la familia Kardashian-Jenner.

${ }^{86}$ Expresión coloquial mexicana para referirse al dinero.
} 
Su hermana menor, Isabel, también se había trasladado a casa de los padres con sus tres hijos. El marido de Karen, Armando, y el marido de Isabel, Alfonso, viven juntos en California desde que Armando ayudó a Alfonso a encontrar trabajo descargando camiones de mudanza. Después de varias visitas al comercio y haber respondido el cuestionario-interrogatorio necesario para obtener un mínimo de confianza, me he decidido a preguntar cómo es el funcionamiento del apartado. Sé que usa este método porque durante las anteriores visitas había visto como ella se lo ofrecía a algunas posibles clientas, y también como algunas acudían al comercio para pagar un porcentaje de la cantidad total de alguna mercancía que ya habían comprado. Karen saca de una cajonera que está al lado de la caja registradora un cuaderno donde apunta todos los apartados. Me hace un gesto con el dedo índice, doblándolo en forma de gancho, señalando con esto que espere un momento y no comente nada en voz alta. Es entonces cuando me doy cuenta que hay una clienta en la tienda, más pendiente de escuchar nuestra conversación que de ver la mercancía. Una vez esta clienta abandona toda esperanza de conseguir algún chisme y se marcha, Karen habla el cuaderno y empieza su explicación.

Hay que saber a quién, porque a algunas le da pena [vergüenza] y a otras coraje [enfado]. Yo primero les enseño lo que hay y se lo pongo muy bonito, porque la neta [verdad] sí tengo cosas bien lindas. Si les gusta y lo quieren, pues se lo pueden llevar o apartar, pero ahí depende de si son de fiar o no.

Hay gente que síles fías, porque sabes que manejan [recursos] y son gente seria. Otros igual no tanto pero sí te pagan porque se creen muy nice [elegantes], aunque luego anden comiendo frijoles, y algunos ni con dinero en mano, por eso es importante checar [comprobar] quién es quién. 
A mí no me han hecho muchas malas pagas, pero si se de una diva muerta de hambre que ya la hizo [no pagar] en varios sitios, yo si viene le digo que eso ya está apartado o lo que sea, no quiero enfrentamientos, pero tampoco que me quede mal.

Grabación de audio, Sahuayo, 24 de septiembre, 2012

Karen explica las tres categorías en las que enmarca a sus clientes relacionándolos no tanto con su capacidad económica sino con el capital social que poseen. En el caso de Sahuayo, el denominado capital social parte de varias premisas. Como señala Coleman (1988), el capital social se percibe como el entramado de expectativas de reciprocidad y la imposición grupal de las normas de la comunidad, por lo que los poseedores de capital social, en tanto que elemento capacitador para el acceso a los sistemas financieros que ofrecen una alternativa a los formales, son capaces de acceder a ciertos recursos a través de él. Más importante que señalar quiénes son los poseedores del capital social es analizar cuáles son las fuentes de capital social dentro de la comunidad.

Eso se sabe si eres de aquí, por ejemplo, desde chiquitos ya sabemos quién tiene y quién se hace, nos conocemos de siempre. Además, somos familias grandes y si no es por mí, será por mis primas, la gente es muy chismosa. Yo a los que aparto son gente de misa, que ayudan y no andan armando mitote [escándalo]. Que tengan dinero pues ya es aparte, hay gente que sí y otros que tienen sus carencias, pero sé que su palabra vale. Otros igual están atascados de dinero, pero son malos pagadores, se creen que a una le regalan la mercancía, no se..., mis hijos también comen. 
Karen se queda en silencio, mira hacia la calle y me pide que guarde la grabadora. Acto seguido entra una mujer de unos 50 años con las que parecen ser sus hijas buscando alguna bolsa color café. Mientras la señora es atendida por Karen las hijas miran zapatos. Yo sentada en una esquina de la tienda, al lado de un gran espejo saco la libreta mientras la señora pregunta a Karen por su hermano menor y los niños. Cuando la mujer termina de realizar las preguntas pertinentes sobre la familia, me mira con gesto de curiosidad y pregunta a Karen si voy a trabajar en la tienda. Karen sonríe y zanja la cuestión con la frase -nos ayuda con las cuentas-. Unos veinte minutos después ya se marchan con unos zapatos para la menor y sin la bolsa.

Karen sale un momento de la tienda y vuelve con dos tejuinos ${ }^{87}$ y algo de botana ${ }^{88}$. Son algo más de las 10 de la mañana y el día se presenta tranquilo, faltan cuatro días para cobrar la quincena y a estas alturas del mes la gente no suele tener dinero para comprar zapatos. Con la grabadora en la mochila y en una conversación off the record, Karen me explica más detalladamente cuáles son las características que deben cumplir los clientes a los que se les hace el apartado.

En primer lugar, tenemos a aquellas personas cercanas, porque son del barrio o las familias se conocen y sabemos que son de fiar. A esa gente incluso se da por hecho que si le gusta algo se lo puede llevar cuando

\footnotetext{
${ }^{87}$ Bebida originaria del Estado de Nayarit de maíz fermentado con piloncillo y sal. Se sirve fría con helado de limón. En Sahuayo durante las horas de más calor un vendedor ambulante sirve tejuinos en la calle Constitución.

${ }^{88}$ Acepción mexicana para referirse a comida de preparación rápida para tomar entre horas. En este caso, fueron unas papas fritas con salsa valentina.
} 
quiera, porque son los mismos que van a la comunión de tus hijos, que te encuentras comprando tortillas. Algunas veces entran en la tienda solo para saludar y ver qué tienes nuevo y tienes que ser buen vendedor, y ofrecerles, animarles a que se lo lleven. Yo como vendo zapatos pues sé por dónde hay que tirar, y si vienen hombres con la mujer o las hijas pues hay que presionar. Algunos hombres no quieren hacer mucho gasto en mujeres y hay que convencerles o decirles que otro sí le compra a la mujer cosas, para que por puro coraje ellos también paguen.

Eso se aprende cuando tienes marido, porque si es buen hombre tiene a la mujer consentida, aunque hay de todo. Es mucho más fácil con las hijas, porque los padres sí las consienten y nosotras pues aprendemos de dónde se tira para conseguir lo que queremos.

El otro día vino una chica con su madre, yo las conozco porque son vecinas, y la madre apartó una bolsa muy bonita y dos pares de zapatos. La chica estaba muy contenta, la tienen como una princesa porque es la única mujer, todos los demás son hombres, te puedes imaginar. La madre esperó a que le dijese el total para lanzarle la puya [crítica] a la chica, diciéndole -esto lo paga tu padre, que es un señor, no como el ratero ese que te anda buscando, ese te va a tener vendiendo bolillos-. Imagínate, yo no dije nada, pero ya luego mi cuñada me contó qué pedo [pasa] con la señora.

Para que veas, yo a esa señora lo que quiera, porque tienen caudales y es familia trabajadora que tienen una vulcanizadora ${ }^{89}$ y son conocidos, pero

\footnotetext{
${ }^{89}$ Establecimiento donde se reparan llantas y neumáticos
} 
si la chica se junta con ese gato ${ }^{90}$, entonces ya hay que tener cuidado, porque si me dejan a deber va a ser la madre la que me dé, y ya la estoy poniendo en el compromiso y se ve feo. Yo creo que no se lo van a permitir, pero ya vi otros casos y hasta me ha pasado de venir la familia a decir a este no, a ver si por falta se vuelve a casa y deja de hacer el pendejo [estúpido].

Reconstrucción de notas de campo, Sahuayo, 24 de septiembre 2012

A través de esta narración de un caso particular acontecido durante la última semana, se ponía de manifiesto que el capital social que en un principio se había observado como condicionante del acceso a este tipo de financiamiento no solo dependía del posicionamiento familiar. Como ya señalase acertadamente Wright en Classes (1994) y Class Counts (1997) el concepto de "estructura de clases" no es capaz de abarcar la compleja realidad de la formación de las clases, así como explicar la variabilidad del capital social en cuanto a su capacidad de acceso a financiación. La formación de las clases es la formación de actores colectivos organizados que cumplen unas expectativas, pero también ejecutan los mandados característicos de las clases. De este modo, cualquier comportamiento subversivo dentro de la clase puede ser considerado factor de expulsión de la misma y, como consecuencia, factor que produzca un desgaste en el capital social.

Con el discurso anteriormente mencionado por parte de la madre a la hija, se puede reconocer un intento de mostrar a la chica una necesaria conciencia de clase, que implica hacerla entender tanto las obligaciones, como normas que la clase solicita a sus individuos. Aunque los lazos familiares pueden ser considerados la base inicial por la que

\footnotetext{
${ }^{90}$ Persona que tiene un rango inferior sobre la que su superior manda.
} 
se establecen las posiciones de clase, la permanencia a esta clase depende de las relaciones sociales que se establezcan.

En el caso de esta chica podemos observar cómo su posición de clase directa es la clase media acomodada, mientras que el posible noviazgo con una persona de clase inferior es advertido por su familia como un posible descenso de clase, algo que se debe evitar. Para ello se solicita la ayuda de los componentes de la clase social, a través de una muestra de las posibles repercusiones que el noviazgo puede acarrear, generando la exclusión en parte de las actividades cotidianas que ahora forman parte de su cotidianeidad.

En la siguiente entrevista, realizada un mes después se matizan algunas consideraciones realizadas y se describen otras tipologías de cliente. Karen con la libreta de los apartados abierta y comprobando cuáles pueden ser los tipos de clientes de su comercio, señala la existencia de otro sector.

El segundo sector capaz de acceder al sistema de apartados es aquellos que, sin disponer de capacidad económica para hacer frente al pago total de la mercancía, sí tienen la suficiente confiabilidad como para acceder a los apartados. En este caso, se señala que los individuos pertenecientes a este sector son de clases sociales más bajas, pero con el capital social suficiente para poder acceder al sistema. Cuando se solicita a Karen que aporte algún ejemplo de este grupo, relata la historia que se reproduce a continuación.

Este verano vino a la tienda una señora que buscaba unos zapatos para su hija pequeña. Quería unos parecidos a estos de aquí (señala unos dorados con tacones altos y adornos de cristal). Yo sé que esta señora no tiene para comprar zapatos de fiesta, pero tenía que ir a la boda de un 
sobrino y necesitaba que la hija se viera bonita. El sobrino se casaba en Zamora, en el Santuario, y no podía ir con cualquier cosa. El caso es que la señora tiene al marido enfermo, primero que tenía depresión, y ahora se la pasa en los bares tomando [bebiendo alcohol] y no trabaja, y la pobre doña pues hace lo que puede, cose, vende por catálogo y por las mañanas hace desayunos.

Ella mantiene la casa, los hijos ya se le casaron, pero todos andan fuera, uno en Guadalajara y otro en el DF. Yo creo que no ayudan mucho a su madre..., la seño tiene que cuidar de la hija pequeña. A la chica la quiere hacer princesa y ya sabes... casarla bien, aunque yo creo que así no son las cosas, allá cada uno.

El caso es que vino a ver si me podía ir pagando los zapatos de a poco, también hizo eso con el vestido que le compro allá enfrente, y pues pasa cada mes a darme 100 pesos o lo que pueda. Yo confió que me lo va a pagar, pero ese gasto es mucho para ella. Ahora en fiestas pasó a dar 20 pesos, porque se gastó todo en comprar mercancía para vender, aunque casi ni tenga, pasa para dar como fe de vida y que no piense que se le olvidó, pero yo la veo que no puede, pero hay que tener alma y no ir solo a ganar dinero. Uno de los hijos era amigo de mi hermano y la seño siempre fue buena con todos, no más le salieron los hombres cabrones.

Grabación de audio, Sahuayo, 9 de octubre 2012

Como ya me advirtió en el pasado, también hay ejemplos de personas que apartan y encuentran muchas dificultades para posteriormente realizar el pago. En este caso, la 
motivación de los clientes es otra. Un ejemplo, en palabras de Karen, son los clientes que acuden a la tienda unas semanas antes de la celebración de la fiesta de la Revolución Mexicana, 20 de noviembre:

El otro día vinieron por aquí mujeres de Jiquilpan. Yo ya las conozco porque el marido de una es de Sahuayo, pero se lo llevó. Vinieron a ver la tienda y les enseñé las bolsas que tengo dentro ${ }^{91}$. Se llevaron dos, muy contentas ellas.

Pues les tomo los datos para que ya me lo paguen y me dice una, mejor te lo deposito porque no vamos a venir aquí todos los días. A mí eso me da igual, porque les di la cuenta con la que yo hago los depósitos y listo, pero yo sé que lo hacen para luego decir que son bolsas originales que se las traen del DF.

Luego comen con medio de tortilla, pero bien se gastan lo que no tiene en hacer ver, y hablan de los de Sahuayo... No me gusta quemar a la gente, pero ya verás que en la fiesta andan haciéndose las fresas [snob].

Grabación de audio, Sahuayo, 5 de noviembre de 2012

En el segundo grupo de potenciales clientes que apartan, dentro de los múltiples ejemplos que pude encontrar, estos dos serían representativos de dos variantes. En los dos casos el cliente carece del dinero necesario para realizar el pago íntegro, pero la diferencia principal es la actitud ante la compra. En el primer ejemplo podemos observar cómo la

\footnotetext{
${ }^{91}$ En referencia a las bolsas clonadas de marca.
} 
ayuda para realizar el pago fraccionado se considera como un favor, un acto de generosidad del comerciante hacia el cliente que genera una reciprocidad que supera el mero acto de transferencia económica, generando empatía y una red de apoyo. En el segundo ejemplo es el cliente el que reclama el pago fraccionado y las condiciones de compra, considerando que el vendedor se debe a los dictámenes del consumidor. En este caso el cliente rompe cualquier proceso de reciprocidad, entendiendo que él, como consumidor, es quien tiene el control. Como me confirmó Karen, pasadas las fiestas de la Revolución, ella estaba en lo cierto y las señoras habían confirmado que las bolsas eran auténticas, enviadas por un familiar desde Canadá.

El tercer ejemplo de cliente tardaría más en aparecer, aunque Karen ya había mencionado la existencia de este tipo de cliente, nunca me comentó ningún ejemplo del mismo hasta un día en el que yo me encontraba en la tienda y pude observar in situ la escena.

Fiestas en Honor a la Virgen de Guadalupe. Me he levantado a las 5 de la mañana para acudir al Santuario de Guadalupe en Sahuayo. Después de comer unos churros y beber un Nescafé con leche y alcohol he asistido a las mañanitas. Cuando se ha hecho de día me fui a dormir un poco, luego pasaré por la tienda de Karen.

En la tienda, Karen: -Como ves tenemos un puro desmadre [desorden] en fiestas, ¿Qué te han parecido las mañanitas? Yo hace tiempo que no voy, por los niños, pero se ve bien linda Sahuayo desde allá arriba-. En esos momentos entra una mujer, de unos veinte años con unas proporciones 
irreales que fácilmente se identifican como cirugías estéticas. Da los buenos días y empieza a mirar el género con mucho detenimiento.

Percibo que Karen se ha puesto tensa y empieza a explicarme la historia de cómo la virgen se apareció a Juan Diego y que ella siempre que le pide ayuda la virgen la escucha, como aquella vez que la hija se puso con mucha fiebre y la virgen la ayudó. Yo escucho el relato mientras observo sutilmente a la mujer.

Por norma habitual cuando entra un cliente en la tienda Karen corta la conversación conmigo y me sitúa en un segundo plano, mientras ella atiende a los clientes. Al no producirse este comportamiento entiendo que Karen no está muy interesada en atender a esa clienta y usa la conversación sobre la Virgen de Guadalupe para mostrarse ocupada. La clienta, muy educadamente pide a Karen que la atienda, disculpándose por interrumpir la conversación, y Karen va hacia ella mientras diceahora te sigo contando-.

La chica está buscando unos zapatos azules, con mucho tacón, y Karen va a la parte de atrás para buscar unos de su número. Mientras, la clienta mira las bolsas y revisa en el espejo que tiene junto a mí su maquillaje. Una vez. Karen llega con los zapatos, la chica le pregunta si también tiene alguna bolsa que le convine, Karen me mira y se dirige otra vez al fondo de la tienda para salir con tres modelos diferentes, todos en el mismo tono de azul. Cuando la clienta se decide por los zapatos y la bolsa, Karen va hacia la máquina registradora y saca directamente el cuaderno de los apartados. 
Intento pasar desapercibida leyendo apuntes anteriores del trabajo de campo. Noto que la clienta me mira mientras mantengo los ojos pegados a las páginas del cuaderno y acierto a oír como en tono jocoso le comenta a Karen- ¿No está muy mayor para estar estudiando? -. Se despide muy educadamente de las dos y se marcha.

En ningún momento ha mencionado su nombre, ni el que iba a pagar a través del apartado, ni ninguna seña de identidad. Karen se va al fondo a dejar los bolsos que le había mostrado a la chica y tarda en salir más de lo habitual.

Una vez sale me mira, parece que necesitaba un rato para tranquilizarse y evaluar hasta qué punto me puede comentar esta historia. Yo sin entender que ha sucedido ante mis ojos, pero percibiendo que es algo de lo que Karen no quiere hablar le comento que ya se me hace tarde y ando cansada por las mañanitas. Ya volveré otro día.

Reconstrucción de notas de campo, Sahuayo, 3 de diciembre de 2012

Cuando se terminaron las fiestas, o como comúnmente se llaman, el maratón Guadalupe-Reyes, se volvió a realizar entrevistas a los comerciantes para recoger datos sobre las fiestas, así como los niveles de endeudamiento que sus clientes habían contraído. Por este motivo se volvió a entrevistas a Karen, omitiendo lo que sucedió en la anterior conversación. La respuesta a esta actitud por parte de Karen no llegaría hasta el final de nuestra relación, recogida en el último apartado de este capítulo. 
La tienda tiene menos mercancía y Karen está muy contenta con las ventas que hizo durante las fiestas. Los familiares de Karen que viven en Estados Unidos habían estado unas semanas en Sahuayo, incluido su marido, por lo que ella había pasado más tiempo con la familia. Su marido Armando la había traído varios cosméticos que guarda en la parte trasera de la tienda. Ella explica que todavía no los va a vender, porque ahora la gente está con poco dinero y no conviene sacar nuevo género, piensa esperar hasta febrero o marzo, así serán novedad y la gente los comprará. Armando le ha planteado la posibilidad de hacer pedidos de cosméticos y más cosas. Él se encargará de enviar las cosas por paquetería. Así ella tendrá género que no se encuentra en México y a precios más baratos.

Mientras explica su nueva estrategia de negocio saca la libreta donde apunta los apartados y me enseña cómo en este último mes casi ha terminado con la libreta. En las últimas páginas, correspondientes al mes de diciembre, se observa el aumento de ventas, así como algunos nombres con una estrellita dibujada a su lado, otros con un círculo. Karen explica cuál es el código que usa para marcar a cada cliente.

Las estrellas las coloca junto a los clientes sobre los que no hay ninguna duda, familiares, amigos cercanos y personas de su confianza. En este caso se despreocupa (hasta cierto punto) de que la deuda se pague dentro de unos plazos. Cuando la persona está señalada con un círculo son clientes a los que hay que controlar mejor por ser nuevos, apuntando la fecha de compra y los días en los que pagan. También apunta la descripción de lo que se llevaron, además del precio, para saber qué cosas les gustan y si son buenos pagadores les enseña cosas parecidas. 
En el caso de las personas que no tienen ninguna marca junto a su nombre, este tipo de clientes son aquellos que ya han comprado otras veces en la tienda, han pagado los productos y son lo que podríamos calificar como clientes habituales. Además de los nombres y el precio de la mercancía, también recopila los números de teléfono, algunas indicaciones como el barrio, apodo y el nombre de algún pariente con el que Karen ubica mejor quien es quien en su libreta.

Reconstrucción de notas de campo, Sahuayo, 12 de enero 2013

Resulta llamativo que la catalogación que Karen realiza de sus clientes es diferente en cuanto a la descripción que en un inicio realizó en las entrevistas y cómo ella los cataloga en su libreta de apartados.

Mientras en el caso de las entrevistas ella habla de las cualidades que configuran un buen cliente, como por ejemplo, el índice de confiabilidad que según ella pueden tener, el capital social individual o familiar, así como la actitud de sacrificio y de honor de aquellas personas con dificultades para pagar la compra, en el caso de la libreta, ninguna de estas características aparece representada. Las categorías de la libreta están más centradas en el ámbito empresarial, los clientes se catalogan en tres grupos no relacionados con los anteriores. Los confiables por proximidad, los dudosos por ser nuevos clientes o carecer de confiabilidad o capital social, y un gran grupo entre los cuales no existe ninguna división en torno a su confiabilidad, sacrificio u honor, solo señalados a través de la carencia de señalización como clientes habituales.

En el intento de que Karen realice algún tipo de paralelismo entre sus definiciones anteriores y las que aparecen en la libreta le señalo en nombre al azar de una mujer que 
se encuentra sin ninguna señal y le pregunto qué tipo de clienta es. Karen se acerca a la libreta para leer el nombre y me contesta

-Esta señora compra bastantes cosas, tiene tres hijas jóvenes, todas muy guapas y güeritas. Ella tiene una esteticien [comercio que ofrece servicios de peluquería y estética en general] a unas calles de aquí, mi hermana y yo vamos allí a que nos hagan las piernas y nos corten el pelo, lo hace muy bien. Piensa que aquí nos conocemos todos, y para muchas de mis clientas yo también soy clienta, si no me puede dar 500 pesos, me hago las uñas. -

Reconstrucción de notas de campo, Sahuayo, 12 de enero 2013

Entre los clientes de Karen, aunque algunos de ellos pueden no llegar a abonar íntegramente el valor de la mercancía adquirida, la devolución “en especies” es válida. En este caso estaríamos ante un entramado en el que comerciantes de diferentes productos apartan bienes bajo el aval de su propio negocio, no por el valor inmobiliario del mismo, sino por el desempeño de su actividad, que permite crear una red clientelar en la que los apartados tejen una red de relaciones afianzada en las capacidades tanto económicas como practicas del deudor.

Aunque el concepto de redes clientelares es comúnmente utilizado en la esfera política, en este caso, la red clientelar intenta definir una estructura social generada por los comerciantes al apartar parte de sus productos o servicios a otras personas del gremio. Con ello se persigue el acceso al consumo en otros establecimientos utilizando como aval el acceso que el cliente ofrece al consumo en su propio establecimiento. Esta 
característica apuntada por Karen como un elemento posibilitador para conseguir un apartado presenta la capacidad de generar una red extensa, en la que los comerciantes consiguen financiamiento a través de la reciprocidad.

Durante las siguientes semanas se entrevistó a otros comerciantes que utilizaban el sistema de apartado en establecimientos ajenos y, entre los cuales, la clasificación de sus clientes era similar a la expuesta por Karen. Existía una diferencia en cuanto al discurso de Karen, ya que ninguno de ellos comentó la existencia de clientes que sí pagaban los apartados, pero eran considerados malos clientes por el vendedor.

Aunque en un primer momento se realizaron las entrevistas sin mostrar ninguna categoría con la intención de reafirmar o falsear las categorías expuestas por Karen, en última instancia se preguntó por este tipo de clientes, si podían ser una categoría válida para analizar a los participantes en los apartados. En tres ocasiones se mencionó este tipo de clientes, y en las tres, después de un momento de silencio, se justificó el silencio con el desconocimiento de qué tipos de clientes podían ser aquellos. Ante esta carencia, y deseando completar todas las categorías que se habían presentado en las primeras entrevistas con Karen, se decidió dejar esta cuestión para más adelante y mantener el seguimiento del informante.

A principios de 2013 se habían conformado los primeros grupos de Autodefensas en Michoacán. Las noticias que llegaban desde Tierra Caliente eran pocas y se comentaban solo con personas de confianza, generando una tranquilidad ficticia entre la población. Entre los comentarios que durante esas semanas circularon por la Ciénaga de Chapala se encontraban aquellos que hablaban de la situación de los habitantes de La Ruana, Tepalcatepec y Buenavista, los tres municipios que se habían levantado en armas contra el narco. Muchos se relacionaban con los abusos que habían estado sufriendo los 
habitantes y relataban como un doctor (el doctor Mireles) se había cansado de atender a jovencitas que habían sido secuestradas y devueltas a sus familias embarazadas.

El surgimiento de las autodefensas se percibió como un levantamiento similar al de Cherán en 2011, que expulsó a madereros, policía y políticos de su término municipal. Casi nadie sabía lo que estaba ocurriendo, solo se tenía una certeza: si no era necesario, era mejor evitar viajar al sur del Estado.

Las cosas tampoco estaban muy tranquilas en $\mathrm{Jalmich}^{92}$ ya que los Caballeros Templarios (Michoacán) y el Cartel de Nueva Generación (Jalisco) se disputaban esta región. Antes de terminar el año, el 27 de diciembre de 2012, había desaparecido el sacerdote Santiago Álvarez Figueroa cuando se dirigía en coche a festejar las fiestas junto a su familia en Paredones. Era sacerdote en Jacona y, poco después de cruzar la cabecera municipal de Jiquilpan, había desaparecido, por lo que el Bosque y el Cerro de San Francisco eran los lugares donde se perdía la pista del sacerdote. Los habitantes de la región estaban acostumbrados (hasta el punto en el que estos hechos pueden ser costumbre), a la desaparición de personas, aunque se habían dado casos de desaparición entre jóvenes de la región, por lo general eran hombres sobre los que caían interrogantes que cuestionaban hasta qué punto no eran casos de un ajuste de cuentas.

En el caso del sacerdote, la población sintió que fue una factura del status quo. Las parroquias organizaron misas para rezar por el sacerdote y su pronta liberación. En Jiquilpan el duelo fue mayor, tanto porque su familia era de allí como porque unos meses antes, el 27 de noviembre, el municipio había recibido la distinción de Pueblo Mágico. Esta distinción había generado durante unos meses un fuerte sentimiento identitario en el municipio que había reafirmado el deseo en ver Jiquilpan como un ideal de pueblo

\footnotetext{
92 Jalmich es como comúnmente se conoce a la región que se encuentra en la frontera de los Estados de Jalisco y Michoacán
} 
mexicano, con su historia revolucionaria y sus plazas tranquilas. La desaparición del sacerdote había sido un choque contra la realidad de la región para muchos jiquilpenses. Aquellos que intentaron mantener la ilusión entendiendo este acontecimiento como un hecho aislado, tendrían los próximos meses para ver su ideal fracturado.

La violencia estaba presente en la cotidianeidad de la región, en la que se había normalizado el silencio. El día a día en los municipios se mantenía entre la cautela de los actos, discursos y el miedo. Desde el inicio, la investigación se había realizado con prudencia, ya que la situación de falta de seguridad y amenaza constante no facilitaba la realización de una etnografía.

Sin embargo, durante los primeros meses de 2013 la situación se había vuelto más tensa, implantándose una "cultura de terror" (Taussig, 2002), en la que se había normalizado la violencia. Para la mirada externa, el quehacer de los habitantes de la región, sus trabajos, sus visitas familiares y sus desplazamientos se mantenían bajo la incertidumbre, como una comunidad que está jugando a la ruleta rusa y en la que sus actores solo pueden esperar no ser el siguiente.

Las narrativas que se recogieron durante este periodo legitimaban en muchas ocasiones los actos de violencia, explicando que siempre existían motivos, siempre había algo que justificase hasta cierto punto lo ocurrido. A mediados de marzo, se retomaron las entrevistas con Karen.

Karen se muestra sorprendida con mi visita, cuando la tienda se queda vacía y empieza a recoger me comenta que ya pensaba que me había marchado a la madre patria ${ }^{93}$. Tiene algo que mostrarme y orgullosa y

\footnotetext{
${ }^{93}$ En referencia a España.
} 
emocionada me enseña una nueva libreta. La libreta no está destinada a apuntar los apartados, sino a un nuevo plan empresarial que había diseñado con su hermana. No comenta mucho más y me pide que espere a que llegue su hermana, Isabel, para explicarme bien de qué se trata.

Mientras termina de recoger me deja la libreta de apartados para que pueda observar cómo muchos de los nombres que habían sido apuntados durante la campaña navideña ya están tachados, muestra que confirma que las deudas han sido cubiertas por los compradores.

Aún quedan cinco nombres pendientes, son sumas de dinero superiores a dos mil pesos y Karen explica que al tratarse de tanto dinero se entiende que el tiempo para depositar el monto es mayor.

Reconstrucción de notas de campo, Sahuayo, 12 de marzo 2013

La utilización del verbo "entender" enmarca parte del funcionamiento de los apartados. Al ser un sistema informal, carece de una regulación estatal, de contratos o criterios fijos sobre los que estipular los días de cobro, los intereses o las penalizaciones, pero la informalidad llega más allá de la carencia de estos criterios.

En los casos en los que se ha estado presente mientras se negociaba el apartado, se ha presenciado cómo esta negociación cuenta con normas sociales sobreentendidas, las cuales no se mencionan en el acuerdo. Se entiende que tienes más plazo para pagar, se entiende que puedes pedir apartar un producto porque somos conocidas, se entiende que la confianza, reciprocidad y el compartir unos mismos valores morales te permiten acceder a facilidades en la compra. 
Esta utilización del verbo entender confirma que, en este sistema de compra, el funcionamiento del apartado lleva implícitos acuerdos que superan el mero hecho de comprar unos zapatos. Las relaciones se entretejen entre la comunidad haciendo a cada individuo participe de ellas, condicionan la manera de "entenderse" (autoreconocerse a través de la comunidad). El individuo forja este tipo de relaciones manteniendo un equilibrio entre las relaciones que le permiten el consumo y practicar un exceso de confianza que pueda dañar estas relaciones.

\subsubsection{Isabel, la motivadora del plan}

Isabel entra en la tienda con dos de sus tres hijos. Los niños acaban de salir de la escuela y dejan sus mochilas al fondo de la tienda para jugar con el celular de su madre. Isabel se presenta, es unos años más joven que Karen y el parecido entre las dos es notorio. Mira la libreta sobre la mesa y, con un gesto de orgullo y satisfacción, me comienza a explicar cuál es ese fantástico plan empresarial que han diseña durante los últimos meses.

La idea nos llegó por nuestra prima. En navidad estaba muy mal porque le quiere hacer una fiesta de quince años a la niña y no tiene mucho dinero. Ya le dijimos que nosotras somos madrinas y le cooperamos, pero el caso es que tenía ahorrado, pero lo gastó en la operación de mi tío.

Alfonso y Armando han insistido en que ellos pueden enviarnos cosas del gabacho, porque una tía de Alfonso compra cosas para enviar al DF y se hace dinero con el negocio, pero tampoco tenemos el dinero que nos pide para hacer las compras. 
Pensamos en armar una tanda, así Monse consigue dinero para la fiesta y nosotras además de ahorrar tenemos dinero para comprar. Ya llevamos un mes, y nos llega el paquete en una semana, yo estoy emocionada.

Mi hermana me ha dicho que tú estudias estas cosas y, bueno no sé si esto te vale, pero... es una buena idea. Te explico, somos diez, mi prima Monse, nosotras dos y Paulina, que es nuestra cuñada. También ayuda la Guadalupe, amiga de nuestra madre y su hija. Monse añadió a una vecina y el resto son amigas nuestras de siempre.

Somos diez, para diez meses, ya se ha avisado que el pago a cada una se hace a los dos meses, para que nosotras paguemos a la tía de Alfonso y con lo que saquemos se paga la tanda. No sabíamos que cuota poner y hemos hecho cálculos de cuánto necesitamos y qué le parecía a la gente. Lo hemos puesto en mil al mes y así tenemos margen y es una cantidad buena, para la fiesta y para nuestras compras.

Con el dinero hacemos el pedido, porque hay que hacer el ingreso, y las cosas nos las envía para que lleguen el siguiente mes. Con las ganancias de la venta nosotras damos la tanda a cada una cuando le toque y así tenemos dinero en movimiento para hacerlo todo.

Tuvimos que buscar a gente que tenga capacidad y sea seria, por eso lo hemos hecho entre familia y amigas, así no hay problema. A todas les parece bien que se pague después, porque saben para qué es esto y además quieren tener preferencia para comprar algunas cosas.

Grabación de audio, Sahuayo, 12 de marzo 2013 
Isabel se mostraba entusiasmada con el nuevo plan y arrebató el celular a sus hijos para mostrarme algunas cosas que ya habían pedido. Me enseñó el perfil de Facebook de la tía de Alfonso, que aparecía bajo el seudónimo de MissMac ${ }^{94}$, en él había una colección de fotografías donde se mostraba ropa de fitness, zapatos, zapatillas deportivas, vestidos, blusas y productos cosméticos de varias marcas, entre las que destacaba MAC Cosmetics. Uno de los productos que más expectativas había creado era la paleta Mac contouring ${ }^{95}$, un producto no comercializado todavía en la región que según palabras de Isabel y Karen iba a venderse muy bien.

Como muestra la figura 1, la tanda consiste en diez componentes, cada una de ellas abonará mil pesos mensuales a Karen e Isabel. Cuando fueron preguntadas sobre quién de las dos sería la encargada de los cobros afirmaron que eso lo llevarían entre las dos. Los mil pesos mensuales de cada participante hacían un total de diez mil pesos al mes, durante diez meses para que cada una de ellas recibiese en el orden estipulado la misma cantidad que habían invertido.

Al tratarse de una paga con efecto retroactivo, los abonos del primer mes serían asignados a la participante del turno correspondiente tres meses después. Este margen que habían diseñado las organizadoras cumplía con sus necesidades de conseguir liquidez para realizar sus compras, ofreciéndoles el margen necesario para ello.

Tal como explicaron en un inicio, el primer mes se hacía el pedido y se depositaba el dinero en una cuenta bancaria, el segundo mes se recibía el paquete con los productos,

\footnotetext{
${ }^{94}$ Por motivos de confidencialidad el nombre ha sido sustituido, al igual que en el caso de los participantes en la investigación.

${ }^{95}$ El contouring es una técnica de maquillaje que utiliza cosméticos de diferentes tonalidades para definir y realzar la estructura facial. Aunque la técnica se remonta al siglo XIX, el uso más habitual estaba relegado al cine y televisión, por ofrecer una gran cobertura y enfatizar los rasgos que podían desdibujarse por el efecto de la iluminación en el set de rodaje. En 2012 Kim Kardashian publicó varias fotografías en las que se mostraba la utilización de esta técnica, por lo que se popularizó entre la población. En 2013 aparecieron las primeras paletas para la realización de esta técnica enfocadas al público no profesional.
} 
y el periodo entre la recepción de los productos y el vencimiento del tercer mes era el necesario para vender lo suficiente y así recuperar la inversión. La tanda había empezado a funcionar a principios del mes de febrero, por lo que ya habían recaudado dos meses de pagos, veinte mil pesos, y estaban esperando el producto para la venta.

El valor total del primer pedido a la tía de Alfonso ascendía a ocho mil pesos, en su mayoría productos cosméticos y ropa deportiva. Como explicaron Karen e Isabel, el segundo mes no habían realizado un pedido porque querían saber primero como era la calidad de los productos y, si todo iba bien para principios de abril, realizarían un pedido mayor.

En la figura 1 también se presentan los lazos de amistad que mantiene cada participante con el resto, así como el parentesco presente entre algunas de ellas. Contando con una breve descripción facilitada por Karen e Isabel de cada una de ellas, así como la justificación del orden para el cobro de la tanda, se puede apreciar que confluyen en las decisiones varios condicionantes.

En primer lugar, expondremos más extensamente la relación existente entre las participantes. Isabel, la hermana menor de Karen, tiene 27 años. Se casó con Alfonso después de que naciera su primer hijo, por lo que es considerada la más "moderna" de la familia. A diferencia de su hermana, ella no muestra tanto interés por la asistencia a la iglesia y sueña en voz alta con trasladarse a Estados Unidos donde vive su marido. Su marido Alfonso encontró trabajo en el norte gracias a la ayuda del marido de Karen, y ahora intenta por todos los medios conseguir dinero para poder asentarse en California y llevarse a Isabel y sus hijos 


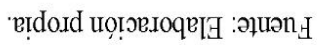

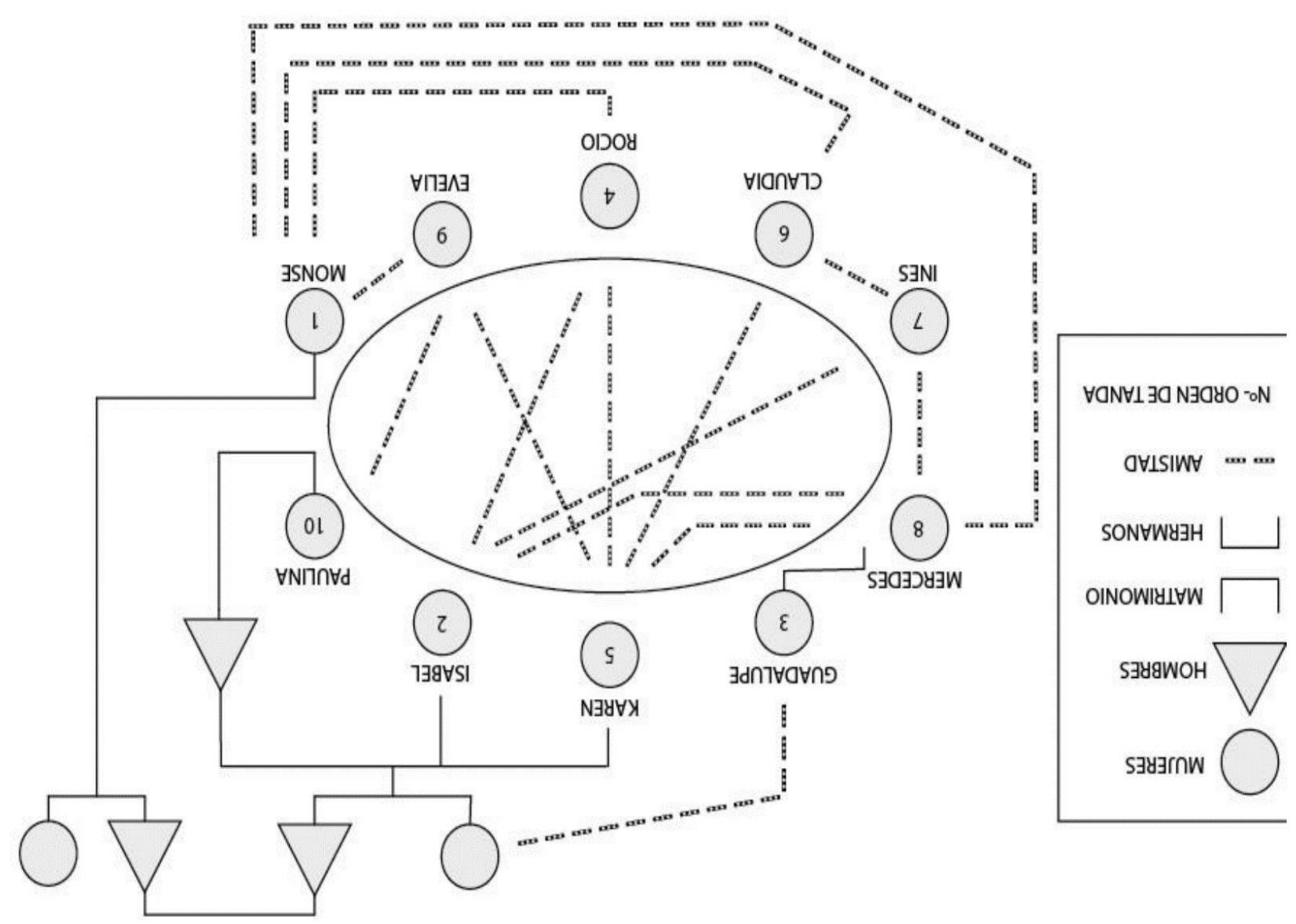

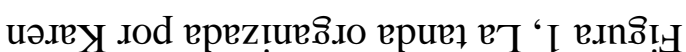


Este plan no parece hacer mucha ilusión a Karen que se muestra reticente a las aspiraciones de su hermana, aunque nunca muestre una confrontación directa con las ideas que Isabel.

Paulina es la cuñada de las dos. Casada desde hace unos años con el hermano de ambas, José Antonio, formara parte de la tanda, aunque el dinero aportado a la misma sea en origen parte del salario de su hermano.

Para terminar de describir a los participantes que forman el subgrupo de familiares directos o indirectos de las organizadoras hay que mencionar a Monse, prima de Karen e Isabel y uno de los motivos para organizar esta asociación. Monse es una mujer de 45 años, hija del hermano mayor del padre de las organizadoras. Durante la infancia de Karen e Isabel, Monse las cuidó y jugó con ellas convirtiéndose en una figura entre hermana mayor y madre joven. La relación con Karen es mucho más cercana, siendo su confidente y ocupándose de ayudarla a cuidar de sus hijos. Monse solo tienea hija, enviudó muy joven y nunca estuvo interesada en volver a casarse. La hija de Monse, que este año cumple los 15 , es uno de los motivos por los que esta tanda se pone en funcionamiento, ya que su madre, al igual que el resto de la familia, quieren prepararle una fiesta de quinceañera. Ella, al igual que el resto de su familia, goza de un nivel de vida elevado para la región, aunque no pueden ser calificados como ricos. Descienden de una familia que se dedicó al transporte de mercancías, primero como arrieros y luego con transporte a motor. Hace tres generaciones compraron varios locales en las calles más céntricas de Sahuayo, lo que les ha permitido tener varios negocios que les permiten tener un buen nivel económico.

Fuera del ámbito familiar, pero con un tipo de relaciones que podemos calificar como parentesco ficticio, están Guadalupe y su hija Mercedes. Guadalupe tiene la misma edad que la madre de Karen e Isabel, cincuenta y tres, y son amigas desde la infancia. La 
relación se extiende varias generaciones, ya que los abuelos de ambas eran primos. Las organizadoras se refieren a Guadalupe como su tía, posiblemente porque su madre solo tuvo hermanos varones, por lo que Guadalupe fue una hermana para su madre. Su hija Mercedes no tiene una relación tan estrecha con las organizadoras, ya que paso parte de su juventud estudiando en Guadalajara. Sus estudios de licenciatura y el tener parte de sus relaciones de amistad en la capital de Jalisco han hecho que, aun viviendo en Sahuayo, no tenga en el municipio una notable red social. Karen y en especial Isabel consideran que Mercedes está disgustada con estar en Sahuayo, pero no ha tenido otra opción. El marido de Mercedes fue al norte a trabajar como comercial, pero cuando pasó un año ya nunca se supo de él. Según el relato de Isabel, hubo un primer momento de duelo, en el que se pensaban que le podía haber sucedido lo peor, pero pronto llegaron las noticias de que andaba con otra mujer. Mercedes nunca llegó a formalizar el divorcio y no sabe cuál es el paradero de su marido, por lo que ella, junto con su madre, sacan adelante al único hijo que tuvo la pareja.

Las otras cinco participantes son amigas tanto de las organizadoras como de Monse. Evelia es vecina de Monse. Las hijas de ambas son amigas y van juntas al colegio por lo que las madres tienen una relación muy estrecha. El marido de Evelia participa en muchas iniciativas relacionadas con la Iglesia y la Presidencia Municipal, por lo que son considerados una familia con prestigio y poseedora de valores morales.

Rocío es amiga tanto de las organizadoras como de Monse. Durante su infancia, fue vecina de las hermanas, viviendo en la misma calle, por lo que forma parte de la red de amistades de la familia desde hace años. Inés es amiga de Isabel y Mercedes, las tres son las más jóvenes de la asociación, no alcanzando ninguna de ellas la treintena. Casada y con dos niños pequeños, no tiene mucho tiempo para estar con sus amigas, aunque 
dentro de sus planes desea tener una tienda en el centro parecida a la de Karen e Isabel cuando sus hijos estén un poco mayores y vayan al colegio.

La ultima participante de la asociación, Claudia, es quizá la más cuestionada por Isabel. Claudia fue durante varios años la pareja que deseaban los padres de Karen e Isabel para su hermano José Antonio. Karen y Monse tienen una buena relación con ella, pero Isabel no está muy de acuerdo con la elección porque considera que es una falta de respeto hacia Paulina. Claudia está casada y espera a su primer hijo por lo que Karen considera que su anterior noviazgo con José Antonio puede pasar a un segundo plano y participar en la tanda.

La asignación de los turnos se realizó bajo el consenso de todas las participantes, siendo Karen la que habló con todas ellas. El primer turno pertenece a Monse, justificado por su necesidad de efectivo para celebrar la fiesta de quince años a su hija. En este caso, Monse y los primeros turnos recibirán un crédito, mientras para las últimas en cobrar, la tanda tendrá la característica de un modo de ahorro. Después de Monse le sigue Isabel, que alegó que estar en los primeros turnos les facilitaba un mayor margen para la compra de mercancía. El tercer turno fue otorgado a Guadalupe, sin que ella lo solicitase, como una forma de agradecimiento por su colaboración en la asociación. Para equilibrar los turnos, su hija Mercedes fue asignada al turno octavo. Rocío seria la cuarta en cobrar y Karen la quinta, posicionándose en la zona intermedia de rotación. Para los últimos turnos el orden que se diseñó fue Claudia la sexta, Inés la séptima, Mercedes la octava y Evelia la novena. Evelia no tuvo problemas en ser de las ultimas en cobrar ya que consideraba que, con su participación, estaba ayudando a su vecina Monse a pagar la celebración de la niña. El décimo turno, y ultima en recibir la tanda, seria Paulina, cuñada de las organizadoras. Paulina había entrado en la tanda más por obligación o compromiso con la familia del marido que por deseo propio, pero tanto sus cuñadas como el marido habían 
insistido en su participación, por lo que accedió a tener el último turno, aunque no estaba especialmente ilusionada con ello.

La investigación de esta tanda se realizó con el permiso de Karen e Isabel para concretar entrevistas con las demás participantes. Ellas fueron las facilitadoras de la información inicial que aquí se ha mostrado. Más adelante se presentarán los resultados de las entrevistas abiertas y la convivencia con las participantes de la tanda durante los meses que estuvo en funcionamiento.

El día anterior avisaron que la mercancía había llegado y hoy estarán colocando las cosas a primera hora de la mañana. El escaparate está cubierto con papel continuo de tal modo que no permite ver lo que está sucediendo dentro, la puerta permanece cerrada por lo que hay que llamar para poder entrar.

La tienda ha sufrido un gran cambio, ya que ahora tiene nuevas estanterías y se han colocado dos mesas pequeñas con espejos a modo de tocador para la venta de cosméticos. En el centro de la tienda hay dos cajas grandes abiertas y el suelo está lleno de envoltorios de plástico transparente que han sido tirados mientras sacan los productos. En la tienda, las dos hermanas y Paulina miran detenidamente cada artículo y discuten sobre el precio de venta de cada uno. Mientras tanto, Karen, apoyada en el mostrador con una nueva libreta y una calculadora, apunta cada producto y busca con el celular cuál es el precio de cada uno de ellos en internet, Isabel empieza a abrir las cajas de maquillaje. 
MissMac les ha enviado una lista donde aparece el valor en mayoreo de cada artículo, así como una sugerencia de precio de venta en el local. Karen hace sus cuentas y Paulina intenta recoger la tienda y colocar las cosas. Isabel prueba las esperadas paletas de Mac y se hace selfies para apreciar el resultado.

Karen muestra la libreta buscando aprobación a sus cuentas. En ella se aprecia que ha aumentado en un veinte por ciento el valor de la ropa, blusas y leggins, y un treinta por ciento el de los zapatos y zapatillas deportivas. En cuanto a los cosméticos les han enviado de dos tipos, unos originales de la marca Mac, con un valor en origen de tres mil pesos y otros de diferentes marcas en los que han invertido dos mil pesos. Isabel señala que los cosméticos hay que venderlos caros, porque no se consiguen fácilmente, y hay que sumarle el gasto de ir a Guadalajara a por ellos, que es lo que tendrían que hacer si no los compran aquí. Por esos motivos, Karen les aumenta el porcentaje a los cosméticos, llegando al sesenta por ciento sobre el valor de compra al mayoreo.

Cuando Paulina termina de recoger la tienda, barrer y echar colonia para eliminar el olor de las cajas, ocasionado seguramente durante el transporte, Isabel ya ha publicado en su perfil de redes sociales las fotos de los productos y ha dado aviso a todas sus conocidas de que ya se encuentran a la venta.

Retiran el papel del escaparate y esperan ansiosas la llegada de clientes. La siguiente semana empiezan las vacaciones de Semana Santa y es un buen momento para atraer a las personas que quieren estrenar ropa en las vacaciones, o aquellas que tienen algún viaje planeado y quieren lucir 
bien. Paulina se macha porque insiste en que debe realizar varias compras en el mercado.

En ese momento Paulina indica que debe ir al mercado a comprar y luego hacer la comida por lo que su tiempo para ayudar a las hermanas ha terminado. Siendo la primera vez que consigo coincidir con Paulina me ofrezco a acompañarla en sus compras y dejar para después el seguimiento de las ventas de Karen e Isabel.

Reconstrucción de notas de campo, Sahuayo, 22 de marzo 2013

\subsubsection{Paulina, la participante no voluntaria}

Paulina es una mujer bajita, joven y dispuesta a ayudar en lo que haga falta. $\mathrm{Su}$ marido José Antonio trabaja vendiendo compresores y maquinaria agrícola por lo que tiene horario comercial y puede ir a casa a comer todos los días. Paulina trabajó antes de casarse ayudando a su madre realizando arreglos florales, pero, desde que se casó, está volcada en el hogar y espera quedarse embaraza pronto.

La familia de Paulina no tiene el nivel económico de su marido, por lo que Karen y especialmente Isabel consideran que con José Antonio hizo un buen negocio. Este es uno de los motivos por los que Paulina siempre se muestre servicial a cualquier requerimiento de las hermanas y, en asuntos económicos, considera que ella no tiene voz en el sueldo de su marido.

Antes de comenzar las compras en el mercado, Paulina propone tomar un licuado, por lo que nos dirigimos a un lateral del mercado de abastos donde sirven almuerzos y preparan licuados. 
Sentadas en la barra con nuestro vaso de licuado propongo que ella me comente cuál es la opinión que tiene sobre la tanda en la que participa. Al principio ella muestra su conformidad sin objetar ningún problema en participar en el plan de sus cuñadas, considera que son buenas comerciantes y saben lo que hacen, por lo que se siente segura de que conseguirán mucho beneficio. Al ser preguntada por el número de turno que le ha sido asignado guarda silencio por unos segundos, frunce el ceño y mira hacia un puesto de carnitas mientras parece que evalúa sus próximas palabras

-A mí me parece bien, dentro de un año vamos a tener un buen ahorroresponde.

Como es comprensible no muestra ninguna disconformidad con su participación en su discurso, pero se muestra tensa hacia las preguntas. Rápidamente cambia de tema y me pregunta que voy a hacer esta semana santa, y cuando le explico que no tengo nada planeado y seguramente me quede en Jiquilpan intentando ahorrar algo de dinero, ella arquea las cejas y añade-nosotros también, ahora tendremos que ahorrar.

De vuelta en la tienda de Karen después de despedirme de Paulina, veo que hay muchas mujeres en el local en el que ahora solo está Karen. La saludo desde fuera y viendo que no tiene tiempo para hablar, ya que intenta atender a varias clientas al mismo tiempo le indico a través de señas que pasaré a verla en los próximos días.

Reconstrucción de notas de campo, Sahuayo, 22 de marzo 2013 


\subsubsection{Guadalupe y Mercedes. La participación de la tanda como excusa para}

mantener las relaciones de amistad

Una vez finalizadas las vacaciones de Semana Santa y cuando los niños ya habían vuelto a los colegios, se volvió a la tienda de Karen para comprobar cuál había sido el resultado de las ventas, así como hacer un seguimiento de la tanda. En este mes se otorgaría el primer turno de la tanda correspondiente a Monse.

Karen está sola en la tienda, en la que se puede apreciar a simple vista que las ventas han ido bien. Quedan algunas ropas deportivas y calzado, pero ya no hay nada de maquillaje. Karen se muestra contenta con el resultado, aunque está enfada con su hermana.

El día de la primera venta, su hermana se marchó con unas amigas para probar las paletas de contouring a casa de una de ellas y la dejó sola en la tienda cuando estaba llena de gente. Sin embargo, señala que, gracias a Isabel, tenga clientes nuevas, muchas de ellas atraídas por la difusión que su hermana ha estado realizando a través de las redes sociales. Ahora ella está seleccionando los productos para el próximo pedido, en el que añadirá lentes de sol, llaveros y blusas.

Reconstrucción de notas de campo, Sahuayo, 8 de abril 2013

-Estoy mirando para pedir esto, del maquillaje es de donde más se saca, pero no quiero pedir mucho porque ya llevaron muchas clientas, prefiero traer cosas nuevas. Los zapatos no salen rentables porque el envío es caro, 
mejor cosas pequeñas, creo que voy a pedir extensiones ${ }^{96}$, son caras pero sí lo pagan. -

Grabación de audio, Sahuayo, 8 de abril 2013

En relación a la tanda, Karen me señaló que ya había pagado a Monse su turno a primeros de mes. Monse organizaría la fiesta de quince años para inicios de julio porque, al contar con el dinero de la tanda, ya había apartado la quinta (recinto donde se celebraría la fiesta) desde hace meses. Se había llevado unas cuantas cosas para regalar a su hija, lo que había hecho reducir el monto total que debía pagarse a Monse, un gran negocio en palabras de Karen. Los apartados habían aumentado considerablemente, manejando ahora una lista de casi cincuenta personas que habían recurrido a este método de pago para llevarse productos. En la libreta se observaba un aumento de los nombres que no estaban señalizados como de plena confianza, Karen justificó este dato por el número de nuevas clientes que la venta de productos importados había atraído, no preocupándose en exceso por ello.

Gracias a la ayuda de Karen, conseguí concertar una cita con Guadalupe y Mercedes en su casa, para realizar una entrevista en la que me expusiesen sus motivaciones para la participación en la tanda. Ese mismo día, después de comer, me encontraría con ellas.

\footnotetext{
${ }^{96}$ Extensiones de pelo.
} 
La Casa de Guadalupe se ubica en el mismo barrio en el que residen Karen e Isabel. Es una casa grande con una cochera para dos coches y patio trasero.

En la entrada aparece una gran fotografía del Papa Juan Pablo II junto a una imagen de la Virgen de Guadalupe y algunas velas. Me reciben en el salón, donde ya tienen preparada una jarra de agua de Jamaica y una bandeja de botana. Guadalupe es una mujer de unos cincuenta años, de gesto serio. Las numerosas fotografías que cuelgan de las paredes hacen ver retratos de sus hijos y antepasados. Por una foto familiar que se encuentra sobre el televisor se adivina a calcular seis hijos, cuatro varones y dos mujeres.

Guadalupe comienza a explicar que ya todos están casados y viven con su familia, hace una breve pausa que incomoda a Mercedes para luego añadir:

-pero por suerte tengo aquí a Mercedes que me ayuda con las cosas del hogar-.

Mercedes es una chica joven, de unos veintisiete años, al igual que Isabel. Su manera de vestir y el que no muestre tanto interés hacia mí como extranjera, me hace entender algunas de las características que ya me avanzaron Karen e Isabel cuando me hicieron una breve descripción de ellas.

Aprovechando esos datos, y mientras Guadalupe sigue en la cocina preparando comida, pregunto a Mercedes sobre sus estudios en Guadalajara. Mercedes estudio la licenciatura en Geografía en la 
Universidad de Guadalajara y ahora intenta entrar en alguna dependencia pública. Guadalupe llega con un plato de tamales dulces que deja sobre la mesa mientras nos avisa que los dejemos enfriar un poco y espera a que empiecen las preguntas. Ella comenta que es amiga de Asunción (madre de Karen e Isabel) desde que son niñas.

-de cuando los niños podían jugar por la calle, no como ahora que hay que tenerlos guardados en casa. Yo a las chicas las quiero mucho, porque se han criado todos juntos y son muy trabajadoras, en eso salieron a la madre-

Cuando les comentaron el plan que tenían para conseguir traer productos importados les pareció bien y dijeron que les iban a ayudar.

-Yo sé que Karen es formal y, si ella lo ve, será porque puede funcionar. Nosotras no tenemos muchos gastos y podemos pagar la tanda, además hay que ayudar, porque Karen nunca dice nada, pero el marido algunas veces manda y otras no. Dios nos dijo que hay que ayudar. -

Reconstrucción de notas de campo, Sahuayo, Casa de Guadalupe, 8 de abril 2013

Karen nunca había mencionado que su marido no cubriese todos sus gastos, presentando su trabajo en la tienda como un entretenimiento que le ofrecía la posibilidad de no estar en casa esperándole. Sin embargo, Guadalupe indicó que, en realidad, su trabajo en la tienda era por necesidad, para poder hacer frente a los gastos cuando su marido no le enviaba la remesa. 
El niño de Mercedes, de unos dos años, empieza a llorar y Guadalupe se levanta para atenderle en la habitación de al lado. Es entonces cuando Mercedes matiza

-en realidad los dos turnos los va a pagar mi madre, yo no tengo trabajo. Yo no quería, pero mi madre quiere que salga y tenga amigas. Tú entiendes, yo soy de aquí, pero volver después de años... yo en Guadalajara estaba muy bien, tenía rentado un depa muy bonito y trabajaba en unas oficinas, pero pues con el niño me dieron la patada y la ciudad está cara. Además, no hay donde dejar al niño, está complicado. -

Reconstrucción de notas de campo, Sahuayo, Casa de Guadalupe, 8 de abril 2013

Guadalupe vuelve con el niño en brazos y a la pregunta sobre cómo se asignaron los turnos responde que a ella le parece bien, tiene uno pronto y el otro es el octavo, ya se hizo cuentas y el primer turno le toca en junio, perfecto, según ella, para comprar ropa para las fiestas de Santiago Apóstol, y el segundo en noviembre comprar los regalos de navidad. Además del nieto que sujeta entre los brazos tiene seis más y todos se reúnen en su casa a pasar las navidades por lo que le viene bien recibir la tanda en noviembre y con ella comprar los regalos antes y que le salgan más baratos. Sobre lo que se muestra disconforme es la selección de participantes:

-Yo a todas no las conozco, se quién son, pero nada más. De las hijas de Asunción no tengo ninguna pega, y confió, pero hay algunas que no se de qué árbol salen. Karen dice que no hay ningún problema, que ella se 
encarga, pero en estas cosas ya se sabe, hasta que no está cerrado el círculo...-

Aunque le pido algún dato que me ayude a identificar a algunas de las cuestionadas participantes en la tanda, ella sonríe y me responde con unespero no tener razón, pero pocas veces pasa- y se niega a señalar a ninguna por el momento.

Reconstrucción de notas de campo, Sahuayo, Casa de Guadalupe, 8 de abril 2013

Guadalupe insiste en que Mercedes me presente a Inés, otra participante y amiga de Mercedes. Nos intercambiamos los teléfonos y decidimos que ella me llamará en unos días.

\subsubsection{Inés, la maximizadora del beneficio}

La reunión con Mercedes e Inés se había pospuesto dos veces. El mes de abril había sido un caos en la región y la movilidad entre los municipios se volvió muy complicada. Los grupos de autodefensa se extendieron hasta la región Jalmich y los carteles, buscando zonas seguras donde fortalecerse, habían elegido la región de la Ciénaga de Chapala para confrontarse con ellos. El resultado de estas tácticas de combate fue la imposición de un toque de queda por parte de los Caballeros Templarios durante las últimas semanas de abril.

Había amenazas de bomba dirigidas a las autoridades de una veintena de municipios, entre los que se encontraban aquellos pertenecientes al DDR 089. Debido a esto, las oficinas de gobierno y presidencias fueron evacuadas y muchos comercios habían 
cerrado durante varios días. El transporte de viajeros fue cancelado y la población solo salía de sus casas para comprar comida o visitar a alguien cercano.

La situación que vivían los habitantes de la región chocaba frontalmente con los discursos presentados desde los canales de televisión nacionales. Mientas en los medios de comunicación calificaban la situación de guerra, a través de la ventana no se observaban escenas bélicas, sino calles vacías en las que solo se podía afirmar que hubiese habitantes en esas casas gracias al movimiento de una cortina y alguna luz encendida en el patio. Las redes sociales reflejaban una realidad muy distinta. Los medios de comunicación presentaban las noticias sobre Michoacán como una situación intolerable, en la que el gobierno debía poner fin a las autodefensas, en cuanto grupos paramilitares que se oponían al estado de derecho en la región. Por otro lado, internet se posicionaba en el otro extremo, con perfiles que exaltaban las actividades de las autodefensas y se ilusionaban en ver en los acontecimientos una mecha que pudiese prender en el resto de la nación y llamar a la revolución contra el gobierno corrupto.

La población de la Ciénaga también se encontraba dividida, pero las discusiones y enfrentamientos ideológicos no se hacían patentes, no se quería hablar del tema y se esperaba a que todo se normalizase de algún modo. Cuando tu casa es el campo de batalla y tu integridad física se pone en riesgo, la idea de ser el próximo mártir de la revolución o el defensor del estado de derecho impuesto desde la capital no resulta tan atractiva como en la pantalla, ya sea de la televisión o la computadora.

A principios de mayo, la población empezó a hacer su vida cotidiana otra vez. Este acto no significaba que el temporal hubiese pasado y un nuevo aire de estabilidad y seguridad llegase a la región. Más bien nos habíamos acostumbrado, habíamos sido buenos ciudadanos y nos habíamos quedado en casa unos días y después, 
independientemente de cómo estuvieran las cosas teníamos que seguir con nuestra vida. La reunión con Mercedes e Inés se programó para el 6 de mayo en la tienda de Karen.

En la tienda solo está Karen. La mercancía de importación ha sido sustituida por peluches, bolsas y los zapatos que vendía antes de traer las cosas de Estados Unidos. Karen se muestra sorprendida con mi llegada ya que nadie le había dicho que pasaría por allí para encontrarme con Mercedes. Al tener casi una hora de margen entre la cita con Mercedes y mi llegada me ofrezco para traer unos cafés mientras Karen me cuenta las últimas novedades de Sahuayo.

Reconstrucción de notas de campo, Sahuayo, 6 de mayo 2013

-Las cosas se han puesto bien feas, ¿verdad? Bueno... ya hice el pedido, te aviso cuando llegue. Ahora ya no me queda nada, pero lo calculé mal. No me acordé que el viernes es el día de la madre, y podía haber vendido mucho, pero ya qué. Mi hermano fue a Guadalajara a comprar varias cosas, yo no fui porque las cosas se pusieron pesadas y no era plan. Compró peluches y zapatos. Los zapatos son como los que compro yo, porque hablé con la tienda y les dejé el aviso, pero los peluches... ha hecho lo que ha querido, yo no sé si los voy a vender porque son pequeños y huelen a camión.

Mi hermana ya cobró su turno y se ha comprado un celular nuevo, luego dice que ahorra, pero en cuanto tiene varo le quema en las manos. El 
pedido lo he hecho yo sola porque si es por ella solo encargo cosas para sus amigas, y todas me deben todavía los apartados del mes pasado. -

Grabación de audio, Sahuayo, 6 de mayo 2013

El día de la madre es una buena oportunidad para vender ropa y maquillaje, ya que en México es una fiesta nacional en la que los familiares regalan a las madres, además de organizar comidas con la familia. Cuando Karen decidió no realizar otro pedido hasta comprobar la calidad de la mercancía y el resultado en ventas que obtenía durante el primer mes no tuvo en cuenta esta celebración, por lo que hasta junio no recibirá nuevos productos.

Durante el tiempo que estuve en la tienda varias personas entraron preguntando por maquillaje y artículos importados, pero Karen ya no disponía de ellos por lo que los clientes se iban con las manos vacías y ella se apenaba por no haber tenido en cuenta esta fiesta para sus ventas. La libreta de apartados había visto aumentar el número de nombres considerablemente, y se preguntó a Karen por cómo se iban cerrando las deudas de los clientes.

-Mal, muy mal. Bueno tú estabas en Jiquilpan y ya has visto, tuve la tienda cerrada tres días, y los demás casi no entraba nadie. Pocas se han pasado por aquí, aunque sí me llamaron para decir que ya iban a venir, cuando las cosas estuviesen más tranquilas. Yo las entiendo porque tampoco he salido mucho, yo no llevé a los niños al colegio, se quedaron en casa. Pero el apartado ahí está, y el gasto del pedido, y la tanda. -

Grabación de audio, Sahuayo, 6 de mayo 2013 
Mercedes llama por teléfono para confirmar que ya estoy en la tienda de Karen, llega veinte minutos tarde, pero afirma que ya está por llegar. Karen se muestra desconfiada de mi reunión con Mercedes e Inés y me pone sobre aviso.

-Ten cuidado que dices, esas viejas son bien chismosas. -

Mercedes e Inés entran en la tienda, peinadas y maquilladas como si fueran a asistir a alguna fiesta, lo que resulta un poco artificial para un lunes por la mañana. Después de las respectivas presentaciones, Inés propone ir a una cafetería cercana y, al despedirnos de Karen, ella busca el contacto visual que reafirme la advertencia que me había hecho anteriormente.

Una vez sentadas en una mesa y con nuestra bebida servida, Inés empieza a preguntar sobre la investigación y cómo decidí venir a la Ciénaga. Aunque no convencida de mis explicaciones y utilizando estas preguntas como un tipo de preliminares, se lanza a preguntarme sobre Karen e Isabel.

Las preguntas giran en torno a las ganancias de la tienda y si yo le puedo conseguir el contacto con la doña de California. Utiliza como excusa querer comprar algunas cosas y ahorrarse así la comisión de Karen. Después de una media hora de evasivas y proponer que esa información quizá pueda ser dada en el futuro, Mercedes e Inés se sienten lo suficientemente satisfechas con su objetivo para colaborar con la investigación. 
-Yo le entré a la tanda porque Isabel insistió. Lo vendió muy bonito, que si era para ayudar a su prima y además ellas iban a comprar importado y nos hacían precio. Pero yo pensaba que podíamos pedir, no que era lo que ellas traían. Le dije el otro día a Isabel que quiero una bolsa, y le envié la foto, a ver si es verdad todo lo que dice y la tengo el próximo mes. La tanda está muy bien, así ahorras y también tienes la exclusiva de la tienda. Para verano voy a comprar unas cosas, tengo una boda y un bautizo y necesito zapatos- explica Inés.

Reconstrucción de notas de campo, Sahuayo, 6 de mayo 2013

Por las palabras de Inés empiezo a entender que la falta de comunicación entre las hermanas, o más bien, el ímpetu que Isabel ha mostrado los primeros meses con el plan de negocio ha hecho que el plan original se vaya desvirtuando poco a poco.

Durante las entrevistas, Karen e Isabel nunca habían mencionado la posibilidad de que las participantes en la tanda obtuviesen algún tipo de beneficio sobre los productos como condición de su participación, y menos algún descuento de los mismos. Parece que las tácticas comerciales de Isabel estaban ocasionando un aumento en las expectativas de las participantes. Aunque en un primer momento el discurso de Inés señalaba a Isabel como la generadora de esas expectativas sin ninguna prueba, Mercedes empezó a explicar sus planes, lo que hizo que la sospecha no fuera descabellada.

-Estas cosas [refiriéndose a las tandas] son muy común en pueblos y con gente cerrada. Yo participé en varias en Guadalajara, pero eran de la universidad. Aquí se recurre a amigos y familiares para que ayuden 
porque la gente pasa muchos apuros. La gente de fe nos ayudamos, pero también hay que buscar algún beneficio porque no es solo ayudar a los demás y no cuidarte tú. Por eso Isabel sabía que si no nos ofrecería algo no le entrábamos a su plan. -

Reconstrucción de notas de campo, Sahuayo, 6 de mayo 2013

A diferencia de su madre, Mercedes espera que su participación en la tanda sea reconocida, tanto a nivel económico como moral, bajo un enfoque de participación altruista, aunque señala que intentara encontrar el beneficio de esta actividad adquiriendo cosas a bajo precio.

\subsubsection{La fiesta de quince años}

Hoy se celebra la fiesta de quince años que dio origen a la tanda. Karen e Isabel insistieron en invitarme a la celebración. Monse y su hija viven en Jiquilpan por lo que la misa es en una de las iglesias principales de la localidad y la posterior fiesta en una quinta a pocas cuadras de mi residencia.

Reconstrucción de notas de campo, Sahuayo, 6 de julio 2013

La fiesta de los quince años se inicia con una misa, denominada Misa de Acción de Gracias en la que se venera a la virgen. Este ritual de paso simboliza la transición de niña a mujer a través de varios elementos. Sumado a la misa, la niña debe lucir una 
vestimenta que simula los pomposos vestidos de las princesas de los cuentos, estar peinada y maquillada. Durante la misa, su madrina o padrino colocara una medalla de la virgen en el cuello de la joven, bendecida anteriormente. Los padres, padrinos y madrinas forman parte de la comitiva que acompaña a la quinceañera junto con sus chambelanes ${ }^{97}$ con los que durante el banquete posterior realizará un baile. Entre las diferentes tradiciones de este ritual de paso, hay algunas anteriores a la ceremonia, como el momento de maquillarse o guardar los juguetes, y algunas que se realizan durante el banquete posterior a la misa, entre las que destaca el regalo de su ultimo juguete, o el cambio de calzado de la chica, protagonizado por el padre que descalza a su hija para calzarla con zapatos de tacón.

Más allá de la propia celebración como ritual de paso para la joven, la familia hace un gran desembolso de dinero, entendiendo que, con esta ceremonia, presenta a su hija en sociedad volviéndose una mujer que puede tener pretendientes para un futuro casamiento.

La celebración organizada por Monse cumplía todos los requisitos para ser una fastuosa fiesta de quince años. Su hija Itzel lucía un vestido rojo con pequeños cristales incrustados en los volantes de una gran falda. Tanto el peinado como las joyas de la muchacha simulaban a la perfección la imagen de princesa de cuento de hadas que se pretende en estas celebraciones. Monse estaba muy contenta con el evento, aunque en varias ocasiones su alegría se tornó tristeza cuando pensaba en lo orgulloso que se sentiría el padre la Itzel si estuviese allí con ella.

\footnotetext{
${ }^{97}$ Los chambelanes son hombres jóvenes que acompañan a la quinceañera. Su nombre proviene de la denominación que los oficiales de una casa real recibían cuando prestaban servicio en la cámara del rey. En las fiestas de quince años mexicanas, los chambelanes suelen ser familiares de la misma edad que la joven, primos, hermanos, vecinos y compañeros de clase. El número de chambelanes varía en cada celebración, aunque por regla general no suelen ser más de quince ni menos de cinco.
} 
Karen, con la disculpa de alejarnos de la zona donde se está sirviendo la comida para fumar, me explica cómo está resultando la tanda y cuáles son los problemas que está encontrando.

-La neta me arrepiento. No de la tanda, sino de la gente que está. La tanda es buena idea, mi turno es el próximo mes y eso me va a aliviar bastante, pero estas mujeres ya me tienen harta. El otro día la tuve con Mercedes porque me quiso regatear unos zapatos, había más gente en la tienda y ella armando mitote que si me estaba haciendo un favor y yo solo pensaba en dinero. Al final por evitar el enfrentamiento le hice descuento, pero ya no saqué nada y además se fue ofendida. Mi hermana, muy emocionada al principio, pero ya casi ni va a la tienda, y no digamos en ayudar con algo, solo me escribe al whatsapp para pedirme que aparte algo a alguna amiga, así que todo lo que te conté sobre seleccionar a los clientes se ha ido a la chingada, me está metiendo en un compromiso muy grande. Le estoy sacando dinero, pero a futuro, porque entre los apartados y los dos meses de tanda que quedan pendientes al final no sé si le voy a perder. -

Reconstrucción de notas de campo, Sahuayo, 6 de julio 2013

Karen se encuentra preocupada porque empieza a intuir que la tanda requiere de un ordenamiento en las relaciones sociales y un control sobre los participantes que ella no tuvo en cuenta en el inicio. También en otras conversaciones me había indicado que existen tensiones entre las participantes, como por ejemplo entre ella y su hermana. 
Hasta ese momento no se había preguntado a Karen cuál era el motivo por el que seleccionó este tipo de financiamiento frente a los otros, ya que Karen cuenta con una cuenta bancaria, por lo que podía haber pedido un crédito en su sucursal que la evitase recurrir a un sistema financiero informal. Dado que la tanda se encontraba en la mitad de su rotación y empezaban a surgir problemas se decidió realizar esa pregunta en esta etapa.

-La tanda... pues es que la cuenta de Bancomer es de mi marido, también estoy yo, pero él la controla, y no quiero que vea lo que gano o dejo de ganar. El dinero de la tienda es mío, para mis hijos, porque de los hombres te debes fiar lo justo. Monse participa en una tanda, luego te presento a la doña que se encarga, y así la conoces. Monse vino a la tienda a ver si podía hacer algo para sacar unos pesos, pero ya ves que hay poco que hacer además de vender. Entonces ella dijo lo de hacer una tanda con nosotras, algo pequeño, para completar con la otra. Isabel ya lo vio claro, con una tanda un poco más grande nos daba para el pedido, estaba desde que se lo dijo Alfonso buscándole el modo.

Las tandas aquí son muy comunes, el fallo fue mío, porque no tenía que ser yo la organizadora. Monse o Isabel se tenían que haber hecho cargo, pero Monse porque tiene muchas cosas y mi madre dijo que me hiciera cargo yo porque Isabel no da confianza. Claro, yo sí, porque si la tanda va mal, pues está la tienda, pero al final todos a lo suyo y yo les quedo mal. -

Reconstrucción de notas de campo, Sahuayo, 6 de julio 2013 
Según las palabras de Karen, la tanda se había organizado para cubrir dos objetivos, la fiesta y la compra de mercancía importada. Ninguna de las dos cosas había sido propuesta directamente por Karen, aunque la compra de productos la beneficiaba directamente a ella. Con la tanda, Monse conseguía el dinero para celebrar la fiesta, pero el objetivo de Isabel no perseguía un enriquecimiento monetario.

Isabel se había convertido en una especie de "It girl"98 de la región. Su continua exposición en las redes sociales y la promoción de los productos importados habían hecho crecer considerablemente su influencia en el ámbito de la moda. Igualmente había aumentado considerablemente su capital social, siendo percibida como una "cazadora de tendencias" a la que muchas mujeres seguían para emular sus ropas o maquillaje.

Este proceso por el que Isabel ganaba protagonismo se completaba con la posibilidad que ella estaba ofreciendo de facilitar las compras de ciertos productos a sus seguidoras, aunque aquello supusiera una pérdida de control por parte de Karen de los apartados de su comercio.

De vuelta al banquete Karen me presenta a Elena y Humberto. Tienen una ranchería en Jiquilpan y Elena es la organizadora de la otra tanda en la que participa Monse.

En la mesa se habla del último escándalo ocurrido en la región entre muestras de asombro por parte de algunos y comentarios jocosos sobre el excandidato del PRI a la alcaldía de Jiquilpan. La noticia se supo el dos de julio, aunque los comentarios eran continuos desde entonces, aprovechando con ellos la crítica política entre los partidarios

\footnotetext{
${ }^{98} \mathrm{El}$ término "It girl" es una frase en inglés que hace referencia a una joven que posee una cualidad (Iteso). Aunque en origen el termino se utilizó para denominar un poder de atracción independiente de la belleza como una cualidad física o mental, el término se popularizó gracias a la película $I t$, estrenada en 1927. En la actualidad el término es usado para denominar a las mujeres poseedoras de sex appeal que, a través de su presencia en las redes sociales, su red de relaciones sociales y su personalidad son capaces de marcar tendencias en la moda y estilo de vida.
} 
de un partido u otro. El excandidato, Oscar Francisco Servín y su esposa habían sido capturados en Playa del Carmen, Quintana Roo acusados de secuestrar a una señora de sesenta y siete años a la que reclamaban una deuda. Era poca la información que se tenía sobre el asunto. La familia de los acusados no había sido vista desde entonces por el municipio y se suponía que evitarían mostrarse en público durante una temporada. Las conversaciones, ante la falta de datos, giraban en torno a cómo la gente de Jiquilpan (refiriéndose únicamente a la cabecera municipal) apoyaba de manera incondicional al PRI, pero aquellos que perteneciendo a Jiquilpan, residían en otras localidades del municipio, se flotaban las manos ante la oportunidad de criticar al "partido de Jiquilpan" y, por extensión, al clientelismo político (Hagene y González de la Fuente, 2016) que ciertas personas profesaban como un acto de adoración hacia la familia Cárdenas y el PRI. La fiesta termino con Karen e Isabel ayudando a Monse a llevar todos los regalos de Itzel al coche. Todo había sido un éxito y la pequeña había tenido su gran día.

\subsubsection{La última cuota}

Durante varios meses, la investigación se había enfocado en otras personasy, en el mes de noviembre, con motivo de comprobar cómo había resultado el pago de las cuotas, se concertó una cita con Karen. Este mes era el último en el cual las participantes debían abonar su cuota mensual, aunque todavía la tanda se alargase dos meses más debido a su carácter retroactivo.

La tienda de Karen ha cambiado mucho desde la primera vez. Ahora los productos están más enfocados hacia la cosmética o cuidado personal y los zapatos se han visto recluidos a un pequeño lugar al fondo de la tienda. 
Hay una zona, en unos de los laterales para lencería, donde también se exponen aceites y cremas de la marca Victoria’s Secret. Es más que evidente que la mayoría de los productos son de importación y el nuevo color de las paredes hace que la tienda luzca más grande de lo que es. Antes de entrar observo que en el escaparate hay un cartel con nombres, no muy llamativo y colocado en la parte inferior del cristal.

Karen está quitando el polvo de varios productos y me invita a pasar. Aunque no había tenido oportunidad de pasar por la tienda en los últimos meses, había mantenido el contacto a través de Facebook y, en su último mensaje, me pedía que fuera a visitarla porque debía contarme algo muy importante.

Reconstrucción de notas de campo, Sahuayo, 4 de noviembre 2013

-Ya se te echaba en falta, imagino que has estado ocupada con tus entrevistas... ¿Has visto el cartel? Me están quedando mal las amigas de mi hermana, algunas solo han pagado la mitad, otras ni eso. ¡Tuve una pelea con ella por esto... la diva! Mira, -saca del cajón la libreta de apartados- todos las que están con la línea azul son suyos, y ella ahora no sabe. Me dijo que ya va a hablar con ellos, yo ya me cansé y esta mañana he puesto el cartel. Ya estoy de vuelta, me anda valiendo madres [me da igual] quedar a bien o no, total, la gente va a lo suyo. ¿Te acuerdas de Mercedes? Casi le tiro de los pelos. Vino el sábado, a primera hora, a cobrar la tanda. Como no tenía el dinero aquí se enfadó y empezó a 
criticar todo. Armó un drama... tuve que llamar a Isabel para que viniera a la tienda y así poder ir yo al banco a por su dinero.

Era día dos y sábado, estaba todo abarrotado, una hora me estuve en el banco y mientras la mugrosa quejándose en la tienda. Cuando terminé, llego a la tienda y me la encuentro con una bolsa llena de cosas, perfume, lencería y maquillaje, $y$ dice "pues igual no tenías y me lo llevo en especies". Isabel como si nada. Le doy el dinero y hace amago de agarrar la bolsa. Yo ahí ya perdí los nervios, porque me quería ver la cara de pendeja, esta no lo paga y encima me anda quemando [criticando]con medio Sahuayo.

Al final se rompió la bolsa, yo solo vi unos calzones [bragas] rosas volando por la tienda y de los puros nervios le dije “¿tú para que quieres esos calzones?". Luego me dio pena, pero lo hice sin pensar-

Grabación de audio, Sahuayo, 4 de noviembre 2013

Karen, al ver que yo no entendía dónde estaba el error de sus palabras, me explicó, como se explican los chismes, en voz baja, apagando la grabadora y mirando hacia la puerta para asegurarse que nadie entra y puede escuchar la conversación.

Su marido y Armando fueron juntos la última vez a California. Armando a mí no me dijo nada, pero hace dos años, cuando vino en Navidad, me preguntó por Mercedes y me contó que el marido andaba con otra. Mercedes no había dicho nada y estaba muy digna con que su marido le 
mandaba de todo. El caso fue que luego lo mató... bueno, eso dijo, y yo claro llame a Armando para ver que se podía hacer, él ya me dijo que no. Pero pues obvio a la madre le iban a preguntar, por lo menos dar el pésame. La neta yo igual sí fui comentando el caso a una clienta o en otro sitio, pero pues, si se muere alguien de aquí, rápidamente se sabe. La madre después del susto fue a hablar con Mercedes y le dijo que la culpa era de ella. Ahora no se hablan, y eso que tiene un nieto, pero la señora dice que ni se le parece... Yo no sé qué paso, pero Mercedes le dijo a su madre que la culpa fue de Armando, y que él también anda así por allí, aunque yo no diga. Nuestras madres son amigas, pero esta es bien venenosa, por eso te dije "ten cuidado" pero yo no tuve. Pero ahí muere y la neta a ti te lo digo porque me arde, ese pinche mamón batea a la izquierda ${ }^{99}$.

Reconstrucción de notas de campo, Sahuayo, 4 de noviembre 2013

Las deudas no habían sido el factor principal por el que Karen y Mercedes habían roto su amistad, sino el detonante de una confrontación que se originó hace tiempo. La confianza y reciprocidad que habían servido como aglutinantes para la participación en la tanda también arrastraban, junto con ellas, una trayectoria vital conjunta en la que los conflictos pasados participaban en el presente como factores condicionantes, no solo del funcionamiento de la tanda, sino construyendo una sociabilidad que se basaba en deudas morales. Mercedes consideraba que la poca o nula atención que recibió en el pasado su marido para que no le fuera infiel era una deuda contraída por Karen a la cual podía

\footnotetext{
${ }^{99}$ Expresión coloquial para dar a entender que alguien es homosexual.
} 
recurrir. El recurrir a esa deuda moral no se hacía en momento de necesidad, sino con venganza y resentimiento esperando el momento para cobrarse la deuda de manera que ella saliese triunfante. En el caso de Karen, ella entendía que la deuda moral era de Mercedes hacia ella, por haber guardado la deshonra en el ámbito privado y no expresar su opinión, así como los detalles que su marido le había dado sobre el asunto. La tanda fue el catalizador de esta confrontación, en la cual ninguna de las dos quedo satisfecha asumiendo que la otra se encontraba en deuda.

\subsubsection{Nunca tiene razón quien no tiene dinero}

El mes de enero se entrega la última cuota de la tanda, correspondiente a Paulina. La tienda de Karen luce con menos mercancía y el cartel de malas pagas ha aumentado en comparación con el anterior.

Se organizó una reunión con Paulina y Karen para terminar con el seguimiento de la tanda y comprobar cuáles han sido los resultados. En la entrada se encuentra Paulina revisando algunos productos y guardándolos en cajas. Karen está apoyada en el mostrador con sus libretas y la calculadora.

Es posible que haya envejecido prematuramente o esté demasiado cansada, pero los tacones y el maquillaje que solía llevar han sido sustituidos por unas zapatillas de deporte y la cara recién lavada. Pide que me siente junto a ella, en el rincón entre el mostrador y los probadores que desde el principio siempre había sido mi rincón de observar. 
Se va hacia la parte trasera de la tienda para buscar un asiento y cuando ya está cómoda me explica cuál fue la resolución de su plan empresarial.

-Voy a cerrar la tienda. ¿Recuerdas lo que te dije antes de navidad? (nuestra última conversación había sido en noviembre, cuando me explicó su enfrentamiento con Mercedes).

Los dos últimos meses había hecho frente a las últimas cuotas de la tanda ella sola y, aunque las ventas de navidad la habían ayudado, no la permitieron comprar más género. Tuvo que posponer el pago de Evelia, que debía ser a primeros de diciembre para el mes siguiente y todavía no tenía dinero para pagar a Paulina. La pelea con Mercedes había tenido repercusiones en Isabel que, al posicionarse defendiendo a su hermana, se ganó la desconfianza de parte de sus "seguidoras".

Estas, a su vez, decidieron no pagar los apartados que tenían pendiente en la tienda, por lo que las deudas aumentaron y ya se daban por perdidas. Karen renegaba de la idea de la tanda y de su suerte.

Reconstrucción de notas de campo, Sahuayo, 25 de enero 2014

-Ya no sé qué pensar. Mercedes se montó un drama y claro Guadalupe con sus amigas las chismosas... en unas semanas lo sabe hasta gente de Zamora. A mi marido lo pararon por la calle para decirle que yo era muy mal portada, acababa de llegar a Sahuayo por fiestas. A él le hace gracia y dice que las viejas somos bien venenosas, pero yo así con la tienda no puedo. 
Yo a Paulina la voy a pagar con mi dinero (eleva un poco la voz para que Paulina pueda oír lo que dice) pero así no son las cosas. Meses con el pendiente de la tanda, la tienda y los pedidos para cerrar y quedar mal con mi hermano (se refiere al marido de Paulina, José Antonio). Mucha gente no me ha pagado, pero si con el cartel no lo hacen... ¿Qué hago? -

Grabación de audio, Sahuayo, 25 de enero 2014

Le pido me enseñe su libreta de apartados para observar cuántas personas quedan pendientes de abonar la compra y cuáles son las cantidades. En los últimos meses no ha aceptado apartados, la última anotación es de noviembre. Casi todas las personas pendientes de pagar realizaron la compra entre julio y septiembre por lo que es difícil recuperar ese dinero después de tantos meses y con el capital social de Karen por los suelos. Al ver en páginas anteriores su clasificación de clientes con estrellas y círculos, intento animarla señalándole que este era un buen método.

-Sí que lo era, pero muchos nuevos clientes son un riesgo. Isabel no tiene la culpa, quiso ayudar, pero una tienda en un sitio pequeño se mantiene por clientes de confianza no por las niñas fresas ${ }^{100}$. -

Grabación de audio, Sahuayo, 25 de enero 2014

Mientras Paulina y Karen terminan de embalar las últimas cosas de la tienda voy a buscar la bolsa de basura para recoger del suelo los últimos plásticos y cartones. Dentro

\footnotetext{
${ }^{100}$ Mujeres con un nivel económico alto que utilizan los marcadores sociales de clase para evidenciar su estatus económico.
} 
de la bolsa hay dos libretas, las que compró cuando inicio su plan, en una pone Tanda y en otra MissMac.

\subsubsection{Ni tanto que queme al santo, ni tanto que no lo alumbre}

Meses después de nuestra última reunión encontré a Isabel en una cafetería del centro del Sahuayo. Ella estaba recogiendo un pastel que había encargado para el cumpleaños de uno de sus sobrinos. Sin dudarlo mucho, me invito a la fiesta de cumpleaños, y aunque no tenía ningún regalo le agradecí la invitación y la acompañé.

La fiesta es del hijo mayor de Karen, que cumple ocho años. Karen, ocupada en la cocina, prepara la comida mientras Paulina termina de decorar el patio en el que ya está instalado un inflable con forma de castillo para que los niños jueguen.

Los invitados empiezan a llegar y, para mi sorpresa, Guadalupe y Mercedes llegan con un regalo para el niño y algo de comida. Entre familiares, amigos de la madre y los compañeros de clase del niño, la fiesta congrega a gran parte de los habitantes de una de las zonas con mejor nivel económico de Sahuayo.

Cuando la fiesta ya toca a su fin, más por decisión de los padres, ya que los niños muestran su intención de alargar la fiesta todo lo posible, la casa empieza a quedar vacía y el jardín se parece a una zona de guerra en la que las víctimas han sido hamburguesas, vasos de plástico y globos. Por la hora que es, ya perdí el ultimo autobús que me lleve a Jiquilpan y Karen me indica que ella me lleva en cuanto recoja un poco y el señor del inflable 
se marche. Una vez conseguimos dejar la casa, y con los niños de Karen jugando con sus primos y la abuela, Karen saca el auto de la cochera. El maletero está lleno de bolsa con pequeños objetos, todos similares.

-Ahora estoy haciendo invitaciones y recuerdos. Mira, aquí tengo varios, estos son para un bautizo, los vamos a poner con una bolsita de caramelos, y esta (señalando una invitación) es para una boda de septiembre-.

Reconstrucción de las notas de campo, Sahuayo, 7 de junio 2014

El supuesto desgaste de capital social que Karen había sufrido durante el tiempo en el que se había realizado la investigación ya no estaba patente. Parecía como si todas las disputas hubiesen quedado atrás y, aunque ahora ella se dedicaba a otra cosa, seguía teniendo la confianza suficiente para recibir encargos y realizar esas invitaciones. Ante mi sorpresa por cómo habían cambiado las cosas en estos meses, Karen sonrió.

No te engañes, yo con Mercedes sigo igual, pero mi madre y Guadalupe insisten que hay que guardar las formas, somos casi familia. Con Inés es diferente, porque ella no es del barrio y es la metiche ${ }^{101}$ que lo hizo todo. Mercedes ya no va con ella, ahora me ayuda con estas cosas (refiriéndose a las invitaciones).

Reconstrucción de las notas de campo, Sahuayo, 7 de junio 2014

\footnotetext{
${ }^{101}$ Persona que se inmiscuye en asuntos ajenos.
} 
Guadalupe y Asunción, madres de Mercedes y Karen respectivamente, habían solucionado la disputa. El recurso que habían utilizado era el de proximidad, apelando al sentimiento de clase y al parentesco ficticio que las unía. Mercedes y Karen, para evitar más daño en su capital social y seguir perteneciendo a este grupo elitista, no habían tenido más opciones, se aliaron frente al otro, como externo de su comunidad, a Inés.

Habían colocado a Inés en el papel de chivo expiatorio, mientras las demás solo habían sido víctimas de sus malas artes. El que Inés fuera de otro barrio (más humilde) se señalaba como uno de los factores que habían sido indispensables para ser catalogada como elemento extraño y perturbador.

Una vez llegadas a Jiquilpan y, antes de bajarme del coche, le pregunto sobre un dato de la investigación que en las relecturas del diario de campo estaba señalizado como pendiente. La pongo en situación - ¿Recuerdas cuando me explicaste los tipos de clientes que podían usar el apartado...? dijiste que algunos tenían dinero, pero no eran buenos clientes, pero nunca me explicaste qué tipo de clientes eran esos- Karen intenta hacer memoria mientras mira por el retrovisor, luego con una sonrisa condescendiente y mirándome como si fuese una niña me dice,

-Hay muchos, pero tú no los ves. Bueno, si los ves, pero no sabes quién son, yo sí. Muchas mujeres que entraban a la tienda luego no venían a pagar, venia otro, bueno pagadores. Gente que hay que respetar. Yo con ellas no tengo problema, eran las mejores clientas porque el dinero no era suyo, pero no me gusta que luego manden a un raterito para pagarme el apartado, eso se ve bien feo. - 
Reconstrucción de las notas de campo, Sahuayo, 7 de junio 2014

Ante mi gesto de comprender a lo que se refería, zanjó la conversación y despidiéndonos me baje del coche. Después de esa noche nos volvimos a ver varias veces, aunque poco a poco el saludo se convirtió en un simple gesto y un saludo de dos conocidas con prisas por llegar a otro lado.

Karen me había señalado un tipo de clientes a los que difícilmente se hacía mención, pero que convivían con ellos, compraban en sus tiendas y sobre los que trazar una línea que los diferenciase del resto era difícil cuando no absurdo. El dinero no provenía de un salario, pero era dinero, aunque su origen fuesen las actividades ilegales. Esas clientes, mujeres jóvenes, gastaban grandes sumas de dinero en ropa, complementos y maquillaje. En realidad, eran las mejores clientas posibles de una tienda como la de Karen, con mucho dinero que gastar en caprichos. Con el paso del tiempo oí muchas definiciones para referirse a ellas, narco-novias, narco-morras, princesas de los cárteles. No necesitaban llevar dinero, nadie iba a negociar un apartado o fiado con ellas, su poder radicaba en conversaciones de alcoba que podían sentenciar rápidamente a una persona.

Los comerciantes, Karen entre ellos, no hablaban mucho del asunto, era el modo de normalizar la situación y no hacer destacar demasiado el poder y control que estas mujeres podían tener en ciertas ocasiones. Ese mismo poder y control que sufrían ellas, sumado a los celos y la dominación de sus amantes, era un poder que tenian ellas en la comunidad, aunque no quisieran. En muchos casos eran chicas jóvenes, hermosas, a las que solo se les podía criticar tener amigos peligrosos, pero la narcocultura imponía una jerarquización estricta que asemejaba el trato a estas mujeres con sus homologas en la 
jerarquía militar. La mujer del Coronel puede tener lo que quiera, pagar como quiera y hacer lo que quiera, siempre que le parezca bien al Coronel.

Existían dos perspectivas, se percibían como "nuevos ricos" excesivos en su ostentación, incluso vulgares, pero con un nivel económico superior a la clase acomodada que durante generaciones había ocupado la clase social superior. Por otro lado, eran los mejores clientes y ofrecerles servicios demostraba fidelidad. Negarles el acceso a una tienda o una reunión no estaba contemplado como algo posible. Ahora convivían con ellos y sus actividades no se ponían en duda, solo se intentaba que sus trabajadores no fuesen la conexión entre unos y otros. Querían un trato de igual a igual, pero por el otro, lo preferible era que cualquier trámite o comunicación se realizase a través de la figura de un trabajador intermedio, similar a un diplomático que uniese los dos reinos.

\subsection{Elena, la doña de la tanda}

La Fiesta de Quince años de Itzel, celebrada el 6 de julio de 2013, me ofreció la oportunidad de conocer a Elena y a su marido. Elena se ofreció a ayudar en la investigación después de las explicaciones de Monse (prima de Karen e Isabel). Ella organizaba una tanda en la que también participaba Monse, en la que el funcionamiento era diferente ya que los objetivos y motivación de la misma no eran comparables con el intento de plan empresarial que las hermanas habían emprendido.

Elena era una señora de 54 años, casada con (ella siempre hablaba de su marido refiriéndose a él como "el amor de su vida”) Humberto. Juntos habían tenido cinco hijos, tres chicas y dos chicos. Las chicas ya estaban casadas, una vivía en Tangamandapio ${ }^{102}$,

\footnotetext{
${ }^{102}$ Localidad cercana a Jiquilpan.
} 
las otras residían en Morelia porque habían recibido estudios universitarios y trabajan en la capital.

Este hecho enorgullecía profundamente al matrimonio que, aunque rancheros del mundo rural, habían invertido gran parte de sus ahorros en los estudios de sus hijos. El hijo mayor trabajaba en Estados Unidos. Hace años había ido a Chicago a visitar a unos familiares y, desde que regresó de ese primer viaje, tuvo como objetivo regresar y quedarse en Estados Unidos. A través de una beca de estudios y mucho trabajo, había conseguido un buen empleo en el gabacho y ya hacia allí su vida. En casa solo quedaba el hermano pequeño, Rodrigo, que ese año cumplía los 24 años.

Humberto era el dueño de un rancho que pertenecía a la demarcación territorial de Jiquilpan. Aunque ellos residían en la cabecera municipal, siempre remarcaban que eran gente de rancho y preferían la tierra a la plaza. Sus hijos habían sido criados para enfrentarse a la desaparición de los ranchos y del mundo rural, por eso, en palabras de Elena, "los jóvenes tienen que estar preparados para el futuro, nosotros ya somos pasado". Elena no se había criado en un rancho, sus padres habían llegado a la región cuando eran jóvenes para trabajar. Gran parte de su familia era originario del Distrito Federal y, quizá por ello, Elena valoraba la vida en el rancho, la naturaleza y la vida tranquila. Su manera de ver el mundo estaba enmarcada en las contrariedades que acompañan a parte de su generación.

Ella había nacido en 1959, aunque se calificaba como hija de los sesenta, y las fotografías del álbum familiar atestiguaban que sus padres habían sido uno de tantos jóvenes capitalinos que se habían trasladado al interior del país buscando la reconexión con la naturaleza y una vida alejada del consumismo. 
Una semana después de conocerles pude concretar una cita. Ellos pasarían a buscarme y me llevarían al rancho, donde comeríamos y tomaríamos café.

A poca distancia de Jiquilpan, pero por un camino a veces de asfalto y a veces de tierra, llegamos al rancho de Elena y Humberto. Aunque no hay una demarcación que señale donde termina el terreno, la entrada está decorada con un arquito de metal que da la bienvenida y un camino de tierra que lleva hasta una casa pequeña.

La casa es utilizada como segunda residencia y la edificación no tiene casi paredes salvo aquellas que son las fachadas del edificio. En el interior hay varias camas queen size ${ }^{103}$, una gran mesa y una torreta de sillas de plástico en un rincón junto a la puerta de entrada. Los cables de la electricidad cuelgan de las paredes y se extienden por los techos como guirnaldas unidas a las paredes y techo por unos clavos que sobresalen de las vigas de madera. Una pared está reformada con ladrillo, pero las demás son de adobe lo que hace que el suelo siempre esté lleno de arena y polvo. Arreglaron esa pared hace unos años, cuando una tormenta hundió esa parte del tejado. En las paredes hay varios posters de grupos de banda que se alternan con imágenes de la Virgen de Guadalupe, el Papa Juan Pablo II y las figuras en yeso de San Pancracio ${ }^{104}$ y San Judas Tadeo $^{105}$.

\footnotetext{
${ }^{103}$ Camas de gran tamaño, 1,60 mts. De ancho, 1,90 m de largo.

${ }^{104}$ Uno de los primeros mártires del cristianismo, es considerado como el santo de los afligidos por la pobreza, de la fortuna y de los juegos de azar.

105 Es el santo que tiene mayor devoción en México. Patrono de las causas difíciles o desesperadas, su imagen se reproduce en esculturas de yeso o estampas.
} 
En la parte trasera del edificio, y cobijado por una techumbre de lámina, está la cocina. La zona para cocinar dispone de un hornillo de leña y varias construcciones con ladrillo de adobe donde encajar las ollas o el comal $^{106}$.

Elena se ha puesto a preparar todo para la comida y ha mandado a su marido a que de un agua al cazo de cobre que estaba colgado en el techo de la casa. Mientras nosotras encendemos el fuego y, a modo de broma, me encarga asar los chiles ${ }^{107}$. Doña Elena organiza las bolsas que ha traído en el coche, hago cuentas de las camas en relación con la familia, Desde la cocina hay tres camas grandes, una cuna y una cama plegable apoyada en una pared.

Cuando Elena regresa, le pregunto cómo se organizaban para dormir allí todos juntos a lo que ella responde:

-Nosotros en la del centro, los chicos junto la ventana y las niñas a este lado, la cama esa es para alguna visita y la cuna la trajo mi hija hace unos meses, porque cuando estos eran bebes había otra cuna, pero se echó a perder cuando se hundió el tejado. -

Humberto llega con el cazo limpio de polvo, lo deja en la mesa y se despide, él se va a ver a las vacas y no volverá hasta que la comida esté en la mesa.

Aunque originalmente la invitación había sido planteada como un momento de esparcimiento con una comida y café en el campo, por la

\footnotetext{
${ }^{106}$ Recipiente de cocina generalmente circular y plano, a modo de plancha, utilizado para cocinar las tortillas.

${ }^{107}$ Cuando se asan los chiles provocan que la persona que está cerca de ellos tosa y estornude.
} 
cantidad de comida que tiene Doña Elena ${ }^{108}$ pronto adivino que me va a tener trabajando toda la mañana.

Doña Elena (al igual que muchas personas de la región) siente curiosidad, no tanto sobre mi investigación, sino sobre cuál es mi visión de la región, cómo les veo yo a ellos, y cuando le digo que no me gustan las ciudades grandes, ella reafirma mi recelo a vivir en la urbe y comienza a explicar su experiencia con la gran ciudad.

-Yo de chica iba todos los años al D.F. a casa de mis tíos, me gustaba mucho ver tiendas y estar con mis primos. Mis padres se vinieron a Jiquilpan porque mi papa encontró trabajo aquí y querían tener su casita con jardín.

Aquí la infancia es tranquila, yo vivía cerca del centro y podía ir al colegio caminando todos los días. Por entonces te pasabas toda la tarde jugando en la calle, no como ahora que los niños ni salen de casa, antes era más vida de pueblo. A mí esto siempre me gustó, pero pues de morrita [niña] lo que quieres es conocer y apunto estuve de irme al D.F. Cuando tenía 18 quería irme a vivir con mi tía, pero después de Tlatelolco ${ }^{109}$ ya no quise. Un primo mío se quedó dañado de aquello y en pocos años murió, se quedó loco.

\footnotetext{
${ }^{108}$ Aunque aquí me refiera a ella como Elena en algunas ocasiones, siempre la trate de usted y me réferi a ella como Doña Elena como es costumbre en la región y especialmente con las personas con las que se tiene una gran diferencia de edad.

${ }^{109}$ Hace referencia a la Matanza de Tlatelolco ocurrida el 2 de octubre de 1968 en la cual el gobierno de México reprimió el Movimiento Estudiantil de 1968. El Movimiento estaba compuesto por estudiantes de la UNAM y el IPN además de otras universidades, profesores, diferentes movimientos sociales y población civil. Reunidos en la plaza de Tlatelolco, el grupo paramilitar Batallón Olimpia abrió fuego desde las azoteas a la multitud. Con el apoyo de fracciones de la policía y el ejército mexicano, el gobierno de México reprimió el movimiento aniquilando a sus dirigentes realizando detenciones ilegales, torturas, persecuciones y desapariciones forzadas. Hasta la fecha no se sabe el número de asesinatos, heridos y desaparecidos.
} 
Me quedé aquí y conocí a Humberto. A mi padre no le pareció bien porque Humberto y su familia son muy católicos y a mí me habían dado una educación socialista pero ya sabes el dicho, "Cuando te toca, aunque te quites; cuando no, aunque te pongas". Tampoco creas que a la familia de Humberto le parecía bien. Humberto compró esto (refiriéndose al rancho) y aquí nos vinimos hasta que ya no les quedó otra y de aquí a la iglesia.

La casa de Jiquilpan es la de mis padres. Cuando mi padre murió, mi madre nos abrió la puerta. Allí todo es más fácil, hay electricidad y agua, aquí la pusimos hace unos años, con un generador. -

Doña Elena ya tiene el cazo de cobre en el fuego y ha vaciado un cubo de manteca de cerdo en él. Yo, mientras, aso los tomates y ella va unos segundos al interior de la casa para salir con un molcajete ${ }^{110}$. Vuelve a entrar en la casa para sacas a la mesa exterior varias bolsas con carne de cerdo.

-Te voy a enseñar a preparar carnitas al estilo Michoacán, ¿las has probado?, ¿están buenas verdad? De lunes a jueves preparo carnitas y se las bajo a un vecino que las vende en la tarde-noche. Mira, primero hay que calentar la manteca, siempre en cazo de cobre para que luego agarren color y cuando ya está así se va metiendo la carne, primero la maciza y costilla... la cabeza de lomo es lo más sabroso y esto para después. -

Doña Elena había agarrado una gran pala de madera con la que removía los trozos de carne.

\footnotetext{
${ }^{110}$ Utensilio de cocina fabricado con piedra volcánica tradicional de la cocina mexicana. Se asemeja a un mortero con una superficie cóncava donde se muelen los alimentos con el tejolote (una piedra que hace la función de mano de mortero). Se emplea para elaborar salsas.
} 
Los vapores de la manteca hirviendo impregnaban cualquier cuerpo que se opusiera entre ellos y el cielo, impregnando la techumbre de una capa de grasa que se sumaba a las anteriores. Doña Elena "remaba" con su gran pala de madera moviendo grandes trozos de carne mientras yo seguía moliendo con el molcajete.

- ¿Te interesan las tandas? Me dijo Monse que estás entrevistando a su prima porque hicieron una tanda. La mía es muy diferente, nosotros no lo hacemos por tener dinero, ni para comprar cosas, nosotros intentamos ayudar. -

Doña Elena para de remover el cazo y añade el buche y el cuerito a la mezcla. Después, poco a poco, añade agua de una garrafa que tiene en la mesa a la mezcla. Una vez ha dejado la pala sobre la mesa y se limpia el sudor con el mandil se sienta a mi lado y pidiéndome que deje de hacer salsa saca un cuaderno de anillas de su bolsa.

-Esto que yo hago lo hago por ayudar, porque hay mucha gente que, trabajando toda la vida, no tiene seguro y, aunque en Jiquilpan estén arreglando banquetas y poniendo todo bonito ${ }^{111}$, hay gente que pasa mucha necesidad, y a ellos no les llega lo "mágico".

Yo siempre la hago de diez turnos, cinco meses. Una empieza en abril y termina en agosto. La otra es de septiembre a enero. En febrero y marzo no hay tanda porque ya tuve malas experiencias. La de abril funciona bien para la gente que quiere ahorrar en verano, igual tienen una boda o

\footnotetext{
${ }^{111}$ Hacía varios meses que habían empezado varias obras en el municipio. Las obras en el centro estaban auspiciadas por el reciente nombramiento de Pueblo Mágico que había provocado la reforma de fachadas y la modernización del centro urbano.
} 
comunión, o van a visitar a algún familiar. En septiembre siempre hay más gente, porque con esa se hace la navidad, pero febrero y marzo no, porque esos meses la gente está pensando en Semana Santa y los primeros ya se sabe... al que no le cuesta, lo hace fiesta, y la tanda no es para eso.

Reconstrucción de las notas de campo. Cerro de San Francisco, Jiquilpan. 15 de Julio 2013

Doña Elena, a diferencia de Karen e Isabel, llevaba años realizando la tanda, dos cada año. Por su experiencia en las asociaciones rotativas de crédito, había ideado un calendario, eliminando los meses que atraían a participantes conflictivos o evitando que los que según ella "eran los peores meses para tener dinero" formasen parte de la tanda.

-Yo siempre hago diez turnos, para que duren lo que tienen que durar y luego el que quiera me puede decir si quiere un turno, o dos, o no entra esta vuelta.

Los turnos que no se ocupan me los quedo yo y listo, eso de meter a gente para cubrir turnos es el motivo por el que luego la gente se queja. Algunas veces me ha pasado que había más gente que turnos, si eran muchos se hacia otra tanda, pero si no se le da turno para la próxima.

Ahora está ya casi termina, faltan dos turnos y el de hoy, que se lo pago el sábado porque el chico está en Zamora trabajando. Me acompañas el sábado y le conoces. Estamos seis, mi hijo lleva dos turnos y Monse otros dos, yo me quedé con los tres que quedaron libres y luego están Fernanda, 
Estefanía y Jorge con uno. Monse tiene dinero, aunque algunas veces ande apurada, pero esto le viene bien para no derrochar. Mi hijo Rodrigo está ahorrando para comprarse un coche y, como no tiene mujer, le llevo yo las cuentas. Fernanda es buena amiga, nosotras organizamos cosas con la iglesia y le gusta ayudar en todo, y luego están Estefanía y Jorge, que sí necesitan la tanda.. -

Reconstrucción de las notas de campo. Cerro de San Francisco. 15 de Julio 2013

Para Doña Elena existía una gran diferencia entre la tanda de Karen y la suya. Parecía estar al tanto de la tanda de Karen y evité hacer cualquier mención a la misma, aunque ella, pensando con ellos que la comparación me ayudaría a reconocer las diferencias más rápido, utilizó la comparación entre ambas habitualmente.

Aunque en los dos casos, las personas participantes en la asociación habían alegado la ayuda mutua para participar en la tanda, en el caso de Elena la ayuda se apoyaba en el hecho de que la tanda era regular, se repetía de manera cíclica no solo por el hecho de ayudar a una persona de manera puntual, sino con la intención de formar parte de la comunidad y presentar una opción que se mantuviera en el tiempo como sistema financiero institucionalizado en su persona.

La otra diferencia principal entre las dos tandas era que, en esta, las personas, aun manteniendo relaciones de amistad entre ellas, accedían a la asociación en calidad de individuos de diferentes clases sociales y con diferentes necesidades. Para algunos era un método de ahorro que les imponía una disciplina de la quizá careciesen, pero para otros era una necesidad, ya que no tenían muchas más opciones para conseguir crédito y poder ahorrar su dinero. 
La colaboración y compromiso que aceptaban los participantes de la tanda de Elena no estaba enfocado únicamente hacia una ayuda individualizada, o unas normas morales impuestas por la comunidad en tanto dadoras de capital social y marcadoras de clase.En este caso, la colaboración y compromiso se hacía en torno a la comunidad, no por buscar un estatus, sino por ser partícipe de una ayuda para la comunidad.

Mientras la primera atendía a los imperativos colaborativos individualistas imperantes en la economía capitalista en los que la asociación debe resultar beneficiosa a las partes en cuanto colaboradoras para alcanzar un objetivo, en esta segunda tanda se observó, posiblemente condicionado por la visión socialista de la comunidad que tenía Elena, la demarcación de unos objetivos sociales en los que la tanda no se realizaba con el objetivo de alcanzar objetivos individuales, sino que por encima de ellos existía un objetivo comunitario que dominaba sobre el resto. Los objetivos individuales en esta tanda eran beneficios secundarios de su propio funcionamiento.

Como se puede observar en la figura 2, estaban presentes en la participación tres sectores de clases. Elena y Monse pertenecen a la cabecera municipal de Jiquilpan y, aunque ellas no puedan ser calificadas como personas de clase alta en cuanto a sus ingresos, la posesión de propiedad las posicionaba como personas con recursos económicos

El segundo sector está compuesto por Humberto y Fernanda, que también tienen posesiones, pero de menor valor, ya que el rancho o la casa de Fernanda en una localidad rural de Jiquilpan no tienen el mismo valor que las propiedades de las primeras en la cabecera municipal. Aun así, Humberto tenía la producción lechera, aunque como posteriormente se verá reflejado en las entrevistas, esto no le aportaba unos recursos económicos importantes. Rodrigo, el hijo de Humberto y Elena se colocó en este sector 
Figura 2, La tanda de Elena
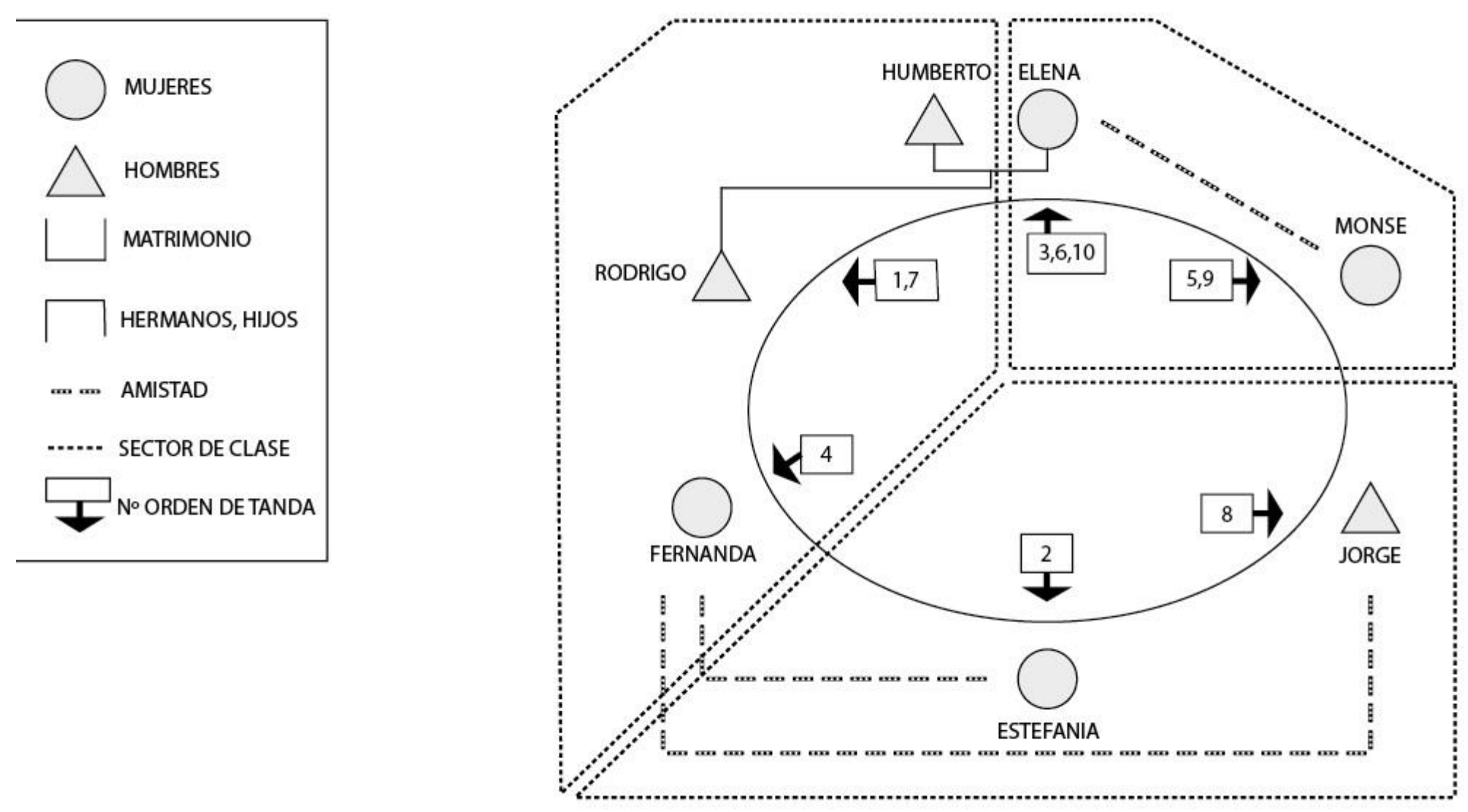

Fuente: Elaboración propia 
porque se tuvo en cuenta que las propiedades de Elena una vez pasasen en herencia a sus hijos serian repartidas en cinco, por los que la herencia recibida por Rodrigo no sería tan significativa.

El último sector está representado por Estefanía y Jorge. Estefanía tiene una hija, pero nunca se llegó a casar y el padre de la niña hizo su vida con otra mujer. Esto la convierte a ella en el único sustento de la casa, trabaja peinando y cortando el pelo, no tiene seguro social y su trabajo es informal. Jorge vive en una localidad rural de Jiquilpan, aunque cuando tiene trabajo se va a Zamora a trabajar en las berries ${ }^{112}$. Aunque hay meses que consigue cubrir sus gastos y los de su familia sin problemas, le diagnosticaron hace unos meses diabetes e intenta ahorrar para hacer frente a los gastos médicos.

Los turnos se repartieron según las necesidades de cada participante. Estefanía y Fernanda necesitaban el dinero pronto y se les dieron números de la primera mitad, pero como apunta Doña Elena, ella siempre intenta alternar los números y a las mujeres darles el par, porque así cobran a mitad de mes, que es cuando más falta hace. Jorge no necesita crédito, sino ahorrar, y se le dio de la segunda mitad. Los demás números los repartieron entre Monse, su hijo y ella, intentando que estuviesen equilibrados. Al hijo le había dado el primero para que se motivase, y viera que así se podía ahorrar para el coche.

Después de una hora en la que periódicamente Doña Elena removía con la pala de madera los trozos de carne del cazo de cobre, y en la que yo había estado apuntando en el cuaderno de campo y echando leña al fuego por partes iguales, ya estaban listas las carnitas. Humberto y Rodrigo

\footnotetext{
112 Zamora está a una hora en autobús de Jiquilpan. El municipio es un gran productor de fresa y frutos rojos, siendo la primera a nivel nacional. Gran parte de su producción está enfocada hacia la exportación a los Estados Unidos por lo que en la región se asientan empacadoras y su cultivo, recolección y empaque genera muchos puestos de trabajo en la región.
} 
aparecieron por la casa como si el olor de carne ya cocinada les hubiese indicado el momento justo en el que deberían dejar sus trabajos para sentarse a la mesa. Doña Elena cortaba la carne mientras yo calentaba tortillas.

Sentados en la mesa y, después de bendecir la comida dándole gracias al altísimo, comenzamos a comer. Humberto y su hijo hablaban de una vaca que estaba a punto de parir mientras Doña Elena me seguía explicando algunos detalles sobre asociaciones rotativas y la economía de la región, siempre bajo los atentos ojos de Humberto.

-Cada turno son doscientos a la quincena, dos mil por turno, que está muy bien para ahorrar o sacarte de un apuro. Yo, como tengo tres turnos, pago seiscientos y Rodrigo y Monse cuatrocientos. Esta tanda la llevo haciendo desde... yo creo que, como cuatro años, y nunca he tenido problemas.

Empecé porque una vecina, los que viven en el rancho que está por allí, tuvo gastos médicos, el marido se rompió la pierna y tuvo que contratar a alguien para que le ayudase con las vacas. Como funcinó muy bien y mucha gente me pidió entrar pues ya se hizo costumbre. También porque a mí me conocen y saben que soy seria con el dinero.

En la iglesia celebramos kermes para arreglar alguna cosa, y para poner flores en las fiestas, porque así la iglesia se ve más bonita. No tenemos dinero, pero nos gusta que la iglesia esté bien, los santos no tienen culpa de que sus fieles sean pobres, suficiente nos ayudan. -

Reconstrucción de las notas de campo. Cerro de San Francisco, Jiquilpan. 15 de Julio 2013 
Doña Elena sentía que, con la organización, estaba haciendo un servicio a la comunidad, en la que ofrecía financiamiento a aquellas personas que por su situación económica o laboral no tenían posibilidad de acudir a nadie más. Una vez terminamos de comer y recoger todo bajamos de nuevo hasta Jiquilpan donde nos despedimos después de concretar otra reunión el sábado para conocer a Jorge, uno de los participantes de la tanda que esa quincena recibía el pago.

\subsubsection{Jorge, consigue financiamiento para su tratamiento médico a través de}

\section{la tanda}

El sábado por la mañana había quedado en reunirme con Elena en el tianguis ${ }^{113}$. Después de dar una vuelta a los puestos de ropa y comida encontré a Elena sentada en un puesto de pantalones de mezclilla y blusas. Estaba hablando con una señora, parecía joven, aunque los años le pesaban.

-Os presento, ella es Rosario, la mujer de Jorge. Él no ha podido venir, dice no se siente bien, llego anoche de Zamora, pero tiene un tirón en la espalda y está en la cama. Rosario vende pantalones, mira a ver si te gusta alguno-.

Reconstrucción de notas de campo, Jiquilpan, 20 de Julio de 2013

Buscar ropa de mi talla se había convertido en un imposible en la región, por lo que la propia Rosario, al verme, advirtió que no tenía nada tan largo, pero quizá una blusa

\footnotetext{
${ }^{113}$ Mercadillo ambulante que se instala una vez a la semana en la localidad
} 
sí me quedase. Después de un rato mirando ropa y negar con la cabeza ante algunas vestimentas, como una playera con la bandera estadounidense, compré una blusa negra, solo para que ellas sintiesen que habían obtenido ganancia.

Ya avanzada la mañana, Elena se despidió de nosotras para ir a hacer unos mandados. Rosario estaba pendiente de la venta y de un hijo pequeño que andaba por allí. Debido a esto, la siguiente reconstrucción se presenta fragmenta, porque nuestra conversación original se realizó es estas condiciones.

-Yo le agradezco a Doña Elena lo que hace, porque es una ayuda muy grande poder contar con ella.

Nosotros vivimos por la carretera, antes de entrar en Jiquilpan, solo vengo aquí el sábado para vender y no hago apartados, bueno, igual si una vecina o familiar me dice, pero es raro, yo esto lo hago para ganar dinero, no para hacer amigos.

Hemos hecho cuatro tandas, una el año pasado, otra cuando empezó Doña Elena y otra cuando iba a nacer el chamaco (señala al hijo pequeño), con esta cuatro. Si tienes el dinero del seguro encuentras algo en qué gastar, a los pobres todo nos sale caro. Con la tanda ahorramos porque Jorge ya está mayor y el médico nos dijo que hiciéramos un puerquito [ahorro] para el futuro.

Los que trabajan en la empacadora sí tienen pago por el banco ${ }^{114}$, pero para eso hay que tener palanca ${ }^{115}$ y además los encargados prefieren

\footnotetext{
${ }^{114}$ Refiriéndose al pago telemático.

115 Apoyo de una persona que ya trabaja dentro de la empresa.
} 
chicas jóvenes, dicen que ellas tienen más cuidado con la fruta, luego las andan invitando y algunas lo dejan porque si les dices que no se ponen violentos. Por eso Jorge nunca me dejó trabajar, dice que mejor pobre que correteada ${ }^{116}$. -“

Reconstrucción de las notas de campo, Jiquilpan. 20 de Julio de 2013

Rosario estaba pendiente de las ventas y cada cierto tiempo saludaba a algún conocido o conversaba con alguien que pasa delante del puesto intentado vender sus productos. Ella, al igual que Elena, consideraba la tanda un servicio social y, por las palabras de Rosario, se acertaba a identificar la alta estima que tenía a Elena y a toda su familia.

Como ella se dedicaba a la venta de ropa se le preguntó por el sistema de apartados, pero rápidamente señaló que ella no lo utilizaba salvo en ocasiones especiales con algún cliente de su máxima confianza. Aunque se pudiera dar el caso, no consideraba este método de financiar el consumo de sus clientes ya que, como ella indicó, era un método que producía clientela a través de otorgar un favor, pero no era útil en el caso en el que el vendedor no pudiese permitir dar esos favores. Aunque el sistema de apartados había sido considerado anteriormente como un instrumento que funcionaba a través del capital social de los clientes, desde la perspectiva de Rosario también podía producir capital social para el vendedor, ya que ofreciendo el apartado los clientes también contraían una deuda moral a través de un favor. Este sistema no era viable para Rosario porque, como ella consideraba, no estaba en posición de dar favores a nadie.

\footnotetext{
${ }^{116}$ Expresión coloquial que indica cuando una mujer tiene varios hombres pretendiéndola.
} 
En segundo lugar, había hecho mención a las dificultades que encontraban para ahorrar dinero, ya que vivían con muchas carencias por lo que siempre podían encontrar algo en lo que invertir el dinero. Muchos organismos, tanto económicos como sociales,

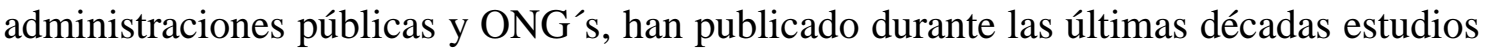
en los que presentan la ausencia de ahorro como uno de los problemas principales de las personas con menos recursos económicos.

Esta carencia de ahorros se justifica en muchas ocasiones con el déficit de cultura financiera pero el desconocimiento no resuelve el problema de falta de ahorros desde una perspectiva social teniendo en cuenta las carencias que este sector tiene. Con los limitados recursos que tenía la familia de Rosario para salir adelante, el ahorro solo podía producirse a través de un compromiso con una persona que, a través de la confianza, podía administrar el dinero sin que ellos tuviesen la tentativa de suplir alguna de sus carencias con ese dinero.

Elena ejercía ese papel, a la vez paternalista y dominante, que intentaba redirigir los ahorros de la familia hacia las necesidades principales no permitiendo que el dinero se perdiese en cubrir otro tipo de necesidades secundarias. El problema que Rosario enfrentaba no era de incapacidad de ahorro, sino la dificultad que encontraba al intentar jerarquizar sus necesidades y las de su familia, para encontrar aquellas que eran prioritarias y cuáles podían ser secundarias. Este hecho se ve reflejado en la siguiente conversación.

-Ha habido veces que no sabía qué hacer. Jorge trabajó en un taller en Zamora, y el dueño se sacaba mucho dinero, pero a él no le daba mucho, cuando no tenía clientes, no le pagaba, pero Jorge había estaba allí. Tuvo 
que dejar el trabajo porque el señor abusaba. Ahora con las frutillas ya va mejor, pero su cuerpo no da más y cuando me trae dinero yo no sé ni en qué debo gastar. En comida y ropa para los niños, pero, si sobra pues dan ganas de comprar algo rico, algún capricho. Hay gente que tiene para lo que necesita y más, y van a tomar café, o se comprar ropa bonita, nosotros andamos apurados siempre y cuando te cae algo quieres también ser feliz y disfrutar.

Los pobres no disfrutamos, yo veo la novela y veo esas casas y esas viejas con dinero y coches. Luego claro que te dan ganas porque te ponen el caramelo en la boca, pero tú tienes que comprar comida y cuidar de los hijos. -

Reconstrucción de las notas de campo. Jiquilpan, 20 de Julio 2013

Rosario ya estaba recogiendo el puesto para irse a casa a preparar la comida. $\mathrm{Su}$ hermano había llegado con una camioneta para guardar la mercancía. Había estado con ella unas dos horas y durante ese tiempo había vendido varias cosas, pero en total no creo que hubiese ganado más de 300 pesos.

\subsubsection{Las fiestas de San Cayetano}

San Cayetano es un barrio próximo al centro de Jiquilpan. La iglesia en honor al patrón celebra el siete de agosto las fiestas del barrio en honor a San Cayetano, patrón del Pan y el Trabajo.

El edificio de la iglesia había sido levantado por los propios vecinos entre mediados de la década de los sesenta y finales de los setenta. La construcción se hizo a 
través de faenas (trabajo comunitario) en los que los jóvenes y hombres del barrio trabajan levantando el edificio mientras otros vecinos aportaban dinero para el material y donaban la comida y bebida para los trabajadores. San Cayetano era un barrio muy colaborativo donde todo el mundo se conocía. El padre que había promovido la construcción de la nueva iglesia, cuando la anterior ya se encontraba casi en ruinas, el Padre Panchito, era recordado por los vecinos de mayor edad con mucho cariño. Había ayudado a los necesitados y siempre portaba un botecito en el que pedía para construir la iglesia.

Durante los años de construcción, se había institucionalizado la celebración de kermes para recaudar fondos que consistían en la venta de comida, rifas y lotería. Los alimentos y los premios siempre eran donados por la gente del barrio por lo que, gracias a la colaboración de todo el vecindario, el proyecto pudo salir adelante.

Las fiestas empezaban el 29 de Julio y terminaban el día grande 7 de agosto, formando un novenario en honor a San Cayetano. Además de las misas y procesiones, la fiesta había aumentado en popularidad con los años, y ahora se instalaban juegos mecánicos, había bailes populares fuera del templo y se había convertido en tradición la quema del castillo, el torito ${ }^{117}$ y el palo encerado en el que participaban los jóvenes.

Durante esos nueve días, San Cayetano atraía a gente de todo Jiquilpan y alrededores convirtiéndose en una de las fiestas más populares del municipio. En las calles y, especialmente en el atrio de la iglesia, se colocaban señoras cocinando los antojitos mexicanos $^{118}$, allí es donde encontré a Elena, junto a una gran olla de tamales y uchepos $^{119}$.

\footnotetext{
117 Juegos pirotécnicos.

${ }^{118}$ Los antojitos son comida vendida en la calle. Entre ellos, los más vendidos durante las fiestas eran los tamales, enchiladas, flautas, tostadas, gorditas, tacos y quesadillas.

${ }^{119}$ El tamal es un plato característico de la gastronomía mexicana, elaborado con masa de maíz rellena de carne, vegetales o chile. Los uchepos son una variante del tamal, plato típico de la Tierra Caliente del Estado
} 
-Qué bueno que estés aquí, esta fiesta es lo más bonito. Por ahí anda Rosario que nos está ayudando con la kermés, y también Fernanda que esta con nosotras en la tanda. Ya este mes termina, pero ya se organizó la otra, ahora ya somos diez, en la de septiembre hay más gente porque empiezan a pensar en navidad. -

Reconstrucción de las notas de campo, Jiquilpan, 3 de agosto 2013

Rosario apareció con su marido llevando cada uno una garrafa de agua fresca, una de Jamaica y otra de horchata. Jorge, el marido de Rosario, se presentó y, aprovechando que él estaba cansado y yo tenía todas las intenciones de comer todo lo que pudiese durante esas fiestas, le invité a unos tamales si me dejaba hacerle algunas preguntas.

-Ya ve ando mal de la espalda y estas mujeres me traen en chinga [¿?] con la kermés. Yo solo muy devoto de San Cayetano porque él siempre ayudó a los pobres, a los necesitados y el Padre nos dijo que San Cayetano es uno de los santos más cercanos a Dios. La iglesia da despensas, vestido y juguetes a los que están peor, allá en el cerro, todo esto es para sacar dinero y seguir haciendo cosas. Eso es bueno, porque es una labor comunitaria y hay que ayudar a otros para que luego te ayuden.

Doña Elena es muy buena. Ella hace esto hace años (en referencia a las kermeses) y a sus hijos los enseñó así. Yo también quiero que mis hijos se

de Michoacán, elaborados con leche. A diferencia del tamal, estos son dulces permitiendo variedades con fruta, como los uchepos de la región de Zamora realizados con arandanos o frambuesas. 
eduquen con estos valores morales, ya les digo `lo que San Cayetano nos da, nosotros se lo damos a los que lo necesitan'.

A Doña Elena y Don Humberto los conozco desde que era niño y ellos son padrinos de uno de mis hijos. Cuando necesitamos ahorrar, le pedimos si podemos entrar a la tanda. Una vez tuvimos mucha necesidad y nos prestó dinero, pero yo prefiero juntar con la tanda, porque sí se puede, aunque hay que hacer sacrificio. Doña Elena solo hace tanda con los que necesitan, no para caprichos, ya sabe... 'Dios no cumple antojos, ni endereza jorobados', eso lo decía mi madre, que Dios la tenga en su gloria. -

Reconstrucción de las notas de campo, Jiquilpan, 3 de agosto 2013

Jorge y Rosario habían aportado las aguas frescas para recaudar fondos. El mismo se reconocía como necesitado en algunas ocasiones, pero, al mismo tiempo, consideraba que era necesario también ayudar a personas que se encontraban en su misma situación o peor.

Durante el trabajo de campo realizado durante el primer año de mi estancia en la región pude diferenciar claramente dos realidades que convivían en el mismo espacio, pero en ocasiones parecían antagónicas. Por un lado, la población con mayores recursos se sentía más identificada con los patrones culturales y de consumo que provenían de los Estados Unidos y Europa; por otro lado, las personas con menos recursos mantenían las tradiciones y el espíritu comunitario que les había ayudado en el pasado a prosperar como comunidad. 
Estos dos enfoques, que se podían encontrar representados en los habitantes de los dos municipios indistintamente, generaban un autoreconocimiento dentro de la comunidad que resultaba antagónico con lo que era esperado en relación a su posición económica.

Las personas con mayores recursos sentían que eran una población marginada, individuos que vivían muy alejados de su realidad ideal, la gran ciudad, los restaurantes y cafés donde poder lucir sus nuevas adquisiciones. Todos ellos, en mayor o menor grado, ansiaban conocer o residir en Estados Unidos o Europa reconociendo que su localidad no era más que una ciudad de provincias donde no podían desarrollarse. Este sentimiento de superioridad que solo el dinero puede otorgar a su dueño les producía insatisfacción mientras, a través de la televisión por cable que se podían costear, observaban la vida de California o Miami.

En contraposición a ellos, estaban las personas con menos recursos. Dependientes como eran de la cooperación entre la comunidad, al desarrollar lazos sociales fuertes asentados en la reciprocidad y el apoyo comunitario disfrutaban viendo cómo sus proyectos, por pequeños que fuesen, podían ser llevados a cabo gracias a la ayuda de los demás.

La fiesta de San Cayetano era una representación de ello, sin ser una iglesia glamurosa y sin la necesaria ostentación que se observaba en otras fiestas parecidas, la comunidad se reunía con el único fin de disfrutar de la reunión y colaborar con el mantenimiento tanto de la iglesia como de aquellas personas que necesitasen ayuda. El dinero recaudado durante las fiestas se invertiría en repartir despensas entre la población más pobre, ayudar al mantenimiento de escuelas y al bienestar de la comunidad. 


\subsection{Humberto, el prestamista}

Durante los siguientes meses visité a Elena asiduamente. En septiembre conformó otra nueva tanda. Esta vez, el número de participantes aumentó a once, compartiendo dos hermanas un mismo turno. Como ya avanzó Elena en las primeras reuniones que tuve con ella, esta segunda tanda del año tenía más interés por parte de sus vecinos y gente de su comunidad. Durante los últimos meses del año y, en especial en las fiestas de navidad, la gente quería ahorrar o recibir un crédito para hacer frente a todas las fiestas de este periodo. Esta tanda había terminado en enero, sin que nadie hubiese incumplido su obligación y quedando todos igual de satisfechos que con la anterior. Los meses de febrero y marzo no se realizaban tandas, y en abril se conforma la siguiente, esta vez con ocho personas. Monse y Elena se quedaron con dos números cada una para cumplir así la rotación de cinco meses. En ocasiones los participantes se mantenían durante varias tandas, como en el caso de Jorge que se había mantenido constante en su participación desde el año pasado. Otros solo participaban de manera esporádica, permitiendo que nueva gente entrase en el sistema o sus turnos quedasen a disposición de la organizadora y sus colaboradoras.

Los primeros meses del año 2014 habían sido difíciles para conseguir entrevistas y la movilidad se hacía complicada debido a los continuos enfrentamientos entre autodefensas y los cárteles. Durante las primeras semanas de abril, estos enfrentamientos habían tenido lugar en Jiquilpan y Sahuayo, imponiendo el toque de queda. El año anterior también se había impuesto un toque de queda durante estas fechas que había dificultado las entrevistas con Karen. Esta vez ya me encontraba trabajando en Zamora, lo que hacía difícil mi traslado a Jiquilpan. En varias ocasiones mi intención de llegar a Jiquilpan se había visto truncada en la central camionera cuando me habían confirmado que todos los 
trayectos hacia Jiquilpan y Sahuayo habían sido suspendidos. Por la región corría el rumor de que La Tuta, líder de los Caballeros Templarios, se había resguardado en Sahuayo ante la persecución que las autodefensas. Este dato no era del todo descabellado teniendo en cuenta que La Tuta había ejercido como docente en el municipio hace años y mucha población guardaba un especial cariño hacia su persona.

La presencia de policía federal y ejército en la región había aumentado considerablemente con el traslado de efectivos de otras regiones del estado, y la Ciénaga de Chapala se había convertido durante unos meses en el campo de batalla. A primeros de mayo, y después de un mes de enfrentamientos, decenas de elementos de la Secretaría de la Marina (SEMAR) llegaron a Jiquilpan, en lo que se esperaba fuera un efecto de choque para inclinar la balanza hacia las fuerzas armadas del Estado. En los días anteriores se habían producido múltiples balaceras, algunas de ellas durante más de tres horas. La población, una vez más, había permanecido durante semanas encerrada en casa o realizando los mínimos movimientos requeridos para conseguir alimento y mantener el trabajo y así los ingresos.

A finales de mayo, y con la mentalidad que el año anterior percibí en la población totalmente interiorizada ${ }^{120}$, visité Jiquilpan con la intención de realizar algunas entrevistas y comprobar que los amigos e personas participantes en la investigación estaban bien. Elena se mostró sorprendida de verme, al igual que pasase con Karen el año anterior. Durante esas semanas, el deseo de estar en otro lugar es tan fuerte que el hecho de que una persona extranjera decida por elección propia permanecer en ese lugar se hace incomprensible. Era en estos casos cuando yo tenía que buscar el lado positivo y

\footnotetext{
${ }^{120}$ Hago referencia a este tipo de conductas en el capítulo anterior, donde explico cómo después de semanas casi encerrada en casa y teniendo la máxima precaución, llega un momento en el que una ligera sensación de paz hace que la cotidianeidad siga adelante, sabiendo que las cosas no están solucionadas, pero sin más alternativa que continuar.
} 
reafirmarme en mi compromiso con la investigación. Sería absurdo negar que tuve en varias ocasiones la tentación de abandonar, pero los propios acontecimientos también conseguían motivar mi interés en conocer mejor la región.

Elena me informaba periódicamente del desarrollo de la tanda y, ante la constancia del buen desarrollo de la misma, me enfoqué en realizar entrevistas a Humberto y su hijo.

\subsubsection{Aquí no tenemos huevitos al gusto}

Humberto, después de un tiempo y ante la insistencia de su mujer, aceptó participar en la investigación. Él se mantenía externo a la tanda, y aunque apoyaba económicamente, nunca consideraba que fuese su obligación estar al tanto de los pagos o expresar su criterio en cuanto a la selección de los participantes. Don Humberto tenía 57 años y consideraba que su vida ya estaba organizada: todas las mañanas se levantaba muy temprano para ir a cerro y estar con las vacas y era extraordinariamente puntual con las comidas. También le servía un solo vistazo al cielo y oler el aire para afirmar, sin equivocarse jamás, que tiempo haría mañana. Tenía la cualidad de permanecer en silencio la mayor parte del tiempo, pero siempre estaba atento a lo que se hacía y decía alrededor suyo. Cuando por fin accedió a participar en el estudio fue la primera vez que le vi hablar más de tres frases seguidas.

-Aquí se vive muy bien, aunque algunos anden de revoltosos. Hay que respetar y tener fe, así uno se gana el cielo. A Elena la conocí cuando estaba muy chavito y me gustó, yo sabía que era ella. A mi madre no le pareció, porque sus padres eran de fuera y pensaba que me iban a llevar. Ya sabe, nos fuimos al ranchito. Mi familia pensó que me habían hecho un 
amarre $^{121}$ y hasta mando al sacerdote para que el hablase con nosotros, pero el sacerdote nos ayudó y nos dieron la bendición, aunque el padre de Elena siempre me miró torcido [con desconfianza]. Luego hicimos la familia. Ahora ya solo nos queda Rodrigo, que es el más joven y le gusta el rancho, tengo que enseñarle-.

Reconstrucción de notas de campo, Jiquilpan, 30 de mayo 2014

Humberto recibía la ayuda de Rodrigo para las tareas del rancho ya que su movilidad se había visto reducida con los años. Las hijas habían recibido estudios y se habían marchado hacia años, solo el hijo pequeño ayudaba a su padre.

-El rancho va bien, pero se saca poco dinero porque el precio de la leche es el que es ${ }^{122}$. De las ayudas se encarga Rodrigo, porque son muchos papeles y él sabe cómo organizar eso, aunque no crea que nos dan mucho. Este gobierno prefiere traer leche de China y arruinar a los de aquí. Yo aguanto por el hijo, para que tenga un medio de ganarse la vida, pero no sé si durará. -

Reconstrucción de notas de campo, Jiquilpan, 30 de mayo 2014

${ }^{121}$ Conjuro que persigue el enamoramiento de la persona a la que se destina el amarre.

${ }^{122}$ Humberto, al igual que muchos de los ganaderos de la región, destinaba su producción a la planta de Liconsa ubicada en Jiquilpan. Liconsa es una compañía paraestatal del gobierno mexicano destinada a programas de abasto social. Industrializa y comercializa leche de los productores locales a un precio estipulado con el fin de asegurar el abastecimiento del producto a toda la población. 
Además de las vacas, Humberto tenía gallinas, dos cerdos y una porción de tierra destinada para la agricultura de autoconsumo en el rancho. Aunque el rancho cubría parte de sus necesidades alimentarias, eran dependientes de la compra de otros productos como jabones, aceites y grano.

-Nosotros no somos campesinos ni rancheros. Mis abuelos sí lo eran, porque nos hacíamos los guaraches y las cobijas, ahora la mitad de mi casa está hecha por los chinos... una de mis hijas dice que es... vegetariana o algo así. Yo estoy en medio porque cuando era joven ya algunas cosas solo las hacían las mayores, como los rebozos [prenda de vestir femenina]. Pero nací pegado a la tierra y aquí me he de morir. Hace unos años uno de mis nietos se dio un berrinche en el rancho, porque tenía miedo a las vacas, la nueva generación viene diferente. -

Reconstrucción de notas de campo, Jiquilpan, 30 de mayo de 2014

Elena me había comentado en uno de nuestros encuentros que ellos habían prestado dinero en algunas ocasiones, cuando la necesidad era muy grande y no había tiempo para que el problema fuese solucionado por una tanda. Con esa información y después de realizar varias reuniones con Humberto, pregunté sobre ello, ya que Elena me indicó que en esas circunstancias era él quien se hacía cargo.

-Sí, algunas veces hemos prestado dinero, pero solo a personas que sabemos lo necesitan. Nosotros somos personas muy religiosas y tenemos 
que ayudar. Algunas veces ha sido por enfermedad, porque hay mucha gente que no tiene seguro y, si te pasa algo, hay que pagarlo. Sí está muy caro el médico. Otras veces ha sido porque se había averiado el coche, o alguna maquinaria, y sin eso no se puede trabajar, aquí somos una comunidad, y nos ayudamos mucho. -

Reconstrucción de notas de campo, Jiquilpan, 9 de junio 2014

Los valores morales y religiosos, así como el sentir comunitario, hacían posible que las personas con menos recursos que necesitaban urgentemente de dinero pudiesen acudir a sus vecinos en busca de ayuda. Este tipo de préstamos se otorgaba sin intereses, basados en la piedad y misericordia del prestatario para realizar un préstamo inscrito en el bien común. Todo ello en un contexto en el que también había prestamistas que practicaban la usura en la región.

-Hay algunos que se aprovechan, hay un caso, el hijo de una señora que es vecina nuestra, que pidió a uno de esos para gastar, na[da] más que por puro vicio, y luego lo andaban chacaleando [amenazando]. La madre vino a pedir ayuda, pero yo no le di préstamo porque la deuda iba a ser de la señora y era el hijo el que tenía que dejar de andar de puro vicioso. Platiqué [hablé] con un amigo de Sahuayo que tiene un taller para que le diera trabajo, y así pago la deuda. Si hace falta yo presto, pero para algunos es mejor que no, porque no te pagan y además siguen por el mismo camino. - 
A diferencia de los sistemas financieros formales, los préstamos otorgados en el sistema informal requieren de unos conocimientos profundos sobre el solicitante de préstamo. Como presenta Humberto, el préstamo puede ser otorgado o rechazado por diferentes motivos, pero, el que la solicitud de préstamo se niegue, no significa que se eluda la ayuda, sino que se busca el método más efectivo para solucionar la falta de dinero. En el caso del joven, Humberto reconoció que el problema era el tipo de vida que estaba llevando y que la ayuda económica suya o de su madre no solucionaría sus deudas mientras estuviera siguiendo los mismos patrones de consumo. El cambio de vida fue posible al conseguir un trabajo con el que sufragar sus deudas y con él, como dijo Humberto, -no le quedaba tiempo para andar de vicioso-.

\subsubsection{La llegada de los pochos ${ }^{123}$. Las remesas colectivas para la comunidad}

\section{de origen}

Con las fiestas en honor a San Cayetano, las calles del barrio lucían sus guirnaldas de banderines. Elena y Humberto me habían invitado a festejar con ellos el día grande de la fiesta, 7 de agosto, con una gran comida en su casa. Ese año, a diferencia del anterior, toda la familia se había reunido y el hijo mayor de la pareja, Antonio, visitaba Jiquilpan después de tres años. Antonio había llegado con su mujer, hija de mexicanos, pero nacida en Estados Unidos. Tenían dos niños, uno había nacido hacia menos de un año y el otro tenía tres años. Además de Antonio, estaban por allí las hermanas y Rodrigo, todos muy contentos enseñándome los regalos que su hermano les había traído.

La mujer de Antonio, Kaitlin, era la primera vez que visitaba Jiquilpan. Su familia era originaria de Colima $\mathrm{y}$, aunque entendía muy bien el español, algunas veces

\footnotetext{
${ }^{123}$ Los conocidos como pochos son hijos de migrantes mexicanos nacidos en los Estados Unidos. Este calificativo no tiene connotaciones negativas.
} 
encontraba dificultades para hablar fluidamente en el idioma. Doña Elena intentaba ayudarla, aunque cuando Kaitlin decía la palabra en inglés era Antonio quien le traducía. El hijo mayor de la pareja recibía lecciones aceleradas del español por parte de sus primos, mientras Rodrigo estaba más interesado en aprender inglés que en ayudar a su sobrino con el español. Después de la comida tuve oportunidad de hablar con Antonio y Rodrigo mientras fumábamos fuera de la casa y bebíamos unas chelas [cervezas].

-Allí tenemos varias organizaciones de migrantes, en una de ella fue que conocí a Kaitlin. Algunos de Jiquilpan colaboramos con la fiesta y enviamos algo de dinero, porque eso es bueno para la comunidad y, aunque estemos lejos, somos de aquí.

La fiesta es una excusa para que la gente se acerque a Dios y viva en comunidad. Además, es importante que los niños aprendan el español y jueguen con sus primos, ellos son mexicanos, también gringos, pero más mexicanos porque aquí tienen la familia. Yo al principio no iba a ninguna reunión [se refiere a las reuniones de las asociaciones de migrantes], pero un año por navidad me dijeron que iban a hacer carnitas, y me ganaron por panzón, luego conocí a esta chulada [refiriéndose a Kaitlin que había salido a estar con nosotros]. -

Reconstrucción de notas de campo, 7 de agosto de 2014

Aunque en un principio di por hecho que Doña Elena había explicado a su hijo mi tema de investigación, él sintió curiosidad y, después de preguntarme varios detalles sobre el mismo, añadió: 
- También hay una doña que organiza tandas en la agrupación, y hacen kermes para las fiestas, pero lo que más, las colectas para México. Hay algunas que son para el pueblo, y en esas nos organizamos los de Jiquilpan, luego hay otras para el programa del gobierno, pero yo en esas no participo porque no me fio. También han empezado a dar becas de estudio, los más viejitos lo tienen todo muy organizado, algún día nos tocara a nosotros seguirle...--

Reconstrucción de las notas de campo, 7 de agosto de 2014

Las colectas de asociaciones de migrantes, en el caso de Jiquilpan, iban organizadas por una agrupación de vecinos que destinaba ese dinero a despensas, juguetes y ayudar a las colonias con menos recursos del municipio.

Antonio y su familia estuvieron hasta mediados de agosto. Durante el tiempo que estuvieron observé cómo su hermano Rodrigo se mostraba muy interesado en la vida estadounidense, el estilo de vida que tenía su hermano en el norte y las posibilidades que podía tener el en conseguir allí trabajo. Todas estas conversaciones se realizaron mientras Elena y Humberto no estaban presentes por lo que, al año siguiente, cuando lo encontré un día en el Bosque, le pregunté sobre sus planes de vida a largo plazo.

\subsubsection{Rodrigo, los lazos familiares a veces atan}

Hasta ese momento Rodrigo siempre se había mantenido al margen cuando acompañaba a Elena y Humberto. Aquel día, por casualidad, lo encontré mientras yo estaba con unos amigos y él estaba con los suyos. Era una tarde calurosa, como suele 
suceder durante los meses de verano, empezó a llover con fuerza a las seis de la tarde y siguió así durante horas. En el Bosque de Jiquilpan hay algunas palapas donde resguardarse de la lluvia y allí fue donde nos encontramos. Aunque no soy partidaria de introducir conversaciones personales, el me dio su consentimiento para utilizar los datos que me había comentado para la investigación, siempre que su anonimato estuviese garantizado. Lo que sigue es una reconstrucción de aquella conversación.

-A mí la tanda no me ayuda a ahorrar, eso es mentira, pero mi madre quiere verlo así. Me está pasando lo mismito que pasó con mi hermano. Yo trabajo todos los días, y estoy pendiente del rancho, pero mis padres dicen que cuando necesite, ya me darán. No es cuestión de que me den o no, el pedo es que yo ya soy un hombre. Aquí hay mucha gente así, a mi compa (señala a un amigo) le pasa lo mismo.

El rancho siempre va a ser suyo y el dinero también. Vivo bien y si le digo a mi madre que necesito dinero para algo me lo da, pero el tema es que no tengo un jornal, y no puedo organizarme. Mi hermano también estuvo así, y al final probó suerte en el gabacho. Le fue bien. Yo me quedaré un tiempo más, pero también me iré. No pagan mucho por la leche y quiero viajar. -

Reconstrucción de las notas de campo, Jiquilpan, 17 de junio de 2015

La confesión de Rodrigo cambió la percepción que durante el último año había mantenido sobre su participación en la tanda. En un principio había aceptado que su participación era un acto altruista en el cual participa voluntariamente consiguiendo con 
ello el beneficio del ahorro. Esas palabras me indicaban que su participación no era voluntaria, sino pasiva, viéndose como un agente que no tenía más opciones, determinado por el deseo familiar de que participase y ahorrase. Tampoco disponía del dinero que le podía reportar su trabajo, ya que su familia no lo veía como destinatario de un salario, sino más bien participe de un proyecto colaborativo, al igual que Humberto y Elena hacían en otros ámbitos en los cuales el enriquecimiento personal no formaba parte. Rodrigo perseguía como meta conseguir unos ingresos fijos y poder conseguir un enriquecimiento personal que le permitiese invertir o gastar su dinero bajo los deseos y necesidades personales.

La decisión de introducir este caso en la etnografía no está motivada por su valor a la hora de entender o analizar las motivaciones de los participantes en los sistemas financieros informales, ni tan siquiera porque su participación en el mismo no sea del todo voluntaria, sino para evidenciar un dato importante en cuanto a discursos y conductas relacionadas con las generaciones más jóvenes. En el caso de Rodrigo (y como posteriormente pude constatar el de muchos jóvenes provenientes de las pocas familias que habían mantenido su producción agropecuaria en la región), además de las dificultades que encontraban a la hora de rentabilizar sus explotaciones, había otros condicionantes que interrumpían el cambio generacional y la continuación de las actividades agropecuarias. El principal escollo al que se enfrentaban las nuevas generaciones era un cambio de mentalidad, el individualismo hacia recaer en los jóvenes la responsabilidad del cambio de sistema productivo, convirtiendo a los jóvenes en agentes aislados de una transformación no organizada bajo patrones comunitarios. Las nuevas generaciones se enfrentaban a un futuro donde los consejos de sus padres habían perdido validez, donde la única frase que podía albergar parte de razón era el grito de "Sálvese quien pueda". Mientras sus padres habían supuesto el lazo comunitario y la 
cooperación intra-familiar como un sistema capaz de dotar de sentido y fuerza a la región, los jóvenes entendían que solo a través de una producción más competitiva, la búsqueda del beneficio personal como elemento motivador, y la estructuración de los lazos comunitarios e intrafamiliares a modo de contrato mercantil, era posible la continuación de las explotaciones agropecuarias. Esta confrontación entre dos generaciones había producido que muchos jóvenes optasen por emigrar, ya sea a las grandes ciudades, o a otros países buscando un trabajo remunerado y la libertad que esos lazos comunitarios y la cooperación intra-familiar no les daba.

\subsection{Gustavo, trabajador de una casa de empeño}

Durante los meses de verano de 2014 la región de la Ciénaga de Chapala había estado más tranquila después de una Semana Santa con toques de queda y sin posibilidad de trasladarse por las carreteras sin extremar las precauciones. En junio, mientras realizaba algunas entrevistas a Humberto, intenté ampliar la investigación buscando otros sujetos que prestasen dinero lo que me llevó a visitar varias casas de empeño. Aunque desde 2012 había realizado algunas entrevistas a dueños de casa de empeño, en las que resaltaban su actividad como un servicio casi filantrópico con la que ofrecían ayuda a las personas necesitadas, la colaboración de algunos dueños de casas de empeño había sido dificultosa cuando no imposible.

En junio conocí a Gustavo, un hombre de treinta años de Sahuayo. Llevaba dos años trabajando en una casa de empeño de la localidad. La casa de empeño se situaba en el centro de Sahuayo, a unas pocas calles de la plaza principal. En el interior se exhibían algunas pantallas de televisión, reproductores de música y bocinas, y la entrada estaba franqueada por dos motos. Al fondo había una cristalera como medida de seguridad en la 
atención al cliente. Gustavo, en el interior y protegido por un cristal de varios centímetros, atendía a una señora. Cuando hubo terminado y asegurándose que no hubiese más personas en la tienda, abrió la puerta para hacerme pasar. Nos habíamos conocido unos días antes y habíamos quedado en que ese viernes me enseñaría la casa de empeño. En su mesa de trabajo había varios instrumentos para verificar la autenticidad de los billetes, así como contratos de empeño, una balanza de precisión y algunas herramientas que en un principio no pude identificar, como posteriormente descubrí, tenían como función autentificar el oro y los metales preciosos. En la parte trasera de la tienda estaba la caja fuerte. Allí guardaban las piezas de oro, anillos y colgantes en su mayoría, monedas antiguas y el dinero. Todas las joyas empeñadas estaban guardadas en bolsitas de plástico individuales junto con el número del recibo y los datos del cliente. Entre las joyas no había mucha variedad, salvo algunas excepciones. Se podían dividir en dos categorías, anillos de compromiso y alianzas de boda, las más numerosas, y colgantes y medallas de la virgen u otra figura religiosa. Era evidente que además de su valor económico, que se calculaba en relación al peso de la joya, también guardaban un valor sentimental que la casa de empeño no se cuantificaba como valor real.

-Hay algunas de estas [comenta Gustavo mientras guarda la caja con las piezas de oro] que se la pasan entrando y saliendo de la tienda. Una vez vino una mujer a recuperar una medalla, porque la había traído su cuñado y era de su abuela. Yo no se la pude dar, la tuvo que comprar cuando ya paso el plazo, pero se la guardamos para ella. Pero la mayoría, si no devuelven el dinero se funden, no valen nada por el trabajo que llevan, solo por el oro. Algunas veces las viejas de puro coraje con el marido nos 
traen la alianza, pero lo habitual es gente que necesita el dinero y no tiene otra-.

Reconstrucción de notas de campo, 20 de junio de 2014

La persona que viene a la casa de empeño buscando obtener dinero a través de algún bien debe firmar un contrato en el que específica el valor por el que ha sido tasado la pieza, ya sea oro, electrónica o un vehículo. La hoja de papel que se entrega al cliente reproduce en su parte delantera sus datos personales, una descripción de la pieza, su valor y el dinero que el establecimiento presta, además del número de cuotas y la cantidad que debe abonar que debe abonar.

-El dinero que reciben depende, si traen oro les podemos dar hasta el $80 \%$ del valor [el valor se calcula por el peso de la pieza], con los celulares, computadoras y electrodomésticos es diferente. Si son nuevos y están bien puede llegar hasta el 50\%, pero es raro, lo normal es un 30-40\% porque ya están fuera de garantía y son más difíciles de vender si no lo recuperan. Los vehículos los checa un amigo del dueño [de la casa de empeño] que es mecánico, y él nos dice cómo lo ve, igual que con la maquinaria. El oro lo calculamos con la cotización del día, pero con las demás cosas tenemos que ver cómo están.

El dinero lo reciben en el momento, con la pieza y una acreditación ya vale. Luego los pagos se hacen en relación al valor, si es un coche tienen más chance [oportunidad], con cosas pequeñas suele ser seis u ocho meses, el interés también depende del producto, en tecnología hay menos 
margen de ganancia, para conseguir dinero tienes que devolverlo en unos tres meses. Lo que la gente no entiende es que no importa cuánto pagaste por un celular, si ya tiene dos años y vas a tardar meses en devolver el dinero, tú lo vas a pagar otra vez y nosotros solo lo podemos vender por un $10-20 \%$ de su valor de compra-.

Reconstrucción de notas de campo, 20 de junio de 2014

Gustavo tiene en la tienda las piezas de oro y algunos aparatos tecnológicos pero la mayoría de bienes se encuentran en un almacén a unas cuadras de la tienda. Cuando el dueño del bien no cumple con los pagos tiene dos opciones: en el caso de un empeño de gran valor económico como un vehículo, o con valor sentimental, como una pieza de oro, tiene opción de postergar el pago aumentando los intereses, lo que se traduce en un nuevo empeño, esta vez con peores condiciones para el cliente. En el caso de tecnología y maquinaria, este servicio no se permite ya que, con el paso del tiempo, los productos pierden su valor. La casa de empeño oferta el producto a un precio reducido, siempre mayor a su valor de empeño. Gustavo me explica que la casa de empeño lleva unos años utilizando las redes sociales con este fin. Por el reducido tamaño del local y también porque la gente no está acostumbrada a visitar casas de empeño para comprar, tienen una página en Facebook que les permite subir fotografías de los productos. Cada dos meses, hacen un remate de los bienes no recuperados que tiene bastante éxito, especialmente en tecnología y vehículos.

Durante los siguientes días visité asiduamente la casa de empeño. Gustavo me dejaba pasar al otro lado del mostrador y le ayudaba a escribir etiquetas. Esos días varias personas visitaron la tienda, algunas para empeñar y otras para adquirir algún producto. 
Lo que sigue son diferentes testimonios de los clientes con una breve descripción de cada uno.

Una mujer, de alrededor de cuarenta años entró hoy en la tienda. Vino directamente a la ventanilla y sacó de una bolsa dos piezas de oro. Una era un crucifico pequeño, la otra una medalla de la virgen. Antes de dejarlas en el cajón, para que Gustavo pudiese valorarlas, agarró cada una y las besó, santiguándose después. Gustavo las pesó y examinó con cuidado, a continuación, hizo unos cálculos e informó a la señora de la cantidad que le podía dar por las dos, 700 pesos. Posteriormente, y sin que la mujer hubiese indicado si le parecía bien o mal el precio evaluado, Gustavo sacó una hoja de contrato y empezó a tomarle los datos. La mujer miraba fijamente las medallas al otro lado del cristal de seguridad mientras decía en voz alta sus datos. Cuando terminaron, Gustavo le mencionó que ella ya sabía cómo iba esto [omitiendo los plazos de pago e interés], la mujer tomó la hoja de contrato y agradeciéndole la ayuda se fue apenada con los 700 pesos.

Gustavo me explicó después que la señora ya había empeñado varias veces esas piezas. Su marido trabajaba en Estados Unidos y, cuando no mandaba nada a su familia, la señora tenía que empeñar alguna cosa para conseguir dinero.

Reconstrucción de notas de campo, 21 de julio de 2014 
Los primeros días en la casa de empeño pude comprobar que realizar entrevistas a las personas que acudían al establecimiento para empeñar algún bien iba a resultar una tarea complicada. Los clientes de la casa de empeño acudían al local avergonzados por tener que acudir a este tipo de financiamiento que consideraban el último recurso ante la falta de dinero. Las diferencias en la actitud entre hombres y mujeres hicieron que preguntase a Gustavo cuál era su teoría ante estas dos actitudes.

-Los hombres vienen a empeñar porque tiene otra deuda, algunos con prestamistas, otros con algún compadre. Es eso o que quieren tener varo para invertir en algún negocio. Cuando vienen las mujeres es porque no tienen, muchas no trabajan o ganan muy poco y empeñan lo poco que tienen, generalmente oro-.

Reconstrucción de notas de campo, 23 de junio de 2014

Ante las dificultades que estaba encontrando en entrevistar a las personas que empeñaban sus bienes, debido a que muchas de ellas se negaban a la entrevista, decidí preguntar a personas de mi círculo social sobre el tema. Algunas personas reconocieron que habían utilizado las casas de empeño en el pasado, aunque prefirieron no hablar directamente de su experiencia, sino explicar las motivaciones de manera generalizada.

Reunión con Adela, Lourdes, Claudia y Rosa en una cafetería del centro de Sahuayo. Después de explicarles los problemas que estoy encontrando para entrevistar a usuarios de casas de empeño, les pido su opinión sobre 
las mismas y si tienen alguna experiencia con este tipo de establecimientos.

-Yo sí empeñé una cosa hace unos años, fue cuando iban a operar a mi marido. Le operaron de una hernia y le llevamos a Guadalajara, pagamos casi 20.000 pesos. La familia nos dejó, y también teníamos ahorros, pero entre traslados, medicamentos y revisiones... Después mi marido estuvo sin trabajar varios meses y como estaba apurada empeñé algunas alhajas para salir del paso. Algunas las pude recuperar, no todas, pero me salvó el momento. Es normal que la gente no quiera hablar sobre eso, luego lo piensas y si necesitas no pasa nada por empeñar, pero en el momento se siente muy feo-

Claudia había pasado por una mala época desde la operación del marido, pero ahora tenía trabajo y aquel momento de carencia económica quedaba lejos en el tiempo, por lo que hablaba abiertamente de él.

-Mi madre me dio unos aretes y yo lo lleve todo, menos una medalla de la Virgen que tengo de la boda, esa se la puse a Oscar [su marido] con una cadenita para que lo protegiera. Cuando salí con el dinero me fui a casa casi corriendo, cerré la puerta y me la pase llorando tres días. No le dije nada a Oscar, pero al final se lo dijo mi madre. Hubo cosas que se las quedó la casa, porque luego tuvimos más gastos en el hospital, pero salimos adelante. -

-Oscar se puso muy mal- explica Rosa mientras consuela a Claudia-pero gracias a Dios que se recuperó y está con nosotros. Tú hiciste lo que tenías que hacer porque a tus hijos no les falto de nada gracias a ti. Hay que 
tener fe y hacer lo que haga falta. Yo por suerte no he tenido que empeñar nada, pero conozco a mucha gente que sí.

Eso que decías que los hombres y las mujeres son diferentes cuando empeñan es cierto, y te voy a explicar por qué. Para los hombres el dinero es suyo, y ellos tienen el modo de ganarlo. Si empeñan es porque algo quieren o algo deben. Para nosotras es diferente, porque nosotras le andamos pensando, esto para la hija, esto para cuando el hijo se case, y claro, quitar a los hijos la herencia es muy duro. Digo con las alhajas, porque siempre hay algunas que andan comprando celulares y luego lo tienen que llevar a empeñar porque no pueden pagarlo. -

-Eso le pasó a una vecina mía- interrumpió Lourdes que hasta el momento se había mantenido al margen de la conversación- se compró un celular en Coppel, uno grande, de estos nuevos que están trayendo ahora. Debía alguna cuota y un día vinieron los de cobranza preguntando por ella, yo sabía que estaba en casa porque la había visto desde la azotea cuando colgaba la ropa, pero dije que no. Así un día tras otro y ya fue a empeñarlo para pagar lo que debía. Luego me dijo que no había sacado las fotos y quería recuperarlo, pero no se pudo. Dice que no le dieron tiempo porque se lo quedó uno de la tienda y le borró todo. Pero ella siempre anda así, sacando cosas de Coppel y luego reclamando, sí abusan, pero vuelve. -

Rosa y Adela confirman que, si bien es cierto que el empeño de una posesión es un último recurso al que se recurre por necesidad, también hay muchos clientes que utilizan el empeño para liberarse de otras deudas contraídas por un consumo fuera de su alcance. Rosa termino de confirmar esta idea. 
-Yo creo que la mitad de las cosas que hay en las casas de empeño son de Coppel y Elektra. La gente las compra a 12 meses y cuando van por la mitad ya se les hace mucho y lo empeñan para conseguir cerrar la deuda con la tienda. Por eso hay tantas televisiones y celulares. Lo pagan dos veces: en Coppel y otra en la casa de empeño si lo recuperan. Luego llega uno a la casa de empeño y lo compra a la mitad, pero claro, en la casa de empeño tienes que comprar poniendo el dinero y hay gente que no puede o no tiene. -

-Hay gente a la que no le gustan las cosas de segunda mano- dice Adelami cuñado compró unas bocinas y le salió un cucarachal por la noche. Igual lo ves bonito, pero no sabes si está maltratado y en unos días te deja de funcionar. -

Las cuatro asienten con la cabeza. Gustavo ya me había indicado que la venta de celulares, aparatos de música y computadoras era la más difícil porque muchas personas desconfían de las condiciones en las que se encuentra el producto. Intentando encauzar la conversación hacia las motivaciones que tienen los clientes para usar el empeño como método de financiamiento les pregunto si conocen algún otro caso de empeño.

-Yo sí- Claudia que había relatado sus problemas cuando su marido estuvo enfermo- una vecina empeñó varias cosas de su suegro cuando este murió, para comprarse un coche. Otras las vendió a la casa de empeño, porque también compran oro. Ella no dijo nada, pero yo reconocí una medalla que siempre llevaba. No se luego que pasó, estaba muy bonita, pero yo se la hubiese dejado. - 
-Sí, también hay cosas de muerto- Rosa se santigua- si no tiene necesidad lo mejor es guardarlo, o dejárselo puesto, pero llevarlo a empeñar... no sé, a mí no se hace.

La conversación desembocó en cuál debería ser el destino de los objetos personales de un fallecido, Claudia y Rosa defendían que lo mejor era guardar estos objetos como recuerdo del fallecido, Lourdes consideraba que una herencia de ese tipo [una medalla de oro] debía ser usada por el heredero como muestra de respeto y continuidad de la tradición y Adela se mostraba poco interesada con la conversación aunque al final objetó que eso era muy personal y dependía de la relación que se guardase con el fallecido.

Reconstrucción de notas de campo, 26 de junio de 2014

Durante la conversación habían relatado diferentes ejemplos de empeño en el que se presentaban las siguientes motivaciones que llevan al uso de las casas de empeño:

-Por carencia económica originada por un imprevisto como un problema médico.

-Para conseguir dinero con la intención de comprar.

-Para conseguir dinero por algún bien al que no se le da uso.

-Para saldar alguna deuda, ya sea con prestamistas o establecimientos que ofertan el pago fraccionado.

Estas motivaciones atienden a dos circunstancias. La primera está enfocada en el financiamiento en la cual el cliente debe disponer de una cantidad económica de la que carece pero que considera puede reunir en el futuro y así recuperar el bien empeñado. La 
segunda circunstancia es no contar con ese dinero que se necesita, ni tampoco confiar en la posible recuperación del bien, pero no reconocer esta posibilidad de pérdida y decidir empeñar esperando que en el futuro exista la posibilidad de recuperación. Debemos tener presente que los objetos empeñados que no se recuperan suponen, en el caso de la casa de empeño en la que trabaja Gustavo, alrededor de un $30 \%$ del total, según los datos facilitados por Gustavo. Esta cantidad hubiese reportado mayores beneficios a sus dueños si la decisión de los mismos hubiese sido venderlos y no empeñarlos. Aunque mucha gente no consigue saldar su deuda por acontecimientos que suceden mientras esa deuda debe ser saldada, también hay clientes que no contemplan la posibilidad de vender por el valor sentimental que el objeto pueda tener. De este modo, y ante la negativa de vender por sentir que el desapego a ese objeto supone un desapego emocional que no están preparados para asumir, prefieren la opción de considerar que "han perdido" ese bien, antes que asumir que "se despojaron" de él.

La compra de bienes en la casa de empeño ofrece la oportunidad de adquirir a menor precio, pero también tiene aspectos negativos:

-El cuestionable estado de los bienes.

-El rechazo del cliente potencial hacia objetos personales de otras personas por la capacidad de estos para evocar el recuerdo de su anterior dueño. En este caso encontramos el rechazo de los consumidores a comprar objetos religiosos como medallas y crucifijos, objetos rituales, como alianzas y objetos representativos de sus anteriores dueños, como aretes y anillos. El resto de objetos que llegan a empeñarse no poseen la misma carga simbólica que los objetos de oro a los que se les considera "usados" y deben ser fundidos para configurar otros nuevos. 
Con estas categorías realizadas con la colaboración de sujetos entrevistados fuera del ámbito de una casa de empeño, retomé las visitas al establecimiento donde trabajaba Gustavo con intención de conseguir entrevistar a algunos de sus clientes y buscar una confirmación de estas categorías o ampliarlas.

\subsubsection{La casa de empeño}

Los meses de verano habían convertido a Michoacán en el ojo del huracán mediático de los noticieros. El 27 de junio se realizó la detención de Mireles y, con ella, las autodefensas se habían fraccionado. Surgieron nuevos grupos, algunos absorbidos por el aparato estatal y otros intentaban mantener su actividad, aunque de la resistencia y ataque a los carteles se había pasado a la supervivencia de las autodefensas. La detención de Mireles supuso un duro golpe, tanto operativo como moral, y la población perdía poco a poco la esperanza. Aunque el debate en torno a si las actividades de las autodefensas podían ser juzgadas como legítima defensa, o solo eran otros grupos criminales que intentaban hacerse con el control del territorio se mantenía en los medios de comunicación, el golpe de efecto generado con otra noticia generó lo que para algunos significó una "cortina de humo" y, para otros, el fin de la atención en las autodefensas y el seguimiento al caso de Mireles.

La noticia, que zanjó los debates que la inseguridad y el número de homicidios generaron durante meses, tenía todos los ingredientes para ser un guion de Luis Estrada ${ }^{124}$. El 15 de julio el fiscal general Jesús Murillo denunció la situación en la que operaba un orfanato que durante décadas había estado en Zamora. La denuncia apuntaba que las condiciones del lugar eran deplorables y los niños sufrían maltratos. La policía federal

\footnotetext{
${ }^{124}$ Director, guionista y productor de cine mexicano. Unos meses después de los acontecimientos que se relatan, en octubre de 2014, se estrenaría "La dictadura perfecta", película que relata la relación de los medios de comunicación con el gobierno de la Republica.
} 
intervino en las dependencias del orfanato con un gran dispositivo junto con unidades móviles de todas las cadenas de televisión del país que convirtieron la noticia en un nuevo ojo de huracán. A los hechos apuntados por la fiscalía, pronto se sumaría en palabra de los reporteros: abusos sexuales, palizas, plagas de ratas y chinches, y sospechas de homicidios y enterramientos en el patio, la noticia llegó a periódicos y noticieros internacionales. Aunque meses después, la directora del orfanato fuera exculpada por su avanzada edad y parte de las acusaciones nunca fueran probadas, el traslado de los niños a otros centros, el debate sobre las condiciones en las que operan los orfanatos y el apoyo que Rosa Verduzco, la directora del centro, tuvo en el pasado y durante todo el caso del matrimonio Fox ${ }^{125}$, ocuparon los espacios informativos. Michoacán seguía en los noticieros nacionales pero las autodefensas, inseguridad y homicidios habían pasado a un segundo plano.

Después de las fiestas de Sahuayo volví a reunirme con Gustavo con la intención de validar los datos que meses antes había recabado. La tienda estaba semivacía debido a, como apuntaría Gustavo, la visita de familiares durante las fiestas. Esto ocasionaba la recuperación muchas cosas del empeño. Los apoyos económicos de los migrantes ayudaban a recuperar bienes empeñados o a saldar deudas, por lo este periodo se consideraba el inicio de un nuevo ciclo de endeudamiento.

-Los televisores y electrodomésticos se han pagado, y los que no, los ha comprado gente. Se nota que durante las fiestas viene la familia del

\footnotetext{
${ }^{125}$ El orfanato recibió apoyo económico, además de la defensa de su directora, por parte de Vicente Fox y su mujer Marta Sahagún, originaria de Zamora.
} 
gabacho y ayuda mucho. Ahora en unos meses muchos volverán a empeñar, para tener dinero en las fiestas o navidad. -

Reconstrucción de notas de campo, Sahuayo, 12 de agosto 2014

Gustavo leyó un pequeño esquema que yo había confeccionado en donde se resumían las motivaciones para recurrir a una casa de empeño, así como los aspectos negativos de comprar los bienes que estos comercios ofertaban. Aunque estuvo de acuerdo en varios puntos, en otros casos consideró que se debían realizar matizaciones.

La gente no empeña porque el bien no tenga uso, para eso lo venden. Lo utilizan como excusa para traer alguna cosa, pero no para empeño sino para vender. Aquí no lo compramos, porque en realidad no somos tienda, hay otras casas que depende lo que sea, sí pueden comprar algo, nosotros solo hacemos empeño y compra de dólares. Lo más habitual es que no tengan dinero y necesiten, o que deban a algún prestamista y el que les dio dinero no acepte bienes para saldar la deuda. Yo conozco a algunos que sí les parece bien que lo devuelvan en coches, oro y algún aparato electrónico, pero también hay uno que no quiere, y solo acepta dólares. Entonces vienes aquí y te piden que les des la cantidad en dólares, tú ya sabes para quién es.

De estos [se refiere a aquellos usuarios que no están seguros de poder recuperar lo empeñado, pero aun así no contemplan la opción de vender y mantienen la esperanza de recuperar el objeto de algún modo] también hay, mujeres. El año pasado tuve un pleito en la tienda con dos. Una había 
empeñado una medalla de su madre y la hermana ya sabía. Ella al final dejó de pagar y por lo que me enteré, la hermana no le dejó dinero, sino que vino y la compró cuando ya la deuda se dio por impagada. A la semana apareció la mujer muy enfadada porque la medalla se la llevó su hermana y decía que yo había dado el aviso. Estas andaban enfadadas por unas tierras, yo le dije que esto era un negocio, pero ella armó el drama y al final vino el marido a por ella. Aquí traen mucho de disputas familiares, pero a mi... [hace un gesto con la mano que indica que ese tipo de problemas no son de su incumbencia]. Lo normal con el oro es fundirlo, pero algunas veces, sí se venden, la familia se entera y viene a buscarlo.

Reconstrucción de notas de campo, Sahuayo, 12 de agosto de 2014

Durante las siguientes semanas acudí a la casa de empeño con asiduidad esperando que algún cliente estuviese dispuesto a ser entrevistado. Aunque en un primer momento fue complicado encontrar la colaboración de los clientes, mi presencia en la tienda hizo posible que algunas personas que acudían a la casa de empeño para pagar su mensualidad se acostumbrasen a mi presencia y accedieran a responder algunas preguntas. La investigación de bifurcaría en dos sistemas financieros diferentes, la casa de empeño en la que trabajaba Gustavo y su participación en una tanda familiar que empezaría ese mes de agosto. Para facilitar la lectura de los datos, en este apartado nos centraremos en las entrevistas realizadas a los usuarios de las casas de empeño y postergaremos la tanda de Gustavo para otro capítulo. 


\subsubsection{Gerardo, los abonos chiquitos que fueron creciendo}

En el mes de octubre un hombre de unos treinta años acudió varias veces a la casa de empeño. La primera vez observó los bienes que se encontraban a la venta y preguntó a Gustavo sobre las condiciones de empeño. Cuando hubo conseguido respuesta a sus preguntas se marchó para regresar unos días después. Quería empeñar un televisor que traía en el coche. Gustavo le pidió lo trajera a la tienda y, después de comprobar que se encontraba en buenas condiciones, le dio un valor aproximado para el empeño.

El hombre, de nombre Gerardo, dudó por unos minutos y posteriormente accedió a rellenar el formulario y presentar su credencial de elector para formalizar el empeño. La televisión de 19 pulgadas de la marca Samsung fue empeñada por un valor de mil pesos. El pago que se había negociado era quincenal, de 250 pesos en cinco quincenas, en el que ya se incluían el $25 \%$ de interés. Si durante los próximos dos meses y medio no realizaba el pago, tendría una quincena de margen para saldar su deuda o la televisión sería vendida por la tienda. Una vez hubieron terminado todos los trámites y manteniéndome hasta entonces como observadora le propuse a Gerardo realizar una pequeña entrevista, a lo que accedió siempre que mantuviese su anonimato.

-La pantalla la compré en julio. Estaba en oferta y Coppel te permite pagar poco a poco. Mira aquí tengo el recibo de Coppel [La pantalla tenía un valor de 2.999 pesos al contado que a través del crédito Coppel se ofertaba en 24 quincenas de 170 pesos cada una. La cantidad abonada en total, sumados los intereses del crédito ascendía a 4.080 pesos. El interés que se aplicaba era de $36.01 \%$, mayor que la casa de empeño, pero con un periodo de tiempo muy superior. Mientras la casa de empeño ofrecía 
el crédito a dos meses y medio, Coppel permitía que la devolución se realizase durante un año completo, 24 quincenas. Cuando Gustavo fue a empeñar el televisor había pagado siete quincenas, todavía tenía pendientes diecisiete quincenas, cada una de 170 pesos, 2890 pesos].

Hasta ahora he pagado los intereses, pero necesito dinero porque mi hijo se ha roto el brazo y hay que pagar al médico.

Reconstrucción de notas de campo, Sahuayo, 10 de octubre de 2014

Gustavo me indicó que la suma ofertada por la casa de empeño era reducida porque en aparatos electrónicos el plazo se reducía considerablemente. Las posibilidades de venta de un producto tecnológico descendían con el paso del tiempo, al igual que su valor. Por eso la casa de empeño ofrecía poco dinero por ellos y en cortos plazos, o los clientes devolvían rápidamente lo prestado o había que deshacerse del producto lo más rápido posible.

En los siguientes meses Gerardo abonaría las cantidades acordadas recuperando la televisión, aunque la última vez que visitó la casa de empeño para recoger la televisión, señaló que la deuda con Coppel había aumentado. El impago de la cuota de Coppel durante una quincena había reportado un aumento de la deuda: al interés inicial, se había sumado un $6 \%$ sobre la cantidad vencida provocando que la televisión aumentase el precio de compra inicial. Como en muchas ocasiones, los usuarios del pago fraccionado de Coppel no disponían durante el periodo de pago del dinero necesario para realizar quincenalmente los abonos, por lo que el interés aumentaba, lo que provocaba el aumento de la deuda. Si el impago se realizaba durante los primeros meses del crédito, la suma del porcentaje por demora no suponía un gran problema, cuanto más se acercaba el momento 
de finalizar el préstamo, este interés generaba nuevas deudas al ser calculado sobre la cantidad ya desembolsada por el cliente.

-Con Coppel uno ya sabe que va a pagar dos o tres veces por una misma cosa, pero ni modo. Si tienes cosas buenas y viene un apuro, como lo de mi hijo, siempre puedes empeñar, sino tienes que andar pidiendo dinero y la gente es muy sangrona [avariciosa]. Mejor arreglar estas cosas así que pedir prestado, los compromisos no hacen amigos. -

Reconstrucción de notal de campo, Sahuayo, 3 de enero de 2015

\subsubsection{Ana María, remesas, deudas y el futuro de sus hijos}

Ana María llegó a la casa de empeño a principios de diciembre. Había traído una pulsera y una cadena de oro, que guarda en una bolsita de terciopelo. Gustavo, después de validar que fuese realmente oro y pesar las dos piezas, le dio a la mujer una cifra aproximada del dinero del que podía disponer si se decidía a empeñar. También le ofreció la posibilidad de vender las dos piezas si quería conseguir más dinero. Ana María, después de oír todas las posibilidades, explicó a Gustavo que necesitaba el dinero para comprar un celular, quería regalarle uno a su hijo mayor por navidad, pero la cantidad que este le ofrecía por las joyas no le alcanzaba para comprar uno. Entonces Gustavo le enseñó alguno de los celulares que tenía en el local. Aunque él no era participe de recibir mucha tecnología, su jefe defendía que disponer de celulares y computadoras atraía clientela más joven, menos preocupada en contraer deudas que las personas mayores. Después de ver 
varios modelos y, ante las dudas que la clienta tenía sobre la elección, decidió que volvería con alguno de sus sobrinos para que la ayudasen a elegir.

Una semana después de su primera visita, regresó a la casa de empeño acompañada por un joven. Estuvieron durante un tiempo mirando los celulares, mientras el chico preguntaba los precios de cada uno de ellos. Finalmente se decidió por un smartphone de la marca Huawei. El precio total del teléfono era superior al valor de las dos piezas que una semana antes había traído a la tienda. Aunque ella, en un principio, propuso completar el valor de las joyas con abonos mensuales, Gustavo le indicó que esa propuesta era imposible, ya que los productos comprados en la casa de empeño se debían abonar en el momento. La casa de empeño no daba crédito para las compras.

Ana María miró el teléfono y, después de unos segundos buscando en su cabeza alguna opción que le permitiese llevarse el regalo para su hijo, propuso la venta de las joyas. Gustavo volvió a realizar el mismo ritual, pesando y verificando su autenticidad, para después explicarle a la mujer que, de ese modo, sí podía comprar el celular, y además recibir 200 pesos. Ana María no parecía muy conforme con vender la pulsera y la cadena, ya que al principio había acudido con la intención de empeñarlas, no de venderlas. Finalmente decidió vender las piezas y llevarse el dinero y el celular.

Cuando la transacción hubo finalizado y ante el interés que su sobrino por seguir viendo pantallas de televisión, estuvieron en la tienda media hora más, que fue utilizada para entablar conversación con la señora y poder, de este modo, preguntarle sobre su experiencia en la casa de empeño.

Aquí los celulares son más baratos que en Coppel, son usados, pero mientras funcione. David [hijo de Ana María] quería uno desde hace 
meses, y es muy buen chico. Si puedo evitar Coppel mejor, porque luego hay que ir todas las quincenas, puedas o no, y si no pagas a tiempo te sube el precio. Ahí compre el refrigerador y cada vez que lo veo, no se me olvida lo caro que salió, mejor hacer las cosas así. Mi madre, si necesitaba, prefería siempre la casa de empeño a pedir prestado, luego todo son reclamos, y con la familia [mira que su sobrino no esté cerca para oír la conversación] es lo mismo. Aquí yo ya he terminado.

Reconstrucción de las notas de campo, 8 de diciembre de 2014

\subsubsection{Esteban, empeñar los bienes para evitar los males}

A partir del mes de febrero, la casa de empeño empezó a aumentar su clientela con la venta y empeño de algunos de los regalos o bienes recuperados durante la navidad. Los meses siguientes llenaron las estanterías del local y los pagos recuperaron el ritmo normal. Si en el mes de diciembre algunos habían recuperado los bienes con la ayuda de familiares, el momento de bonanza ya se había difuminado y las deudas resurgían.

Las dificultades para encontrar personas dispuestas a participar en la investigación se mantenían y, aunque durante las visitas podía ser testigo de la mecánica de empeño o venta de joyas, las personas rehusaban dar muchos detalles sobre sus problemas económicos.

En el mes de marzo llegó Esteban a la tienda. Nos conocíamos hacía varios meses por tener amigos en común, y aunque él no conocía muchos detalles sobre mi investigación, estuvo dispuesto a participar en ella, siempre que su anonimato estuviese garantizado. 
Había acudido a la casa de empeño para informarse, y aunque Gustavo se mostró dispuesto a solucionar cualquier duda, Esteban rápidamente le informó que se iba a reunir allí con el dueño, por lo que durante la espera estuvo ojeando algunos productos y conversando con nosotros de manera distendida. Una media hora después y habiendo avisado a Gustavo de su tardanza, llegó el dueño, Manolo. Al ver que allí estaba Esteban le pidió que fueran a una cafetería cercana a hablar por lo que tuve que esperar a que Esteban se pusiera en contacto conmigo para conocer cuál era el motivo de su visita a la casa de empeño. Mientras, Gustavo me dio algunas pistas.

Cuando viene Manolo es porque hay dinero. A mí me deja con estas cosas [señalando al interior de la tienda] pero si es varo viene él. Los coches y las herramientas las maneja él, así no me da comisión por el empeño.

Reconstrucción de las notas de campo, 16 de marzo de 2015

Manolo, el dueño de la casa de empeño, regresó después de varias horas para recoger parte del dinero recaudado durante los últimos días. Interesado por mi presencia en la casa de empeño y dado que (como comprobaría más tarde) Esteban le había hablado de mí, se mostró dispuesto a participar en la investigación. Nos sentamos los dos en la parte trasera de la tienda, donde se guardan las cosas de mayor valor y, después de explicarle brevemente mi interés por la casa de empeño, comenzó a explicarme algunos asuntos de su establecimiento que hasta el momento habían quedado pendientes. 
- La casa de empeño era antes de mi tío, pero, cuando empezaron a nacer sus nietos en el gabacho, me la vendió para irse allí con sus hijas, no tuvo varones. Una casa de empeño es buen negocio porque aquí la gente se endeuda mucho, estas cosas vienen de Coppel [indicando con la mirada algunas pantallas y computadoras que estaban detrás], ellos son nuestros mejores clientes. La gente compra sin conocimiento, luego andan pidiendo a la familia, pero saben que así se queman y vienen aquí. Cuando la gente anda de chamba en chamba está de pufo en pufo ${ }^{126}$. Gustavo me dijo que está por aquí una española, pero no sabía para qué. Tienes que tener claro que los mexicanos siempre le encontramos el modo. Yo tengo cuenta en Bancomer, pero esas ratas no me van a dar nada si no demuestro lo que gano y, si lo hago, el pinche gobierno ya anda reclamando su parte. Es todo una rueda. Yo no sé quién trabaja para quién, si los bancos para los políticos o los políticos para los bancos, pero ya mi padre decía "el banco y el médico, lejos", razón, siempre te lían. Por eso aquí prefieren hacer las cosas así, si tienes familia de confianza hacen una tanda y, si no, pues se empeña algo o se pide, aunque hay que tener cuidado si se pide. Cuando hables con Esteban ya te contará si quiere. -

Reconstrucción de las notas de campo, 16 de marzo de 2015

Manolo decidió terminar ahí la conversación y agarrando la bolsa donde había guarda el dinero y algunas joyas se marchó.

\footnotetext{
${ }^{126}$ De trabajo en trabajo, de deuda a deuda
} 
Aunque nuestro encuentro había sido muy breve, Manolo señaló que el uso de los sistemas informales, o aquellos formales que consistían en el empeño, estaba condicionado por las carencias económicas, pero también por el alto índice de economía sumergida.

Una semana después, Esteban se puso en contacto conmigo. Quedamos en un restaurante céntrico para el almuerzo del viernes. Por los pocos datos que tenía sobre él, sabía que tenía varios negocios y presumía de tener un buen coche. Cuando le conocí, varias conocidas me indicaron que era un buen partido por su nivel económico.

-No creas que ando mal, pero sí necesito dinero con urgencia, por eso el otro día me reuní con Manolo. El año pasado le metí un varote [mucho dinero] a un taller que tengo. Va bien, pero tuve que pedir algo de dinero porque la maquinaria está cara. Ahora, estos meses, me andan reclamando y pues hay que sacarle de algún lado. -

Reconstrucción de las notas de campo, 27 de marzo de 2015

Esteban no pretendía dar muchos detalles sobre su motivación para acudir a la casa de empeño, por lo que fue necesario realizar algunas preguntas concretas para redirigir la conversación, aquí se muestran algunas respuestas. 
-Al banco no, para pedir al banco hay que tener todo el dinero allí y según vean luego te llega alguno pidiéndote cuota $^{127}$. Como se dice... perfil bajo, ¿no?, eso es lo que hay que hacer. Yo pago por mis trabajadores, así tienen seguro, pero el contador siempre deja algunas cosas fuera, este pinche gobierno quiere saber hasta cuando vas a cagar... perdón, pero sí lo quieren saber. Allí de donde tu eres, ¿cómo es? -

Reconstrucción de las notas de campo, 27 de marzo de 2015

Después de explicarle que en España también hay economía sumergida, Esteban sigue explicando por qué acudió a la casa de empeño.

-El caso es que pedí dinero a un compadre, es un tipo peligroso y las amistades hasta que se debe. El otro día fue al taller y dejó un aviso, por eso le he traído a Manolo la hidrolavadora, la compré hace poco, está nueva. Yo se la dejo y que la rente si quiere, él tiene seguro para estos casos. Me da 10.000 por ella y ya así le bajo al tipo, no quiero cargos de conciencia. -

Reconstrucción de las notas de campo, 27 de marzo de 2015

Los pagos se realizarían mensualmente. Manolo le había dado mucho margen para devolver el dinero porque contaba con sacar beneficio mientras la hidrolavadora estuviese en su poder. Esteban, mientras, pagaría su deuda con el prestamista y continuaría

\footnotetext{
${ }^{127}$ En la región existía la sospecha de que el cobro de cuotas por parte de los grupos criminales y los ingresos en los bancos estaban relacionados. En algunas ocasiones se extorsionaba a ciertos clientes con datos a los que el banco solo tenía acceso por lo que se acusaba a alguno de sus trabajadores de colaborar con estos grupos.
} 
trabajando en el taller. Aunque muchos detalles no fueron facilitados por Esteban, parte de la información sobre este empeño llegaría a través de amigos en común.

Esteban había pedido dinero a un prestamista de la región. Como la devolución del dinero se había retrasado varias semanas, el prestamista había enviado a unas personas a presionar a Esteban. Ante las negativas de Esteban para darles el dinero, generadas por sus limitados ingresos durante aquellos meses, habían balaceado el local desde una motocicleta. Uno de sus trabajadores había resultado herido y Esteban había optado por recurrir a Manolo para que le ayudase a saldar su deuda cuanto antes para evitar males mayores.

La deuda fue saldada con el dinero obtenido por el empeño de la hidrolavadora y alguna ayuda familiar. Casi un año después, cuando se estaba concluyendo el trabajo de campo, otras personas me informaron que habían levantado (secuestrado) a Esteban y la familia tuvo que desembolsar mucho dinero para recuperarlo.

\subsubsection{La tanda de Julia}

Retrocediendo unos meses, en el mes de agosto de 2014, Gustavo empezó a formar parte de una tanda organiza por su tía. Durante ese mes, todos los participantes debían pagar 500 pesos de enganche cada uno. El dinero sería destinado a pagar a Julia sus honorarios como organizadora. Este tipo de tandas, denominadas de numero muerto, se constituyen bajo la organización de una persona externa que, al no participar en la tanda, recibe una cantidad de dinero al inicio de la misma.

La tanda estaba compuesta por 10 personas, todas familiares de Julia. La rotación comenzó en septiembre, teniendo una duración de diez meses, de septiembre de 2014 a 
julio de 2015. Cada participante debía abonar 1.000 pesos cada principio de mes y por turno recibirían 10.000 .

Gustavo me puso en contacto con Julia a finales de agosto, cuando la tanda ya había sido constituida. Nos reunimos en su casa. Julia, de unos 50 años de edad, tenía preparada una libreta encima de la mesa para mostrarme cómo era el funcionamiento de la tanda. La primera parte de la entrevista se dedicó a enumerar a los participantes de la misma.

Esto lo hago para ayudar a la familia, los jóvenes ahora no tienen el hábito de ahorrar y hay que enseñarles, todos los años hago una. Mira, primero ya anuncio que se va a hacer y vienen a decirme si le entran este año, también me explican si necesitan o van a ahorrar y con eso yo voy dando los números para organizar. La primera va a ser Teresa, mi hermana, porque el año pasado la deje la última y con lo del anterior y este quiere irse al gabacho a visitar a sus nietos. Después va Carlos, mi hijo, porque anda apurado, así paga lo que debe del auto. En noviembre le toca a Gustavo, yo a este niño le quiero mucho. Mi hermana [la madre de Gustavo] se volvió a casar cuando el padre de Gustavo murió, y para mi es como si fuese un hijo, es muy trabajador. Ahora se está arreglando la casa y me pidió si podía ponerle de los primeros para empezar a poner la cocina. Para diciembre recibe el dinero Irene, una sobrina, porque tiene muchos gastos, ya sabe... regalos. Luego va Janett, la esposa de mi hijo mayor, y de seguido Ignacio y Daniel, los hijos de Carla. Estos andan queriendo poner un negocio, no les gusta estudiar. En abril lo recibe Vanessa, que por entonces ya debe haberse aliviado [dar a luz], el otro día cuando hablé con ella me dijo, si es niño lo llamará Santiago, yo creo 
Figura 3, Diagrama de parentesco de los participantes en la tanda

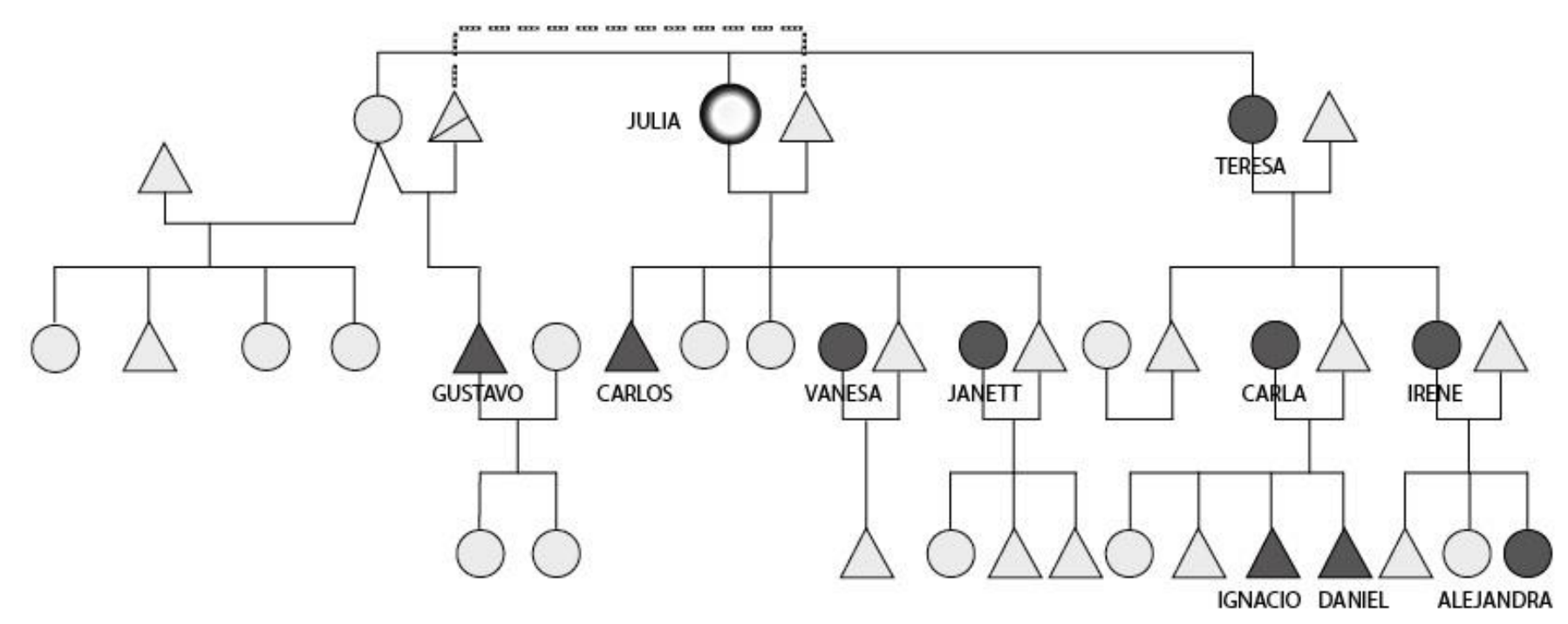

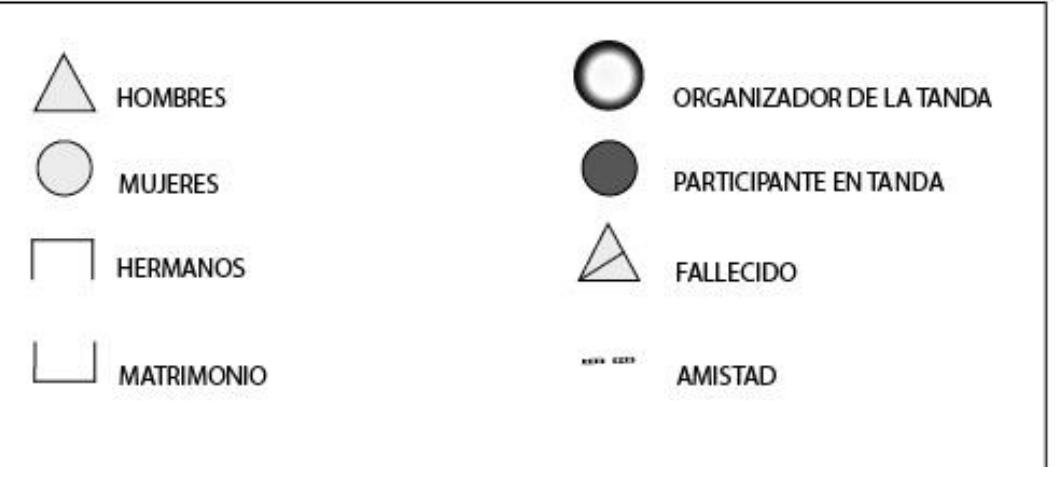

Fuente: Elaboración propia 
Figura 4, La tanda de Julia

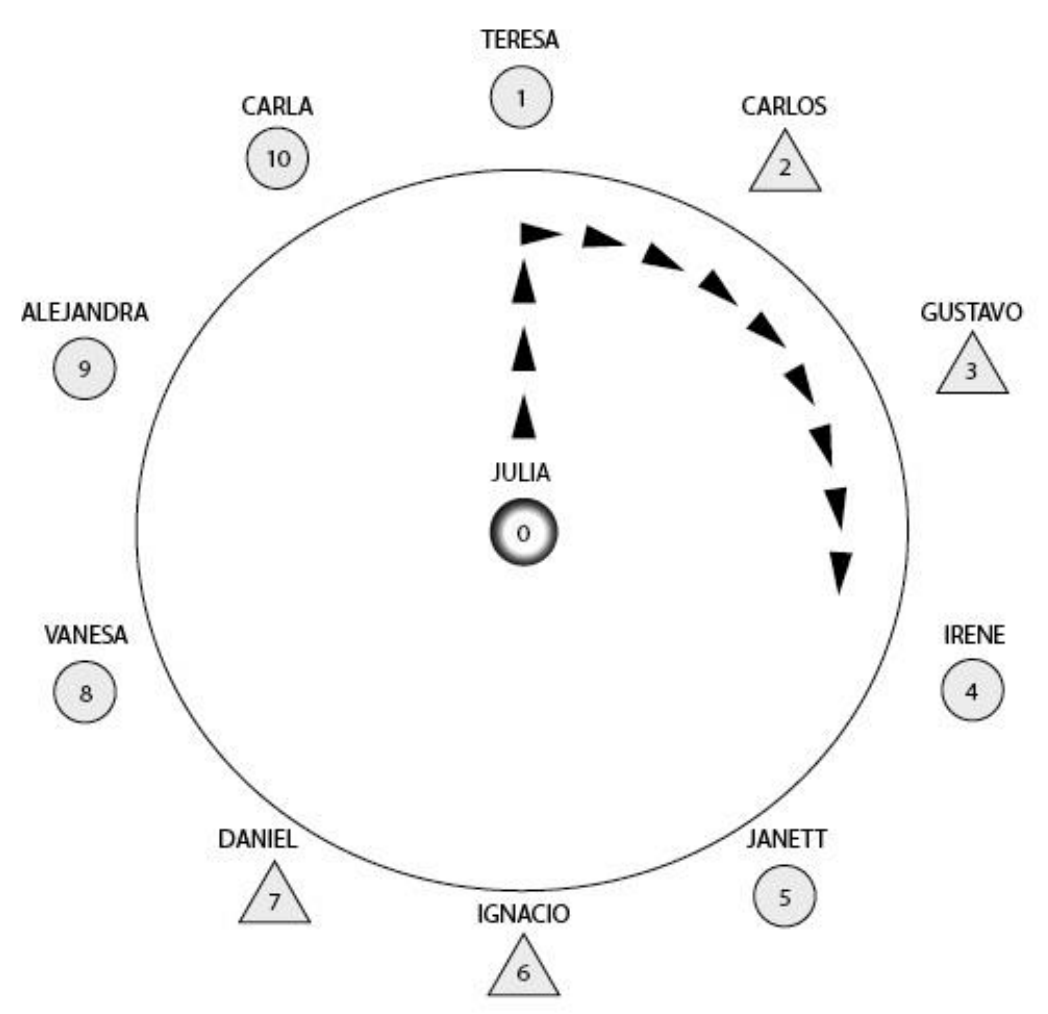

Fuente: Elaboración propia 
que lo hizo en las fiestas. Las últimas son Alejandra, hija de mi sobrina Irene, y Carla, que siempre dice querer estar de las ultimas para ahorrar. Estos son todos, ya ve, la familia así nos organizamos, el caso es tener disciplina y quitarse de vicios para tener dinero.

Reconstrucción de las notas de campo, 29 de agosto de 2014

Con la ayuda de Julia confeccioné un diagrama de parentesco que representase más fácilmente los diferentes niveles de parentesco que existían en la tanda y como cada uno de ellos se relacionaba con Julia. Así mismo organice un gráfico sobre el orden de los turnos. Julia me invitó a acompañarla en los días de cobro, ya que era ella quien visitaba a sus familiares cada mes. El mes siguiente visitamos a su hermana Teresa, la primera en recibir la tanda.

Teresa vivía en un fraccionamiento privado cercano al panteón municipal de Sahuayo. En la casa también estaban Carla e Irene. Tenían dispuesto todo para ver la novela en la televisión del salón, con comida y bebida de sobra para hacer una fiesta. La tanda permitía reuniones periódicas con los familiares o, en este caso, ver la novela juntas y comentar el desarrollo de los personajes principales del drama que se retransmitía por la televisión.

-Con la tanda quieras que no, se ahorra mucho, es una manera de mover el dinero. Si dejas el dinero en casa, vas agarrando de a poco y se termina. De este modo siempre guardas para la tanda y cuando recibes ya se hizo el puerquito - explica Teresa durante la publicidad de la novela. -Para mí lo mejor es en Navidad, porque llega la familia de mi marido y hay mucho 
gasto. Con la tanda compro regalos y la comida. Ellos siempre nos regalan muchas cosas y hay que corresponder, qué menos. Esta navidad nos vamos a reunir en mi casa- Irene recibía la tanda en diciembre. Estábamos en septiembre, pero ella ya estaba organizando algunas cosas para la navidad. Con la visita de varios familiares le había pedido a su madre varias camas y cobijas que estaban empacadas en la entrada

-Esto de la tanda está muy bien, lo hace mucha gente. El detalle es participar con gente de confianza, como la familia. Los extraños pueden ser muy responsables, pero si te quedan mal, no puedes andar luego reclamando. Estas cosas son para hacer en familia, y si no, fracasan. Yo voy la última porque no necesito ahorrar, para mí esto es ahorrar para las vacaciones de verano- Carla interrumpió la frase cuando el espacio publicitario concluyó y comenzó de nuevo la emisión de la novela.

Reconstrucción de las notas de campo, 5 de septiembre de 2014

Todas confiaban que el desarrollo de la tanda se hiciera sin ningún problema y afirmaban que dentro del ámbito familiar los peligros que este tipo de sistema financiero tenían se minimizaban.

Al comienzo de diciembre Irene debía recibir su asignación de la tanda. Volví a la casa de Teresa donde se encontraban Carla, Irene y la hija de esta, Alejandra. La mesa del comedor estaba llena de bandejas y cazuelas llenos de comida y se disponían a celebrar las fiestas en Honor a la Virgen de Guadalupe con una cena familiar. Mientras Carla, Irene y Alejandra cocinaban, Teresa y Julia se sentaron en el sofá para comentar como estaba transcurriendo la tanda. 
-Irene ya recibió su parte- señala Teresa- Ignacio y Daniel están tardando un poco en pagar, están chavos, pero en unos días ya tendrán el dinero porque su padre les mando a trabajar con un amigo que tiene un restaurante, así aprenden cómo se hace. -

Reconstrucción de las notas de campo, 9 de diciembre de 2014

Teresa justificaba la tardanza en aportar la cuota de sus dos nietos con la juventud de estos, siendo ella el aval de su pago en unas semanas. Con posteriores comentarios pude constatar que, aunque el sistema contaba con diez participantes, todo giraba en torno a Julia y Teresa, como cuidadoras de que sus hijos, las mujeres de sus hijos y sus nietos cumpliesen por el bien de todos. Hay que tener en cuenta que cuatro de las participantes eran familia política de alguna de ellas, por lo que la tanda también servía para seguir manteniendo un control sobre las finanzas de sus hijos de manera indirecta.

-Vanessa se fue hace unos días. Como tiene nacionalidad gringa se fue ahora para tener allí al niño. También lo hizo con el mayor. Va a casa de su tía, ahora que está de seis meses puede viajar, en marzo nace mi nieto. Me da rabia no estar allí, pero entiendo que para los chicos es mejor, entre que hace papeles, volverá en julio o agosto. Yo creo que para las fiestas de Santiago. - Julia está un poco enfadada con el hecho de tener que esperar tanto tiempo para ver a su nieto y, aunque reconoce que tener la nacionalidad estadounidense es una ventaja para ellos, el que Vanessa sea la más independiente de la familia no acaba de gustar a Julia. -Mi hijo 
David se hace cargo de los pagos, aquí se ha quedado con el mayor que va a estar en mi casa hasta que regrese su madre.

Reconstrucción de las notas de campo, 9 de diciembre de 2014

El resto del día lo pasamos con el resto de la familia, oportunidad que se aprovechó para constatar que Julia y Teresa ejercían un control sobre las mujeres de sus hijos. En un principio, observando como la tanda era motivo de reunión todos los meses, se consideró que este sistema financiero estaba siendo utilizado como excusa para mantener fuertes los lazos familiares y garantizar con ello la unión de la familia. Fue después, gracias a pequeños detalles, como la actitud extremadamente servicial que mostraban Vanesa, Janet, Carla e Irene hacia Julia y Teresa, cuando se pudo comprobar que la tanda era una forma de dominación. Todas ellas eran mujeres cuya actividad principal son las labores domésticas no remuneradas en su hogar por lo que el salario de sus maridos era el ingreso principal que recibían, independientemente de las ayudas económicas que en algunos casos recibían los niños de sus abuelos maternos. Con la tanda, Julia y Teresa mantenían un cierto control sobre estos ingresos cuartando la libertad de las esposas.

Ante estas observaciones e intentando reunirme con Janett sin que la presencia de Julia pudiese entorpecer nuestra conversación, pedí ayuda a Gustavo para reunirme con su prima.

La reunión con Janett se celebró a primera hora de la mañana, buscando un espacio de tiempo entre la hora en la que los niños eran acompañados a la escuela y la visita al mercado. En una cafetería, algo sorprendida con mi interés por reunirme con ella, Janett explicó los motivos de su participación y cuáles eran los beneficios que ella encontraba en la tanda. 
-La tanda es buena si quieres ahorrar o si necesitas dinero, porque cuando tienes de los primeros turnos es como si te diesen un préstamo. Además, todos nos conocemos y sabes que de seguro todos pagan su cuota y no hay problemas- Como era previsible, Janett estaba repitiendo las mismas motivaciones que ya habían explicado antes Julia y Teresa. Sin intención de presionarla, pero haciéndole ver que era curioso que cuatro de las participantes fuesen las esposas de los hijos de la organizadora y su hermana, ella entendió cuál era mi interés en hablar con ella. - Tienes razón. No digas nada a Julia, pero obvio Vanesa puede tener al niño aquí y luego inscribirlo en la embajada. Yo no digo nada, pero entiendo que Vanesa aproveche para visitar a su familia y estar fuera de la vigilancia de Julia. Anselmo [hijo de Julia] lo entiende, porque él también está cansado. Todos los años llegan con que organizan una tanda para que ahorremos, nosotras nos hacemos pendejas porque no queremos discutir. Para cuando te pagan tu tanda ya te andan diciendo cómo te lo debes gastar, son así. Cuando nos casamos, Julia entró en la casa y me miró todos los armarios, la conoce todo el mundo por ser una metiche [cotilla], y su hermana igual-

Reconstrucción de las notas de campo, 26 de junio de 2015

Una vez comprobada la teoría sobre el control que establecían Julia y Teresa sobre las esposas de sus hijos y con la tanda ya finalizada, espere al año siguiente para ponerme 
en contacto con Julia y comprobar si todos los participantes de esta tanda se mantenían en la siguiente.

Me reuní con Julia con la intención de comprobar si el esquema de participantes a la tanda había variado. Habíamos acordado vernos en casa de Teresa, una vez más para ver la novela.

-Este año Ignacio y Daniel no participan, en la pasada teníamos que andar detrás de ellos para que pagasen su cuota. Decían que querían dinero para montar un negocio y luego resulta que se han ido a vivir a Guadalajara. - Señala Julia decepcionada por el comportamiento de los hermanos.

-Eso es porque Carla siempre les ha dejado hacer lo que han querido. Si fueran mis hijos no hubiese pasado. - Teresa intento durante un tiempo justificar el comportamiento de sus nietos, pero al final tuvo que reconocer que no estaban dispuestos a comprometerse con la tanda.

-Ahora entro Marta, la esposa de Jorge [hijo de Teresa] y Monse [hija de Julia]. Entre mujeres nos organizamos mejor, hombres solo participan Gustavo y Carlos. Con la mujer de Gustavo no tengo mucha confianza, además Gustavo siempre insiste que él se hace cargo y Carlos no está casado. Si no fuera por nosotras estos hijos no tendrían ni como vestirse. Se hacen mayores pero una madre siempre tiene que cuidar de los suyosJulia.

Reconstrucción de las notas de campo, 5 de febrero de 2016 


\section{BLOQUE V. CONCLUSIONES}

En esta investigación se han presentado datos etnográficos que pretenden aportar conocimiento tanto de los sistemas financieros alternativos como de las dinámicas sociales de las que dependen durante su desarrollo. Para ello, nos hemos servido de un marco teórico multidisciplinar que abarca tanto la teoría económica como la antropológica.

Hemos comprobado, a través de los testimonios recogidos durante el trabajo de campo, que el postulado capitalista de la maximización del beneficio también convive con actitudes de ayuda mutua, caridad y reciprocidad.

Como primer objetivo de esta investigación se propuso describir y analizar los sistemas formales e informales presentes en la Ciénaga de Chapala, realizando para ello un análisis de los factores que intervienen en la selección de cada sistema por parte de los individuos, exponiendo los mecanismos de selección que los organizadores y prestamistas utilizan para la inclusión o exclusión de participantes y realizando un seguimiento de cada modalidad con el fin de observar el funcionamiento de cada sistema y el proceso de financiación a través de los diferentes roles sociales, ahorradores, prestamistas, prestatarios y avalistas.

El paisaje financiero de la Ciénaga de Chapala, las normas, acciones y procesos internos que configuran las transacciones entre ahorradores, solicitantes de crédito y prestamistas, presentan diferentes estructuras articuladas entre si que componen un sistema complejo donde las estrategias para solventar el ahorro y el crédito se conforman en diferentes esferas. El sistema formal ofrece diferentes opciones, algunas fuera de las posibilidades reales de parte de la población, como la banca multiple y las tarjetas de crédito. Dentro del sistema financiero formal, el recurso mas utilizado es la financiación 
del consumo a través del pago fraccionado, con unas altas tasas de interés y fuertes penalizaciones que convierten este tipo de préstamos en abusivos. La metodología para el cobro utilizada por estos establecimientos, amenazas y coacciones, provoca que el impago de este tipo de prestamos sea en muchas ocasiones el primer paso para adentrarse en una cadena de endeudamiento donde el préstamo familiar, prestamistas locales y casas de empeño provocan el desgaste tanto del capital social como de la capacidad económica.

Las casas de empeño, consideradas por la población como último recurso del que disponen en situación de necesidad, cumplen el objetivo de ofertar un préstamo a través del empeño de algún bien de valor del que pueda disponer el cliente. Durante la etnografía se realizó el seguimiento de un trabajador de este tipo de establecimientos, Gustavo. Gracias a él se desarrollo una clasificación de las motivaciones principales de sus clientes y una descripción del funcionamiento de la casa de empeño donde él trabajaba. También se entrevistó a varios clientes para confirmar las diversas motivaciones señaladas por Gustavo durante las entrevistas.

Los sistemas financieros informales son utilizados por la desconfianza en las instituciones, la exclusión de los sistemas financieros formales o la capacidad generadora de lazos sociales.

Los apartados como el homólogo informal del pago fraccionado, permiten el consumo sin aplicar intereses a la compra. El acceso a este tipo de financiamiento esta condicionado por el capital social, siendo indispensable la pertenencia a la comunidad. Aunque el vendedor pueda considerar que un cliente no es apto para acceder a este tipo de financiamiento, la comunidad puede ejercer suficiente presión para doblegar su voluntad. Un ejemplo de esta dinámica la podemos encontrar en el capítulo dedicado a Karen, en el cual, para la selección de clientes, la vendedora está sujeta a la presión social ejercida por la comunidad. 
La kérmes, celebración comunitaria donde se persigue como objetivo la colecta de dinero, puede ser analizada como un "hecho social total", guardando semejanzas con la descripción que Mauss (2010) realizó sobre el potlatch. La celebración de una kérmes crea comunidad, independientemente de que su objetivo sea el bien del grupo (como en el caso de las organizadas para la recolecta de una iglesia o un barrio), o el dinero se destine al apoyo de algún miembro de la comunidad (celebraciones destinadas a los migrantes, familias con bajos recursos o miembros de la comunidad que necesitan dinero para costearse estudios o tratamientos médicos). La participación en estas celebraciones permite el acceso a otros sistemas de financiación, la socialización de los miembros de una comunidad en la kérmes genera el capital social necesario para formar parte de las tandas o conseguir comprar a través de un apartado. Son sistemas de paso, procesos por los cuales los individuos pueden ingresar en la comunidad y ser confiables, adquirir el capital social necesario para acceder a otros sistemas financieros alternativos. La participación en la tanda de Elena (capítulo 2) solo es posible perteneciendo a la comunidad generada en torno a una iglesia, donde la confiabilidad se alcanza a través de compartir los mismos valores morales y participar en las kermeses organizadas por la comunidad.

Las tandas, asociaciones rotativas de crédito, son configuradas en torno a la perspectiva de reciprocidad que sus participantes comparten. En la investigación se han analizado tres tipos de tanda, cada una de ellas inscrita en una clase social. La primera de ellas, organizada por Karen, es una tanda de carácter retroactivo, que persigue dos objetivos concretos para su organización, costear la compra de productos de importación para el comercio de la organizadora y financiar la celebracion de la fiesta de quince años de la hija de Monse (prima de la organizadora). Esta tanda fue compuesta por mujeres de 
clase media alta o clase media, que en su mayoría accedieron a participar como un compromiso de clase o buscando un reconocimiento en su entorno social como individuos colaborativos.

Aunque los objetivos en un primer momento quedaron definidos dentro del ámbito de la reciprocidad y colaboración, pronto se desarrollaron estrategias de maximización que provocaron disputas entre las participantes, no sintiéndose satisfechas con los beneficios adquiridos en la tanda, ya que deseaban mayores privilegios por su colaboración. Las disputas provocaron el enfrentamiento entre dos grupos de participantes de la misma clase social, que fueron solventados haciendo recaer la responsabilidad de la conflontacion en una tercera persona no perteneciente a la misma clase social. La adcripción de clase y la trayectoria vital de las dos personas enfrentadas hizo posible que se considerase necesario el mantenimiento de un status quo entre miembros de una misma clase, presentando un corporativismo de clase.

La segunda tanda analizada en la etnografía, organizada por Elena, es una tanda periódica celebrada dos veces al año. En ella participan personas de diferentes clases sociales, todas pertenecientes a la misma comunidad. La asignación de turnos, a diferencia de la tanda de Karen, era mas flexible, un participante podía disponer del número de turnos que considerase oportuno. Con ello, Elena perseguía evitar la necesidad de buscar participantes que no estuviesen interesados en participar, ofreciendo la posibilidad de mantener una tanda periódica independientemente del numero de participantes, si había pocos, ella podía quedarse con los turnos sobrantes. Esta tanda, organizada con el objetivo de ser un sistema informal regular de la comunidad, permitía que los miembros mas vulnerables de la comunidad dispusieran de financiación gracias a sus vecinos. La asociación era dependiente del capital social de la organizadora, que 
también participaba en kérmes y poseía la capacidad de generar lazos sociales en la comunidad.

La ultima tanda estudiada esta conformada en el ámbito familiar de Julia y Gustavo. Siendo una tanda periódica, en este caso la organizadora (Julia), no participa en la tanda, recibiendo una cantidad de dinero por su trabajo similar a un turno de la misma (el denominado número muerto). Los objetivos perseguidos por los participantes son muy variados, no estando ninguno de ellos en situación vulnerable, ni precisar dinero con urgencia. Esta tanda se configura como una estrategia de ahorro que permite, dentro del ámbito familiar, la ayuda colaborativa de sus miembros para alcanzar objetivos individuales. La organizadora además de recibir una remuneración por la organización, también consigue mantener un control sobre el dinero del que disponen sus hijos y sobrinos a través de la invitación a participar en la tanda de las esposas de estos. Este hecho, advertido por las esposas como una estrategia de control y dominación de la matriarca hacia las esposas de los varones de la familia, convierte a esta tanda en un sistema financiero destinado al mantenimiento de lazos familiares e implanta la economía del afecto (Ahmed, 2004) capaz de unir a los sujetos en colectividades y conducir la conducta de los individuos.

En el caso de la selección de participantes en las tandas se observó como estas dinámicas variaban notablemente dependiendo de la clase social de los miembros. Mientras las personas de bajos recursos debían poseer capital social, y en especial el reconocimiento de la comunidad como individuos confiables para acceder a los sistemas financieros informales, en las clases medias y altas no se mantenía esta pauta. En la tanda de clase media, de carácter familiar (la tanda organizada por Julia), y la tanda de clase media-alta (Karen), la estrategia era inversa. Los participantes usaban su capital económico con el fin de obtener capital social a través de su participación. Esta 
diferenciación de clase remarca las diferentes estrategias que están presentes en un mismo sistema financiero informal, siendo utilizado como un mecanismo de acceso a la financiación, pero también con el fin de generar lazos sociales y afectivos capaces de fortalecer a la comunidad.

El último sistema financiero informal estudiado en la etnografía son los préstamos otorgados por prestamistas locales. Para ello se entrevistó a un prestamista, Humberto, que al igual que su mujer Elena, desempeñaban una actividad que permitía a los miembros de su comunidad acceder a financiamiento. Los préstamos otorgados por Humberto perseguían ofrecer a sus vecinos ayuda económica, por lo que los intereses y plazos se negociaban buscando el beneficio mutuo. En contraposición al caso de Humberto, se presentó durante la etnografía la situación económica de Esteban, que había recurrido a un prestamista local, que en un principio calificó de compadre, para financiar la compra de maquinaria para su taller. Cuando la devolución de la cantidad acordada no se pudo realizar, Esteban fue amenazado y violentado, siendo su taller baleado como advetencia.

El segundo objetivo centra su atención en señalar cuales son las pautas sociales que intervienen en la conformación de los grupos que usan los sistemas financieros informales, asi como las penalizaciones sociales que produce el incumplimiento de los acuerdos. También se ha contemplado exponer la articulación de los diferentes sistemas y la producción de cadenas de endeudamiento.

Las penalizaciones por impago que en el caso de los sistemas financieros formales se centran en aumentar los intereses de la deuda o la pérdida de patrimonio, sin embargo, abarcan la esfera social de los deudores en los sistemas financieros informales. Estos, al depender para su participación de alguna o varias de las tres dinámicas principales presentadas durante la investigación, el don como obligación de dar, recibir y devolver, la posesión de capital social, y la influencia de las economías afectivas, desarrollan 
penalizaciones en torno a ellas que llevan al acoso, amenaza, desprestigio con el consiguiente desgaste del capital social e incluso ostracismo de la comunidad. Las penalizaciones dependen tanto de la afinidad anterior a la participación en el sistema informal de los miembros como de la clase social o situación particular de cada uno.

El deseo de consumo o la carencia económica son las motivaciones principales para la adquisición de deudas por parte de los individuos y el consiguiente encadenamiento de deudas. Debemos diferenciar claramente que la participación en un sistema financiero informal no siempre persigue el acceso a un préstamo, por lo que la adquisión de deudas se produce únicamente en el caso de no poder cumplir los requerimientos estipulados al ingreso en el sistema. Si bien es cierto que todos los individuos son susceptibles de quedar en deuda, ya sea económica o moral, con sus vecinos, debemos tener en cuenta que el uso de estos sistemas no siempre origina una deuda. Los sistemas financieros informales, destinados en origen a solventar la financiación, son en muchos casos amortiguadores de las deudas contraídas en los sistemas financieros formales, especialmente en los pagos fraccionados de Coppel y Elektra, y en las casas de empeño. Como amortiguadores, cubren la deuda de los sistemas formales, trasladando la deuda a sistemas comunitarios donde además de la deuda económica, esta se convierte en una deuda moral y un compromiso social. En este proceso fagocitan las relaciones sociales y familiares provocando conflictos dentro de la comunidad, generando que los créditos individuales se conviertan en deudas colectivas. Esta premisa, expuesta en el título de la investigación como un interrogante que busca entender como a través de pequeños préstamos se producen grandes deudas y como estos créditos individuales se convierten en deudas colectivas, "Micro-créditos o Macrodeudas", sirve de columna vertebral al estudio de estas dinámicas de préstamo y consumo y endeudamiento. 
La hipótesis principal que se ha desarrollado durante la investigación plantea el análisis de los sistemas financieros informales como mecanismos utilizados por los habitantes de la región de la Ciénaga de Chapala para desempeñar funciones financieras incrustadas en el tejido social con el fin de atender las necesidades de la población en riesgo de exclusión de los sistemas financieros formales. Las modalidades financieras incrustadas en el tejido social, dependientes del capital social han sido encontradas durante la etnografía como elementos capacitadores de recursos para la población en riesgo de exclusión o con limitada capacidad económica, pero como señalábamos anteriormente, dentro de la población con mayores recursos estos sistemas financieros son utilizados como capacitadores de la generación de capital social. Esta diferenciación es un síntoma de las diferentes percepciones presentes en la región. Entre las personas con menos recursos el acceso a los sistemas financieros informales es indispensable a la hora de precisar financiación. A diferencia de ellos, los individuos con una estabilidad económica utilizan estos sistemas para generar lazos sociales, aumentar su capital social e incluso posicionarse dentro de su clase a través de su participación, utilizando su desempeño en un sistema financiero informal como un marcador de clase.

Una de las críticas más recurrentes durante los últimos años al uso del concepto de capital social postula que, con el uso del término capital, se podía interpretar que se estaba capitalizando la esfera social. Durante esta investigación, en múltiples ocasiones, he intentado atisbar esta perspectiva como ejercicio teórico. El resultado, apoyándome en los datos obtenidos durante la etnografía, no me permite afirmar que esta suposición esté presente en la comunidad estudiada. Ahora bien, los discursos y practicas recogidos durante el trabajo de campo pueden señalar una direccionalidad inversa: a través de los sistemas financieros alternativos se socializa el capital. 
Se presentaron dos sub-hipotesis vinculadas a la principal con el fin de profundizar en el origen y las dinámicas que los sistemas financieros informales.

La primera sub-hipótesis planteaba que estos sistemas eran una importación, no siendo característicos del mundo rural. En este caso podemos presentar múltiples matizaciones. Los apartados, versión informal del pago fraccionado, es la adaptación que diversos comercios han utilizado para poder competir con las facilidades que tiendas departamentales de implantación nacional ofrecen a sus clientes. Ante la desventaja de los comercios pequeños que no pueden financiar el consumo de sus clientes por carecer de los mecanismos, el capital y el margen de beneficios de las entidades de Coppel y Elektra, estos han optado por una versión que selecciona a los clientes en base al capital social, confiabilidad y reconocimiento social de la comunidad donde se asienta el comercio. El fiado, similar al apartado en cuanto permite obtener un bien sin desembolsar íntegramente la cantidad de este, si estaba presente en el mundo rural, pero solo era utilizado para los bienes de primera necesidad o aquellos que poseían una utilidad productiva y por tanto necesarios para obtener recursos, como maquinaria, herramientas o mercancía. La kérmes en origen es una práctica utilizada por congregaciones religiosas o comunidades conformadas en torno a una iglesia con el fin de recaudar dinero para caridad o mantenimiento de la iglesia. Su presencia ha estado en el mundo rural durante siglos, siendo las kermeses características no de un entorno concreto, sino de una religiosidad que conforma la identidad de la región. Las tandas, ampliamente utilizadas en México son una importación. No hay que olvidar que las tandas han irrumpido en el medio rural a través de la práctica de los migrantes, que al retornar a sus municipios de origen, han expandido su utilización.

La segunda sub-hipotesis pretende analizar la confluencia de tres dinámicas sociales articuladas entre sí, el don como obligación moral, la posesión de capital social 
como facultad que permite la confiabilidad y la intervención de las economías afectivas. El don como obligación moral que implica reciprocidad entre los miembros esta presente en los sistemas financieros informales donde las relaciones entre los participantes son simétrica. En el caso de los apartados, Karen ofertaba esta posibilidad a los clientes de su total confianza, incluso insistía en la compra de algún producto a través de este mecanismo entendiendo con ello que ella, en tanto comerciante, tenia una obligación moral hacia sus clientes habituales. Los clientes habituales también entendían que el ofrecimiento de Karen ya era en parte un primer incentivo que debía ser recompensado recibiendo el bien y devolviendo (pagando su valor). Esta dinámica provoca que en muchos comercios los clientes habituales no entren salvo si saben que van a comprar algo, sintiéndose en la obligación de recibir el bien financiado como regalo que reconoce su confiabilidad. Las kermeses y las tandas son más susceptibles de presentar dentro de sus dinámicas la necesidad de posesión de capital social, o la producción de este, y el desarrollo de economías afectivas en tanto sistemas financieros basados en la asociación de miembros en colectivos. En el último caso, los prestamistas locales, las relaciones son asimétricas, y aunque el capital social pueda ser un elemento indispensable para acceder al préstamo, las propias dinámicas de dominación del prestamista sobre el prestatario hacen que la reciprocidad este coaccionada por un compromiso que puede abarcar desde el ámbito personal hasta la obligación contractual de devolver la cantidad prestada.

En esta investigación hemos pretendido mostrar los sistemas financieros informales utilizados por los habitantes de la Ciénaga de Chapala como estrategias de financiamiento utilizadas con diferentes motivaciones. Su uso, participación o exclusión, asi como los discursos, prácticas y conductas muestran que el uso de los sistemas financieros informales, percibidos como una alternativa a los sistemas formales, fagocitan 
las relaciones sociales, trasladando las deudas económicas a la esfera de las relaciones sociales. 


\section{BLOQUE VI. BIBLIOGRAFÍA}

Adler Lomnitz, L. (1975). Cómo sobreviven los marginados. CDMX, México: Siglo XXI.

- (1977). Networks and Marginality, Tr. Cinna Lomnitz. Nueva York, E.U.A.: Academic Press.

Ahmed S. (2004). Affective Economies. Social Text 79, Vol. 22, no 2, pp. 117-139. Duke University Press.

Aguilar, T. (2012). Desarrollo económico e integración territorial de la región LermaChapala. CDMX, México: UNAM.

Algazi, G. (2002). Some Problems with Reciprocity. Endoxa: Series filosóficas, nº 15 pp.43-50. Madrid, España:UNED.

Althusser, L. (2003). Ideología y aparatos ideológicos del estado. Buenos Aires, Argentina: Nueva Visión

Althusser, L. y Balibar, E. (1978). Para leer el capital. CDMX, México: Siglo XXI.

Anderson, R.T. (1966). Rotating Credit Associations in India. Economic Development and Cultural Change, $\mathrm{n}^{\circ}$ 14, pp.334-339.

Aparicio, S., Giarraca, N. y Teubal, M.(1992). Transformaciones agrarias en Argentina: el impacto sobre los sectores sociales.. En Jorrat, R y Sautu, R. (Coord.) Después de Germani. Exploraciones sobre la estructura social en Argentina. Buenos Aires, Argentina: Paidós.

Appadurai, A. (1991). La vida social de las cosas. Perspectiva cultural de las mercancías. CDMX, México: Grijalbo. 
Ardener, S. (1964). The Comparative Study of Rotating Credit Associations. Journal of the Royal Anthropological Institute, n 94, pp, 201-209.

Bada, X. (2003). La participación cívica comunitaria transnacional de los clubes michoacanos. En López Castro, G. (Coord.) Diáspora michoacana. Zamora, México: El Colegio de Michoacán A.C. y Gobierno del Estado de Michoacán.

Bagley, B. M. (2011). ¿Por qué se está perdiendo la guerra contra la droga? (II): de cucarachas, Estados incapaces y legalizaciones nebulosas. Colombia: Fundación Razón Publica. Recuperado de: http://www.razonpublica.com/index.php/conflicto-drogas-y-paz-temas30/1761-por-que-se-esta-perdiendo-la-guerra-contra-la-droga-ii-de$\underline{\text { cucarachas-estados-incapaces-y-legalizaciones-nebulosas.html }}$

Bagnasco, A. (1994). Fatti sociali formatí nello spazio. Cinque lezioni di sociologia urbana e regionale. Milano: Franco Angelí.

Baker W. E. (1990). Market networks and corporate behavior. En Am. J. Social. nº 96, pp. 589-625.

Barth, J. (2009). The Rise and Fall of the U.S. Mortgage and the Credit Markets. Nueva Jersey, E.U.A.: John Wiley and Sons.

Baudrillard, J. (2010). El sistema de los objetos, Madrid, España: Siglo XXI.

Benítez, R. (2009). La crisis de seguridad en México. Nueva Sociedad, no 220, pp. 173-189.

Blau, P. (1964). Exchange and Power in Social Life, Nueva York, U.E.A.: John Wiley and Sons.

Blomström, M. y Hettne, B. (1990). La teoría del desarrollo en transición, CDMX, México: FCE. 
Boehm, B. (1985). Cultura criolla y migración en la Ciénaga de Chapala. En Relaciones. Estudios de Historia y Sociedad, n 24, pp. 89-99. -(1994). Guadalajara y Chapala: historia de una relación regional. Siglo XIX y principios del XX. En Ávila Palafox, A. (Coord.) El Occidente de México en el tiempo. Guadalajara, México: Universidad de Guadalajara.

Boissevain J. (1974). Friends of Friends: Networks, Manipulators, and Coalitions. Nueva York, U.E.A.: St. Martin's Press.

Bouman, F. y O. Hospes (1994). Financial Landscapes Reconsidered. Boulder, E.U.A.: Westview.

Bourdieu, P. (1979). Les trois états du capital cultural. En Actes de la Recherche en Sciences Sociales, $\mathrm{n}^{\circ}$ 30, pp. 3-6. -(1980). Le senspratique. París, Francia: Les Editions de Mínuit. -(1980). Le capital social: notes provisoires. En Actes de la Recherche en Sciences Sociales, $\mathrm{n}^{\circ} 31$, pp. 2-3. -(2006) La objetivación participante. En Apuntes de investigación del CECYP, $\mathrm{n}^{\circ} 10, \mathrm{pp} .87-101$.

Burt R. S. (1992). Structural Holes. The Social Structure of Competition. Cambridge, E.U.A.: Harvard University Press.

Cabrera, F. (2011). Sobre las etnografías del capitalismo. Maguaré, n²5, pp. 9-20.

Campbell, C. (1995). The Sociology of Consumption. En Miller, D. (Coord), Acknowledging consumption. Londres, Inglaterra: Routledge.

Campos, P. (1998). Las tandas en México: un enfoque de acción colectiva. Sociología, no 37 , pp. 189-212. 
Cardoso, F.H. y Faletto, E. (1969). Dependencia y desarrollo en América Latina, CDMX, México: Siglo XXI.

Carneiro, M. J. (2006). Pluriatividade da agricultura no Brasil: uma reflexão crítica. En: Schneider, S. A. Diversidade da agricultura familia. Porto Alegre, Brasil: UFRGS.

Carpenter, T. G. (2012). The Fire Next Door: Mexico's Drug Violence and the Danger to America. Washington, E.U.A.: Cato Institute.

Carrier, James. (2005) A Handbook of Economic Anthropology. Northampton, Inglaterra: Edward Elgar Publishing.

- (2012) A Handbook of Economic Anthropology. Second edition. Northampton, Inglaterra: Edward Elgar Publishing.

Castells, M. y Portes, A. (1989). World Undermeath: The Origins, Dynamics and Effects of the Informal Economy. En Portes, A.; Castells M. y Benton, L.A., (Coords). The Informal Economy. Studies in Advanced and Less Developed Countries. Baltimore y Londres, E.U.A. e Inglaterra: The Johns Hopkins University Press.

Chamoux, M.N., Dehouve D., Gouy C., Pepin, C. (1993). Prestar y pedir prestado: relaciones sociales y crédito en México del siglo XVI al XX . CDMX, México: CIESAS, CEMCA.

Chavolla Mc Ewen, J. (2014). Reconciliando el patrimonio cultural religioso y cívico en Jiquilpan, México. Culturales, nº 2, pp. 81-107.

Chomsky, N. (2007). Failed states: The abuse of power and the assault on democracy. Londres, Inglaterra: Macmillan. 
Clammer, J. (1985). Anthropology and Political Economy. Theoretical and Asian Perspectives. Londres, Inglaterra: Macmillan.

Coleman, J. S. (1988). Social capital in the creation of human capital. En American Journal of Sociology, $\mathrm{n}^{\circ}$ 94, pp. 95-121.

- (1990). Foundations of Social Theory. Cambridge, E.U.A.: Harvard University Press.

Cornejo, R. A. y Galicia, M. (2011). Las Instituciones Microfinancieras: ¿Satisfacen las necesidades de financiamiento de los microempresarios del Distrito Federal?". Memorias del XV Congreso Internacional de Contaduría y Administración. CDMX, México: Universidad Autónoma de México. México.

Covarrubias, F. y Ojeda A. (2009). Poblamiento y agricultura en la Ciénaga de Chapala, México. CDMX, México: Instituto de Investigaciones Sociales y Humanas, Instituto Politécnico Nacional.

Covarrubias, F., Cruz, M. y Ojeda A. (2012). El desarrollo de la agricultura en la Ciénaga de Chapala. En Tecsistecatl, nº 9, pp. 2-13.

De Soto, H. (1987). El Otro Sendero, La revolución informal. CDMX, México: Diana.

Douglass, M., Isherwood B. (1990). El mundo de los bienes. Hacia una antropología del consumo. CDMX, México: Grijalbo.

Durand, J. y Massey, D.S. (2003). Clandestinos Migración México-Estados Unidos en los albores del siglo XXI. Colección América Latina y el Nuevo Orden Mundial. CDMX, México: Miguel Ángel Porrúa.

Durkheim É. (1982). La división del trabajo social. Madrid, España: Akal .

Elster, J. (1992). El cemento de la sociedad: las paradojas del orden social. Barcelona, España: Gedisa. 
Epstein, K., Smith, G. (2007). Bloomberg. Recuperado el 7 de 3 de 2014, de The Ugly Side Of Microlending: https://www.bloomberg.com/news/articles/2007-1212/the-ugly-side-of-microlending

Espinosa, R. y Villarreal, M. (1999). Las mujeres, las malas rachas y el endeudamiento. En Vázquez, V., Género, sustentabilidad y cambio social en el México Rural. CDMX, México: Colegio de Posgraduados en Ciencias Agrícolas, Instituto de Socioeconomía.

Fabian, J (1983). Time and the Other. How Anthropology Makes its Object, Nueva York, E.U.A.: Columbia University Press.

Fine, B. (2002). The world of consumption: the material and cultural revisited. London, Routledge.

Fine, L. (1999) The Developmental State is Dead-Long Live Social Capital?. En Development and Change, n⿳30, pp. 1 -19.

Flores, A. (2015). Las cajas populares de Sahuayo, Michoacán olvidaron el quinto principio cooperativo: Educación, formación e información. “¿Son cooperativas realmente? En Actas del $20^{\circ}$ Encuentro Nacional sobre Desarrollo Regional en México. AMECIDER-CRIM, UNAM.

Fuentes Díaz, A. y Paleta, G. (2015). Violencia y autodefensas comunitarios en Michoacán, México. En Íconos. Revista de Ciencias Sociales, nº53, pp. 171186.

Gamble, S. D. (1944). A Chinese Mutual Savings Society. En Far Easter Quarterly, no 4, pp. 41-52. 
Geertz C. (1962). The Rotating Credit Association: A “Middle Rung” in Development. En Economic Development and Cultural Change, $n^{\circ}$ 10, pp. 241-263.

-(1963). Peddlers and Princes. Chicago, E.U.A.: University of Chicago Press.

Godelier, M. (1967). Sistema, estructura y contradicción en El Capital: Problemas del estructuralismo. CDMX, México: Siglo XXI.

-(1976). Antropología y economía. Barcelona, España: Anagrama.

-(1998). El enigma del don. Barcelona, España: Paidos.

-(2000). Economía, fetichismo y religión en las sociedades primitivas. Madrid, España: Siglo XXI.

González y González, L. (1979). Sahuayo. Morelia, México: Gobierno del Estado de Michoacán.

Goulder, A. W. (1960). The Norm of Reciprocity: A Preliminary Statement. En American Sociological Review, vol. 25, n² 2, pp. 161-178.

Gramsci, A. (1980). Notas sobre Maquiavelo, sobre la política y sobre el Estado moderno. Madrid, España: Nueva Visión.

-(1998) Cartas desde la cárcel. Buenos Aires, Argentina: Nueva visión.

Granovetter, M. (1974), Getting a Job: A Study of Contracis and Careers. Cambridge, E.U.A.: Harvard University Press.

Graziano da Silva, J. (1996). A nova dinâmica da agricultura brasileira. Campinas, Brasil: Universidade Estadual de Campinas, Unicamp.

-(1999). O novo rural brasileiro. Campinas, Brasil: Colección Pesquisas, Unicamp. 
-(2002). Velhos e novos mitos do rural brasileiro. Recuperado en: www.rlc.fao.org/prior/desrural/graziano.pdf

Guber, R. (2005). El salvaje metropolitano. Reconstrucción del conocimiento social en el trabajo de campo. Buenos Aires, Argentina: Paidós.

Gudeman, S. (2001). Anthropology of Economy. Oxford, Inglaterra: Blackwell Publishers.

Guerra, F. (1988). México del antiguo régimen a la revolución. CDMX, México: FCE

Gunder Frank, A. (1967). Capitalism and underdevelopment in Latin America. NY, E.U.A.: Monthly Review Press.

- (1976). América Latina: subdesarrollo o revolución. CDMX, México: Era.

Gutiérrez, R. (2016). Los límites de la política social durante el sexenio de Peña Nieto. En Economía UNAM, vol. 13, nº 39, pp. 26-62.

Hagene, T. y González-Fuente, I. (2016). Community Adaptations to Polotical Clientelism in Twenty-First-Century Mexico. En Latin American Research Review, vol.51, n², pp. 3-23.

Harris, M. (1998). Introducción a la Antropología General. Madrid, España: Alianza Editorial

Hart, K (1973). Informal Income Opportunities and Urban Employement in Ghana. En Journal of Modern African Studies, vol. 11, nº1, pp. 61-89.

Harvey, D. (2010). The Enigma of Capital and the Crisis of Capitalism. Oxford, Inglaterra: Oxford University Press. 
Hayek, F. (1976). Law, Legislation, and Liberty. The mirage of social justice. Chicago E.U.A.: The University of Chicago Press.

-(2004). El Nuevo Imperialismo. Madrid, España: Akal.

-(2005). Camino de servidumbre. Madrid, España: Alianza.

Hertz, E. (1998). The Trading Crowd. An Ethnography of the Shanghai Stock Market. Cambridge,Inglaterra: Cambridge University Press.

Ho, K. (2009). Disciplining Investment Bankers, Disciplining the Economy: Wall Street's Institutional Culture of Crisis and the Downsizing of "Corporate America”. En American Anthropologist, n¹11, pp. 177-189.

Jevons, W.S. (1875). Money and the Mechanisms of Exchange. London, Inglaterra: Kegan Paul, Trech, Trübner \& Co.

Kay, C. (2007). Latin America's Agrarian Transformation: Peasantization and Proletarianization. En Bryceson, D.F. y Kay, C. (Coords.), Disappearing Peasantries? Rural Labour in Africa, Asia and Latin America. Londres, Inglaterra: Intermediate Technology Publications.

Keller, J., Keller, J. y Davids, G. (1998). River Basin Development Phases and Implications of Closure. En Journal of Applied Irrigation Science, $\mathrm{n}^{\mathbf{o}} 33$, pp. 145-163.

Kerry, J. N. (1976). Studying Voluntary Associations as Adaptive Mechanism: A Review of Anthropological Perspectives. En Current Anthropology, no 17, pp.23-47. 
Klein, E. (1992). El empleo rural no agrícola en América Latina. Documento de Trabajo $\mathrm{N}^{\circ}$ 364.Programa Regional de Empleo para América Latina y El Caribe. Santiago, Chile.

Klein, P. A. (1994). Beyond Dissent. Essays in Institutional Economics. Armond, NY, EUA: M.E. Sharpe.

Kurtz, D.F. (1973). The Rotating Credit Association: An Adaptation to Poverty. En Human Organization n ${ }^{\circ}$ 32, pp.49-58.

Kurtz, D.F. y Showman, M. (1978). The Tanda: A Rotating Credit Association in Mexico. En Ethnology n ${ }^{\circ} 17$, pp.65-74.

Ledilla, J. (1997). ¿El fin de toda ilusión? Neoliberalismo, relaciones económicas trasnacionales y reforma agraria en la Ciénaga de Chapala, Michoacán. En Relaciones, nº71, pp. 211-257.

Levi, G. (2002). Reciprocidad mediterránea. En Tiempos modernos: Revista Electrónica de Historia Moderna, vol.3, nº7.

Lévi-Strauss, C. (1981). Las estructuras fundamentales del parentesco. Barcelona, España: Paidos Ibérica.

Lewis, O. (1961). Antropología de la pobreza: cinco familias. CDMX, México: FCE. -(1965). Los hijos de Sánchez: Autobiografía de una familia mexicana. CDMX, México: FCE.

Lewis, W. A. (1955). Teoría del desarrollo económico. CDMX, México: FCE.

Light, I. (1972). Ethnic Enterprise in America. Business and Welfare Among Chinese, Japanese, and Blacks. Berkeley, E.U.A.: University of California Press. 
-(1984). Immigrant and ethnic enterprise in North America. En Ethnic and Racial Studies, nº7, pp. 195-216.

-Bonacich E. (1988). Immigrant Entrepreneurs: Koreans in Los Angeles 19651982. Berkeley, E.U.A.: University of California Press.

Loury G. C. (1977). A dynamic theory of racial income differences. En Wallace, P.A. y La Mond, A. M. (Coords.) Women, Minorities, and Employment Discrimination. Lexington, E.U.A.: Heath.

-(1981). Intergenerational transfers and the distribution of earnings. En Econométrica, no 49, pp. 843-867.

Malthus, T. R. (1951). Ensayo sobre el principio de la población. CDMX, México: FCE.

Mansell Carstens, C. (1995). Las finanzas populares en México: El redescubrimiento de un sistema financiero olvidado. CDMX, México: Instituto Tecnológico Autónomo de México.

Mauss, M. (2010) Ensayo sobre el don. Forma y función del intercambio en las sociedades arcaicas. Madrid, España: Katz.

Marini, R.M. (1977). Dialéctica de la dependencia. CDMX, México: Era.

Márquez Covarrubias, H. (2006). El desarrollo participativo transnacional basado en las organizaciones de migrantes. Problemas del desarrollo. En Revista Latinoamericana de Economía, vol. 37, n¹44, pp.121-144.

Marx, K, (2009). El Capital. Libro I. Capítulo VI inédito. CDMX, México: Siglo XXI. -(2007). El Capital. Libro I. Tomo I-III, Madrid, España: Akal. 
McCracken, G. (1990). Culture and Consumption: New Approaches to the Symbolic Character of Consumer Goods and Activities. Bloomington, E.U.A.: Indiana University Press.

Meillassoux, C. (1999). Anthropologie économique des gouro de Cotê d'Ivorie. Paris, Francia: Éditions de l’école des hautes études en sciences sociales.

Meyer, J. (1980). La segunda Cristiada en Michoacán, 1932-1940. En Actas del II Coloquio de Historia y Antropología Regional. El Colegio de Michoacán, México.

-(1994). La cristiada. La guerra cristera, 1973. CDMX, México: Siglo XXI. -(2003.) El Sinarquismo, el cardenismo y la iglesia. CDMX, México: Tusquets Editores.

Miller, D. (1987). Material Culture and Mass Consumption. Oxford, Inglaterra: Basil Blackwell.

-(1995). Consumption and commodities. En Annual Review Anthropology, n²4, pp. 141:161.

-(1998). Material cultures: why some things matter. Londres, Inglaterra: Routledge.

Mises, L. v. (2001). La acción humana: Tratado de Economía. Madrid, España: Unión Editorial.

Morton, K. L. (1978). Mobilizing Money in a Communal Economy: A Tongan Example. En Human Organization, nº37, pp. 50-56. 
Moztezuma, M. (1999). Clubes de migrantes zacatecanos, expresión organizada del migrante colectivo. Ponencia, XXII Congreso de la Asociación Latinoamericana de Sociología, Concepción, Chile.

Narotzky, S. (1997). New Directions in Economic Anthropology. Anthropology, Culture \& Society. Londres, Inglaterra: Pluto Press.

-(2002). Reivindicación de la ambivalencia teórica: La reciprocidad como objeto clave. En Endoxa: Series Filosóficas, nº 15, pp. 15-29.

-(2004). Antropología económica. Nuevas Tendencias. Barcelona, España: Melusina.

-(2013). Economías cotidianas, economías sociales, economías sostenibles. Icaria. Barcelona: España.

Neiman, G., Bardomas, S. (2001). Continuidad y cambio en la ocupación agropecuaria y rural en la Argentina. En Neiman, G. (Coord). Trabajo de campo: producción, tecnología y empleo en el medio rural. Buenos Aires, Argentina: Ciccus.

North, Douglass C. (1986). The New Institutional Economics. En Journal of Institutional and Theoretical Economics, $n^{\circ}$ 142, pp. 230-237.

-(1994). Instituciones, cambio institucional y desempeño Económico. CDMX, México: FCE.

Palerm, J. V., Urquiola, J. I. (1993). A Binational System of Agricultural Production: The Case of the Mexican Bajio and California. En: Aldrich, D., Meyer, L. (Coords). Mexico and the United States: Neighbors in Crisis. San Bernardino, E.U.A.: The Borgo Press.

Paz, Octavio (1990). El ogro filantrópico. Barcelona, España: Seix Barral. 
Pérez Correa, E. (2002). Lo rural y la nueva ruralidad. En: Pérez Correa, E. y Sumpsi, J. (Coords). Políticas, instrumentos y experiencias de desarrollo rural en América Latina y Europa. Madrid, España: Ministerio de Agricultura, Pesca y Alimentación

Piore, M., Sabel, Ch. (1984). The Second Industrial Divide. NY, E.U.A.: Basic Books.

Polanyi, K. (2011) La gran transformación. Los orígenes políticos y económicos de nuestro tiempo. CDMX, México: FCE.

-(2009). El sustento del hombre. Madrid, España: Autor-Editor.

-Arensberg, C., Pearson, H. (1976). Comercio y mercado en los imperios antiguos. Barcelona, España: Labor.

Pongratz, H. (1990). Cultural tradition and social change in agriculture. En Sociologia Ruralis, vol. XXX-1, pp. 5-17.

Popkin, S. L. (1979). The Rational Peasant: The Political Economy of Rural Society in Vietnam. Berkeley, E.U.A.: The University of California Press.

Portes, A. (1995). En torno a la informalidad: ensayos sobre teoría y medición de la economía no regulada. CDMX, México: Flacso Editores.

-Landolt P. (1996). The downside of social capital. En The American Prospect n²6, pp.18-22.

- Haller, W. (2004). La economía informal. Santiago de Chile, Chile: CEPAL.

Powelson, J. P. (1991). The Moral Economy. Ann Arbor, E.U.A.: University of Michigan Press. 
Presbich, R. (1950) Crecimiento, desequilibrio y disparidades: interpretación del proceso de desarrollo económico. En: Estudio económico de América Latina, 1949. NY, E.U.A.: Naciones Unidas.

Putnam, R. (1993). The Properous Community. Social Capital and Public Life. En The American Prospect, nº13, pp. 35-42.

Rey, P.P. (1971). Colonialisme, Neocolonialisme et Transtion aur Capitalisme. Paris, Francia: Maspero.

Ricardo, David (1959). Principios de economía política y tributación. CDMX, México: FCE.

Richard, A., Rudnyckyj, D. (2009). Economies of Affect. En Journal of the Royal Anthropological Institute, $n^{\circ} 15, \mathrm{pp} .57-77$.

Røyrvik, E. (2011). The Allure of Capitalism. An Ethnography of Management and the Global Economy in Crisis. NY, E.U.A.: Berghahn.

Rouse, R. (1992). Making Sense of Settlement: Class Transformation, Cultural Struggle and Transnationalism among Mexican Migrants in the United States. En: Schiller, N., Basch L., Blanc-Stanton, C. (Coords). Towards a Transnational Perspective on Migration: Race, Class, Ethnicity and Nationalism Reconsidered, Annals of the New York Academy of Sciences, vol. 645, NY,E.U.A.: The New York Academy of Sciences.

Sahlins, M. (1987). La economía de la edad de piedra. Madrid, España: Akal. 
Salas, H., González de la Fuente, I. (2013). Nueva ruralidad: procesos sociolaborales y desagrarización de una sociedad local en México (1980-2010). En Gazeta de Antropología, 29(2), artículo 03.

Salas, H., Velasco, P. (2013). Los rostros rurales de dominación en el neoliberalismo actual. En Revista Margenes, vol.10, nº13, pp. 7-14.

Sandoval, A., Ochoa, M.A. (2010). Grupos locales, acceso al agua y su problemática de contaminación en la Ciénaga de Chapala, Mich. En Economía, sociedad y territorio, vol. 10, no 34, pp. 683-719.

Schaffhauser, P. (2013). Las distancias de la cercanía. Una aproximación a la rivalidad regional entre Sahuayo y Jiquilpan, Michoacán. En Relaciones. Estudios de historia y sociedad, n³4, pp. 157-179.

Schneider, S. (1994). O desenvolvimiento agrícola e as trasformacoes da estructura agraria nos paises do capitalismo avancado: a pluriatividade. En Revista Reforma Agraria n²4, pp.106-132.

-(2003). A pluriactividade na agricultura familiar. Porto Alegre, Brasil: Editorial UFRGS.

-(2006). A diversidade da Agricultura Familiar. Porto Alegre, Brasil: Editorial UFRGS.

Scott, J. C. (1976). The Moral Economy of the Peasant. Rebellion and Subsistence in Southeast Asia. New Haven. E.U.A.: Yale University Press.

-(1990). Domination and the Arts of Resistance. Hidden Transcripts. New Haven, E.U.A.: Yale University Press.

Simmel, G. (1988). Sobre la Aventura. Barcelona, España: Península. 
Smith, A. (2009). Investigación sobre la naturaleza y causas de la riqueza de las Naciones. Madrid, España: Editorial Tecnos.

Stiglitz, J., Ocampo J.A., Griffith-Jones, S. (Coords). (2010). Time for a Visible Hand. Lessons from the 2008 World Financial Crisis. Oxford, Inglaterra: Oxford University Press.

Sunkel, O., Paz, P. (1975). El subdesarrollo latinoamericano y la teoría del desarrollo. CDMX, México: Siglo XXI.

Taussig, M. (2002). Colonialismo y el hombre salvaje. Un estudio sobre el terror y la curación. Bogota, Colombia: Norma.

Terradas, I. (2002). Is reciprocity an enlightening concept to address contemporary issues?. En Endoxa: Series Filosóficas n¹5 pp.33-42.

Tetreault, D. (2007). Los proyectos de abajo para superar la pobreza y la degradación ambiental en dos comunidades del México rural: Ayotitlán y La Ciénaga, Jalisco, México. Guadalajara, México: Universidad de Guadalajara.

Teubal, M. (2001) Globalización y nueva ruralidad en América Latina. En Giarraca, N. (Coord.) ¿Una nueva ruralidad en América Latina? Buenos Aires, Argentina: CLACSO-ASDI.

Thompson, E.P. (1971). The Moral Economy of the English Crowd in the Eighteenth Century. En Past and Present, nº 50, pp.76-136.

-(1978). The poverty of Theory and other essays. NY, E.U.A.: Monthly Review Press.

-(1992). Folklore, antropología e historia Social. En Entrepasados, n², pp. 63 86. 
Terray, E. (1972). Marxism and Primitive Societies: Two Studies. NY, E.U.A.: Monthly Review Press.

Van der Ploeg, J. D. (1992). El proceso de trabajo agrícola y la mercantilización. En: Guzmán, E., González de Molina, M. (Coord) Ecología, campesinado e historia. Madrid, España: La Piqueta.

Vargas, P. E. (1993). Lealtades de la sumisión. Caciquismo: poder local y regional en la Ciénaga de Chapala, Michoacán. Zamora, México: El Colegio de Michoacán.

Veblen, T. (1992). Teoría de la clase ociosa. CDMX, México: FCE.

Velasco, H. y Díaz de Rada, A. (2009). La lógica de la Investigación Etnográfica. Un modelo de trabajo para etnógrafos de escuela. Madrid, España: Trotta.

Vélez-Ibáñez, C.G. (1993). Lazos de confianza. Los sistemas culturales y económicos de crédito en las poblaciones de los Estados Unidos y México. CDMX, México: FCE.

Villarreal M. (1997).Las hijas de vecino ante la crisis en el agro. En Valencia, E. (coord.) A dos años: La política social de Ernesto Zedillo, Guadalajara, México: Red Observatorio Social.

Waldinger, R. (1995). The 'Other Side' of embeddedness: a case study of the interplay between economy and ethnicity. En Ethnic and Racial Studies nº18, pp. 555580.

Wallerstein, I. (1991). El moderno sistema mundial. Vol: 1, La agricultura y los orígenes de la economía-mundo europea en el siglo XVI. CDMX, Mexico. Siglo XXI. 
- (1979). The capitalist world economy, Cambridge, E.U.A.: Cambridge University Press.

Walras, L. (1986). Estudios de Economía Social, Segunda Sección. En Vuotto, M. (Coord), Economía Social, Precisiones Conceptuales y Algunas Experiencias Históricas. Buenos Aires, Argentina: Editorial Altamira.

Weber, M. (1969). Economía y sociedad. Esbozo de sociología comprensiva. CDMX, México: FCE.

-(1979). La ética protestante y el espíritu del capitalismo. Barcelona, España: Península.

Weiner, A. (1992). Inalienable Possessions.The paradox of keping while giving. Berkeley, E.U.A.: University of California Press.

Weller, J. (1997). El empleo rural no agropecuario en el istmo centroamericano. En Revista de la CEPAL, nº2, pp. 75-90.

Wester, P. (2008). Shedding the waters. Institutional Change and Water Control in the Lerma-Chapala Basin, Mexico. Wageningen, Países Bajos: Wageningen Universiteit.

Wilk, R., Cliggett, L. (2007). Economies and Cultures: Foundations of Economic Anthropology. NY, E.U.A.: Westview.

Wolf, E. R. (1980). Relaciones de parentesco, de amistad y de patronazgo en las sociedades complejas. En Wolf, E. (Coord). Antropología social de las sociedades complejas, Madrid, España: Alianza Editorial.

-(1990). Distinguished Lecture: Facing Power-Old Insights, New Questions. En American Anthropologist, vol. 92, n³, pp.586-596. 
-(2005). Europa y la gente sin historia. CDMX, México: FCE.

Woolcock, M. (1998). Social capital and economic development: Toward a theoretical synthesis and policy framework. En Theory and Society, n 27, pp. 151 -208.

Wright, E. O. (1994). Clases. Madrid, España: Siglo XXI.

-(1997). Class Counts: comparative studies in class analysis. Cambridge, Inglaterra: Cambridge University Press.

Wu, D.Y.H. (1974). Tokill three birds with one stone: The Rotating Credit Association of the Papua New Guinea Chinese. En American Ethnologist, nº1, pp.565-584.

Zepeda, J. (1989). Sahuayo y Jiquilpan: Génesis de la rivalidad por una región 18801930. En Estudios Michoacanos, N³, PP.63-80.

\subsection{Informes de instituciones y otros organismos oficiales}

Anuario estadístico y geográfico de Michoacán de Ocampo (2015). INEGI.

Banco de México (2010): Reporte sobre el Sistema Financiero (en línea). Disponible en:http://www.banxico.org.mx/publicaciones-ydiscursos/publicaciones/informes-periodicos/reporte-sf/\%7BDC37ABCB26F0-020D-145B-5CF397D62E68\%7D.pdf (consulta en 2012, 17 de mayo)

Censo X General de Población y Vivienda, (1980). INEGI.

Censo XIII General de Población y Vivienda, (2010). INEGI.

CEPAL, (2000). La brecha de la equidad: una segunda evaluación. LC/G.2096. Santiago, Chile. 
Comisión Nacional Bancaria y de Valores, (2012). Reporte de Inclusión Financiera 4, (www.cnbv.gob.mx). México.

Coopers, Lybrand (1997). Non-Bank Financial Institutions: A Study of Five Sectors", informe final, Financial Crimes Enforcement Network, U.S. Department of Treasury.

Encuesta Nacional de Ocupación y Empleo (2007-2014). STPS-INEGI.

Esquivel H. (2009). La importancia de los costos en la industria de las microfinanzas. Informe Pro Desarrollo. México.

Informe, Ingresos por remesas familiares, (2008-2014). Banco de México.

Informe, Indicadores de pobreza, (2014). CONEVAL.

Ley de Distritos de Desarrollo Rural (1988), //www.sagarpa.gob.mx/Transparencia/pot2009/XIV\%20Marco\%20Normativ o/ACUERDO\%2008-08-1998.pdf

Plan de Desarrollo Municipal 2012-2015, (2012). H. Ayuntamiento de Jiquilpan, Michoacán.

Plan Municipal de Desarrollo 2012-2015, (2012). H. Ayuntamiento de Sahuayo. Michoacán. 
